UNIVERSIDADE DE SÃO PAULO

FFCLRP - DEPARTAMENTO DE PSICOLOGIA

PROGRAMA DE PÓS-GRADUAÇÃO EM PSICOLOGIA

Preditores de fatores relacionados à evasão e à persistência discente em ações educacionais a distância

\title{
ELIENAY EIKO RODRIGUES UMEKAWA
}

Dissertação apresentada à Faculdade de Filosofia, Ciências e Letras de Ribeirão Preto da USP, como parte das exigências para a obtenção do título de Mestre em Ciências, Área: Psicologia.

RIBEIRÃO PRETO 


\section{ELIENAY EIKO RODRIGUES UMEKAWA}

\section{Preditores de fatores relacionados à evasão e à persistência discente em ações educacionais a distância}

Dissertação apresentada à Faculdade de Filosofia, Ciências e Letras de Ribeirão Preto da USP, como parte dos requisitos para a obtenção do grau de Mestre em Ciências.

Área de Concentração: Psicologia.

Orientadora: Prof. ${ }^{a}$ Dr. ${ }^{a}$ Thaís Zerbini

RIBEIRÃO PRETO

2014 
Autorizo a reprodução e divulgação total ou parcial deste trabalho, por qualquer meio convencional ou eletrônico, para fins de estudo e pesquisa, desde que citada a fonte.

Catalogação na publicação

Serviço de Biblioteca e Documentação

Faculdade de Filosofia, Ciência e Letras de Ribeirão Preto - USP

Umekawa, Elienay Eiko Rodrigues

Preditores de fatores relacionados à evasão e à persistência discente em ações educacionais a distância / Elienay Eiko Rodrigues Umekawa; orientadora: Thaís Zerbini - Ribeirão Preto, 2014.

243 p.: il.; $30 \mathrm{~cm}$

Dissertação de Mestrado, apresentada à Faculdade de Filosofia, Ciência e Letras de Ribeirão Preto, Universidade de São Paulo - USP. Área de concentração: Psicologia.

1. Treinamento, desenvolvimento e educação; 2. Educação a distância; 3. Evasão; 4. Estratégias de aprendizagem. 
Nome: Umekawa, E. E. R.

Título: Preditores de fatores relacionados à evasão e à persistência discente em ações educacionais a distância.

Dissertação apresentada à Faculdade de Filosofia, Ciências e Letras de Ribeirão Preto da USP, como parte das exigências para a obtenção do título de Mestre em Psicologia.

Aprovada em:

Banca Examinadora

Prof. ${ }^{\mathrm{a}}$ Dr. ${ }^{\mathrm{a}}$

Instituição: Assinatura:

Prof. ${ }^{\mathrm{a}}$ Dr. ${ }^{\mathrm{a}}$

Instituição: Assinatura:

Prof. ${ }^{a}$ Dr. ${ }^{a}$

Instituição: Assinatura: 
"O coração do homem planeja o seu caminho, mas o Senhor lhe dirige os passos".

Provérbios 16:9 


\section{AGRADECIMENTOS}

Agradeço primeiramente a Deus, autor e consumador de todas as obras. Escudo para mim, baluarte eterno e fonte da mais sublime graça.

À minha orientadora, Thaís Zerbini, pela generosidade em compartilhar seus saberes e me guiar ao longo desse percurso.

À banca examinadora, por todas as prestimosas orientações e apontamentos.

Às universidades partícipes, pela conjugação de esforços que propiciaram novos entendimentos.

A todos os colegas do laboratório, por me permitirem partilhar ricas experiências.

À agência financiadora, CAPES, por todo subsídio prestado ao desenvolvimento deste estudo.

Aos meus pais, Kou e Dalva, pelo incentivo constante, amor incondicional e fé em minha pessoa. Agradeço por me ensinarem o real valor do conhecimento e cuidarem de meus caminhos com tamanha dedicação.

Aos meus avós, João e Terezinha, que em meio à simplicidade sempre se constituíram fontes de inspiração.

Ao meu tio José, estimado exemplo de generosidade e dedicação.

A todos que, direta ou indiretamente, se fizeram presentes e contribuíram para a conclusão deste trabalho. 


\section{Resumo}

Umekawa, E. E. R. (2014). Preditores de fatores relacionados à evasão e à persistência discente em ações educacionais a distância. Dissertação de Mestrado, Departamento de Psicologia, Universidade de São Paulo, Ribeirão Preto.

As novas tecnologias de informação e comunicação (TCIs) atreladas a projetos de educação a distância (EAD) expandem a possibilidade de acesso a programas de treinamento, formação e qualificação profissionais ofertados. Todavia, tais progressos tecnológicos cada vez mais disseminados pelo campo da EAD, não foram capazes de evitar a ocorrência da evasão. Nesse sentido, fazem-se necessários modelos de avaliação específicos para ações a distância, capazes de identificar os fatores relacionados tanto à permanência estudantil em cursos de tal natureza, bem como à desistência dos mesmos. O presente projeto de pesquisa objetivou propor e testar um modelo de avaliação de ações educacionais ofertadas a distância, buscando identificar variáveis preditoras de elementos ligados à evasão e persistência acadêmica (contexto de estudo, desenho do treinamento e o próprio estudante) relacionadas às características da clientela (dados sócio demográficos e estratégias de aprendizagem). As universidades partícipes ofertam cursos superiores em EAD. Foram aplicados virtualmente os questionários de Estratégias de aprendizagem e Fatores relacionados à evasão e à persistência em EAD, sendo que os mesmos sofreram alterações a fim de se ajustarem às particularidades dos contextos de ensino superior (validação semântica e/ou por juízes). Foram realizadas análises exploratórias fatoriais (Principal Components e Principal Axis Factoring) e de consistência interna (Alpha de Cronbach). Os resultados indicaram que todas as escalas são estatisticamente válidas e confiáveis. A fim de cumprir o objetivo de testagem do modelo proposto, foi realizada a análise de regressão múltipla padrão. As variáveis sociodemográficas denominadas composição familiar e estado civil e as estratégias de aprendizagem explicaram os fatores ligados à evasão e à permanência em EAD. Tais resultados indicam para a relevância do uso de estratégias que promovam o autogerenciamento dos processos de ensino e aprendizagem, a autorregulação da motivação/ansiedade e a busca por ajuda interpessoal na consecução de resultados acadêmicos positivos, beneficiando o desempenho dos discentes que estudam a distância. Mais estudos são fundamentais a fim de sistematizar os conhecimentos acerca das variáveis que podem contribuir para a permanência ou saída do aluno em ações instrucionais na modalidade EAD.

Palavras-chave: treinamento, desenvolvimento e educação; educação a distância; evasão; estratégias de aprendizagem. 


\begin{abstract}
Umekawa, E. E. R. (2014). Predictors of factors related to dropout and student persistence in distance education actions. Dissertação de Mestrado, Departamento de Psicologia, Universidade de São Paulo, Ribeirão Preto.

The new information and communication technologies linked to distance learning (DL) expand the possibility of access to training programs, professional training and qualifications offered. However, these technological advances increasingly widespread across the field of distance education, were unable to prevent the occurrence of dropout. In this sense, they are necessary assessment models for specific actions at a distance, able to identify the real factors behind the high dropout rates of courses, observed in various educational settings in different countries. This research project aimed to propose and test a model for evaluating educational activities offered in the distance, trying to identify predictors of dropout related to customer characteristics (sociodemographic data, use of electronic tools, learning strategies) and factors related to dropout and persistence in DL (context of study, training and design student himself). The university offers undergraduate courses in participant DL. It was applied virtually the questionnaires Learning strategies and Factors related to dropout and persistence in $D L$, and that they have changed to fit the peculiarities of higher education contexts (semantic validation and/or judges). Factorial exploratory analyzes (Principal Components and Principal Axis Factoring) and internal consistency (Cronbach's alpha) were performed. The results indicate that all scales are statistically valid and reliable. In order to fulfill the objective of testing the proposed model, a standard multiple regression analysis was performed. The sociodemographic variables named family composition and marital status and learning strategies explain the factors related to dropout and residence in distance education. These results indicate the relevance of the use of strategies that promote self-management processes of teaching and learning, self-regulation of motivation/interpersonal anxiety and search for help in achieving positive academic outcomes, benefiting the performance of students who study at a distance. More studies are essential in order to systematize the knowledge about the variables that may contribute to or departure of the student instructional actions in DL mode.
\end{abstract}

Keywords: training, development and education; distance learning; dropout; learning strategies. 
SUMÁRIO

\begin{tabular}{lc}
\hline Resumo & vi \\
\hline Abstract & vii \\
\hline Lista de figuras & $\mathrm{x}$ \\
\hline Lista de tabelas & $\mathrm{xi}$ \\
\hline Apresentação & 1 \\
\hline Capítulo 1. TREINAMENTO, DESENVOLVIMENTO E EDUCAÇÃO DE PESSOAS & 5 \\
\hline Objetivo do capítulo 1 & 5 \\
\hline 1.1. Treinamento, Desenvolvimento e Educação: evolução, tendências e limitações & 5 \\
\hline 1.2. Modelos de avaliação de treinamento presencial & 9 \\
\hline 1.3. Modelos de avaliação de treinamento a distância & 14 \\
\hline Capítulo 2. EDUCAÇÃO A DISTÂNCIA: DEFINIÇÕES, CARACTERÍSTICAS E & 21 \\
AÇÔES PÚBLICAS & \\
\hline Objetivo do capítulo 2 & 21 \\
\hline Capítulo 3. ANẤLISE DA LITERATURA: DESCRIÇÃO E ACHADOS DE & 38 \\
PESQUISA & \\
\hline Objetivo capíto 3 & 38
\end{tabular}

Objetivo do capítulo $3 \quad 38$

3.1. Revisão de literatura: descrição de percurso 38

3.2. Componentes do modelo de investigação: achados de pesquisa 50

\begin{tabular}{ll}
\hline 3.2.1. Características da clientela & 51
\end{tabular}

3.2.1.1. Estratégias de aprendizagem: definições e características 54

$\begin{array}{ll}\text { 3.2.1.2. Achados de pesquisa sobre estratégias de aprendizagem } & 64\end{array}$

3.2.2. Fatores relacionados à evasão e à persistência em EAD (variável critério): $\quad 82$ definições e características

3.2.2.1. Conjunto de fatores relativos ao evento instrucional $\quad 83$

$\begin{array}{ll}\text { 3.2.2.2. Conjunto de fatores relacionados a características dos estudantes } & 93\end{array}$

3.2.2.3. Conjunto de fatores ligados ao contexto que cerca o aluno a distância 97

Capítulo 4. CARACTERÍSTICAS METODOLÓGICAS DA PESQUISA 117

\begin{tabular}{ll} 
Objetivo do capítulo 4 & 117 \\
\hline
\end{tabular}

4.1. Delimitação do problema, objetivos de pesquisa e modelo de investigação 117

$\begin{array}{ll}\text { 4.2. Características da instituição de ensino superior } & 119\end{array}$

\begin{tabular}{ll} 
4.3. Características dos cursos e disciplinas & 122 \\
\hline 4. & 137
\end{tabular}

4.4. População e amostras 137

\begin{tabular}{lr} 
4.5. Instrumentos de medida & 139 \\
\hline
\end{tabular}

4.6. Considerações Éticas 141

4.7. Procedimentos de coleta de dados 141

\begin{tabular}{ll} 
4.8. Procedimentos de análise de dados & 143 \\
\hline
\end{tabular}

4.8.1. Procedimentos de análises exploratórias das estruturas empíricas dos 144

questionários

$\begin{array}{ll}\text { 4.8.2. Procedimentos de análises dos testes de regressão múltipla } & 147\end{array}$

\begin{tabular}{ll} 
Capítulo 5. RESULTADOS & 150 \\
\hline
\end{tabular}

\begin{tabular}{ll} 
Objetivo do capítulo 5 & 150 \\
\hline
\end{tabular}

5.1. Adaptação e validação dos instrumentos de medida 150

$\begin{array}{lc}\text { 5.2. Análises descritivas } & 157\end{array}$

$\begin{array}{lc}\text { 5.2.1. Estratégias de aprendizagem } & 157\end{array}$

\begin{tabular}{ll} 
5.2.2. Fatores relacionados à evasão e à persistência em EAD & 162 \\
\hline
\end{tabular}

5.3. Análises exploratórias fatoriais das estruturas empíricas dos instrumentos 167

$\begin{array}{ll}\text { 5.3.1 Estratégias de aprendizagem } & 167\end{array}$

\begin{tabular}{ll} 
5.3.2. Fatores relacionados à evasão e à persistência em EAD & 174 \\
\hline
\end{tabular}

5.3.3. Síntese dos resultados: verificação de evidências de validade dos instrumentos 181

\begin{tabular}{ll} 
5.4. Análises de regressão múltipla & 181 \\
\hline
\end{tabular}

\begin{tabular}{ll} 
Capítulo 6. DISCUSSÕES & 195 \\
\hline
\end{tabular}

$\begin{array}{ll}\text { Objetivo do capítulo } 6 & 195\end{array}$ 
SUMÁRIO

6.1. Discussões dos resultados de análises exploratórias fatoriais dos instrumentos

6.2. Discussões dos resultados das análises de regressão

200

Capítulo 7. CONSIDERAÇÕES FINAIS

210

REFERÊNCIAS BIBLIOGRÁFICAS

214 
Lista de figuras

\begin{tabular}{lc}
\hline Figura 1. Estrutura geral de desenvolvimento do texto & 3 \\
\hline Figura 2. Diagrama (Carvalho, 2003; Zerbini, 2003) & 7 \\
\hline Figura 3. Conceitos e ações educacionais (Vargas \& Abbad, 2006) & 7 \\
\hline Figura 4. Modelo de Avaliação Integrado e Somativo - MAIS (Borges-Andrade, 1982, & 13 \\
2006) & \\
\hline
\end{tabular}

Figura 5. Modelo de Avaliação do Impacto do Treinamento no Trabalho - IMPACT 13 (Abbad, 1999)

Figura 6. Modelo de Avaliação de Efetividade de Cursos a Distância da Universidade 16 Católica de Brasília (UCB) (Sallorenzo et al., 2004)

Figura 7. Modelo geral de avaliação da Transferência de Treinamento via web no 18

Trabalho (Zerbini, 2007)

\begin{tabular}{ll}
\hline Figura 8. Modelo de investigação proposto por Martins (2012) & 19
\end{tabular}

\begin{tabular}{ll}
\hline Figura 9. Distribuição de alunos a distância segundo o tipo de programa instrucional & 25 \\
\hline
\end{tabular}

Figura 10. Distribuição de cursos a distância ofertados de acordo com o caráter da 25

instituição

\begin{tabular}{ll}
\hline Figura 11. Modelo de investigação proposto & 118
\end{tabular}

Figura 12. Esquema de organização didático-pedagógica do curso "Gestão Estratégica" 134

\begin{tabular}{lll}
\hline Figura 13. Distribuição dos valores próprios (scree plot) da escala de Estratégias de & 169
\end{tabular} aprendizagem

Figura 14. Distribuição dos valores próprios (scree plot) da escala de Fatores $\quad 176$

relacionados à evasão e à persistência em EAD

\begin{tabular}{ll}
\hline Figura 15. Modelo A de análise de predição de Suporte tecnológico e de tutoria & 183
\end{tabular}

Figura 16. Representação do modelo de regressão múltipla para Suporte tecnológico e $\quad 185$ de tutoria como variável critério

\begin{tabular}{ll}
\hline Figura 17. Modelo B de análise de predição de Características exógenas ao curso & 186
\end{tabular}

\begin{tabular}{ll}
\hline Figura 18. Representação do modelo de regressão múltipla para Características & 188
\end{tabular} exógenas ao curso como variável critério

\begin{tabular}{ll}
\hline Figura 19. Modelo C de análise de predição de Características do aluno & 189
\end{tabular}

Figura 20. Representação do modelo de regressão múltipla para Características do $\quad 191$ aluno como variável critério

\begin{tabular}{ll}
\hline Figura 21. Modelo D de análise de predição de Desenho do curso & 192
\end{tabular}

Figura 22. Representação do modelo de regressão múltipla para Desenho do curso $\quad 194$ como variável critério 
Lista de tabelas

Tabela 1. Aspectos metodológicos de estudos desenvolvidos no campo de TD\&E (Abbad, Pilati \& Pantoja, 2003)

Tabela 2. Potencialidades e falhas da EAD (Abbad, 2007) 27

Tabela 3. Principais medidas e dispositivos legais no campo da EAD 33

Tabela 4. Instâncias e ferramentas reguladoras da avaliação da EAD no país 34

$\begin{array}{ll}\text { Tabela 5. Distribuição dos artigos de acordo com as bases de dados consideradas } & 39\end{array}$

Tabela 6. Resultados de buscas nas bases de dados SciELO, Banco de dissertações e $\quad 43$

teses da USP e Banco de dissertações e teses da UnB

Tabela 7. Classificação e definições das estratégias de aprendizagem (Warr \& Allan, 56

1998; Zerbini \& Abbad, 2008)

\begin{tabular}{lc}
\hline Tabela 8. Definições do conceito de autonomia & 59
\end{tabular}

\begin{tabular}{ll}
\hline Tabela 9. Instrumentos destinados à mensuração de estratégias de aprendizagem & 65
\end{tabular}

Tabela 10. Definição dos fatores do instrumento de Zerbini e Abbad (2008) 18

Tabela 11. Relação de variáveis referentes ao evento instrucional com a evasão ou a $\quad 83$

persistência de participantes em cursos a distância (Sales, 2009)

Tabela 12. Vantagens e desvantagens inerentes à emissão de direcionamento 92

educacional segundo Lee e Anderson (2013)

\begin{tabular}{lc}
\hline Tabela 13. Perfil da clientela de EAD (Abbad, 2007) & 95
\end{tabular}

\begin{tabular}{ll}
\hline Tabela 14. O contexto da clientela de EAD (Abbad, 2007) & 98
\end{tabular}

Tabela 15. Resultados de pesquisas nacionais e internacionais sobre "Fatores $\quad 100$

Relacionados à Evasão e Persistência em EAD"

\begin{tabular}{ll}
\hline Tabela 16. Características dos cursos avaliados & 123
\end{tabular}

\begin{tabular}{ll}
\hline Tabela 17. Curso "Licenciatura em Ciências": estrutura e organização & 128 \\
\hline
\end{tabular}

\begin{tabular}{ll}
\hline Tabela 18. Curso "Gestão Estratégica": estrutura e organização & 135 \\
\hline
\end{tabular}

\begin{tabular}{lr}
\hline Tabela 19. População e Amostras & 138 \\
\hline
\end{tabular}

\begin{tabular}{ll}
\hline Tabela 20. Resumo das informações sobre os instrumentos utilizados na pesquisa & 140 \\
\hline
\end{tabular}

Tabela 21. Frequência e porcentagem de respostas dos alunos por instituição de ensino 142 a cada questionário

\begin{tabular}{ll}
\hline Tabela 22. Resultados descritivos de Estratégias de aprendizagem & 157
\end{tabular}

Tabela 23. Resultados descritivos de Fatores relacionados à evasão e à persistência em 162 $\mathrm{EAD}$

Tabela 24. Valores próprios empíricos e aleatórios dos primeiros dez componentes de 169

Estratégias de aprendizagem

\begin{tabular}{ll}
\hline Tabela 25. Estrutura empírica da Escala de Estratégias de aprendizagem & 170 \\
\hline
\end{tabular}

Tabela 26. Valores próprios empíricos e aleatórios dos primeiros dez componentes de 176

Fatores relacionados à evasão e à persistência em EAD

Tabela 27. Estrutura empírica de Fatores relacionados à evasão e à persistência em $\quad 177$ EAD

\begin{tabular}{lc}
\hline Tabela 28. Resumo das informações sobre os instrumentos de pesquisa & 181 \\
\hline Tabela 29. Regressão múltipla padrão para o Modelo A & 184 \\
\hline Tabela 30. Regressão múltipla padrão para o Modelo B & 187 \\
\hline Tabela 31. Regressão múltipla padrão para o Modelo C & 190 \\
\hline Tabela 32. Regressão múltipla padrão para o Modelo D & 193 \\
\hline
\end{tabular}




\section{Apresentação}

Os atuais contextos laborais e de estudo podem ser caracterizados, entre outros elementos, por constantes transformações que não só alteram profundamente suas práticas e instrumentais, bem como exigem dos atores envolvidos - profissionais e estudantes - elevada capacidade de atualização e adaptação. Tais habilidades não só garantem a empregabilidade do indivíduo, mas se tornam elementos chave para o acesso e utilização de ferramentas imprescindíveis à comunicação e produção. $\mathrm{O}$ crescimento vertiginoso de ações educativas a distância (EAD) constitui-se em prova cabal desta modificação que perpassa o presente cenário mundial. A oferta de cursos e treinamentos não presenciais mediante a utilização de novas tecnologias de informação e comunicação (TICs) tem despertado o interesse de muitas instituições de ensino e organizações (Varanda, Zerbini \& Abbad, 2010).

Além de favorecerem a contínua atualização de competências e a aquisição de aprendizagem, os cursos não presenciais ou híbridos seguem as alterações sofridas na esfera social, política e tecnológica, tornando-se uma possibilidade que permite servir a um contingente de pessoas cada vez maior, diminuir custos a médio e longo prazos e otimizar o tempo (Zerbini, 2007; Zerbini \& Abbad, 2008). As atuais transformações que atravessam a área educacional e do trabalho revelam a procura por alternativas mais eficazes que possam responder às demandas do mercado profissional por aprimoramento e qualificação, gerando questionamentos que requerem discussão.

Atualmente, em âmbito nacional e internacional, programas de Treinamento, Desenvolvimento e Educação (TD\&E) atraem olhares pela maneira como vêm sendo oferecidos, uma vez que estes se configuram como ferramentas de significativo valor nas organizações, assim como cursos em instituições de ensino superior que, mais frequentemente, passaram a empregar processos de ensino fundamentados na internet e em novos recursos e mídias tecnológicos. Dessa feita, é fundamental que a qualidade e o êxito de tais ações sejam mensurados, permitindo avaliar se os resultados alcançados correspondem aos objetivos elencados anteriormente pela instituição e pelo próprio evento instrucional.

Em solo brasileiro, o tema da EAD tem ganhado contornos particulares e assumido novo destaque em debates e reflexões que já não mais se restringem aos limites dos seminários e encontros entre educadores. Objeto de diversas políticas públicas, a educação a distância é tratada por programas e ações governamentais que a utilizam tendo em vista a universalização do acesso ao ensino, e já desencadeou notáveis mudanças em legislações 
concernentes ao campo educacional. $\mathrm{O}$ aumento da oferta de ações de ensino em nível de graduação ministradas a distância tem se dado simultaneamente aos debates acerca da sua qualidade, sendo oportunos questionamentos sobre as potencialidades e os entraves estabelecidos pelas revoluções que envolvem as práticas de ensino e aquisição de conhecimentos.

A proliferação de eventos instrucionais ofertados a distância, a promulgação de políticas governamentais e a redação de documentos formais refletindo e reconsiderando propostas educacionais que promovam uma maior popularização do ensino, evidenciam um conveniente momento para a avaliação e debate da EAD como uma das práticas de ensino exequíveis, particularmente para a formação de nível superior.

Dessa forma, fazem-se imprescindíveis averiguações mais vigorosas que ponham à prova a eficiência e empregabilidade de tais esforços instrucionais, objetivando compreender quais são e de que forma se dão os processos de aprendizagem que os subjazem, bem como quais causas e fatores podem sobre eles interferir. Ações sistematizadas de pesquisa na área de avaliação de sistemas instrucionais não presenciais alcançam notória importância, uma vez que consideram as alterações apresentadas pelos treinamentos corporativos, cursos abertos e formação superior ao fazerem uso das TICs e da internet.

As discussões propiciadas por estudos de caráter científico podem contribuir para o delineamento e apreciação de ações educacionais a distância, gerando elementos que auxiliem as instituições de ensino superior que reclamam, diversas vezes, por assistência apropriada para a execução e acompanhamento dos eventos em EAD. Talvez, os reduzidos avanços envolvendo a sistematização de resultados de aprendizagem obtidos por esforços desse feitio (Carvalho \& Abbad, 2006; Castro \& Ferreira, 2006) podem ser justificados pelo aparecimento e emprego hodierno de processos instrucionais de tal natureza no Brasil.

A pesquisa ora apresentada, dessa forma, tem como objetivo propor e testar um modelo de avaliação de ações educacionais oferecidas a distância via internet, intentando cumprir as agendas de pesquisas propostas por Abbad, Pilati e Pantoja (2003), Abbad, Zerbini e Souza (2010), Carvalho e Abbad (2006), Salas e Cannon-Bowers (2001), Sales (2009), Tannenbaum e Yukl (1992), Zerbini (2007), entre outros.

Serão consideradas variáveis antecedentes do referido modelo aquelas relacionadas às características da clientela (estratégias de aprendizagem e perfil sociodemográfico). A variável critério do modelo será o conjunto de fatores ligados à evasão e à persistência em EAD (contexto de estudo, desenho do treinamento e o atributos pessoais do estudante).

A fim de auxiliar o acompanhamento do texto, a Figura 1 mostra a forma como os 
capítulos e as seções estão organizados e sua sequência de exposição no presente estudo.

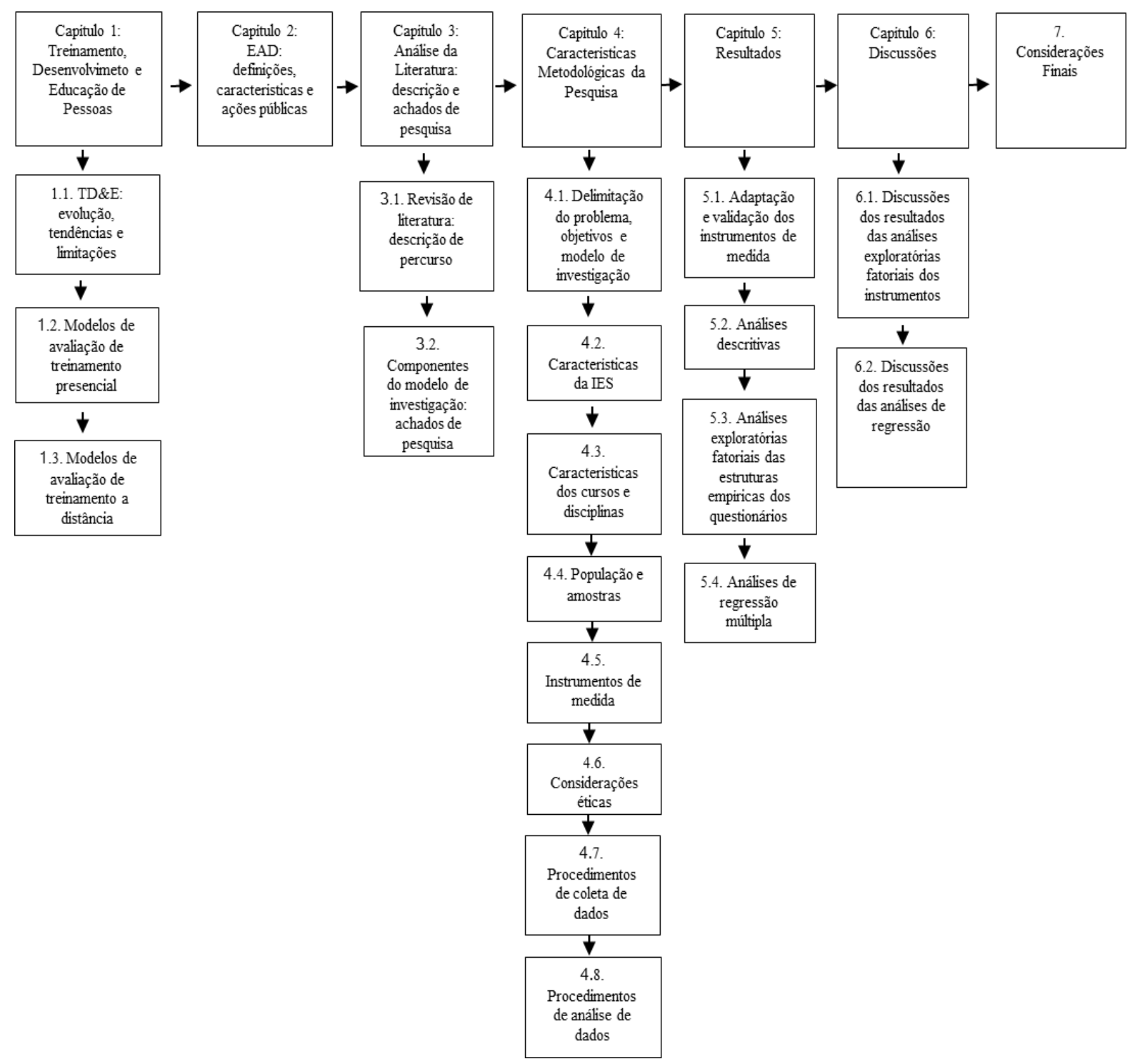

Figura 1. Estrutura geral de desenvolvimento do texto.

O Capítulo 1 discorre sobre os componentes e as propriedades específicas do sistema de Treinamento, Desenvolvimento \& Educação, bem como apresenta um retrospecto acerca dos progressos, tendências e obstáculos concernentes ao subsistema de Avaliação de efeitos de TD\&E. Também são descritos alguns modelos de avaliação destinados a treinamentos presenciais e a distância, disponíveis na literatura internacional e brasileira.

O Capítulo 2 é dedicado à caracterização da modalidade EAD enquanto recurso utilizado, nacional e internacionalmente, para a promoção do ensino em contextos de Organização e Trabalho (O\&T) e por Instituições de Ensino Superior (IES). Situa a EAD no campo da educação, abordando transformações ocorridas nas políticas públicas e legislação 
nacional e os embaraços impostos a sua implementação.

No Capítulo 3 é detalhado o trajeto da revisão de literatura sobre as variáveis de interesse do estudo: Características da Clientela e Fatores Relacionados à Evasão e à Persistência em EAD. Também são apresentados e discutidos terminologias, conceitos, características e resultados de pesquisa relacionados a essas variáveis.

A delimitação do problema, a justificativa e os objetivos da pesquisa se encontram dispostos no Capítulo 4. Ademais, delineia-se o modelo de investigação proposto e são expostas as características das instituições de ensino superior parceiras, dos cursos e disciplinas avaliadas. São delimitados população e amostras, os instrumentos de medida, assim como, os procedimentos de coleta e análise dos dados.

Os Capítulos 5 e 6 apresentam os resultados da pesquisa, bem como as discussões a respeito dos mesmos. As considerações finais acerca do estudo ora em questão, suas limitações e contribuições encontram-se dispostas no capítulo 7. 


\section{CAPÍtUlO 1. TREINAMENTO, DESENVOLVIMENTO E EDUCAÇÃO DE PESSOAS}

\section{Objetivo do capítulo 1}

O presente capítulo se propõe a descrever os componentes e as características de projetos e ações de Treinamento, Desenvolvimento e Educação de pessoas (TD\&E), bem como apresentar os mais notórios progressos e limitações identificados no subsistema de avaliação de eventos formais de TD\&E, especialmente aqueles voltados a ações educacionais em contexto de IES. Também são apresentados alguns modelos de avaliação de eventos instrucionais presenciais e a distância disponíveis na literatura científica.

\subsection{Treinamento, Desenvolvimento e Educação: definições, evolução e limitações}

Atualmente, eventos ocorridos no campo de TD\&E estão se destacando em termos de importância e necessidade, uma vez que os novos contextos de trabalho e ensino reclamam com premência por ações capazes de sanar lacunas de competências ${ }^{1}$ (CHAs) e que promovam sua constante atualização visando o bom desempenho profissional e acadêmico. Frente a tal conjuntura, cada vez mais indivíduos e organizações laborais recorrem aos benefícios advindos dos esforços instrucionais que se refletem, entre outras coisas, em incrementos financeiros, ocupacionais e de mercado; as elevadas quantias que se destinam ao subsídio de programas educacionais fornecem indicações da importância dos mesmos para empresas e pessoas: estima-se que nos EUA os investimentos financeiros em educação continuada ultrapassam $€ 10.000,00$, enquanto que na Espanha o montante gira em torno de $€ 3.000,00$ (Iglesias \& Salgado, 2012). A aplicação de imódicas cifras justifica-se pelos ganhos em termos de aquisição de conhecimentos, aprendizagem efetiva, otimização de desempenhos e produtividade (Iglesias \& Salgado, 2012).

Os processos de TD\&E são descritos enquanto ações empreendidas pelas organizações a fim de preencher lacunas de desempenho funcional e tornar os colaboradores aptos ao exercício de novas atribuições. Para a aquisição de novos CHAs, tais ações de TD\&E apoiam-

\footnotetext{
${ }^{1}$ De acordo com Brandão \& Guimarães (2001) o conceito de competência engloba três distintas dimensões conhecimentos, habilidades e atitudes - essenciais à consecução de propósitos organizacionais/mercadológicos, e que são sistematicamente transferidas pelo indivíduo para o cenário laboral.
} 
se fortemente nas tecnologias instrucionais vigentes (Meneses, Zerbini \& Abbad, 2010).

De forma geral, é possível afirmar a existência de certa falta de concordância quanto aos termos que designam o campo de TD\&E; havendo uma nítida pluralidade de definições e elementos na área, diversos problemas conceituais são observados (Vargas \& Abbad, 2006). Vargas e Abbad (2006) chamam a atenção para tal multiplicidade de compreensões e alertam para a necessidade de uma avaliação mais aprofundada de tais elementos, já que com o passar do tempo, e consequente desenvolvimento da área de treinamento, houve a incorporação de novos termos ainda pouco definidos e compreendidos. Apesar das diferenças conceituais observadas no campo das ações de TD\&E, Abbad e Borges-Andrade (2004) consideram que quando tais estratégias são empregadas corretamente o processo de aprendizagem é favorecido e estimulado. Cabe avaliar quais iniciativas, dentro de suas características e limitações, melhor se adequam aos objetivos educacionais estabelecidos.

De acordo com Bastos (1991), na área de TD\&E quatro conceitos são amplamente utilizados e diferenciados entre si, a saber: instrução, processo sistemático envolvendo a determinação e o estabelecimento de objetivos instrucionais específicos e a aplicação de procedimentos de ensino apropriados ao conteúdo a ser transmitido; treinamento, ações que preparam os indivíduos para um melhor exercício de suas atuais atribuições profissionais ou acadêmicas; desenvolvimento, medidas formuladas e voltadas para o crescimento pessoal e laboral do empregado, sem que exista relação direta com o trabalho ou com as atividades executadas durante o mesmo; e educação, considerada a forma mais ampla de aprendizagem cujos contornos ultrapassam o limiar do mundo do trabalho. Nesse último tipo de programa são envolvidas iniciativas orientadas para tarefas que serão desempenhadas, em um futuro próximo, pelo trabalhador. Logo, a educação pode ser vista como oportunidade de capacitação fornecida pela organização ao indivíduo para ocupação de diferentes cargos dentro da instituição em momentos outros. Cursos técnicos profissionalizantes, cursos de graduação e cursos de pós-graduação são exemplos de eventos dessa natureza (Meneses et al., 2010; Vargas \& Abbad, 2006).

Considerando e tomando por base o diagrama proposto por Sallorenzo (2000), que congrega os termos supracitados, Carvalho (2003) e Zerbini (2003) sugeriram modificações para o mesmo. A primeira alteração envolve a adição de um novo termo, informação, que também possui considerável importância para os eventos educacionais. A incorporação deste elemento é justificável à medida que muitas pessoas necessitam ter acesso aos conteúdos e informações disponíveis, e não a programas sistematizados de treinamento. Uma segunda mudança proposta pelas autoras supracitadas corresponde à transformação do tipo de linha 
que circunda cada um dos termos. Ao invés de linhas contínuas é proposto o uso de linhas tracejadas, que sinalizariam a tenuidade dos limites entre os conceitos que caracterizam cada tipo de ação educacional. A Figura 2 ilustra o modelo proposto por Carvalho (2003) e Zerbini (2003) e exemplifica a extensão dos conceitos até agora citados.

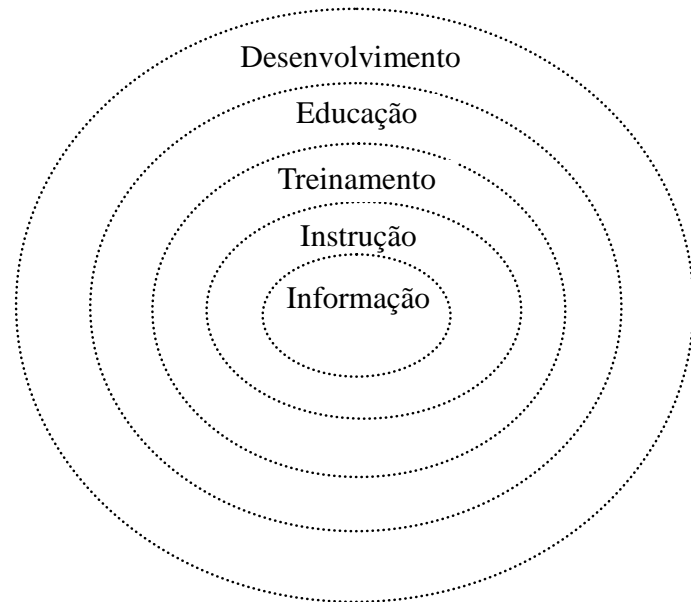

Figura 2. Diagrama proposto por Carvalho (2003) e Zerbini (2003).

Posteriormente, Vargas e Abbad (2006) desenvolveram um terceiro diagrama, com alterações na ordem de posicionamento de dois conceitos: desenvolvimento e educação. Para as autoras, o conceito de educação englobaria o de desenvolvimento, já que o primeiro apresentaria um nível mais elevado de complexidade. A Figura 3 ilustra a abrangência dos conceitos explicitados.

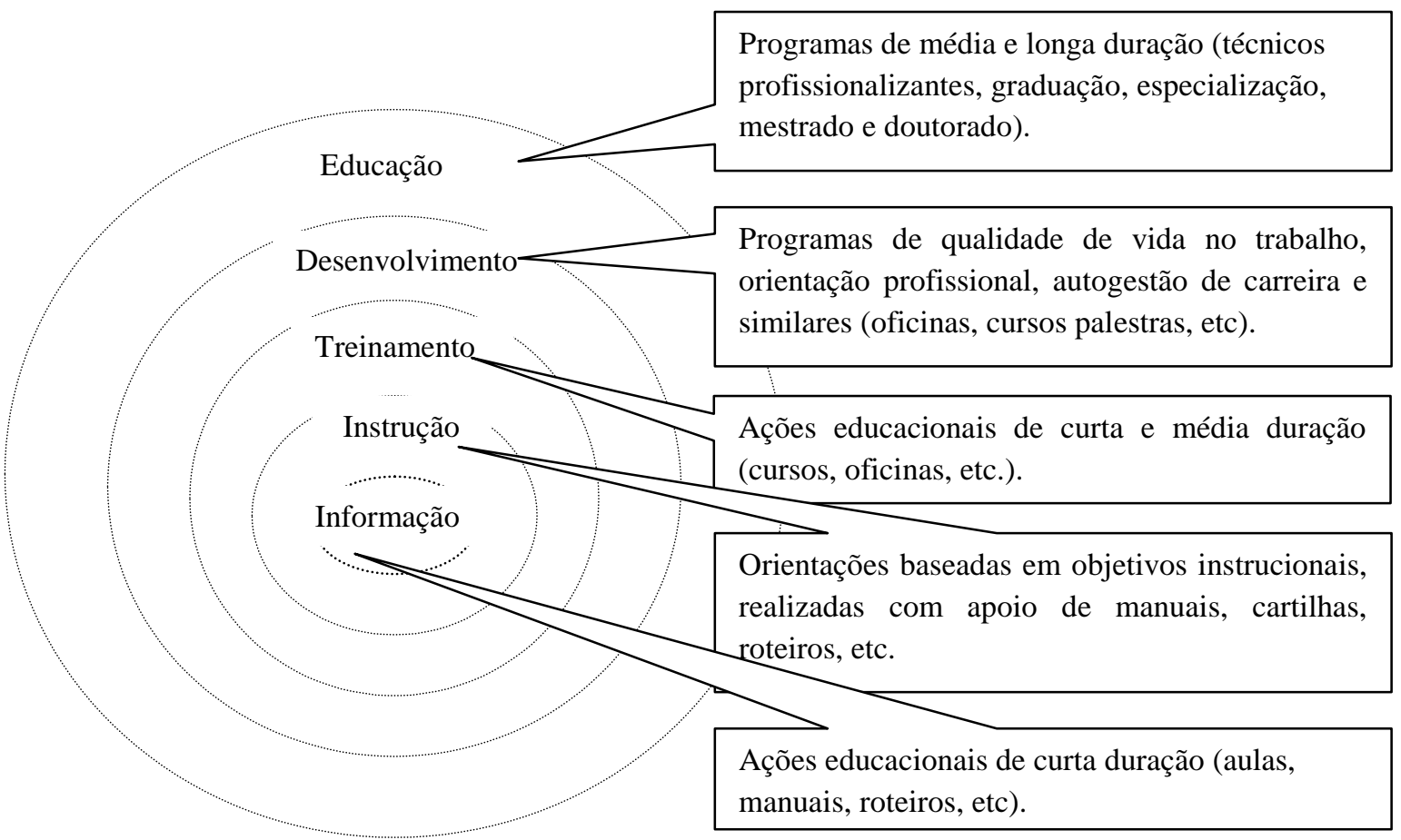

Figura 3. Conceitos e ações educacionais propostos por Vargas e Abbad (2006). 
Grosso modo, pode-se considerar que as ações de TD\&E são estruturadas a partir de três subsistemas basais, a saber: avaliação de necessidades de ações instrucionais; planejamento e execução; e avaliação de treinamento. $\mathrm{O}$ processo de avaliação de necessidades (ANT) é responsável por determinar onde a ação instrucional é necessária, qual conteúdo deve ser treinado e quem são os agentes a participarem da mesma. Seu princípio se dá a partir da verificação ou adiantamento de uma específica necessidade de desempenho. Para tanto, é necessária uma análise acurada da problemática identificada, isto porque, frequentemente, tais queixas decorrem de condições inadequadas de trabalho ou de reduzidos níveis de motivação para o exercício profissional - condições estas que não se constituem como alvo das ações educacionais de TD\&E (Gondim \& Silva, 2004). Havendo a constatação de que o problema de desempenho é passível de resolução por meio de remoção de deficiências de CHAs, inicia-se efetivamente o processo de avaliação de necessidades, realizado a partir das seguintes análises: organizacional, de tarefas e individual.

Após identificadas as lacunas de competências a serem treinadas, o subsistema seguinte, Planejamento Instrucional, tem sua gênese na definição dos desempenhos e competências a serem desenvolvidos pelos participantes. De posse de tais elementos e peças de informação, o processo de planejamento de ações de TD\&E é iniciado pela definição dos objetivos educacionais, ou seja, pela determinação dos desempenhos esperados da parte dos treinandos ao final do evento. O seguinte passo do planejamento de TD\&E corresponde a escolha da modalidade de entrega: para que o planejador defina-se por ações presenciais, a distância ou semipresenciais é preciso que o mesmo analise o perfil demográfico, funcional e profissional dos agentes envolvidos no evento. Os desempenhos perseguidos pelos objetivos educacionais estabelecidos também devem ser levados em conta, pois possibilitam compreender sua complexidade e a necessidade de maior contato, por parte do aprendiz, com determinadas situações. A eficácia de cada modalidade de ensino, a disponibilidade, quanti e qualitativa, dos recursos financeiros, materiais, tecnológicos e humanos também devem ser considerados durante a escolha a ser feita (Abbad, Zerbini, Carvalho \& Meneses, 2006).

Finalmente, as avaliações dos efeitos decorrentes de ações de TD\&E, foco do presente estudo, se constituem como valioso e necessário instrumental para a efetividade e êxito do programa educacional empreendido, especialmente em situações nas quais houve uma elaboração pouco sistemática e criteriosa dos subsistemas de avaliação de necessidades de treinamento e planejamento. Pode-se afirmar que tal subsistema objetiva exercer controle sobre o processo, proporcionar feedback ao sistema, tomar decisões acerca do treinamento e, por fim, torná-lo capaz de promover alterações no ambiente em questão. Inúmeros modelos 
utilizados para tal fim encontram-se disponíveis na literatura, sendo o modelo proposto por Kirkpatrick (1976) um marco pioneiro na área (Borges-Andrade, 2006).

Observando os resultados oriundos de revisões clássicas empreendidas no campo da Psicologia (Campel, 1971; Salas \& Cannon-Bowers, 2001; Tannenbaun \& Yukl, 1992; Wexley, 1984), é possível constatar evoluções e aprimoramentos que atravessam o subsistema de avaliação de TD\&E. Alguns exemplos de tais transformações se ligam a refinamentos dos modelos taxonômicos utilizados, com redefinição de conceitos; inclusão de variáveis ambientais nos modelos avaliativos; emprego de desenhos e delineamentos de investigação experimentais e quase-experimentais acompanhado de pós-testes; adoção de técnicas analíticas e de controle de dados multivariados; inserção de modelos de avaliação multiníveis de treinamento para transferência vertical. Todavia, também se verifica a necessidade de transpor limitações que restringem a eficiência do sistema de TD\&E, tal como: restrições culturais e técnicas no uso de avaliações de aprendizagem; dificuldades de proceder a avaliações em níveis mais abrangentes; inadequações ou falta de manejo de resultados gerados por ações de TD\&E; carência de orientações teórico-metodológicas que embasem avaliações em termos de resultados organizacionais; entre outros. Ademais, pesquisas dedicadas à avaliação da efetividade de ações instrucionais ainda são raras e apresentam incongruências quanto aos objetivos pretendidos (Inglesias \& Salgado, 2012).

Pensando o subsistema de avaliação de TD\&E, é vital que haja competência política e técnica por parte da área envolvida para que os resultados coletados venham a ser transformados em propostas de melhorias para colaboradores, grupos e organização. Pouco adianta identificar falhas, acertos ou lacunas se estes não forem trabalhados no sentido de gerarem ou sinalizarem perspectivas de mudanças estratégicas. A seguir, são apresentados e discutidos os principais modelos de avaliação elaborados com vistas à análise de esforços instrucionais formais, de caráter presencial e a distância.

\subsection{Modelos de avaliação de treinamento presencial}

A avaliação de treinamentos é definida como um processo estruturado que envolve a coleta de dados que permitirão que os eventos instrucionais sejam revistos e aperfeiçoados por meio de decisões ligadas à escolha, emprego, valorização e alteração dos elementos instrucionais vigentes (Goldstein, 1991). De acordo com Abbad (1999), a avaliação de 
treinamento consistiria em um conjunto de atividades, postulados e princípios teóricometodológicos que objetivam produzir informações confiáveis a respeito dos sistemas de treinamento.

É possível afirmar que a avaliação de treinamento possibilita ao profissional envolvido: deter controle sobre as ações educativas implementadas, retroalimentar o sistema, deliberar a respeito do treinamento e torná-lo apto a modificar seu contexto (Meneses et al., 2010).

Após muitos anos de estagnação na esfera das metodologias de avaliação de treinamentos, as tipologias e modelos clássicos utilizados como substrato na aferição dos cursos passaram a ter seus postulados básicos questionados, de modo que enquanto esses modelos se enfraqueciam, os mais contemporâneos ganharam notoriedade por também levarem em consideração variáveis capazes de fornecer dados que contribuem para a análise e avaliação do programa educacional, bem como para a retroalimentação de todos os agentes envolvidos (Campel, 1971; Salas \& Cannon-Bowers, 2001).

Os principais modelos avaliativos clássicos foram desenvolvidos por Kirkpatrick (1976) e Hamblin (1978), e, grosso modo, assentam-se nos seguintes níveis: (1) reação; (2) aprendizagem; (3) comportamento no cargo; (4) resultados/organização; e (5) valor final este último acrescido por Hambin. Para tais autores, os níveis propostos possuiriam caráter sequencial, linear e estariam fortemente correlacionados entre si. Tais aspectos foram profundamente criticados por diversos estudiosos, sendo que Alliger e Janak (1989), após avaliarem inúmeros resultados de pesquisa, concluíram que não havia qualquer confirmação da relação causal entre os níveis, tal como inicialmente foi proposto. Outros trabalhos que investigaram a relação existente entre os níveis reação, aprendizagem e comportamento no cargo também não encontraram evidências de validade nos pressupostos de tais modelos (Abbad, Gama \& Borges-Andrade, 2000; Goldstein, 1991).

No tocante ao estado técnico-científico que assinala o campo da avaliação de treinamento na seara de TD\&E, Abbad et al. (2003) aponta para um expressivo progresso não identificado desde a revisão executada por Borges-Andrade e Abbad (1996). A Tabela 1 resume os aspectos metodológicos mais importantes das pesquisas conduzidas em território nacional e estrangeiro que marcam o referido avanço. 
Tabela 1. Aspectos metodológicos de estudos desenvolvidos no campo de TD\&E (Abbad, Pilati \& Pantoja, 2003).

\begin{tabular}{|c|c|c|}
\hline Método & Pesquisas Estrangeiras & Pesquisas Nacionais \\
\hline Amostra & $\begin{array}{l}\text { Profissionais de ensino médio } \\
\text { completo, estudantes universitários e } \\
\text { nível superior }\end{array}$ & $\begin{array}{l}\text { Profissionais de ensino médio } \\
\text { completo e nível superior }\end{array}$ \\
\hline Organizações & $\begin{array}{l}\text { Instituições públicas e privadas, } \\
\text { universidades, forças armadas e } \\
\text { empresas de diferentes setores } \\
\text { econômicos }\end{array}$ & $\begin{array}{l}\text { Instituições públicas, privadas de } \\
\text { diferentes setores econômicos }\end{array}$ \\
\hline Coleta de dados & Aplicação de questionários & $\begin{array}{l}\text { Utilização de questionários, } \\
\text { entrevistas, análises documentais e } \\
\text { observações diretas }\end{array}$ \\
\hline Delineamento & $\begin{array}{l}\text { Experimentais pré e pós-teste com } \\
\text { grupo-controle }\end{array}$ & Correlacionais de campo \\
\hline Fontes de informação & Autoavaliação, heteroavaliação & $\begin{array}{l}\text { Autoavaliação, heteroavaliação, } \\
\text { análises documentais e bases } \\
\text { secundárias de dados }\end{array}$ \\
\hline Tipos de medida & $\begin{array}{l}\text { Medidas em impacto em } \\
\text { profundidade, com avaliações globais } \\
\text { de efeitos sobre a personalidade e } \\
\text { outros traços disposicionais }\end{array}$ & $\begin{array}{l}\text { Medidas em impacto em amplitude e } \\
\text { em profundidade }\end{array}$ \\
\hline $\begin{array}{l}\text { Período de tempo transcorrido } \\
\text { até a coleta }\end{array}$ & $\begin{array}{l}\text { De quatro semanas (mínimo) à dois } \\
\text { anos e meio (máximo) }\end{array}$ & $\begin{array}{l}\text { De duas semanas (mínimo) à quatro } \\
\text { anos (máximo) }\end{array}$ \\
\hline Análise de dados & $\begin{array}{l}\text { Equações estruturais, regressões } \\
\text { hierárquicas, ANCOVA, MANCOVA } \\
\text { e MANOVA }\end{array}$ & $\begin{array}{l}\text { Regressões múltiplas stepwise e } \\
\text { correlações canônicas }\end{array}$ \\
\hline
\end{tabular}

Em relação ao nível de instrução das amostras utilizadas é possível que as pesquisas nacionais e estrangeiras apresentem certa similitude. De forma geral, nos estudos de ambas as origens, os participantes eram profissionais de nível superior que exerciam diferentes profissões, como médicos, enfermeiros, orientadores educacionais, gerentes e bancários. Nota-se, no entanto, que os estudos brasileiros não empregaram amostras compostas por estudantes universitários. No tocante ao caráter das organizações avaliadas, tanto os estudos nacionais como os estrangeiros consideraram organizações públicas e privadas, principalmente do setor terciário, prestadoras de serviços nas áreas da telecomunicação, saúde, pesquisa, educação, finanças e energia elétrica.

A aplicação de questionários e testes esteve presente entre os procedimentos de coleta de dados de ambas as pesquisas, sendo que no caso brasileiro verificou-se também a realização de entrevistas, análises documentais e observações diretas. Delineamentos 
experimentais do tipo pré e pós-teste com grupo-controle prevaleceram nos estudos internacionais, enquanto que no contexto nacional foram identificados apenas delineamentos correlacionais de campo. No tocante às fontes de informação, poucas pesquisas nacionais e estrangeiras empregaram a heteroavaliação, de modo que análises documentais e consultas a bases secundárias de dados ficaram circunscritas somente aos trabalhos brasileiros.

Em relação aos tipos de medidas, as pesquisas internacionais utilizaram diversos instrumentos que avaliam o impacto em profundidade, atentando para efeitos globais das ações instrucionais sobre a personalidade e outros traços disposicionais do participante. No caso do tempo decorrido desde o encerramento do evento instrucional até a coleta de dados de impacto, as amostras nacionais e estrangeiras se diferenciaram significativamente.

Em virtude das diferenças observadas quanto ao tipo de delineamento adotado pelas pesquisas nacionais e estrangeiras, houve diversidade em relação à escolha de estratégias de análise de dados: no cenário brasileiro o procedimento estatístico mais utilizado foi a regressão múltipla stepwise, enquanto que nos trabalhos internacionais estratégias diversificadas foram empregadas, e.g. equações estruturais, regressões hierárquicas, ANCOVA, MANCOVA e MANOVA.

Havendo o enfraquecimento dos chamados modelos clássicos de avaliação, que enfocavam apenas os resultados produzidos, aqueles de feitio mais contemporâneo vêm ganhando notoriedade por também levarem em consideração componentes capazes de explicar a ocorrência dos resultados de eventos instrucionais (Zerbini \& Abbad, 2007). Dentre tais modelos denominados integrativos, sobressaem-se aqueles desenvolvidos por BorgesAndrade (1982, 2006) denominado Modelo de Avaliação Integrada e Somativa (MAIS) e o Modelo de Avaliação do Impacto do Treinamento no Trabalho, IMPACT, criado por Abbad (1999).

O modelo MAIS - composto por cinco componentes: (1) insumo, (2) procedimentos, (3) processo, (4) resultados e (5) ambiente, sendo que este último é desdobrado em avaliação de necessidades, suporte, disseminação e efeitos em longo prazo - envolve variáveis do curso, do ambiente e da pessoa, anteriores e posteriores à instrução. A Figura 4 apresenta o esquema gráfico do modelo. 


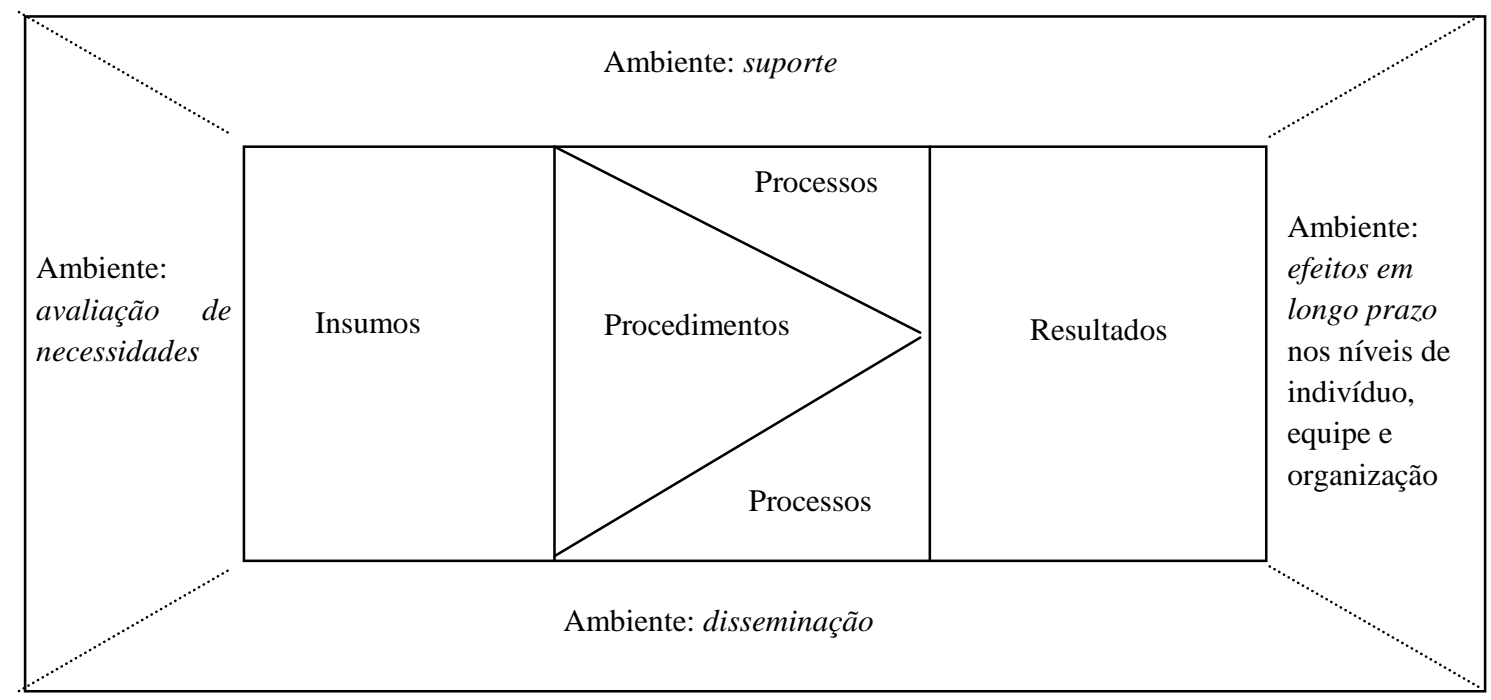

Figura 4. Modelo de Avaliação Integrado e Somativo - MAIS (Borges-Andrade, 1982, 2006).

Inspirado no modelo MAIS, o IMPACT é formado por sete itens, tal como pode ser visto na Figura 5: (1) percepção de suporte organizacional, (2) características de treinamento, (3) características da clientela, (4) reação, (5) aprendizagem, (6) suporte à transferência e (7) impacto do treinamento no trabalho.

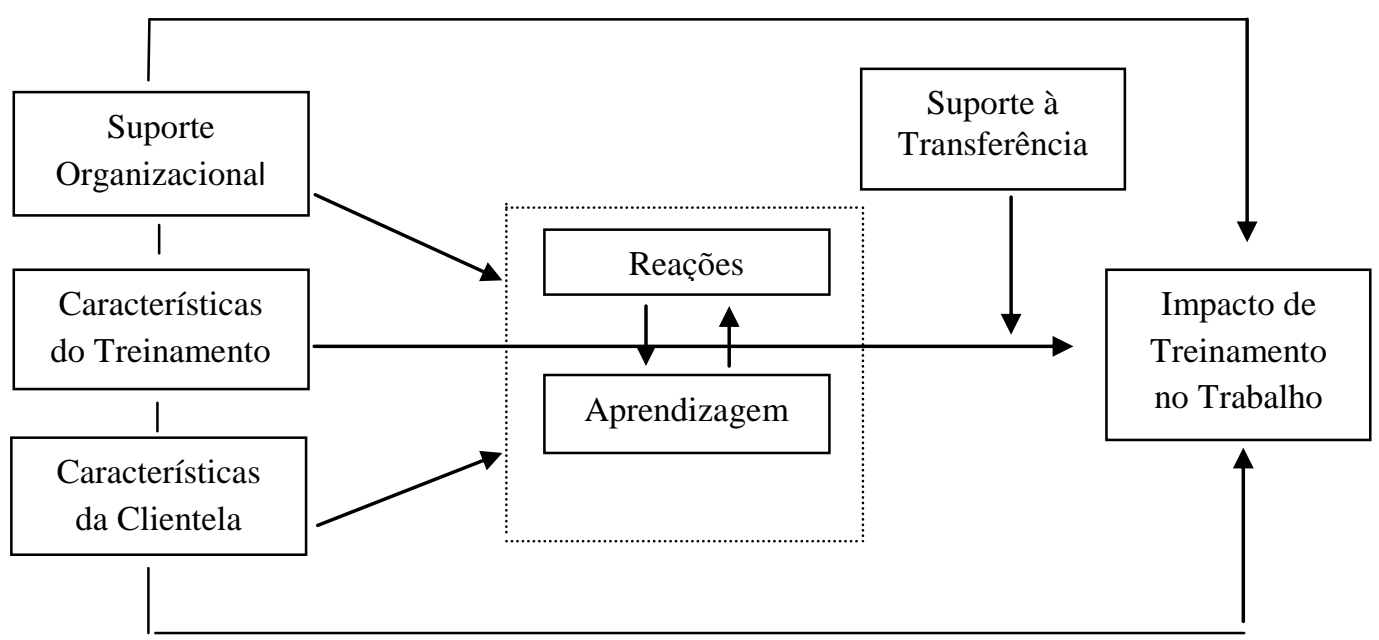

Figura 5. Modelo de Avaliação do Impacto do Treinamento no Trabalho - IMPACT (Abbad, 1999).

A proposição de modelos avaliativos que considerassem variáveis até então relegadas foi de fundamental importância para os fins pelos quais respondem os processos de avaliação instrucional. Todavia, pelo fato de ambos os modelos MAIS e IMPACT terem sido destinados para o ensino presencial, e face ao crescente emprego da EAD como meio de ensino estratégico, intensificou-se a necessidade da criação de modelos e medidas próprios para ações educativas de tal natureza. Desta forma, os modelos destinados à avaliação de 
treinamentos a distância serão descritos na seção seguinte.

\subsection{Modelos de avaliação de treinamento a distância}

A avaliação de cursos ofertados a distância não deve ser considerada tarefa simplória, uma vez que exige cuidados especiais no tocante ao reconhecimento dos elementos que os tornam iniciativas efetivas e eficazes. Por essa razão, é imprescindível que tais cursos sejam considerados a partir de modelos não tradicionais que, costumeiramente, se atentam apenas para os resultados produzidos - como, satisfação dos participantes, aprendizagem, impacto do curso no desempenho funcional, impacto institucional - que, por sua vez, não poderão prever a identificação dos fatores internos e externos ao evento que geram tais produtos (Sallorenzo, Abbad, Botelho \& Silva, 2004). A seguir, discorrer-se-á brevemente acerca de alguns dos esforços de pesquisa que culminaram com a proposição de ferramentas avaliativas para o sistema instrucional a distância.

Referenciando-se no modelo e instrumentos desenvolvidos por Abbad (1999) a fim de avaliar a variável reação, Carvalho (2003) e Zerbini (2003, 2007) verificaram hiatos no que tange à produção de ferramentas de medidas fidedignas e válidas no campo de avaliação de ações educacionais a distância. Dessa feita, as pesquisadoras, ao proporem um modelo avaliativo reduzido, elaboraram e validaram inúmeros instrumentos próprios a eventos instrucionais ofertados via internet, que objetivavam identificar elementos relativos às características da clientela, aos procedimentos de ensino-aprendizagem e ao ambiente do curso (Zerbini, Borges-Ferreira \& Abbad, 2012).

Neste sentido, Carvalho (2003) e Zerbini (2003), em estudos que contaram com a participação de indivíduos inscritos no curso IPGN do Sebrae, desenvolveram e testaram modelos reduzidos de avaliação inspirados, especialmente, no MAIS (Borges-Andrade, 1982) e no IMPACT (Abbad, 1999). O modelo proposto por Carvalho (2003) apresentou os seguintes componentes de investigação: características da clientela, reações ao treinamento, aprendizagem, falta de suporte à transferência e impacto do treinamento no trabalho. Apesar de ser uma variante reduzida do IMPACT, novas variáveis foram inseridas neste modelo, recebendo elas as seguintes definições: (1) aprendizagem, que corresponde no estudo ao número de acertos dos participantes nos exercícios e tarefas de fixação obrigatórios, ministrados ao término de cada capítulo do curso; (2) interface gráfica do curso, compreende 
o aspecto ergonômico do software quanto à navegabilidade e usabilidade do ambiente na internet; (3) falta de suporte à transferência, avalia as percepções dos participantes com relação a inúmeros fatores (ambientais, familiares, comunitários) capazes de interferir negativamente na abertura e conservação de um negócio; (4) impacto em amplitude, medida que afere o grau de uso de estratégias de gerenciamento de um empreendimento, em termos de tratamento aos colaboradores, clientes e fornecedores, ações de desenvolvimento próprio, controle financeiro e jurídico do negócio e iniciativas de marketing e estruturação do ambiente físico.

Já o modelo validado por Zerbini (2003) corresponde a uma versão adaptada à situação de treinamento a distância (via web) e apresenta caráter multivariado composto por quatro componentes, a saber: (1) Características da Clientela, (2) Reações, (3) Falta de Suporte à Transferência e (4) Impacto do Treinamento no Trabalho. O primeiro componente diz respeito aos dados demográficos dos participantes (sexo, idade, região geográfica, nível de escolaridade, experiência na internet, área de negócios de interesse, proprietário de empresa, participações anteriores em cursos a distância, ocupação atual), as estratégias de aprendizagem por eles utilizadas e hábitos de estudo. O componente Reações relaciona-se à satisfação dos participantes em relação às características instrucionais do curso (qualidade dos objetivos de ensino, conteúdos, sequência, avaliações, estratégias e meios, e qualidade das ferramentas eletrônicas), à percepção do treinando acerca da qualidade da interação tutoralunos, domínio do conteúdo e uso de estratégias de ensino. O terceiro componente, Falta de Suporte à Transferência, envolve a avaliação discente quanto ao nível que variáveis do contexto familiar, social e/ou governamental poderiam afetar negativamente o negócio ou a aplicação das habilidades aprendidas no curso. Por fim, o último componente, Impacto do Treinamento no Trabalho, enfoca os efeitos diretos da ação educativa sobre o desempenho do participante em tarefas intimamente relacionadas aos CHAs desenvolvidos no treinamento.

Frente a necessidade de elaboração de instrumentos específicos à avaliação de eventos instrucionais a distância, Sallorenzo et al. (2004) propuseram o Modelo de Avaliação de Efetividade de Cursos a Distância da Universidade Católica de Brasília (UCB), baseado no Modelo IMPACT (Abbad, 1999). 


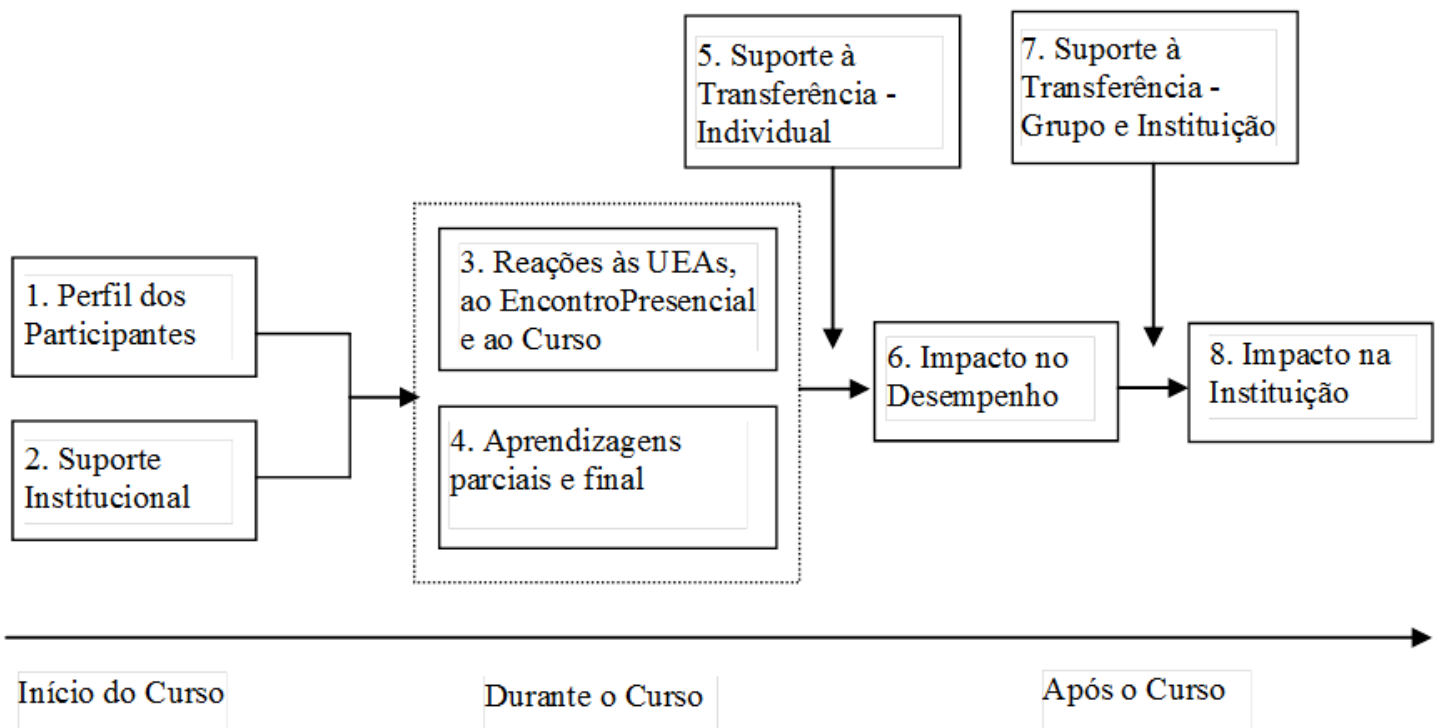

Figura 6. Modelo de Avaliação de Efetividade de Cursos a Distância da Universidade Católica de Brasília (UCB) (Sallorenzo et al., 2004).

O componente Perfil dos Participantes corresponde aos dados demográficos, funcionais, formas de adesão, expectativas e nível de conhecimento na área.

O segundo componente, Suporte Institucional, é descrito em termos das percepções dos participantes e dos superiores imediatos quanto ao apoio ofertado pela instituição a fim de viabilizar a realização dos cursos. Vale dizer que esse componente é medido apenas nos casos de cursos institucionais.

Reações, terceiro componente do modelo, refere-se ao nível de satisfação dos participantes para com a mídia eletrônica, materiais, estratégias pedagógicas, interatividade, interação tutor-aluno e aluno-aluno, e autoavaliação de aprendizagem.

O quarto componente, Aprendizagens Parciais e Final, avalia o grau de apropriação dos conteúdos demonstrado pelos participantes nas atividades de cada unidade de estudo autônomo e ao curso como um todo. Estas medidas são obtidas através de escores atribuídos pelos tutores aos alunos nos exercícios avaliativos dos cursos.

Em relação ao componente Suporte Institucional à Transferência de Aprendizagem, este mensura o apoio fornecido pela instituição à aplicação dos conhecimentos e habilidades adquiridos durante o evento instrucional para o contexto de trabalho. O cotejamento deste componente é realizado por meio das percepções dos participantes dos cursos e seus respectivos superiores imediatos em relação ao referido suporte.

O componente de número seis, Impacto no Desempenho, considera os efeitos dos 
cursos no desempenho funcional dos participantes. A coleta de dados referente a esta medida compreende autoavaliação (percepção dos participantes dos cursos quanto às mudanças ocorridas na própria atuação profissional em virtude das novas aprendizagens) e heteroavaliação (percepção dos superiores imediatos ou outro colaborador externo apto a realizar a avaliação).

O componente Suporte à Transferência para o Grupo e Instituição, corresponde ao apoio institucional dado à disseminação dos conhecimentos e habilidades adquiridos pelos participantes para os grupos e para a instituição. São consideradas as opiniões dos participantes dos cursos e de seus respectivos superiores imediatos a esse respeito.

Por fim, Impacto na Instituição, último componente do modelo, estima as mudanças ocorridas na instituição possivelmente atribuídas ao curso.

Em seu estudo, Coelho Júnior (2004, 2008) desenvolveu e validou um modelo de avaliação de ações instrucionais a distância de caráter empírico e baseado, primordialmente, nos Modelos MAIS (Borges-Andrade, 1982) e IMPACT (Abbad, 1999). O modelo elaborado foi conceitualizado pelo autor como um recorte específico e reduzido de variáveis presentes no MAIS e IMPACT. O primeiro componente presente, Características da Clientela, corresponde aos dados demográficos (gênero, unidade, tempo de serviço, grau de escolaridade) e funcionais (cargo, subsistema de lotação, área fim ou meio, conhecimento anterior de medidas de prevenção à lavagem de dinheiro) dos participantes do estudo. Já o componente Suporte à Aprendizagem relaciona-se ao apoio prestado por pares e chefias a novas aprendizagens no ambiente de trabalho, e ao apoio ao uso (transferência) de novas habilidades no trabalho, adquiridas por meio de ações instrucionais formais (treinamentos), e através, também, de aprendizagens naturais ou espontâneas, ocorridas no ambiente laboral. Avaliando as condições ambientais de apoio à aprendizagem natural e induzida e o seu relacionamento com impacto do treinamento no trabalho, o autor objetivou avaliar a influência do suporte ofertado a tais processos de aprendizagem, conjecturando que as características do ambiente poderiam facilitar, dificultar ou produzir obstáculos à aprendizagem e ao uso de novas habilidades no trabalho, independentemente da forma como elas fossem adquiridas, ou seja, através de treinamentos ou de modo informal.

Em estudo conduzido por Borges-Ferreira (2005) foram validadas quatro escalas de avaliação de treinamentos a distância (Reação ao Desempenho da Tutoria, Reação aos Procedimentos Instrucionais, Reação aos Resultados e Reação à Interface Gráfica), uma escala de Estratégias de Aprendizagem, bem como propostos e testados modelos de predição de Aprendizagem, Reação ao Curso e Estratégias de Aprendizagem. Os resultados obtidos 
neste trabalho permitiram a validação de todas as escalas envolvidas.

Zerbini (2007), com base nos Modelos MAIS e IMPACT, desenvolveu um modelo específico para a avaliação de treinamentos a distância, ofertados pela internet, focalizando a identificação das variáveis preditivas de transferência de treinamento em cursos de qualificação profissional. Analisando um curso gratuito - "Iniciando um Pequeno Grande Negócio" - do SEBRAE (Serviço Brasileiro de Apoio às Micro e Pequenas Empresas), oferecido integralmente pela internet, a autora elaborou o modelo que avaliou o poder preditivo de variáveis individuais (estratégias de aprendizagem), de contexto de estudo (ambiente e procedimentos) e de reações (reação aos procedimentos e ao tutor) quanto à transferência de treinamento para o ambiente de trabalho. A Figura 7 apresenta o Modelo.

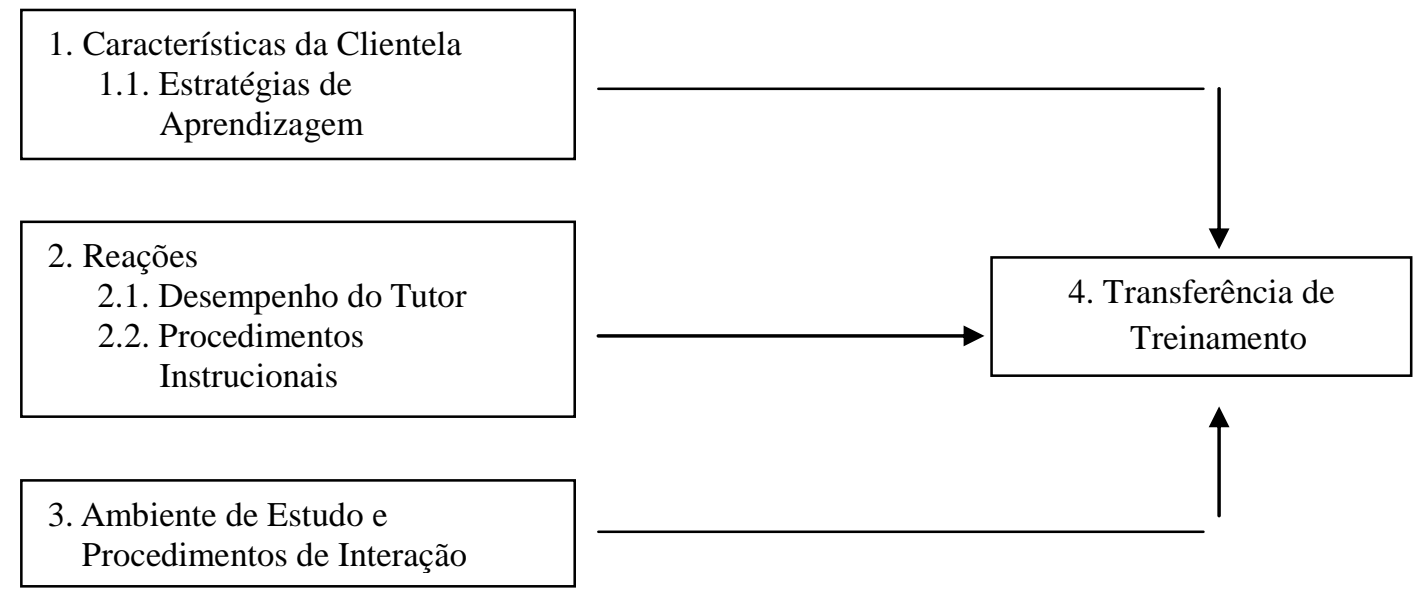

Figura 7. Modelo geral de avaliação da Transferência de Treinamento via web no Trabalho (Zerbini, 2007).

As variáveis envolvidas no modelo supracitado são definidas como:

1. Ambiente de estudo e Procedimentos: aspectos do contexto pessoal de estudo do aluno e do próprio curso que podem dificultar a permanência do estudante no evento instrucional.

2. Estratégias de Aprendizagem: capacidades cognitivas complexas aprendidas pelo indivíduo ao longo da vida. Envolve capacidades cognitivas, habilidades comportamentais e de autocontrole emocional, empregadas pelo aprendiz para administrar os próprios processos psicológicos de aprendizagem, como atenção, aquisição, memorização e transferência.

3. Reações ao Curso: satisfação dos participantes para com características instrucionais do curso e com o desempenho do tutor.

4. Transferência de Treinamento: refere-se à aplicação dos CHAs aprendidos no curso no contexto de trabalho do participante. É medida em termos das respostas dos participantes à 
escala de frequência de aplicação do aprendido no curso no ambiente de trabalho, e das respostas dos participantes à pergunta "Você elaborou o plano de negócios ao final do curso?".

Outro instrumento de avaliação foi desenvolvido por Sales (2009), por meio da proposição e testagem de um modelo estatístico de predição da situação de alunos (concluintes/evadidos) de treinamentos a distância, mediados pela web. Tal estudo, feito junto a egressos de treinamentos fornecidos pela Embrapa aos seus funcionários, incorporou ao modelo de investigação de Zerbini (2007) variáveis relacionadas ao contexto de estudo (ex. fatores situacionais ligados a problemas familiares e de saúde, ao trabalho, à falta de tempo), ao desenho do treinamento (ex. procedimentos instrucionais e desempenho do tutor), e ao próprio estudante (ex. disciplina e interesse e habilidades no manuseio de tecnologias da informação e comunicação). Desempenho do Tutor e Desenho do Curso referem-se ao primeiro conjunto de fatores do instrumento desenvolvido, Disciplina e Interesse do Aluno e Experiências e Habilidades Importantes para Cursos a Distância, referem-se ao segundo bloco e Tempo Disponível para o Curso, Apoio no Trabalho e Questões Familiares estão relacionados às variáveis de contexto. Este instrumento será adaptado e utilizado na presente pesquisa como destacado mais adiante.

Por fim, o modelo avaliativo de ações instrucionais a distância elaborado por Martins (2012) se propôs a reconhecer elementos preditores de aprendizagem vinculados às características da clientela (estratégias de aprendizagem e frequência nos recursos da web) e às reações aos procedimentos instrucionais e ao tutor. Para tanto, a pesquisadora administrou presencial e virtualmente escalas de medida referentes a Estratégias de aprendizagem, Reação aos procedimentos instrucionais e Reação ao desempenho do tutor junto a graduandos matriculados em disciplinas semipresenciais ofertadas a todos os estudantes da instituição parceira. A Figura 8 ilustra o modelo em questão.

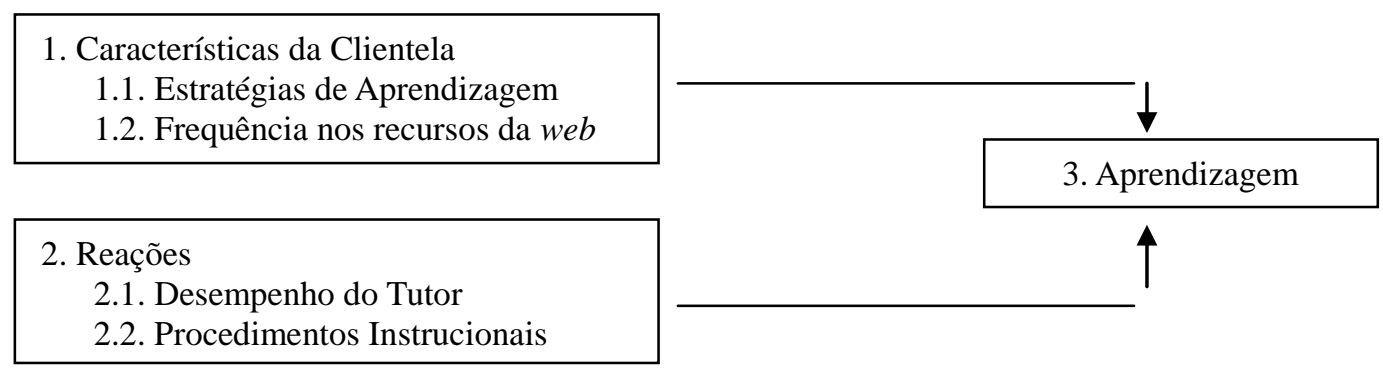

Figura 8. Modelo de investigação proposto por Martins (2012). 
Após a testagem do modelo, a autora verificou que a frequência de uso das ferramentas da web, as estratégias de aprendizagem autorregulatórias e as reações favoráveis aos procedimentos instrucionais explicaram a ocorrência de aprendizagem entre a amostra considerada. Dessa feita, Martins (2012) aponta para a relevância do ambiente virtual de aprendizagem, da comunicação tecida entre alunos e tutores e da utilização de estratégias que promovam o autogerenciamento da aprendizagem e autorregulação da motivação, ansiedade e atenção, no alcance de resultados acadêmicos positivos, favorecendo o desempenho do alunado a distância.

Os esforços dedicados à formulação e testagem de modelos de avaliação, como aqueles aqui apresentados, revelam a importância de iniciativas voltadas a tal subsistema de TD\&E; ações de tal feitio são consideradas de fundamental importância para a efetividade de programas e eventos instrucionais. Mesmo havendo a constatação de significativo progresso teórico-metodológico na seara da literatura especializada em TD\&E, ainda restam lacunas e desafios a serem superados pela área de avaliação, tais como: transpor limitações técnicas e culturais que restringem a execução de processos avaliativos; sanar deficiências teóricometodológicas que fragilizam os esforços de avaliação; melhor compreender e incorporar aos modelos avaliativos os efeitos das novas tecnologias sobre os processos virtuais de ensino; elevar a efetividade de ações que visem avaliar propostas instrucionais deste feitio (Abbad, Pilati \& Pantoja, 2003; Meneses et al., 2010). Neste sentido, a presente pesquisa visa contribuir para com o campo de TD\&E ao fornecer elementos que auxiliem na compreensão dos elementos relacionados ao abandono e permanência acadêmica em cursos a distância. 


\section{CAPÍTULO 2. EDUCAÇÃO A DISTÂNCIA: DEFINIÇÕES, CARACTERÍSTICAS E AÇÕES PÚBLICAS}

\section{Objetivo do capítulo 2}

Este capítulo discorre sobre algumas definições e características da modalidade EAD como um expediente de ensino e sua inclusão em contextos de O\&T e Instituições de Ensino Superior (IES), no Brasil e no mundo. Discute a temática da EAD na esfera das políticas públicas nacionais, revelando a transformação de legislações educacionais e a formulação de ações e programas governamentais para universalização do acesso à educação por meio do ensino não presencial. Considera ainda as potencialidades e os desafios estabelecidos frente às inovações no campo educacional.

Em relação ao estudo ora apresentado este conta com parceiros de pesquisa situados em ambos os sistemas de ensino - privado e gratuito. Desta feita, o debate acerca das políticas públicas educativas se faz imprescindível, uma vez que a extensa preocupação de pesquisa incide sobre a realidade da educação a distância, com o objetivo de posicioná-la, especialmente no cenário nacional, como uma possibilidade educacional exequível tanto para IES públicas como particulares. A intenção, tão logo, não se resume em debater essencialmente ações públicas nacionais, mas revelar que o frescor da temática e o progressivo estabelecimento da educação a distância (EAD) denunciam a incontestável tarefa de examiná-la como um fecundo terreno de investigações científicas.

Os atuais cenários de trabalho e estudo vêm enfrentando modificações de ordens diversas, tais como alterações nos recursos tecnológicos disponíveis, no sistema legal vigente e no processo de veiculação e processamento de informações; é possível constatar a presença de uma nova lógica de aprendizado e utilização de ferramentas diversificadas. Frente a isso, ações de Treinamento, Desenvolvimento e Educação (TD\&E) passaram a gozar de incontestável relevância, uma vez que instrumentalizam indivíduos e organizações com conhecimentos, habilidades e atitudes necessários à sobrevivência, competitividade e diferenciação profissional e organizacional. Frente a um mercado altamente volátil, no qual competências e instrumentais atingem a obsolescência em tempo mínimo, o investimento adequado em iniciativas de TD\&E já se revela como importante elemento de diferenciação competitiva (Meneses et al., 2010). Em virtude da elevada inconstância apresentada pelos contextos instrucionais e laborais, tornou-se questão sine qua non que aprendizes e 
profissionais estejam aptos e disponham de recursos suficientes à atualização e aprimoramento de suas competências. O princípio da educação permanente vem ao encontro desta necessidade e se torna fator decisivo para o êxito pessoal e institucional (Souza, 2002).

As mudanças ocorridas nos panoramas socioeconômicos e tecnológicos passaram a exigir medidas igualmente inovadoras que respondam às demandas e lacunas educacionais geradas. Recursos e estratégias diferenciados estão sendo captados e utilizados nos processos de ensino e aprendizagem, sendo que a expansão e o refinamento da área da tecnologia da informação e comunicação (TICs) em muito contribuiu para tal condição. Em revisão de literatura na área de Psicologia, Salas e Cannon-Bowers (2001) ressaltam as transformações sofridas pelo campo de TD\&E decorrentes das inovações e melhorias cibernéticas. Neste sentido, a EAD está sendo considerada dispositivo apropriado a tal cenário renovador (Souza, 2002).

Elemento estratégico nesta nova realidade instrucional, a EAD ao recorrer às avançadas mídias digitais e ferramentas de interação, como a internet, vem possibilitando que um número cada vez maior de indivíduos não só tenham acesso a conteúdos e informações, mas estabeleçam contato apesar de possíveis distanciamentos físicos. Segundo Iglesias e Salgado (2012), os dispositivos das novas TICs estão sendo tomados como meios de reduzir custos financeiros, barateando os programas de treinamento, e estender o número de potenciais beneficiários das ações de TD\&E.

Cada vez mais a modalidade de ensino a distância vem sendo empregada desde a Educação Básica até o Ensino Superior, passando também por programas de ensino não tradicionais - cursos de caráter aberto, por exemplo (Alves, 2011). Tal multiplicidade de uso talvez se deva, entre outras coisas, a efetividade de tais ações que, segundo apontamentos científicos, não se difere daquela encontrada em eventos educacionais presenciais. Ou seja, independente da modalidade de ensino considerada, quando corretamente delineada e implementada, a EAD pode produzir resultados análogos à educação face a face (Iglesias \& Salgado, 2012).

O termo educação a distância recebe diversas conceitualizações, de modo que cada autor destaca ou prioriza algum aspecto específico desta modalidade de ensino. De acordo com Reis (2009), a EAD corresponde ao processo de ensino por meio do qual conteúdos educacionais são repassados através de meios técnicos de informação, caracterizado pelo distanciamento físico entre o professor e o aluno. Segundo Vargas e Abbad (2006), a educação não presencial corresponde a uma abordagem de ensino-aprendizagem, mediada ou não por instrumentais tecnológicos, que torna possível a ocorrência de diferentes formas de interação 
entre professor-aluno e aluno-aluno (Vargas, 2004).

Apesar das diversas definições existentes, considera-se que todas elas guardam pontos em comum, apresentando uma anuência mínima em relação à EAD quanto modalidade de ensino cujas atividades ocorrem majoritariamente sem a necessidade da presença de professores e aprendizes no mesmo tempo e espaço (Associação Brasileira de Educação a Distância [ABED], 2012). De acordo com Walter (2006), as características elementares da EAD poderiam ser designadas como: (a) distanciamento físico entre professor e aluno; (b) processo de aprendizagem administrado pelo próprio discente e não pelo tutor, que neste contexto desempenha um papel auxiliar e facilitador; (c) relação professor-aluno sustentada por mídias tecnológicas diversas (televisão, internet, intranet, rádio, CD-ROM, material impresso são exemplos de tais recursos); e (d) maleabilidade de conteúdos a serem aprendidos (o aprendiz, de acordo com suas necessidades educativas, estrutura sua aprendizagem).

A despeito de algumas destas considerações, Litwin (2001) considera que a modalidade de educação a distância já não mais se diferencia pela separação entre aprendiz e professor, uma vez que os recursos advindos das TICs permitem que o afastamento físico seja superado por encontros virtuais cada vez mais oportunos, sustentando, assim, processos educativos cada vez mais eficazes. Além disso, a autora alerta para o fato de que o protagonismo do aprendiz em relação à gestão de sua aprendizagem não deve, erroneamente, levar a crença de que o sujeito que estuda a distância não necessita de aporte pedagógico e apoio infraestrutural adequados.

Apesar da introdução e do uso de ferramentas, como a internet e o computador, em contextos de ensino não remeterem a um passado muito longínquo, estes meios, com a popularização dos bens de consumo tecnológicos, vêm sendo massivamente empregados na EAD e impõem ao aluno a distância condições de estudo - ambiente de estudo transposto para o lar, acesso virtual a bibliotecas e demais serviços institucionais - e formas de se relacionar com seus pares (por meio de interações não corpóreas) pouco presentes nas modalidades de ensino tradicionais e que podem afetar os resultados finais da ação educacional (Carvalho \& Abbad, 2006; Dean \& Webster, 2000; Moore \& Kearsley, 1996). As novas tecnologias de informação e comunicação atreladas a projetos de educação a distância expandem a possibilidade de acesso a programas de treinamento, formação e qualificação profissionais ofertados (Abbad, Carvalho \& Zerbini, 2006).

Tendo em vista a presença de características próprias e singulares, tais como uma metodologia flexível e ajustada para indivíduos adultos, a EAD possibilita que estudantes adaptem e conciliem seus estudos com outras atividades, sejam elas profissionais ou pessoais, 
exercendo, consequentemente, um controle mais intenso dos elementos tempo, espaço e ritmo de estudo (Sales, 2009; Yukselturk \& Inan, 2006). Litwin (2001) em estudo sobre EAD destaca a autonomia que gozam os aprendizes no tocante à seleção do tempo destinado para a aprendizagem, graças à ampla gama de recursos disponibilizados pelas TICs e pelas relações firmadas entre instrutores e alunos.

Em relação ao papel desempenhado pelo docente na EAD, este pode ser considerado muito relevante, uma vez que a função de transmissor de informações é substituída por um papel mais complexo que deve primar pela (re)orientação dos processos de aprendizagem dos discentes empregando, para tanto, estratégias que se coadunem com os aprendizes (Litwin, 2001; Pereira, 2003). Além disso, o tutor deve instigar e incentivar os estudantes e fornecer feedbacks que venham a ser úteis na aquisição de competências (Appana, 2008; Pereira, 2003). Um dos principais fatores impeditivos ou complicadores do desenvolvimento e êxito de cursos a distância seria a dificuldade apresentada pelos professores de manterem seus aprendizes atentos e engajados, tarefa esta considerada difícil, já que o estudante na situação de EAD é circundado por um número maior de elementos distratores do que quando presente em sala de aula (Appana, 2008; Belloni, 1999). No contexto do modelo de ensino aqui tratado, é fundamental que o aluno não só domine as ferramentas tecnológicas, mas que se disponha a fazer uso dos instrumentais disponibilizados e tolere alguns aspectos inerentes à modalidade, tal como a limitação dos processos de interação professor-aluno e aluno-aluno (Palloff \& Pratt, 2004).

É visível o aumento vertiginoso que a educação a distância vem experimentando nas últimas décadas em solo nacional: de acordo com o censo realizado pela ABED (2012) durante o ano de 2009 o número total de indivíduos cursando algum tipo de programa instrucional não presencial atingiu a marca de 2.597.357 alunos. Este montante se encontra distribuído da seguinte forma: o número de alunos matriculados em ações educacionais em instituições credenciadas gira em torno de 901.274; cerca de 1.441.298 estudantes realizam cursos de caráter livre; e, cursos corporativos respondem por uma parcela de 254.785 discentes. A Figura 9 ilustra tal arranjo. 


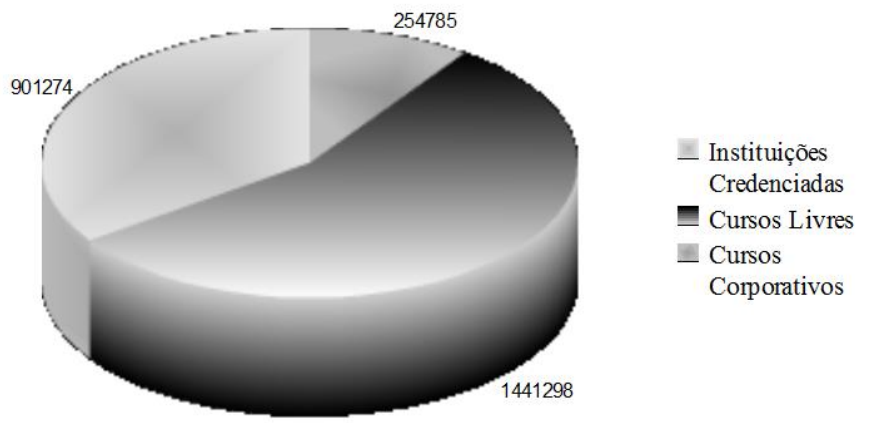

Figura 9. Distribuição de alunos a distância segundo o tipo de programa instrucional.

Vale ressaltar que tais dados referem-se apenas à amostra daqueles indivíduos que responderam ao censo em questão, e não ao universo total de alunos a distância - número este consideravelmente mais elevado do que os apresentados acima. Tendo em vista que no ano de 2003, 52 instituições estavam credenciadas a oferecerem cursos de nível superior em tal modalidade, em 2006, este número já havia saltado para 349 (Instituto Nacional de Estudos e Pesquisas Educacionais Anísio Teixeira [INEP], 2007; disponível em http://www.inep.gov.br). Atualmente, a educação a distância, em termos de cursos ofertados, apresenta o seguinte arranjo: instituições credenciadas, ofertantes de programas variados como Educação de Jovens e Adultos (EJA), graduação, pós-graduação, profissionalizantes, são responsáveis por 1.764 dos cursos oferecidos; 468 cursos a distância são de responsabilidade de instituições de caráter livre; e instituições corporativas respondem por 561 dos cursos não presenciais. A quantia total de programas instrucionais a distância disponibilizados por variados estabelecimentos de ensino é de 2.793 (ABED, 2012). A figura a seguir apresenta a distribuição de tais valores.

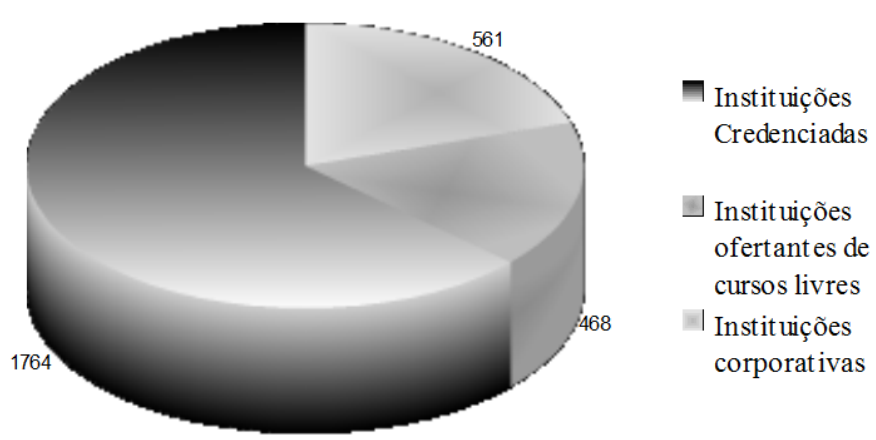

Figura 10. Distribuição de cursos a distância ofertados de acordo com o caráter da instituição.

A educação a distância em contextos organizacionais públicos e privados expande e 
populariza a entrada dos indivíduos no universo educacional e gera condições favoráveis à aprendizagem contínua (Abbad, 2007). Segundo dados do Anuário Brasileiro Estatístico de Educação Aberta e a Distância (ABRAEAD, 2007), a condição da EAD na educação corporativa brasileira apresenta alguns dos seguintes índices:

- A clientela-alvo das ações educacionais ofertadas a distância pelas cem unidades de educação corporativa brasileiras é composta por funcionários diretos $(59,30 \%)$, funcionários indiretos e prestadores de serviços $(33,30 \%)$ e outros $(25,90 \%)$;

- As empresas focam principalmente o nível hierárquico operacional, uma vez que $85 \%$ delas ofertam seus cursos a distância para tal nível;

- Ações de EAD nas empresas visam principalmente o treinamento $(88,9 \%)$, seguido pela reciclagem $(51,9 \%)$ e aperfeiçoamento $(37,0 \%)$;

- Entre a diversificada gama de cursos a distância oferecida pelas organizações, os tipos mais frequentes são: informática $(12,40 \%)$, educação e cidadania $(12,10 \%)$ e gestão $(10,10 \%)$;

- Os cursos a distância ministrados pelas empresas apresentam duração média de 41 horas (mínimo de 8 horas e máximo de 255 horas);

- O nível de adesão dos funcionários aos cursos a distância é considerado excelente $(33,3 \%)$ ou bom $(48,10 \%)$;

- O grau de satisfação dos funcionários com os cursos a distância é bastante positivo, de modo que a maior parte das avaliações atinge o conceito bom $(59,30 \%)$ ou excelente $(37 \%)$;

- As taxas de evasão dos cursos nas empresas oscilam. Os dados revelam que 59,30\% das empresas registraram até $20 \%$ de evasão, enquanto que $18,50 \%$ relataram evasão de 20 a $30 \%$ e $22,20 \%$ das empresas atingiram um índice alarmante superior a $30 \%$.

Em virtude do importante papel que a Educação Corporativa vem assumindo em âmbito nacional, o Ministério da Educação, Ministério do Desenvolvimento, Indústria e Comércio Exterior e o Ministério do Trabalho e Emprego vêm aplicando recursos em programas de educação do trabalhador pelas organizações. Nesse sentido, o profissional brasileiro tem tido sua formação ocupacional estimulada pela utilização da EAD e pelo investimento na profusão de oportunidades de aprendizagem laboral continuada. Algumas das entidades que compõem o Sistema S - SESI, SENAI, SENAC e SEBRAE - se mostram cada 
vez mais comprometidas com a geração de possibilidades de formação profissional a distância, seja na forma pura ou híbrida de ações de ensino-aprendizagem, subsidiadas por diferentes mídias e tecnologias, tais como: ambientes virtuais de aprendizagem (AVAs), computadores, DVD, televisão e rádio. Mesmo a EAD experimentando uma fase de expansão na educação corporativa a sua adoção é considerada recente em muitas instituições nacionais e novas práticas educacionais a distância ainda estão se consolidando em tal terreno (Abbad, 2007; ABRAEAD, 2007; Eboli, 2004).

Independente de se considerar contextos educacionais ou a educação corporativa/profissional, a EAD é uma modalidade de ensino em crescente difusão em todo o mundo. Ainda segundo Abbad (2007), o ensino a distância apresenta potencialidades não exploradas e falhas não sanadas. A tabela abaixo ilustra tais elementos:

Tabela 2. Potencialidades e falhas da EAD (Abbad, 2007).

\begin{tabular}{ll}
\hline \multicolumn{1}{c}{ POTENCIALIDADES } & \multicolumn{1}{c}{ FALHAS } \\
\hline Ampliação do acesso à educação formal. & $\begin{array}{l}\text { Materiais pouco acessíveis aos estudantes de baixa } \\
\text { renda. }\end{array}$ \\
\hline $\begin{array}{l}\text { Ampliação do acesso à formação e } \\
\text { qualificação profissionais. }\end{array}$ & $\begin{array}{l}\text { Uso de mídias e materiais incompatíveis com o } \\
\text { contexto e habilidades do aluno. }\end{array}$ \\
\hline $\begin{array}{l}\text { Desenvolvimento de competências complexas } \\
\text { valiosas como: autonomia, autoestudo, } \\
\text { autoavaliação, administração do tempo, } \\
\text { autogestão de carreira. }\end{array}$ & $\begin{array}{l}\text { Apoio inadequado ao estudo (muitos alunos por tutor } \\
\text { ou, falta de interação com outros, falta de guias, } \\
\text { orientações e mapas de estudo e de tutoria ativa). }\end{array}$ \\
\hline $\begin{array}{l}\text { Utilização de múltiplas mídias de entrega de } \\
\text { materiais. }\end{array}$ & $\begin{array}{l}\text { Falta de preparação prévia do aluno para manusear os } \\
\text { recursos da informática para estudar. }\end{array}$ \\
\hline $\begin{array}{l}\text { Oportunidade de estudo a qualquer hora e em } \\
\text { qualquer lugar. }\end{array}$ & $\begin{array}{l}\text { Dificuldade de estudar em local apropriado. } \\
\text { Horários variáveis e pouco tempo de estudo de cada } \\
\text { vez. }\end{array}$ \\
\hline $\begin{array}{l}\text { Flexibilidade para escolher a melhor maneira } \\
\text { e sequência de estudar. }\end{array}$ & $\begin{array}{l}\text { Materiais sequenciados com rigidez. } \\
\text { Obrigatoriedade de cumprir todas as etapas do curso, } \\
\text { mesmo aquelas que tratam de assuntos e conteúdos } \\
\text { dominados pelo estudante. }\end{array}$ \\
\hline
\end{tabular}

No tocante às problemáticas que afetam a efetividade e consecução de objetivos pretendidos pelo campo da EAD, a evasão acadêmica configura-se como uma das mais sérias ameaças enfrentadas. Mesmo sendo considerada uma relevante questão da área, o fenômeno da desistência educacional vem sendo alvo de poucos estudos científicos, situação esta constatada por Abbad et al. (2006) após realização de análise de literatura sobre o tema. O entendimento a respeito dos fatores e condições que levam indivíduos a abandonarem cursos a distância ainda é limitado, o que contribui para que a esfera educacional e de treinamentos não alcance a efetividade almejada (Salas \& Cannon-Bowers, 2001).

O fenômeno da evasão não é um problema recente e pontual no cenário educacional 
brasileiro e internacional (Amidani, 2004). A literatura nacional e estrangeira apresenta estudos desenvolvidos no campo da EAD voltados à investigação dos elevados índices de abandono em contextos de ensino superior e suas possíveis causas (Henke \& Hussum, 2000; Walter, 2006). Todavia, as lacunas observadas no que tange à investigação da evasão em contextos educacionais a distância ainda são grandes e preocupantes, de modo que a realização de mais estudos sistemáticos sobre o fenômeno se faz premente (Abbad et al., 2006; Brauer, 2005).

Os resultados oriundos de pesquisas a respeito da evasão em tais cenários de aprendizagem ainda são pouco conclusivos e de difícil generalização; parte desta dificuldade pode ser atribuída à falta de consistência teórica do campo e à heterogeneidade de locais e instituições utilizadas nas investigações. Dados provenientes de revisões de literatura sobre o fenômeno chamam a atenção para os elevados índices de abandono em cursos a distância, alertando para a relevância deste problema: em cursos corporativos brasileiros a taxa de evasão ultrapassa 30\% (ABRAEAD, 2008), enquanto que na Ásia mais da metade dos alunos inscritos em programas de educação a distância não concluem seus estudos - na Europa os índices giram em torno de 50\% (Abbad at al., 2006; Shin \& Kim, 1999; Xenos et al., 2002).

Ao se abordar a questão da evasão, é fundamental avaliar que tal fenômeno vem recebendo uma série de definições, de modo que sob tal designação pode-se fazer referência a distintas situações, como: indivíduos que se matriculam, mas não iniciam o curso; alunos que abandonam formalmente o curso após o terem iniciado; estudantes que deixam o curso devido ao fato de não atingirem os requisitos mínimos para conclusão; indivíduos que optam pela troca de curso ou de instituição de ensino (Abbad at al., 2006; Kember, 2000; Tresman, 2002; Vargas, 2004; Xenos et al., 2002).

Assim, o fenômeno da evasão compreende diversas conceituações e termos relacionados ao evento em questão. O conceito de persistência, intimamente ligado ao abandono de eventos instrucionais, é compreendido como sendo o inverso da evasão: enquanto esta última diz respeito às taxas de aprendizes que realizaram sua matrícula no curso, todavia não satisfizeram todos os critérios de aprovação, a persistência é constituída pelo índice de alunos que efetivaram sua matrícula junto ao curso e cumpriram todas as exigências estabelecidas para a consecução do mesmo (Vargas, 2004).

Outro termo agregador de entendimento para a compreensão das problemáticas que afetam a efetividade da EAD é o conceito de barreiras pessoais à conclusão do curso, que abrange diversas variáveis que interferem na ocorrência da desistência/persistência e expressam entraves ou problemas que os discentes podem experimentar durante o curso. 
Brauer (2005) estabelece uma relação entre evasão e barreiras pessoais, de modo que a primeira se relaciona ao momento em que o indivíduo efetivamente desiste da ação educacional, enquanto no segundo o estudante ainda é participante do evento instrucional.

No tocante as razões que levam o aluno a não concluir um programa de ensino a distância, a literatura indica motivos provenientes das características internas dos estudantes, das restrições inerentes aos contextos de estudo do participante e do desenho e execução do curso (Sales, 2009). Encontram-se situadas entre as características pessoais do alunado que influenciam o abandono de cursos a distância: a falta de habilidade do estudante em fazer uso das ferramentas eletrônicas disponibilizadas; a inabilidade de organizar o tempo de estudo e a autodisciplina. Pesquisas indicam que os indivíduos que experimentam maiores dificuldades em relação ao manejo dos elementos eletrônicos do curso possuem maiores chances de se evadirem dos programas educacionais (Abbad et al., 2006; Almeida, 2007; Silva \& Tomaz, 2006). Em seus estudos, Zerbini $(2003,2007)$ propõe a investigação do relacionamento de características de cunho individual do estudante com os níveis de reação, aprendizagem e impacto de treinamento. De acordo com a pesquisadora, tais variáveis contribuem para a compreensão da evasão e da persistência em treinamentos a distância.

As variáveis do contexto de estudo do aluno ligadas a ocorrência de evasão figuram como muito importantes, uma vez que a EAD não só admite maior flexibilidade de horários e locais de estudo, bem como expõe o estudante a uma quantidade mais elevada de estímulos. De acordo com Sales (2009), tais variáveis se relacionam à adequação do ambiente familiar, do trabalho e outras questões que envolvem a vida do discente e que podem interferir nos seus estudos. A escassez de tempo para se dedicar aos estudos configura como um dos principais fatores que pode conduzir à desistência em cursos a distância (Almeida, 2007; Yukselturk \& Inan, 2006). Condições precárias de estudo no lar (Coelho, 2003; Tucho, 2000), pressões domésticas, enfermidades e questões relativas ao trabalho são consideradas como possíveis indicadores de evasão (Almeida, 2007; Vargas, 2004).

Em relação às variáveis do curso relacionadas à evasão, a literatura indica que problemas relativos ao desempenho do professor - como falta de apoio ao aluno; falta de feedback; falta de conhecimentos ou inabilidade para transmiti-los - são considerados uma das causas para o abandono acadêmico (Abbad at al., 2006; Vargas, 2004). Os elementos ligados mais intimamente ao desenho instrucional, tal como os procedimentos adotados, também são tidos como fatores que contribuem para a desistência estudantil (Silva \& Tomaz, 2006).

Cinco diferentes tipos de barreiras à conclusão de cursos a distância foram 
apresentados por Galusha (1997). O primeiro deles corresponde à falta de segurança sentida pelo aprendiz em relação a ações educacionais não presenciais. A próxima barreira se refere a dificuldades em obter feedback ou contato com o tutor. Serviços de tutoria deficientes, cronogramas de estudo inadequados e falta de assistência técnica ao aluno integram o terceiro tipo de barreira. O quarto obstáculo envolve os sentimentos de isolamento e falta de integração vivenciados pelos estudantes. A última barreira corresponde à falta de experiências prévias com programas educacionais a distância; neste caso, o autor alerta para a necessidade de se ofertar suporte e orientação adequados quanto ao estudo e uso das ferramentas disponíveis àqueles indivíduos que nunca obtiveram nenhum contato prévio com tal modalidade de ensino.

Ainda na seara dos desafios vivenciados pelos cursos a distância, e não obstante o crescente interesse e reconhecimento dos benefícios próprios aos mesmos, são identificadas iniciativas perniciosas que transfiguram esta modalidade de ensino em um bem de consumo mercantilizável.

O mercado de negócios ligados à educação vem cada vez mais se preocupando com a EAD, e a atenção de investidores nacionais e estrangeiros já se volta para esse campo altamente promissor. A modalidade tende a se desenvolver ainda mais, alcançando um potencial de crescimento sem precedentes na história do segmento. Os números que indicam o salto deste nicho educacional são dignos de nota e impressionam: somente entre os anos de 2004 a 2007, o número de alunos matriculados em cursos deste segmento cresceu $214 \%$. No ano de 2007, o setor movimentou aproximadamente 1,5 bilhão de reais. Tal aumento se deve a uma conjunção de fatores, entre eles o custo financeiro muito aquém do valor despendido para a realização de um curso tradicional. Estima-se que a EAD continue a crescer, ao menos, 20\% a cada ano no país, de modo que até o ano de 2015 a modalidade terá captado um terço do segmento universitário, e para 2022 a previsão é de que aproximadamente 1,2 milhões de pessoas estejam matriculadas em ações privadas de ensino à distância - representando $16 \%$ do total de inscrições efetuadas (Amorim, 2009; Previdelli, 2012).

Constituindo-se em público crescente, as classes C e D cada vez mais são atraídas pela modalidade a distância. Tais camadas, seduzidas por preços módicos, passaram a ser focalizadas pelas empresas do ramo. Aliás, a realização de parcerias e fusões entre grandes grupos e companhias de ensino a distância denota o aspecto promissor que o campo representa para os investidores: de acordo com especialistas da área educacional, a EAD torna-se uma modalidade lucrativa graças ao alcance de um número cada vez maior de estudantes a expensas de reduzidos gastos econômicos (Amorim, 2009). Segundo dados do 
Censo da Educação Superior de 2007, o setor privado impera na educação superior, de modo que das 2.281 IES existentes, 89\% são de natureza particular. E esse setor ainda domina a oferta de cursos na modalidade de EAD: dos 408 cursos a distância oferecidos por 97 instituições de ensino superior, 260 (63,7\%) eram de caráter privado (INEP, 2009; disponível em http://www.inep.gov.br).

É fundamental refletir sobre esse entendimento que envolve a EAD e a caracteriza como um grande mercado a ser explorado. Tal concepção deturpada pode interferir negativamente nos processos de aplicação de recursos para a melhoria da qualidade do ensino oferecido e transformar instituições comprometidas com a garantia do direito ao ensino e a aprendizagem em um ramo competitivo que prima unicamente pela rentabilidade e ganhos contínuos.

A fragilidade que dificulta a identificação da educação a distância como um processo de ensino-aprendizagem válido e eficaz é decorrente da execução de medidas e projetos assentados na lógica de mercado ou empresarial. Em virtude do relativo atraso brasileiro no emprego de tal modalidade de ensino, foi gerado um escasseamento de estruturas de fiscalização hábeis e diminuto ajustamento ao contexto nacional (Santos, 2006).

Tal delonga brasileira se torna ainda mais evidente quando se toma em consideração instituições governamentais de ensino mundiais que possuem programas muito desenvolvidos de educação a distância, tais como: o Instituto de Gestão Pública e Desenvolvimento Econômico - IGPDE/França; o Instituto Nacional de Administração Pública - INAP/Espanha; a Universidad Nacional de Educación a Distancia-UNED/Espanha; a Universitat Oberta de Catalunya/Espanha; a Universidade Aberta, em Portugal; a Fernuniversität/Alemanha; a Open University da Inglaterra; a United Kingdom's; a Open University; a Universidade Aberta da Grécia; a Norway's NKS e NKI Distance Education/Noruega; a University of South África UNISA; Universidade Payame Noor, no Irã; a Central Radio and Television University da China; University of the Air do Japão; a Universidade Aberta da Coréia; a Escola Canadense do Serviço Público; a Contact North do Canadá; a Vancouver's Open Learning Agency; a Télé-Université, no Canadá; a National University - Teleconference Network dos EUA; a American World University; a UNA, na Venezuela (Abbad, 2007; Bohadana \& Valle, 2009; Peters, 2004; Santos, 2006).

A história e os números que acompanham algumas dessas instituições de ensino impressionam pela magnitude e indicam o considerável abalo causado pela inserção da EAD informatizada. Sendo uma das agências pioneiras no trabalho com o ensino não presencial, a Open University foi criada há mais de 30 anos e atualmente serve cerca de 200 mil alunos. No 
território indiano, situa-se a Universidade a Distância Indira Gandhi reconhecida como a maior universidade aberta do mundo e que conta com 1,5 milhão de alunos (Bohadana \& Valle, 2009). Além disso, a quantidade de universidades internacionalmente reconhecidas, tais como Harvard, MIT e Stanford, que passaram a oferecer cursos baseados na internet cresce consideravelmente (Iglesias \& Salgado, 2012).

À exceção dos interesses escusos e mercadológicos, os eventos educacionais a distância têm transformado a fisionomia do ensino em inúmeros países do mundo, proporcionando oportunidades de estudo para indivíduos e populações que provavelmente não seriam alcançados pelas ações convencionais de sala de aula. Dessa feita, o e-learning, quando bem empregado, permite que minorias sociais, até então relegadas pelos sistemas educacionais e de qualificação profissionais majorantes, tenham ampliado o acesso à formação acadêmica e ao desenvolvimento de diversas competências necessárias ao mundo do trabalho (Abbad, 2007). A utilização reiterada de recursos eletrônicos, como as plataformas de gerenciamento de aprendizagem, está tornando a entrega de cursos e de materiais educativos a volumosos grupos de trabalhadores e estudantes adultos uma realidade concreta e acessível. Tudo isso revela que as tecnologias e a própria internet, atreladas a projetos de ensino consistentes, tanto geram novas possibilidades para a área educacional, bem como estabelecem outros dilemas a serem sanados. Tais disposições vigentes no campo da EAD devem ser consideradas tendo em vista sua relevância e perenidade. Consequentemente, para que essa modalidade de ensino goze de ações de qualidade e apresente propósitos louváveis, é necessário que tais tendências venham a ser confrontadas e solucionadas. Neste sentido, os esforços legais até então empreendidos são de extrema significância para o estabelecimento e legitimação do ensino não presencial.

A educação a distância no Brasil, pensada sob a esfera das políticas públicas, é marcada por alguns acontecimentos nas mais importantes leis, portarias, resoluções e normas que regulamentam a modalidade no país.

Não desconsiderando que o primeiro projeto de lei no Congresso Nacional para criação de uma Universidade Aberta no Brasil data da década de 1970 e que a promulgação da Constituição Federal de 1988 tornou-se um marco para a adoção de uma concepção ampla de educação e sua inscrição como direito social inalienável (Ministério da Educação [MEC], 2009), algumas modificações de natureza jurídico-institucional, de grande impacto para a educação, vieram a complementar os documentos legais, sendo dignas, portanto, de exposição.

A seguir, encontram-se dispostas na Tabela 3 as mais relevantes ações e medidas de 
caráter público-governamental para o segmento da educação não presencial.

Tabela 3. Principais medidas e dispositivos legais no campo da EAD.

\begin{tabular}{lcl}
\hline \multicolumn{1}{c}{ Lei } & Ano & \multicolumn{1}{c}{ Objetivo } \\
\hline $\begin{array}{l}\text { Secretaria de Educação a } \\
\text { Distância (SEED) }\end{array}$ & 1995 & $\begin{array}{l}\text { Organismo estratégico no combate aos problemas de } \\
\text { equidade tendo em vista as acentuadas desigualdades } \\
\text { nacionais, culturas múltiplas e vasta extensão territorial. }\end{array}$ \\
\hline $\begin{array}{l}\text { Lei de Diretrizes e Bases da } \\
\text { Educação Nacional - LDB }\end{array}$ & 1996 & $\begin{array}{l}\text { Fruto de ações subsequentes, especialmente no campo da } \\
\text { legislação educacional. Responsável pela reestruturação e } \\
\text { definição das diretrizes e bases da educação escolar no } \\
\text { país, após o período da ditadura militar, que veio a } \\
\text { normatizar o ensino a distância. }\end{array}$ \\
\hline
\end{tabular}

Artigo 80 da Lei no 9.394/1996 $1996 \quad \begin{aligned} & \text { Destaque para o referido artigo da lei supracitada por este } \\ & \text { apregoar que “o Poder Público incentivará o } \\ & \text { desenvolvimento e a veiculação de programas de ensino a } \\ & \text { distância, em todos os níveis e modalidades de ensino, e de } \\ & \text { educação continuada", sendo dever da União a } \\ & \text { regulamentação dos requisitos para a realização de exames } \\ & \text { e registro de diplomas relativos a cursos de educação a } \\ & \text { distância }\end{aligned}$

Artigo 87 da Lei n ${ }^{\circ}$ 9.394/1996 1996 Assegura a legitimidade da EAD enquanto meio de ensino, bem como sua aplicabilidade.

Decreto $n^{\circ} 5.622 / 2005$.

Vale ressaltar que por meio do já citado Artigo 87 da Lei $n^{\circ} 9.394 / 1996$ é proposta a Década da Educação, segundo a qual o Distrito Federal, estados e municípios, e, supletivamente, a União, deverão ofertar cursos presenciais ou a distância a jovens e adultos escolarizados de forma deficiente e empreender programas voltados à capacitação do corpo docente em exercício, empregando, para tanto, os recursos advindos da EAD. No âmbito da Educação Básica, a educação a distância deve atuar como recurso complementar às atividades de ensino-aprendizagem realizadas presencialmente ou em situações críticas que as façam necessárias. Nesta perspectiva, igualmente relevante, o Decreto $n^{\circ} 5.622 / 2005$ opera no sentido de promover a atualização do conjunto legislativo relacionado à EAD no país, em todas as modalidades e níveis em que a mesma poderia ser oferecida. Tal documento contribui para o avanço da regulação do ensino não presencial, na medida em que estabelece os 
critérios para credenciamento institucional de oferta de cursos de tal natureza, supervisão, controle e avaliação, bem como define o papel e as competências dos sistemas de ensino.

Paralelamente a promulgação das leis e decretos acima citados, foram criadas instâncias e ferramentas de avaliação específicas para a regulação da EAD - instrumentos destinados à autorização e reconhecimento de cursos superiores a distância, credenciamento de instituições e polos de apoio presencial. Alguns de tais elementos jurídicos encontram-se expostos na Tabela 4.

Tabela 4. Instâncias e ferramentas reguladoras da avaliação da EAD no país.

\begin{tabular}{lll}
\hline \multicolumn{1}{c}{ Lei } & Ano & Objetivo \\
\hline $\begin{array}{l}\text { Plano Nacional de } \\
\begin{array}{l}\text { Educação }- \text { PNE } \\
\left(\text { Lei } \mathrm{n}^{\circ} 10.172 / 2001\right)\end{array}\end{array}$ & 2001 & $\begin{array}{l}\text { Estabelece novos caminhos para as políticas e ações governamentais, } \\
\text { afixando objetivos e metas para a Década da Educação. }\end{array}$ \\
\hline
\end{tabular}

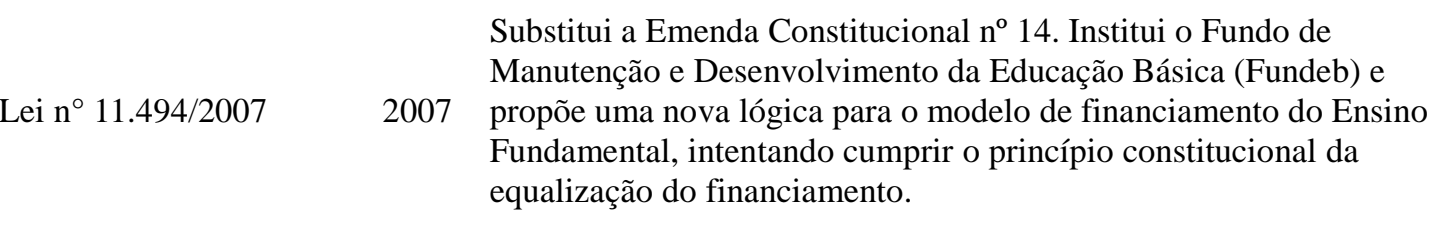

$\begin{array}{ll}\text { Plano de } & \begin{array}{l}\text { Articulado ao PNE, visou garantir equidade nas oportunidades de } \\ \text { acesso à educação de qualidade e de nela permanecer. }\end{array}\end{array}$

Educação (PDE)

Resolução CNE/CES n 2001 Prescreve normas para o funcionamento de cursos de pós-graduação. $1 / 2001$

Portaria Ministerial $n^{\circ}$ $4.361 / 2004$
Sucede à Portaria Ministerial de $\mathrm{n}^{\circ}$ 301/1998 e normatiza os

2004 procedimentos referentes ao credenciamento de instituições para o oferecimento de cursos superiores e formação profissional tecnológica a distância.

Lei $n^{\circ} 12.056 / 2009$

Acrescentando parágrafos ao artigo 62 da LDB, estabelece diretrizes e bases da educação nacional. De acordo com tal lei, a educação a 2009 distância, bem como os recursos e tecnologias a ela vinculados, poderão ser empregados de forma secundária nos processos de formação continuada e capacitação dos profissionais do magistério.

Outras ações e iniciativas governamentais na perspectiva da educação a distância desenvolvidas pelo MEC podem ser destacadas, tais como: a Universidade Aberta do Brasil (UAB), o Sistema Escola Técnica Aberta do Brasil (e-Tec Brasil), a Rede Nacional de 
Formação Continuada de Professores, o Programa Mídias na Educação, o Programa Nacional de Informática na Educação (ProInfo), e a Rede Interativa Virtual de Educação a Distância (Rived).

O Sistema UAB, instituído pelo Decreto $n^{\circ}$ 5.800/2006, está relacionado ao desenvolvimento da modalidade de educação a distância, com o escopo de expandir e interiorizar a oferta de cursos e programas de educação superior. Os objetivos da UAB voltam-se para: a oferta de cursos de licenciatura e de formação inicial e continuada a professores da educação básica; a oferta de cursos superiores para capacitação de dirigentes, gestores e trabalhadores envolvidos com a educação básica dos estados, do Distrito Federal e dos municípios; o oferecimento de cursos superiores nos distintos campos do conhecimento; a ampliação do acesso à educação superior pública; a diminuição das desigualdades de oferta de ensino superior entre as diferentes regiões do território brasileiro; a constituição de amplo sistema nacional de educação superior a distância; o incentivo ao progresso institucional para a modalidade de EAD e à pesquisa em metodologias inovadoras de ensino superior apoiadas em tecnologias de informação e comunicação.

O Sistema Escola Técnica Aberta do Brasil (e-Tec Brasil) - estabelecido por meio do Decreto $n^{\circ} 6.301$, de 2007 - prioriza o avanço da educação profissional técnica na modalidade a distância, visando a expansão da oferta e a universalização do acesso a cursos técnicos de nível médio públicos e gratuitos no Brasil. Em direção semelhante, a Rede Nacional de Formação Continuada de Professores congrega instituições públicas de ensino superior, federais e estaduais, para o oferecimento de cursos nas áreas de alfabetização e linguagem, educação matemática e científica, ciências humanas e sociais, educação física e artes ao público prioritário composto por docentes de educação básica dos sistemas públicos de ensino. Neste caso, o Ministério da Educação atua como organismo prestador de suporte técnico e financeiro, além de coordenar o desenvolvimento do programa que, em regime de colaboração, é efetivado por adesão pelo Distrito Federal, estados e municípios.

O programa Mídias na Educação é ofertado na modalidade a distância e pretende colaborar para a formação de profissionais atuantes no campo da educação, em especial professores da educação básica, capazes de produzir e estimular a prática dos alunos nas diferentes mídias (televisão, vídeo, informática, rádio e material impresso), de forma articulada à proposta pedagógica. No ano de 2009, foram oferecidas 36 mil vagas em cursos de formação continuada para o uso pedagógico das tecnologias da informação e da comunicação.

Em 2007, o Programa Nacional em Tecnologia Educacional (Proinfo) veio a ser criado 
pela Portaria $\mathrm{n}^{\circ}$ 522/1997 e passou a responder por três dimensões: infraestrutura tecnológica, disponibilização de conteúdos digitais (TV Escola e Portal do Professor) e formação de profissionais do ensino e da gestão escolar. O Proinfo é realizado em ação conjunta com os sistemas de ensino e sua função é promover e orientar quanto ao uso adequado da informática no sistema público de educação básica. Dessa forma, são disponibilizados laboratórios de informática, tudo a fim de que tais instrumentos promovam o desenvolvimento não apenas da escola, mas de toda a comunidade circundante. Atrelado a esse programa está o ProInfo Integrado, uma ação formativa voltada à utilização didática-pedagógica das tecnologias da informação e comunicação na realidade escolar, articulada ao fornecimento de equipamentos tecnológicos nos colégios e à oferta de recursos e conteúdos multimídias e digitais disponibilizados pelo Portal do Professor, pela TV Escola e DVD Escola, pelo Domínio Público e pelo Banco Internacional de Objetos Educacionais (http://portal.mec.gov.br/index.php; disponível em 21/11/2011).

A Rede Interativa Virtual de Educação a Distância (Rived) objetiva estimular nas instituições de ensino superior ações de pesquisa, bem como a produção de conteúdos educacionais digitais, na forma de objetos de aprendizagem. Mais especificamente, o Projeto Rived busca avigorar e deslocar o processo de produção de recursos pedagógicos digitais da SEED para as universidades e introduzir novas abordagens pedagógicas, que empreguem os recursos tecnológicos nos cursos de licenciatura das instituições de nível superior por meio da promoção de uma atuação colaborativa e interdisciplinar.

A tendência mundial de intensificação da complexidade das modalidades e ambientes de formação requer a elaboração de alternativas educacionais exequíveis, uma vez que os sistemas de ensino e de qualificação profissional revelam sérias deficiências no atendimento às exigências de qualificação ora requeridas pela sociedade. A promulgação de políticas governamentais e a redação de documentos formais que reavaliem ações e práticas que cuidem do atendimento de necessidades educacionais particulares e favoreçam a universalização da educação, denunciam que esta é uma oportuna ocasião para se pesquisar e debater a educação a distância como uma das possíveis modalidades de ensino. Todavia, por todo território nacional e nos mais diversificados lugares, encontram-se estabelecidas instituições que oferecem uma formação de natureza duvidosa, tanto em termos de metodologias, conteúdos e padrões de qualidade, sobre as quais não se fazem valer as políticas e normatizações de credenciamento, acompanhamento e avaliação. Logo, as iniciativas nacionais de natureza jurídico-institucional devem estar comprometidas, absolutamente, com a democratização e cristalização da oferta de formação superior, pública 
ou privada, de excelência. Nisto se inclui a publicação de diretrizes, normas e sanções para a educação a distância com valor social.

A EAD, subsidiada por programas pedagógicos consistentes, amparada pelos recursos da TICs e tomada como medida política, oportuniza uma nova chance àqueles que não puderam findar seus estudos ou uma primeira oportunidade para indivíduos que, de outro modo, não teriam acesso à formação educacional. Entre tal contingente estão minorias étnicas, moradores de comunidades geograficamente isoladas, habitantes de locais onde não há instituições de ensino e pessoas de baixa renda, que abdicam dos estudos em prol da busca por trabalho para sobrevivência (Abbad, 2007; Santos, 2006). Indubitavelmente, a educação a distância tem a oferecer preciosas contribuições, especialmente em uma nação de medidas territoriais gigantescas e disparidades sociais vexatórias. Contudo, é inadmissível que sejam negligenciados aspectos primordiais no tocante ao delineamento, ajustamento da infraestrutura, seguimento e avaliação das ações e programas, bem como à formação e aprimoramento de docentes buscando assegurar a qualidade deste processo de ensino e o desenvolvimento dos sistemas educacionais.

No próximo capítulo é apresentada a trajetória que susteve as ações de revisão bibliográfica acerca dos objetos de interesse para o estudo em questão. 


\section{CAPÍtulo 3. ANÁlise da LITERATURA: DESCRIÇÃo E ACHADOS DE PESQUISA}

\section{Objetivo do capítulo 3}

O presente capítulo se ocupa com a descrição do percurso da revisão de literatura sobre as variáveis integrantes do modelo de investigação proposto. Além disso, são expostos os conceitos, características e resultados advindos de tal processo sistemático e que se ocupam das variáveis foco do estudo ora em questão, a saber: Características da Clientela e Fatores Relacionados à Evasão e à Persistência em EAD.

\subsection{Revisão de literatura: descrição de percurso}

A presente seção trata do levantamento bibliográfico efetuado nas bases de dados tidas como relevantes em revisões de TD\&E. Ademais, também são apresentados os tópicos, objetos de pesquisa, panoramas e abordagens verificados nas investigações consideradas para a constituição de um corpus de análise empregado no delineamento e definição do campo científico referente aos fatores ligados à evasão e persistência acadêmica na EAD em âmbito nacional e internacional.

É possível verificar uma produção limitada de estudos ocupados com a investigação sistemática da efetividade de ações educacionais a distância. Desta forma, reconhece-se a urgente necessidade de refinamento da modalidade no que tange ao desenvolvimento dos tutores, à adaptação dos cursos ao ambiente de estudo dos discentes, ao emprego adequado das novas ferramentas disponíveis, aos estilos de aprendizagem e hábitos de estudo do aprendiz, elementos estes que possivelmente se encontram relacionados às variáveis que interferem na decisão discente de permanecer ou não no evento instrucional e que, consequentemente, podem dificultar os retornos aos altos investimentos na implementação dessa modalidade de ensino.

Com base na estrutura de percurso de revisão desenvolvida por Martins (2012), a seguir, apresenta-se a trajetória do presente estudo. A fim de sistematizar e contemporaneizar os principais resultados advindos de trabalhos científicos ocupados com as variáveis tidas como de interesse por esta pesquisa, foram empreendidas buscas bibliográficas em bases de dados eletrônicas considerando as obras produzidas no período de 2005 a 2012; a princípio, o 
recorte proposto possibilitaria não apenas angariar os mais coevos achados de pesquisa acerca dos elementos investigados, bem como forneceria contundentes indicativos acerca do estado técnico-científico sobre o qual tais variáveis se encontram assentadas. Estudos de caráter nacional e estrangeiro dispostos na biblioteca eletrônica SciELO, nas bases de dados Web of Science e ProQuest foram analisados, além dos bancos de dissertações e teses da Universidade de Brasília (UnB) e da Universidade de São Paulo (USP).

A revisão bibliográfica objetivou verificar os progressos no campo da elaboração e validação de instrumentos nacionais e internacionais relacionados à avaliação das estratégias de aprendizagem utilizadas pelos participantes de ações educacionais na modalidade a distância e dos aspectos ligados tanto ao abandono quanto à persistência acadêmica em EAD. Os resultados em aspectos quantitativos do levantamento efetuado nas bases de dados mencionadas são apresentados na Tabela 5.

Tabela 5. Distribuição dos artigos de acordo com as bases de dados consideradas.

\begin{tabular}{|c|c|c|}
\hline \multirow[t]{2}{*}{ Bases de dados } & \multicolumn{2}{|c|}{ Resumos } \\
\hline & Levantados & Selecionados \\
\hline SciELO & 2637 & 156 \\
\hline ProQuest & 1497 & 45 \\
\hline Web of Science & 1584 & 74 \\
\hline $\begin{array}{l}\text { Banco de dissertações e teses } \\
\text { da USP* }\end{array}$ & 5390 & 35 \\
\hline $\begin{array}{l}\text { Banco de dissertações e teses } \\
\text { da UnB** }\end{array}$ & 63 & 16 \\
\hline Total & 11171 & 326 \\
\hline
\end{tabular}

O principal propósito deste processo foi granjear elementos e dados a respeito da vigente condição do objeto definido, a partir da investigação do material produzido com foco de análise similar em áreas de conhecimento díspares. Sendo assim, a consideração dos trabalhos tidos em conta, não só contribuiu para que as perguntas de pesquisa fossem situadas no campo com acréscimos de distintos posicionamentos e objetivos advindos de campos de estudos diferentes, como também auxiliou o posicionamento da pesquisadora a partir do arcabouço teórico que sinaliza o movimento que perpassa o trabalho em questão. Favorecendo o reconhecimento tanto de produções científicas inovadoras e de caráter inédito, bem como de aspectos já considerados em diversos estudos, o processo de revisão bibliográfica milita em favor do compromisso ético e social da atividade de pesquisa. Por conta disto, é necessário considerar e ponderar sobre os aspectos de incoerência, a natureza das publicações (revisão, teórica, empírica, relato de experiência, histórica), as metodologias empregadas, inclinações e 
lacunas.

As colocações a seguir descrevem o trajeto percorrido pela revisão bibliográfica; expõem um cenário geral a respeito das mais importantes pesquisas identificadas e os campos de conhecimento que se dedicam ao estudo da temática; debatem aqueles que foram escolhidos segundo os critérios de inclusão previamente elencados; sumarizam os achados de pesquisas que retratam o foco da temática selecionada; e tratam sobre a condição científica que marca o campo de conhecimento voltado ao estudo dos fatores relacionados ao fenômeno da evasão e da permanência acadêmica nas ações de ensino superior ministradas a distância, e sobre o emprego das estratégias de aprendizagem por parte dos estudantes inscritos em cursos online.

A fim de dar continuidade ao processo de levantamento bibliográfico, primeiramente foi definido o tema de principal relevância do próprio trabalho e determinadas as palavraschave, considerando medidas e termos a serem empregados na pesquisa. Inicialmente, trabalhou-se com as palavras-chave: instituições de ensino superior, educação a distância, estratégias de aprendizagem, evasão, distance learning, e-learning, learning, evaluation, e dropout. Cruzamentos entre tais termos e outros vocábulos, tais como: college \& universities, online instruction, training, internet, education, higher education, foram então efetuados totalizando 52 palavras-chave, pesquisadas em português e inglês. Desta feita, os cruzamentos de palavras-chave a serem empregados na presente revisão foram determinados com base no produto encontrado (número de resumos acessados), pertinência e/ou repetições dos mesmos; os termos-chave definidos foram: distance learning, e-learning com college \& universities, higher education, online instruction, evaluation, dropout e persistence.

A SciELO - Scientific Electronic Library Online, é uma biblioteca eletrônica que além de conter obras publicadas em diversos países - Chile, Cuba, Espanha, Portugal e Venezuela conta com um conjunto selecionado de periódicos científicos brasileiros. Uma vez que muitas das buscas realizadas nesta base de dados levaram aos mesmos trabalhos, inicialmente foram selecionados 264 resumos, dos quais 108 foram descartados por se tratarem do mesmo material, chegando-se a um total de 156 resumos. As buscas foram realizadas no mês de agosto de 2011.

Os bancos de dissertações e teses das universidades de Brasília (UnB) e de São Paulo (USP) se deram, respectivamente, por ser considerada referência no país em trabalhos na área da Psicologia Organizacional e do Trabalho - precisamente na qual se insere a pesquisa em questão; e a outra por seu reconhecido papel e relevância de obras que a posicionam como uma instituição de ensino superior mundialmente reconhecida e a maior da América Latina. 
$\mathrm{Na}$ UnB, puderam ser captados 63 trabalhos do banco de dissertações e teses do Departamento de Psicologia Social, do Trabalho e das Organizações, resultados de defesas realizadas no período determinado (2005-2012). Pesquisou-se no banco da USP o amplo campo de Ciências Humanas, de modo que os estudos ligados a EAD estavam situados nas áreas da Psicologia, Educação, Administração, Interfaces Sociais, Língua Portuguesa e Filologia. Ao todo, foram encontrados 5390 trabalhos no referido banco de dados.

As buscas realizadas nas bases de dados ProQuest Academic Research Library e Web of Science - ISI Web of Knowledge, se deram no primeiro semestre de 2012, nos meses de fevereiro a abril. Tal como dito anteriormente, foram consideradas pesquisas situadas entre os anos de 2005 e 2012 adotando-se os critérios de inclusão descritos a seguir: estudos empíricos, instrumentos desenvolvidos e/ou validados, modelos de avaliação sistemáticos (testados de forma estatística), qualidade da revisão e resumos completos disponíveis.

A base de dados ProQuest Academic Research Library abarca pesquisas em vários campos, como Psicologia, Ciência, Humanidades, Ciências Sociais, Educação, Saúde, Direito, Negócios e Artes. Objeto de análise em pesquisas em todos os continentes - desde EUA, China, Coréia, Hong Kong, Reino Unido, Grécia, Irã, entre outros - grande parte dos trabalhos são apresentados sob o formato de estudo de caso, uma vez que esta metodologia é comumente utilizada nas áreas de conhecimento de que decorrem as publicações, e descrevem uma série de situações em que o ensino não presencial foi adotado. Todavia, trabalhos de caráter empírico também foram identificados.

A Web of Science é uma base de dados que congrega trabalhos das áreas de Ciências, Humanidades, Ciências Sociais e Artes. Os resumos presentes nas revistas ou jornais são oriundos, em sua maioria, das áreas da Saúde, Educação, Educação e Tecnologia e Sociais. A busca bibliográfica efetuada nesta base de dados corrobora os achados anteriormente identificados, indicando que as temáticas sobre EAD são investigadas em diversos países, tais como: África do Sul, Austrália, Áustria, China, Espanha, EUA, Estônia, Indonésia, Itália, Japão, Praga, Reino Unido e Ucrânia. A educação a distância vem sendo constantemente utilizada em cenários educacionais díspares, como ciências da saúde (medicina, enfermagem, odontologia, etc), ciências exatas (engenharias, química e estatística) e humanidades (línguas, música e dança). A maior parte dos trabalhos apresenta abordagem qualitativa e é descritiva; tais publicações, que apresentam situações variadas nas quais cursos online foram ofertados, mais tratam dos aspectos particulares do que das similitudes de tais ações.

A partir dos trabalhos captados nas bases de dados consideradas, foi possível situar as categorias de estudos empreendidos a respeito das variáveis de pesquisa consideradas. Alguns 
dos pontos levantados encontram-se dispostos na tabela a seguir. 
Tabela 6. Resultados de buscas nas bases de dados SciELO, Banco de dissertações e teses da USP e Banco de dissertações e teses da UnB (continua).

Educação a Distância; Ensino a Distância; Ensino Superior; Aprendizagem a Distância; Instituições de Ensino Superior; Políticas Públicas de Educação a Distância; Treinamento,

Desenvolvimento e Educação; Treinamento a Distância; Avaliação; Avaliação de Cursos a Distância de IES; Evasão; Abandono Acadêmico; Desistência Acadêmica; Distance Learning; Elearning; Online Instruction; Computer assisted instruction; Learning; Higher Education; Education; Training; Knowledge, Skills \& Abilities; Efectiveness Teaching; Evaluation; College \& Universities; Evaluation Instrument; Dropout.
EAD pensada a partir de diferentes perspectivas:

- Na seara das políticas públicas: discute-se a mercantilização das ações de ensino superior; seu possível emprego no processo de universalização do acesso à formação acadêmica; ou, ainda, como opção educacional que expande os limites dos modelos educacionais mais conservadores e conhecidos;

- No campo da saúde - Medicina, Enfermagem e Fonoaudiologia: significativo número de trabalhos dedicados à temática;

- Avaliação dos efeitos oriundos das TICs nos círculos sociais, nas ferramentas de comunicação e nos atuais processos de ensino;

- Debate acerca da ampliação do acesso aos recursos e mídias digitais; do crescente emprego da tecnologia (computadores e TICs) nos eventos instrucionais; da adoção dos cenários virtuais para a educação e implicações dessa escolha para o desempenho dos discentes e estruturação do próprio campo;

- Investigação do papel da EAD e dos instrumentais tecnológicos disponíveis no ensino de novos idiomas (como inglês ou espanhol) e no trabalho com populações diferenciadas (indivíduos com deficiências ou comunidades menos privilegiadas);

- Delineamento e apresentação da distribuição dos cursos de nível superior em EAD; 
Tabela 6. Resultados de buscas nas bases de dados SciELO, Banco de dissertações e teses da USP e Banco de dissertações e teses da UnB (continuação).

\begin{tabular}{cl}
\hline Variável & \multicolumn{1}{c}{ Palavras-Chave } \\
\hline & \\
& \\
& \\
& Educação a Distância; Ensino a Distância; Ensino \\
& Superior; Aprendizagem a Distância; Instituições \\
& de Ensino Superior; Políticas Públicas de \\
& Educação a Distância; Treinamento, \\
& Desenvolvimento e Educação; Treinamento a \\
& Distância; Avaliação; Avaliação de Cursos a \\
& Distância de IES; Evasão; Abandono Acadêmico; \\
& Desistência Acadêmica; Distance Learning; E- \\
learning; Online Instruction; Computer assisted & instruction; Learning; Higher Education; \\
Education; Training; Knowledge, Skills \& \\
Abilities; Efectiveness Teaching; Evaluation; \\
College \& Universities; Evaluation Instrument; \\
Dropout.
\end{tabular}

\section{Resultados da Busca}

- Reflexão acerca da importância e dos efeitos desempenhados pelo tutor;

- Exposição a respeito dos aspectos ligados à prática docente no ensino não presencial - condições de formação pedagógica e política de tais profissionais:

- Identificação de possíveis elementos potencializadores e limitadores do ensino não presencial;

- Testagem de modelos avaliativos do impacto de treinamento no trabalho via internet;

- Descrição de particularidades envolvendo iniciativas de EAD via internet em instituições brasileiras privadas: estrutura dos cursos, público-alvo, tecnologias utilizadas, métodos de avaliação, etc.;

- Descrição de experiências instrucionais envolvendo o ensino não presencial ocorridas em diversificados cenários (exemplo: instituições educacionais de nível superior e organizações laborais) norte-americanos;

- Relatos de ações por meio das quais o governo chinês vem aderindo a planos nacionais de -learning a fim de oportunizar e promover o acesso ao ensino superior na nação. Dado o notável papel que esta modalidade de ensino representa para o país, diversas pesquisas dedicam especial atenção à avaliação da vigente condição da EAD na região; 
Tabela 6. Resultados de buscas nas bases de dados SciELO, Banco de dissertações e teses da USP e Banco de dissertações e teses da UnB (continuação).

\begin{tabular}{cl}
\hline Variável & \multicolumn{1}{c}{ Palavras-Chave } \\
\hline & \\
& Educação a Distância; Ensino a Distância; Ensino \\
& Superior; Aprendizagem a Distância; Instituições \\
de Ensino Superior; Políticas Públicas de & Educação a Distância; Treinamento, \\
& Desenvolvimento e Educação; Treinamento a \\
& Distância; Avaliação; Avaliação de Cursos a \\
& Distância de IES; Evasão; Abandono Acadêmico; \\
Desistência Acadêmica; Distance Learning; E- & learning; Online Instruction; Computer assisted \\
& instruction; Learning; Higher Education; \\
& Education; Training; Knowledge, Skills \& \\
& Abilities; Efectiveness Teaching; Evaluation; \\
& College \& Universities; Evaluation Instrument; \\
& Dropout.
\end{tabular}

Dropout.

Estratégias de aprendizagem; Dados sóciodemográficos; Uso de ferramentas da web;

Estratégias de Aprendizagem

Autoeficácia - self efficacy; Motivação para

aprender - motivação para o treinamento; Locus de controle - locus of control; Treinabilidade.

\section{Resultados da Busca}

- Esforços de pesquisa no sentido de desmistificar a noção de primazia das modalidades educacionais tradicionais em relação à EAD;

- Avaliação da qualidade dos eventos de e-learning e dos recursos mantenedores de sua eficácia;

- Premente necessidade de que os estudos produzidos transpassem à ordem de meras descrições, mas antes formulem e utilizem modelos sistemáticos de avaliação na tarefa de averiguar a efetividade dessas experiências.

- Necessário o aprofundamento do estudo a respeito das variáveis influentes sobre a qualidade e os resultados das ações de ensino a distância;

- Reconhecimento de uma relação positiva existente entre rendimento escolar mais satisfatório e a utilização adequada das estratégias de aprendizagem dos discentes;

- Análise dos resultados decorrentes do ensino e transmissão de estratégias de aprendizagem aos estudantes com desempenho acadêmico deficitário;

- Forte movimento e preocupação do campo de pesquisa no tocante ao desenvolvimento de instrumentos padronizados e validados que auxiliem a aferição, nos mais distintos níveis instrucionais, das estratégias de aprendizagem; 
Tabela 6. Resultados de buscas nas bases de dados SciELO, Banco de dissertações e teses da USP e Banco de dissertações e teses da UnB (continuação).

\begin{tabular}{|c|c|c|}
\hline Variável & Palavras-Chave & Resultados da Busca \\
\hline Estratégias de Aprendizagem & $\begin{array}{l}\text { Estratégias de aprendizagem; Dados sócio- } \\
\text { demográficos; Uso de ferramentas da web; } \\
\text { Autoeficácia - self efficacy; Motivação para } \\
\text { aprender - motivação para o treinamento; Locus } \\
\text { de controle - locus of control; Treinabilidade. }\end{array}$ & $\begin{array}{l}\text { - Considerável limitação do número de pesquisas de cunho } \\
\text { nacional voltadas ao estudo de tal tema; }\end{array}$ \\
\hline $\begin{array}{l}\text { Fatores Relacionados à } \\
\text { Persistência/Evasãa }\end{array}$ & $\begin{array}{l}\text { Reação ao treinamento/ao tutor/ao instrutor; } \\
\text { Reacão ao TBW/TBC; Reação à e-learning; } \\
\text { Reação aos procedimentos instrucionais. Teorias } \\
\text { de desenho instrucional; TBW/TBC; E-learning; } \\
\text { Ambientes de aprendizagem aberta; } \\
\text { Aprendizagem aberta; Computer assisted } \\
\text { instruction (CAI); Interactive training; Tecnologia } \\
\text { educacional/tecnologia de ensino; Multimídia } \\
\text { interativa (interactive multimedia); Simulator } \\
\text { training devices; Tutor/monitor/instrutor; } \\
\text { Interação tutor - aluno e tutor - tutor; } \\
\text { Persistência; Evasão; EAD. }\end{array}$ & $\begin{array}{l}\text { Identificação de múltiplos fatores ligados à à } \\
\text { permanência/desistência acadêmica, tais como aqueles da } \\
\text { ordem: } \\
\text { - Do evento instrucional cursado; } \\
\text { - De características internas dos próprios estudantes; } \\
\text { - Do contexto que cerca o aluno a distância; }\end{array}$ \\
\hline
\end{tabular}


Tabela 6. Resultados de buscas nas bases de dados SciELO, Banco de dissertações e teses da USP e Banco de dissertações e teses da UnB (conclusão).

\begin{tabular}{|c|c|c|}
\hline Variável & Palavras-Chave & Resultados da Busca \\
\hline Evasão & $\begin{array}{l}\text { Evasão; Abandono Acadêmico; Desistência } \\
\text { Acadêmica; Educação a Distância; Ensino a } \\
\text { Distância; Ensino Superior; Instituições de Ensino } \\
\text { Superior; Treinamento, Desenvolvimento e } \\
\text { Educação; Treinamento a distância; Avaliação; } \\
\text { Avaliação de Cursos a Distância de IES; Políticas } \\
\text { Públicas de Educação a Distância; Dropout; } \\
\text { Distance Learning; E-learning; Learning; } \\
\text { Evaluation; Online Instruction; Education; } \\
\text { Higher Education; College \& Universities; } \\
\text { Training; Knowledge, Skills \& Abilities; } \\
\text { Efectiveness Teaching; Evaluation Instrument; } \\
\text { Computer assisted instruction. }\end{array}$ & $\begin{array}{l}\text { - Avaliação da evasão no ensino de nível superior; na } \\
\text { educação fundamental, média e técnica; em contextos } \\
\text { corporativos; entre outros; } \\
\text { - Evidenciação de múltiplos cenários, instituições e elementos } \\
\text { dificultadores à permanência estudantil; } \\
\text { - Aquiescência quanto à necessidade de se particularizar a } \\
\text { evasão acadêmica ocorrida em contextos de ensino } \\
\text { tradicionais daquela que se dá nos chamados ambientes } \\
\text { virtuais de aprendizagem; } \\
\text { - Carência de pesquisas sistemáticas acerca do referido tema } \\
\text { situadas no campo da EAD; }\end{array}$ \\
\hline
\end{tabular}


Sendo a temática que entremeia e cose todas as variáveis de interesse do presente estudo, é possível verificar que a EAD vem sendo empregada em inúmeras frentes de atuação, tais como: no ensino e aprendizagem de novos idiomas; na transmissão e conscientização de instruções relevantes para o cuidado com a saúde; como ferramenta no trabalho desenvolvido junto a pessoas portadoras de deficiências; no trato de comunidades pouco acessadas pelos programas de ensino tradicionais; nas ações educacionais de nível superior; nas medidas de aprimoramento profissional; e em cursos de pós-graduação (MBAs). As pesquisas levantadas revelam que o ensino não tradicional serve a processos de treinamento de docentes em diferentes países do globo; em território nacional, os programas e planos governamentais lançados pelo MEC fortalecem tal tendência mundial. Os ambientes virtuais nos quais ocorre a aprendizagem e seus elementos e características próprias - como a linguagem utilizada, as formas de comunicação possíveis, os murais e blogs disponibilizados, recursos de áudio e vídeo - também foram tomados como objeto de investigação de alguns trabalhos.

As condições antecedentes aos eventos instrucionais também são investigadas por pesquisas realizadas. Neste sentido, características individuais dos aprendizes (e. g. estratégias de aprendizagem, locus de controle, autoeficácia, motivação, conhecimentos e habilidades prévias, etc) ou variáveis situacionais (e. g. suporte pré-treinamento, suporte à aprendizagem, difusão do treinamento, etc) são considerados no contexto do e-learning. Em relação às variáveis individuais, os dados sociodemográficos (sexo, nível educacional e raça) se destacam como os mais estudados; tal interesse ressaltado é refletido em resultados expressivos estatisticamente. São avaliadas as influências de características populacionais, dimensões psicossociais e medidas de empenho acadêmico na decisão de concluir ou não o evento educacional cursado. Há pesquisas que também se dedicam à investigação dos efeitos do uso de determinadas estratégias autorregulatórias na evasão discente.

No tocante aos elementos situacionais, os trabalhos levantados revelam que os instrumentos e ferramentas que servem de apoio à modalidade de educação a distância, tal como as TICs, não são capazes, unicamente por elas, de promoverem resultados mais satisfatórios na EAD. Todavia, o emprego de determinados métodos e estratégias de ensino em conjunto com procedimentos e técnicas voltados à facilitação do processo instrucional exercem papel importante na melhora da efetividade de eventos dessa natureza.

Alguns dos elementos presentes durante o desenvolvimento dos cursos e que são tratados pelas pesquisas científicas dizem respeito aos procedimentos e estratégias de ensino; as técnicas instrucionais; o papel do tutor/professor; os ambientes virtuais de aprendizagem. A problemática da desistência discente também vem sendo focalizada nos trabalhos dedicados 
ao e-learning.

Diversos estudos interessados em apresentar e debater experiências de avaliação de programas de ensino online vêm sendo produzidos. Encontram-se disponíveis trabalhos a respeito de procedimentos mais adequados à tarefa de avaliação de cursos não presenciais que consideram o rendimento acadêmico dos alunos; de modelos de análise empregados na verificação da relação custos-benefícios e eficácia do distance learning; de metodologias e técnicas de planejamento e verificação de resultados de programas de EAD; e de medidas e/ou modelos alternativos de avaliação. De acordo com apontamentos internacionais, o ensino via web não só proporciona condições favoráveis à avaliação dos eventos educacionais, bem como contribui para a elaboração de modelos destinados a tal fim. Trabalhos, de caráter variado, dedicam-se ao reconhecimento de fatores que exercem influência positiva ou negativa no desempenho de estudantes no distance learning.

Tendo em vista que cursos não presenciais contam com instrumentais e componentes que se diferem daqueles encontrados em programas de ensino tradicionais, tal como chats e fóruns de debate, pesquisas denunciam a premência de se formular meios satisfatórios para apreciá-los. Recursos como os fóruns e chats de discussão são constantemente empregados no e-learning e pouco se assemelham as ferramentas utilizadas em situações presenciais de testagem de conhecimento; por conta disso, estes devem ser considerados objetos de grande importância a serem levados em conta. A atenção recai sobre a forma como ocorre o processo de ensino a distância; as estratégias de aprendizagem envolvendo o monitoramento da compreensão e a busca de ajuda interpessoal; e a análise dos diferentes tipos de contato estabelecidos entre os atores da ação educacional.

Para muitos trabalhos a questão axial a ser tratada gira em torno dos produtos reais da EAD: alcançaria o e-learning os mesmos resultados obtidos pela educação pautada no conhecido modelo de sala de aula. Intentando responder a tal indagação, pesquisas comparativas são executadas considerando variáveis inerentes tanto ao ensino a distância como ao presencial. Tais avaliações comparativas - envolvendo cursos ofertados nas duas modalidades a grupos distintos de estudantes - objetivam aferir diferenças entre os desempenhos discentes decorrentes da natureza da ação instrucional.

Já o aspecto relacional presente na EAD é considerado a partir da análise dos tipos de processos de interação firmados e a quantidade dos mesmos - ou seja, o padrão de frequência dos mesmos - em contraposição ao ensino em sala de aula. Todavia, o campo científico tem alertado para a relevância do desenvolvimento e adoção de medidas mais precisas e rigorosas para o delineamento, execução e avaliação dos contatos virtuais. 
Por fim, as pesquisas também se dedicam ao levantamento e estudo das variáveis relacionadas à decisão de persistir ou evadir-se de cursos não presenciais; variáveis relacionadas ao êxito ou fracasso em modalidades de ensino a distância (planejamento, administração financeira, desenho instrucional, técnicas de ensino e apropriação de conteúdos pelo estudante); emprego dos recursos tecnológicos no apoio ao processo de ensino, e não apenas como incipiente veículo de entrega; desenhos instrucionais apropriados ao e-learning e interface gráfica das plataformas de ensino; transformações nas funções exercidas pelos agentes envolvidos no processo de ensino-aprendizagem a distância; relevância da emissão de feedback em ações instrucionais virtuais - artifício que gera resultados positivos tanto para os discentes quanto para os professores/tutores em contextos de educação superior, contribuindo para a qualificação do ensino-aprendizagem; experiências educacionais diversificadas assentadas no distance learning - mediadas pela televisão ou videoconferências, programas de ensino não presenciais para a formação educacional básica ou média ou em programas de pós-graduação para agentes do campo da saúde.

Tendo-se firmada em todo o mundo como modalidade instrucional oportuna e proveitosa, o distance learning deve ter sua eficácia tomada como objeto de pesquisa, de modo que suas potencialidades e limitações, vantagens e ônus, características e tendências sejam investigados por necessários estudos empíricos. Logo, o tema em questão não deve ser mote para asserções fundamentadas no senso comum; é preciso que as investigações indiquem os meios de se superar os entraves encontrados, e também aproveitar as possibilidades existentes.

\subsection{Componentes do modelo de investigação: achados de pesquisa}

Nesta seção são descritos e discutidos conceitos, características e resultados de pesquisa relacionados às Características da Clientela e Fatores Ligados à Persistência e ao Abandono Acadêmico em EAD. Em seguida, serão apresentados alguns dos resultados de pesquisa mais relevantes levantados através da leitura na íntegra de publicações completas com enfoque nas temáticas consideradas. 


\subsubsection{Características da clientela}

É possível verificar no campo científico o reconhecimento da importância que as características internas dos indivíduos que aprendem, seus hábitos pessoais, expectativas, motivações, interesses e objetivos podem desempenhar na obtenção de competências durante a ação educacional e no ulterior uso dessas capacidades em situações de trabalho (Meneses, Abbad, Zerbini \& Lacerda, 2006). Segundo os autores, o fenômeno da aquisição e transferência de novos conhecimentos e habilidades é possível a todos os indivíduos, entretanto elementos como as condições de apoio à aprendizagem e à transferência e o desenho da ação instrucional devem concorrer para tal alteração de comportamento.

Dessa feita, os trabalhos analisados não só apontam para a necessidade de que medidas de características da clientela sejam consideradas ao se proceder a avaliação de necessidades de ações instrucionais em cenários laborais, mas indicam a inclusão de variáveis sociodemográficas como preditoras de treinamentos bem-sucedidos.

Presente no modelo MAIS (Borges-Andrade, 1982, 2006), o componente “Características da clientela" é composto por elementos físicos e sociais, além de aspectos comportamentais e cognitivos dos treinandos, precedentes ao desenvolvimento do evento educacional, que podem interferir em seus resultados. As características da clientela, no modelo IMPACT de avaliação de treinamento de Abbad (1999), concentram um conjunto de informações demográficas, funcionais, motivacionais e atitudinais dos treinandos. Meneses et al. (2006) organizaram estas variáveis em cinco categorias, a saber:

1. Repertório de entrada: conhecimentos, habilidades, atitudes, expectativas e experiências adquiridas pelo aprendiz previamente ao início do evento instrucional;

2. Sociodemográficas: dados referentes ao sexo, idade, nível escolar, condição socioeconômica (perfil fisionômico da clientela) e à ocupação profissional, tempo de serviço, função, cargo, lotação (perfil profissional e funcional do participante) dos mesmos;

3. Psicossociais: variáveis autorreferentes tais como: locus de controle (percepção dos indivíduos em relação à responsabilidade pelo êxito ou fracasso de suas ações), autoeficácia (crenças do indivíduo em suas capacidades pessoais para motivar-se e acionar recursos cognitivos e cursos de ação necessários ao sucesso das atividades em que se compromete), comprometimento (sentimento de apego a uma instituição de 
trabalho), prazer e sofrimento relacionados à atividade profissional desempenhada;

4. Motivacionais: motivação para aprender e para transferir o aprendido e valor instrumental do treinamento;

5. Cognitivo-comportamentais: estratégias cognitivas, comportamentais e autorregulatórias empregadas pelo estudante para aprender.

O reconhecimento dos elementos que compõem a categoria de repertório de entrada auxilia a composição de turmas segundo a condição inicial dos treinandos; dessa forma, investimentos desnecessários são combatidos, uma vez que se cuida para que indivíduos já detentores das competências almejadas pela ação instrucional não venham a realizá-la. Além disso, tal identificação favorece a plena satisfação das expectativas e necessidades estudantis em relação aos conhecimentos e competências conjeturados no treinamento.

As informações sociodemográficas revelam carências e disposições dos participantes para o evento instrucional. Já as percepções e crenças pessoais a respeito da capacidade de exercer domínio sobre comportamentos, atitudes, entre outros - categoria psicossocial - se vinculam aos efeitos de ações instrucionais.

Diversas evidências científicas comprovam que sujeitos motivados a realizar programas de TD\&E e a aprender as competências ali transmitidas retêm mais satisfatoriamente os conteúdos, bem como os aplicam no trabalho. Logo, o aspecto motivacional do aprendiz interfere nos processos de aquisição, retenção e transferência do aprendido ao contexto laboral.

Por fim, o conjunto de características cognitivo-comportamentais dos aprendizes engloba variáveis como as estratégias de aprendizagem e hábitos de estudos, que são consideradas essenciais para a eficácia do delineamento e entrega da ação educacional. Tomar ciência acerca das predileções do treinando pode facilitar o ajustamento das estratégias empregadas no treinamento ou o desenvolvimento de aspectos no sujeito a fim de elevar seu desempenho durante o evento, sem ter de alterar os modos de proceder vigentes (Meneses et al., 2006).

Características pessoais, cognitivas e motivacionais diferenciadas podem requerer circunstâncias também distintas de aprendizagem, tal como procedimentos e meios a serem empregados em uma ação educacional. Dessa feita, os dados a respeito do perfil da clientela cooperam com o planejamento de eventos instrucionais e de estratégias educacionais mais apropriados às condições do público focalizado (Zerbini, 2007). Considerando, por exemplo, ações educacionais oferecidas a distância que demandam o uso de novos recursos 
computacionais de ensino, seria fundamental considerar prováveis embaraços dos estudantes para fazer uso dos artifícios tecnológicos ou da web, que deveriam servir a um aproveitamento mais satisfatório do curso. Sabe-se que a definição de estratégias e meios instrucionais, no âmbito de cursos ofertados a distância, requer mais tempo do profissional por eles responsável. Diferentemente das modalidades de ensino presenciais, a educação a distância prevê procedimentos específicos, planejamentos preliminares pormenorizados, e tutoria competente (Zerbini \& Abbad, 2010).

Inúmeros pontos que povoam o campo de TD\&E podem ser sanados por meio da investigação de características da clientela, tais como: a aquisição de aprendizagem bem ou malsucedida; a possibilidade de aplicar em novos contextos os CHAs transmitidos; os diferentes desempenhos obtidos pelos participantes de um mesmo programa de TD\&E; a satisfação ou insatisfação com o evento; e quais as principais características que interferem nos resultados decorrentes do processo de ensino-aprendizagem. Tais informações favoreceriam a execução exitosa de programas instrucionais e o emprego de estratégias de ensino adequadas e positivas a todos os participantes desses eventos.

A consideração e o estudo das características individuais em trabalhos científicos pode favorecer o entendimento de como ocorre a aprendizagem em adultos, o reconhecimento dos aspectos beneficiadores do desempenho em tarefas praticadas e auxiliar a elaboração de modelos de caráter teórico de treinamento e de avaliação (Warr \& Allan, 1998; Warr \& Downing, 2000). É necessário que os trabalhos se detenham no estudo de variáveis cognitivocomportamentais - tal como as estratégias de aprendizagem empregadas pelos estudantes durante a realização de programas instrucionais de natureza diversa - e não somente considerem as características mais conhecidas - tais como idade, gênero, motivação, autoeficácia e ansiedade (Meneses et al., 2006; Warr \& Allan, 1998; Warr \& Downing, 2000).

De acordo com Zerbini e Abbad (2010), as características individuais podem exercer uma interferência mais significativa nos resultados de ações educacionais a distância do que naqueles de natureza presencial, uma vez que a aprendizagem efetiva está, nesse primeiro caso, subordinada muito mais ao empenho empreendido pelo próprio sujeito (autogerenciamento da aprendizagem) do que aos recursos educacionais disponíveis. Possivelmente, tais estratégias se diferem significativamente daquelas encontradas nas ações presenciais. Segundo Zerbini (2007), o planejamento instrucional de cursos não presenciais pode ser beneficiado pelo estudo das estratégias de aprendizagem utilizadas pelos discentes e das características apresentadas pelos mesmos; achados advindos de investigações de tal ordem podem apurar o delineamento e a excelência de tais programas de ensino. 
O apuramento de informações referentes à clientela possibilita identificar o perfil dos sujeitos frequentadores de distintos programas de ensino e conhecer quais tipos de estratégias os mesmos empregam para atingir a aprendizagem, ofertando elementos para aprimorar as modalidades educacionais às suas características e necessidades pessoais. Consequentemente, evita-se a inadequada consideração de dados acerca da personalidade, nível de inteligência e motivação em cenários de organizações (Zerbini, 2007).

\subsubsection{Estratégias de aprendizagem: definições e características}

Inseridos em um contexto mundial marcado por constantes e profundas mudanças, os indivíduos cada vez mais são cobrados por competências que envolvem a autoadministração das ações que levam à aquisição do conhecimento - não somente no período de escolarização formal, mas por todo o ciclo de vida; dessa feita, a compreensão acerca dos processos que subjazem à aprendizagem tornou-se elemento chave para a sobrevivência de todos os agentes das sociedades atuais (Bjork, Dunlosky \& Kornell, 2013).

O fenômeno da aprendizagem, ocorrido em contextos escolares ou organizacionais, sofre interferências oriundas de diversas fontes, de modo que os aspectos afetivos, motivacionais e cognitivos apresentados pelos indivíduos que aprendem devem ser considerados como importantes fatores envolvidos em tal mediação.

Compreendido como processo de constante e ativa construção, a díade ensinoaprendizagem exige do aluno a distância o desempenho de um papel ativo, no qual é fundamental que se faça presente a habilidade de firmar metas e objetivos pessoais e de organizar e controlar os próprios recursos a fim de obter resultados instrucionais satisfatórios. Dessa feita, o elemento autorregulador desponta como imprescindível para o aprendiz, uma vez que fornece a este os estratagemas necessários para atingir os resultados almejados (McCormick, 2003).

$\mathrm{O}$ aspecto autorregulado da aprendizagem envolve inúmeros constructos, contudo dentre todos aqueles existentes as estratégias de aprendizagem são os mais investigados e avaliados. O emprego de tais estratégias envolve fatores de natureza diversa, muitos destes possuindo caráter motivacional (Souza, 2010).

O termo estratégia, que guarda sua origem na Grécia, strategia, foi conceitualizado primariamente como "arte geral". Com o decorrer do tempo, tal compreensão foi ampliada 
para a habilidade de estruturar, administrar e aplicar meios e recursos necessários ao atingimento de objetivos específicos (Beluce \& Oliveira, 2012).

Estratégias de aprendizagem podem ser entendidas como sendo ações sistematizadas pelos aprendizes intentando cumprir determinadas tarefas e alcançar metas estabelecidas. Logo, em cenários educacionais que objetivam o alcance da aprendizagem tais variáveis encontram-se intimamente relacionadas aos processos de aquisição, armazenamento e emprego ulterior dos conteúdos apreendidos. Oferecendo subsídios ao processamento de novos conhecimentos, as estratégias de aprendizagem encontram-se positivamente relacionadas com a aprendizagem exitosa, segundo trabalhos da psicologia organizacional ou do campo educacional que focalizam as características próprias do estudante (Oliveira, Boruchovitch \& Santos, 2009; Souza, 2010; Warr \& Downing, 2000).

De acordo com Sonnentag, Niesse e Ohly (2004), em âmbito organizacional as chamadas estratégias de aprendizagem corresponderiam às ações e medidas cognitivas efetuadas pelo sujeito visando a compreensão de determinado objeto. Em definição proposta por Badia e Monereo (2010), as estratégias de aprendizagem são compreendidas como a tomada cônscia e proposital de deliberações ajustadas às condições do contexto em que o evento educacional ocorrerá, e constante em relação ao acionamento de conteúdos de diferente natureza para obtenção dos objetivos de aprendizagem pretendidos.

Além de envolverem recursos distintos, tais estratégias compreendem uma sucessão de ações muito variadas sendo possível, dessa forma, ordená-las de distintos modos. Uma classificação comumente aceita é aquela que diferencia as estratégias de aprendizagem como cognitivas - condutas e pensamentos que permitem que o conhecimento seja armazenado eficazmente - e metacognitivas - procedimentos aplicados pelo sujeito no intuito de planejar, controlar e ajustar seu próprio pensamento. Estando as estratégias de aprendizagem cognitivas voltadas ao cumprimento de tarefas, as estratégias metacognitivas relacionam-se à ordenação, regulação e apreciação das primeiras. Este tipo de monitoramento permite ao estudante verificar se a estratégia utilizada está gerando os resultados pretendidos (Souza, 2010).

Em classificação proposta por Warr e Allan (1998) duas categorias de estratégias de aprendizagem são destacadas em contextos organizacionais e de trabalho: primárias (cognitivas e comportamentais) e autorregulatórias. As primeiras interferem sobre os processos de escolha, processamento, retenção e recuperação de informações, sendo usadas, portanto, na ocasião em que se dá o contato do aprendiz com os conteúdos a serem transmitidos. Por outro lado, as autorregulatórias dizem respeito a motivação da pessoa para aprender, a autogestão de esforços, o automonitoramento do progresso durante a 
aprendizagem, e o controle da ansiedade frente a determinadas situações que estariam dissipando a atenção do aprendiz. Essa segunda categoria afeta de maneira indireta o momento de interação do aprendiz com o objeto de conhecimento, afetando a forma como o mesmo sustém a motivação, gerenciamento, monitoramento do seu progresso e da ansiedade (Zerbini \& Abbad, 2008).

Por considerarem que tarefas de natureza e graus de complexidade distintos requerem diferentes estratégias de aprendizagem para ocorrerem - nesse caso, as estratégias utilizadas pelo indivíduo em ambientes acadêmicos para alcançar a aprendizagem bem-sucedida possivelmente se diferenciam daquelas empregadas em contextos laborais - Warr e Allan (1998) formularam um sistema taxionômico constituído por três grandes componentes, aos quais compreendem variados níveis de análise, a saber:

Tabela 7. Classificação e definições das estratégias de aprendizagem (Warr \& Allan, 1998; Zerbini \& Abbad, 2008).

- Repetição: repetição mental do conteúdo na forma em que este foi ministrado.

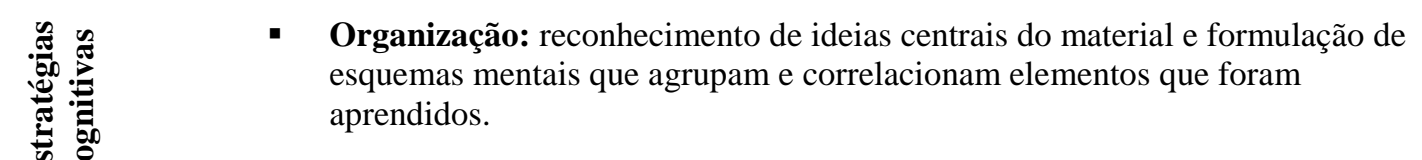

- Elaboração: reflexão sobre implicações e conexões possíveis entre o material aprendido e o conhecimento já dominado.

- Busca de ajuda interpessoal: obtenção de auxílio de outros indivíduos, como pares e professores, a fim de sanar dúvidas sobre o material (representa um

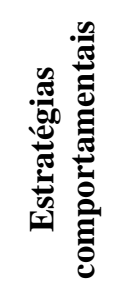
comportamento proativo do aprendiz de solicitar ajuda).

- Busca de ajuda no material didático: obtenção de informações em documentos escritos, manuais de instruções, programas de computador e outras fontes que não envolvam contato pessoal.

- Aplicação prática: aperfeiçoamento do conhecimento através da aplicação prática do que foi aprendido.

- Controle da emoção: controle da ansiedade e prevenção de dispersões de concentração, causadas por sentimentos de ansiedade.

- Controle da motivação: controle da motivação e da atenção, apesar de uma limitação de interesse envolvendo a tarefa a ser aprendida.

- Monitoramento da compreensão: avaliação do processo de aquisição de aprendizagem e alteração do comportamento do indivíduo, quando necessário.

Vale considerar que a proposta de Warr e Allan (1998), de acordo com Meneses et al. (2006), não deve ser compreendida como uma taxionomia, mas como um sistema classificatório de tipos de estratégias diferenciadas, já que os níveis deveriam apresentar 
necessariamente uma noção de sequência e cumulatividade, ou seja, recairiam em uma classificação e hierarquização.

Oliveira et al. (2009) propõem que as estratégias de aprendizagem sejam divididas da seguinte forma: estratégias cognitivas - que compreendem as atividades de ordenar, armazenar e elaborar os conteúdos, e estratégias metacognitivas, que correspondem à estruturação (proposição de objetivos de estudo), monitoramento (conhecimentos acerca da própria compreensão) e a gestão da aprendizagem (conhecimento de como compreender). Dembo (1994) dispõe as estratégias de aprendizagem em duas distintas categorias: estratégias cognitivas e estratégias metacognitivas. As primeiras estariam relacionadas aos processos intelectuais e exerceriam influência direta sobre as tarefas de organização, armazenamento e processamento de informações recebidas. Já os processos cognitivos realizados pelo sujeito de forma consciente, autorregulada e que lhe permite ponderar sobre seu próprio pensar seriam de responsabilidade das estratégias metacognitivas. Estratégias contidas nesta última categoria contariam com um nível mais aprofundado de complexidade, uma vez que as mesmas favoreceriam o autoconhecimento, a compreensão de objetos do conhecimento e o domínio de estratégias apropriadas ao planejamento, controle e regulação das operações mentais essenciais ao entendimento e resolução de problemáticas oriundas do processo de ensino e aprendizagem.

Segundo Oliveira et al. (2009), a complexidade do elemento metacognitivo centrar-seia no fato deste encerrar, concomitantemente, a determinação de objetivos de estudo (planejamento), a percepção sobre a própria compreensão (monitoramento) e o entendimento de como compreender (regulação).

A ponderação sobre o próprio processo de aprendizagem contribui para a tomada do conhecimento e, consequentemente, para o êxito educacional. Não só é importante o uso de estratégias cognitivas, como também discernir sobre em que momento e de que forma empregá-las, sobre a sua serventia e eficácia. Dessa forma, seria possível conceitualizar as estratégias de aprendizagem como importantes recursos utilizados pelo aluno nos contextos de estudo, que não só estarão articulados à tarefa de processamento de informações, mas otimizarão a retomada e o imediato emprego do conhecimento adquirido (Oliveira et al., 2009).

A faculdade humana de compreender o modo pelo qual ocorrem alguns processos cognitivos como a atenção, a memorização ou a compreensão não só possibilita ao indivíduo tomar ciência do processo de aprendizagem, como o reveste de um papel ativo e edificador na elaboração de seu próprio conhecimento; a essa capacidade de estruturar, de guiar o 
entendimento e de apreciar o que foi compreendido, deu-se o nome de metacognição. Exercendo um relevante papel na potencialização do aprender, as estratégias metacognitivas dotam o aprendiz de meios eficazes para lidar com os elementos oriundos do meio e com os seus próprios processos de pensamento (Ribeiro, 2003; Flavell, 1970). As habilidades metacognitivas possibilitariam aos aprendizes refletir acerca das ações tomadas em prol da busca pelo conhecimento, alterando e elaborando novos meios que os permitam sanar dificuldades ou obstáculos (Oliveira et al., 2009).

A utilização constante e sistemática de estratégias metacognitivas, além de contribuir para uma apropriação significativa do conhecimento e para o próprio sucesso acadêmico (Boruchovitch et al., 2006; Oliveira, Boruchovitch \& Santos, 2006 Zimmerman \& MartinezPons, 1986), estaria ligada à predição da aprendizagem e à inteligência, relevando elementos analíticos do cenário no qual se efetiva o aprender (Veenman, Wilhelm \& Beishuizen, 2004).

É importante ter em mente que as estratégias de aprendizagem se distinguem dos chamados hábitos de estudos, que envolvem procedimentos de associação de fatores contextuais e modos de estudar utilizados com o intento de aperfeiçoar os processos de aquisição e manutenção da aprendizagem, e também dos estilos de aprendizagem, que compreendem as predileções sobre os aspectos ambientais e as maneiras de estudo. Segundo Leaver (1997), os estilos de aprendizagem podem ser ordenados em 4 classes distintas, a saber: sensorial (estudantes visuais, auditivos ou sinestésicos), cognitiva (funcionamento cerebral direito ou esquerdo, reflexivo ou impulsivo, tolerante ou intolerante a ambiguidade, global ou sequencial, etc), tipos psicológicos (introvertido ou extrovertido) e preferências ambientais (tolerante ou dependente de luz ou sons, necessidades alimentares, entre outros).

Por sua vez, as estratégias de aprendizagem estão intimamente ligadas ao construto de autonomia, consideravelmente investigado por inúmeros pesquisadores. De acordo com Magno e Silva (2008), este é um conceito de caráter multidimensional que encerra as estratégias de aprendizagem, os estilos de aprendizagem, motivação, elementos afetivos, entre outros. A Tabela 8 apresenta algumas definições, e seus respectivos autores, sobre o conceito de autonomia que foram identificados. 
Tabela 8. Definições do conceito de autonomia.

\begin{tabular}{|c|c|}
\hline Autores & Definição \\
\hline Holec (1981) & $\begin{array}{l}\text { Capacidade de cuidar do próprio aprendizado, mantendo, para tanto, a } \\
\text { responsabilidade por todas as decisões relativas aos inúmeros aspectos que } \\
\text { envolvem tal processo. }\end{array}$ \\
\hline Little (1991) & $\begin{array}{l}\text { Capacidade de distanciamento, reflexão crítica, tomada de decisão, e ação } \\
\text { independente. Envolve o desenvolvimento de uma espécie de relação } \\
\text { psicológica entre o aprendiz e o processo e o conteúdo de sua } \\
\text { aprendizagem. } \\
\text { A autonomia será exibida tanto no modo como o aluno aprende, como na } \\
\text { forma como ele transfere o que foi aprendido para contextos mais amplos. }\end{array}$ \\
\hline Benson (2001) & $\begin{array}{l}\text { Deve ser vista como atributo do próprio aluno no processo de } \\
\text { aprendizagem, e não um método de aprendizagem. Trata-se de uma } \\
\text { capacidade multidimensional que adquire diferentes formas para distintos } \\
\text { indivíduos ou para o mesmo sujeito em contextos ou momentos diversos. } \\
\text { Está associada com a tomada de controle em um processo que envolve o } \\
\text { controle sobre a gestão da aprendizagem, sobre os processos cognitivos, e } \\
\text { sobre os conteúdos da aprendizagem. }\end{array}$ \\
\hline $\begin{array}{l}\text { Guimarães \& } \\
\text { Boruchovitch (2004) }\end{array}$ & $\begin{array}{l}\text { Relativo à faculdade de se autogovernar. Vinculado à Teoria da } \\
\text { Autodeterminação, o conceito de autonomia liga-se à intenção do } \\
\text { organismo de organizar experiências e o próprio comportamento visando } \\
\text { integrá-los ao sentido do self. }\end{array}$ \\
\hline Paiva (2006) & $\begin{array}{l}\text { Sistema sócio-cognitivo complexo, cuja expressão se dá em diferentes } \\
\text { graus de independência e controle sobre o próprio processo de } \\
\text { aprendizagem. Envolve capacidades, habilidades, atitudes, desejos, tomadas } \\
\text { de decisão, escolhas, e avaliação. }\end{array}$ \\
\hline Collins (2008) & $\begin{array}{l}\text { Intimamente relacionada a processos cognitivos, a autonomia envolve uma } \\
\text { forte disposição interna, da parte do aluno, para aprender. Nesse sentido, a } \\
\text { aprendizagem se daria sob condições tidas como relevantes frente à decisão } \\
\text { psicológica já tomada pelo aprendiz. }\end{array}$ \\
\hline $\begin{array}{l}\text { Ribeiro \& Carvalho } \\
(2012)\end{array}$ & $\begin{array}{l}\text { A autonomia acadêmica corresponderia à capacidade de organização frente } \\
\text { ao processo de aprendizagem, identificação de dificuldades/necessidades, e } \\
\text { possíveis meios de superação. }\end{array}$ \\
\hline
\end{tabular}

Dada sua relevância para o controle do próprio comportamento e inspeção do processo de aprendizagem, as estratégias de aprendizagem quando inexistentes ou inadequadamente aplicadas podem ocasionar sérias complicações no aprender. Nesse sentido, indivíduos que conhecem e fazem uso apropriado das estratégias de aprendizagem são capazes de enfrentar uma gama mais variada de situações e desafios de ensino. Ao avaliarem dados oriundos de pesquisas no campo da aprendizagem, memória e processos metacognitivos, Bjork, Dunlosky e Kornell (2013) concluem que os indivíduos podem sofrer influências prejudiciais advindas de crenças e percepções acerca da própria aprendizagem, danosas à efetividade dos mesmos enquanto aprendizes.

Para tais autores, a aprendizagem efetiva decorre não somente da compreensão básica 
dos processos de codificação e recuperação de informações, mas também da conscientização acerca das técnicas, atividades e procedimentos que fomentam a retenção e transferência de objetos do conhecimento. Reflexões e interpretações de possíveis erros e equívocos cometidos são, na mesma medida, elementos essenciais para a aprendizagem exitosa (Bjork et al., 2013).

Tomando as considerações de Valdés (2003), a habilidade de aprender a aprender se assenta no desenvolvimento de uma forma de conhecimento caracterizada como estratégica cuja propriedade essencial não se relaciona ao uso de técnicas de aprendizagem, mas sim na possibilidade de revestir o discente de uma postura ativa e de mediação social na construção do conhecimento (Oliveira et al., 2009). Logo, torna-se de suma relevância que planejadores de cursos, professores e aprendizes reconheçam os diversos tipos de estratégias de aprendizagem existentes, sua aplicação e importância para o aprender.

Contudo, se nota que os aprendizes tendem a utilizar determinados tipos de estratégias de forma espontânea, ao passo que outras, mesmo tendo sido transmitidas, dificilmente são usadas. A partir desse fato, é razoável considerar que tais diferenças de escolha se devem a variações nos aspectos motivacionais, tais como as crenças a respeito da própria inteligência, a autoeficácia, a idade, a série escolar; sabe-se que fatores motivacionais estão interligados às estratégias de aprendizagem, de modo que os primeiros podem alavancar o uso das segundas (Souza, 2010). A relação positiva existente entre a utilização apropriada de estratégias e um desempenho escolar mais satisfatório é testificada a partir da convergência de resultados de pesquisa advindas de estudos como os empreendidos por Oliveira, Boruchovitch e Santos (2011), Oliveira et al. (2009) e Costa e Boruchovitch (2000).

Nesse sentido, em trabalho desenvolvido, Santos, Boruchovitch, Primi, Zenorini e Bueno (2004) alegam que estudos no campo educacional, mais precisamente em cenários escolares, têm comprovado que o ensino de estratégias de aprendizagem aos estudantes fomenta a elevação da autonomia pessoal e incrementa a conscienciosidade e a responsabilidade sobre o próprio processo de aprender. $\mathrm{O}$ autores ainda chamam a atenção para a diminuta produção de pesquisas científicas sobre estratégias de aprendizagem que envolvam discentes brasileiros, especialmente, aqueles do nível superior.

É importante considerar os diferentes tipos de estratégias de aprendizagem utilizados pelos indivíduos como um dos elementos pessoais que concorrem para o êxito da aprendizagem e, tão logo, caracterizam-se como prováveis variáveis desse fenômeno. A reflexão minuciosa visando a compreensão das estratégias de aprendizagem possibilitaria entender a capacidade dos indivíduos enquanto aprendizes e esclarecer de que modo eles podem melhor aprender como se aprende (Warr \& Allan, 1998). 
De acordo com os autores acima citados, as estratégias de aprendizagem compreenderiam um complexo de capacidades mentais, habilidades comportamentais e de controle das próprias emoções empregadas pelos estudantes a fim de dominar seus processos psicológicos envolvidos no aprender, tais como, atenção, memorização, aquisição e transferência. Dessa feita, não haveria uma estratégia dita a melhor, uma vez que cada aprendiz utiliza procedimentos distintos para identificar, controlar e fiscalizar sua aprendizagem, mas opções mais eficientes que se modificam tendo em vista os diversos cenários de aprendizagem (Levin, 1986).

Além de poderem ser aprendidas, as estratégias de aprendizagem são passíveis de modificação por meio de ações de treinamento. Dessa forma, a transmissão e aprimoramento de tais estratégias não envolveriam, necessariamente, alterações nos procedimentos educacionais, mas interfeririam na forma como os discentes se portam ao estudar.

Atualmente, o "aprender a aprender" é tido como elemento vital e diferenciador em contextos educacionais, uma vez que o entendimento acerca desse processo favorece a ocorrência de modificações. Nesse sentido, indivíduos cônscios tanto das estratégias exitosas e malsucedidas, quanto dos passos adotados, podem reavaliar, aprimorar e alterar, de forma crítica e decisiva, os próprios processos de aprendizagem (Oliveira et al., 2009). E considerando que as instituições de ensino desempenham função essencial no encorajamento e apoio ao uso de estratégias apropriadas, é necessário que tais estabelecimentos zelem pela orientação do aprendiz quanto ao emprego e diversificação das mesmas no momento de estudo.

Segundo Zabalza (2005), autora clássica do campo educacional, o processo de aprendizagem formativa assenta-se na constante reconsideração dos procedimentos e caminhos adotados através dos quais os indivíduos atingem o resultado pretendido, ou seja, aprendem. A ação regulada sobre a aprendizagem, tanto pelos professores quanto pelos alunos, favoreceria o desenvolvimento da competência do "aprender a aprender" nestes últimos.

A discussão sobre as estratégias de aprendizagem empregadas em ambientes virtuais de ensino enquanto um conjunto de competências e habilidades indispensáveis para a sobrevivência na sociedade cibernética é tecida por diversos autores, tais como: Alliprandini, Lima, Oliveira e Schiavoni (2012), Badia e Monereo (2010) e Beluce e Oliveira (2012). Os cenários de ensino online apesar de subsidiarem novas possibilidades e perspectivas para as práticas educacionais, também exigem cuidados quanto suas especificidades (Chen \& Paul, 2003; Silva, 2003; Testa \& Luciano, 2010). Dessa feita, a exemplo de ações instrucionais de 
caráter presencial, programas e disciplinas implementados em contextos de AVAs também reclamam pela conformação e implementação de propostas que contemplem as particularidades neles contidos; logo, as estratégias de aprendizagem utilizadas pelos estudantes a fim de promoverem o próprio processo de aprendizagem devem ser consideradas e contempladas por tais ações de planejamento (Beluce \& Oliveira, 2012).

Algumas questões são levantadas por estudiosos preocupados com as problemáticas que afligem os atuais cenários educacionais, dentre as quais se destaca a seguinte controvérsia: ocorrerá o desenvolvimento de estratégias para aprender próprias aos ambientes virtuais e presenciais? De acordo com eles, os contextos de ensino baseados em hipermídias, por apresentarem características particulares, tais como as que se seguem, exercem forte influência no ensino de estratégias: 1) a premência do planejamento, determinação e revisão das próprias deliberações para o alcance de resultados almejados; 2) o contato dinâmico produzido pelas TICs entre os objetos de conhecimento e os indivíduos que interagem e compartilham suas aquisições; 3) o incremento nas possibilidades de aprender novos modos de gerir o conhecimento devido à multiplicidade dos formatos de apresentação dos conteúdos e à simplicidade em criar e alterar redes de conhecimento e aprendizagem (Badia \& Monereo, 2010; Donolo, Chiecher \& Rinaudo, 2004).

De acordo com Kearley e Moore (2005), as iniciativas de ensino a distância implicam em condutas e formas de agir por parte dos discentes que se diferenciam daquelas já conhecidas - refletir e comportar-se de modo autônomo, ponderar acerca do próprio processo de aprendizagem, autogerenciar as tarefas executadas, e cuidar das escolhas efetuadas são alguns exemplos de tais comportamentos - e desempenham papel crucial para o êxito de ações de EAD. Por conta disso, tais ambientes exigem e favorecem a elaboração de competências indispensáveis a um processo de aprendizagem mais independente e maleável, levando em conta tempo, espaço e ritmo daquele que aprende, por meio de uma série de expedientes didáticos ajustados a variadas mídias e recursos tecnológicos (Carswell \& Venkatesh, 2002; Castro \& Ferreira, 2006; Cheung, 2000).

Tendo em vista a eminente relevância das estratégias de aprendizagem e da constante inclusão das TICs em ambientes instrucionais, ambas devem ser tratadas como elementos constituintes dos currículos acadêmicos, rompendo com os tradicionais paradigmas educacionais que vêm sendo substituídos ou modificados, em parte, graças aos novos adventos tecnológicos (Badia \& Monereo, 2010; Coll \& Monereo, 2010).

Por conta disso, tanto o estudo quanto a inovação no ensino e na aprendizagem de estratégias de aprendizagem em cenários virtuais compõem um terreno a ser penetrado, que 
deve considerar os atuais perfis e capacidades dos agentes envolvidos, e os novos contextos, instrumentais e objetivos estabelecidos pelas recentes modalidades de ensino. Estas, por sua vez, por serem mais individualizadas e independentes, possibilitam que os aprendizes se envolvam mais com a autoaprendizagem, e todas essas transformações incidirão sobre os processos de aquisição do conhecimento e as formas de avaliá-la.

Dado o valor atribuído pelas sociedades atuais ao domínio e utilização do conhecimento, a capacidade de administrar e modificar informações disponíveis é considerada uma competência fundamental, que deveria ser estabelecida nos diversificados currículos escolares com considerável distinção. Sobre essa temática, que já foi alvo de inúmeras investidas científicas, é possível encontrar relatos de experiências não só muito interessantes, mas úteis, uma vez que atestam a importância e exequibilidade do ensino do "aprender a aprender" a qualquer indivíduo. Aprendizes aptos a planejar, regular e avaliar por si mesmos os processos de aprendizagem pertinentes a eles próprios, tornam-se capazes de também defrontar as incessantes transformações que atravessam e caracterizam a época vigente (Badia \& Monereo, 2010).

Sabendo-se que eventos instrucionais ofertados a distância estão subordinados muito mais ao empenho do próprio aluno (autogerenciamento da aprendizagem) do que aos recursos instrucionais, as estratégias de aprendizagem utilizadas em ações dessa natureza se distinguem daquelas empregadas em cursos presenciais (Donolo et al., 2004; Zerbini, 2007; Zerbini \& Abbad, 2010). A análise e compreensão acerca das estratégias de aprendizagem podem ser de grande valia para aperfeiçoar o planejamento instrucional de ações a distância, uma vez que favorecem o reconhecimento dos processos individuais de aprendizagem utilizados e dos procedimentos instrucionais mais adequados a cada agente envolvido (Santos et al., 2004; Zerbini, 2007; Zerbini \& Abbad, 2010).

Os achados a respeito das estratégias utilizadas pelos estudantes para aprender em programas a distância podem contribuir para o estabelecimento de aspectos a serem desenvolvidos no sujeito para favorecer seu desempenho durante o curso, sem necessariamente alterar os procedimentos instrucionais. Dessa feita, demonstra-se a relevância e necessidade da elaboração de instrumentos capazes de avaliar as estratégias de aprendizagem empregadas pelos discentes ao longo de ações educacionais desse feitio e mensurar o poder de predição de tais variáveis individuais quanto ao êxito do processo de ensino.

$\mathrm{Na}$ pesquisa ora apresentada, serão consideradas as definições de estratégias de aprendizagem propostas por Warr e Allan (1998) em razão dos autores levarem em 
consideração e aferirem os efeitos advindos da interação estabelecida entre a díade aprendizmateriais/equipamentos instrucionais. Pretende-se identificar quais estratégias - cognitivas, comportamentais ou autorregulatórias - explicam a ocorrência de fatores ligados à evasão/permanência discente, ou em outros termos, ao abandono/persistência acadêmica de indivíduos que estudam a distância.

\subsubsection{Achados de pesquisa sobre estratégias de aprendizagem}

$\mathrm{Na}$ presente seção são descritos instrumentos de medida nacionais e estrangeiros desenvolvidos com o intento de mensurar estratégias de aprendizagem em ambientes educacionais, bem como estudos que se dedicaram à análise do relacionamento entre variáveis. As pesquisas consideradas na revisão de literatura revelam um empenho do campo científico na construção de instrumentos confiáveis e padronizados destinados à avaliação de estratégias de aprendizagem em contextos instrucionais diversos.

Segundo Boruchovitch et al. (2006), a produção de estudos voltados à análise do papel desempenhado pelas estratégias de aprendizagem nas mais diversas etapas da escolarização, embora venha experimentando crescimento, ainda é considerada insuficiente. No panorama científico, foram identificados alguns dos instrumentos de maior relevância que se encontram disponíveis para a mensuração de estratégias de aprendizagem. A Tabela 9 apresenta alguns deles. 
Tabela 9. Instrumentos destinados à mensuração de estratégias de aprendizagem (continua).

\begin{tabular}{lll}
\hline \multicolumn{1}{c}{ Autores } & \multicolumn{1}{c}{ Instrumento } & \multicolumn{1}{c}{ Resultados/Fatores obtidos } \\
\hline & & \\
Zimmerman \& Martinez- & Self-regulated & Entrevista estruturada destinada à avaliação do \\
Pons (1986) & Learning Interview & reprório de estratégias de aprendizagem de \\
& Schedule (SRLIS) & concretas relativas ao ensino/aprendizagem, tais \\
& & como: aprendizagem em sala de aula, estudo em \\
& & casa, realização de tarefas escolares em casa e de \\
& & \\
& & \\
&
\end{tabular}

Weinstein \& Palmer (1987, Learning and Study 1990) (LASSI)

Processamento da informação $(\alpha=0,83)$;

Seleção de ideias principais $(\alpha=0,74)$;

Estratégias de avaliação $(\alpha=0,83)$;

Atitude $(\alpha=0,72)$;

Ansiedade $(\alpha=0,81)$;

Motivação $(\alpha=0,81$.);

Auto-avaliação $(\alpha=0,75)$;

Concentração $(\alpha=0,84)$;

Administração do tempo $(\alpha=0,86)$;

Uso de técnicas e materiais de apoio $(\alpha=0,68)$;
Pintrich, Smith, Garcia, \& Mckeachie (1991)
Motivated Strategies

for Learning

Questionnaire

(MSLQ)
Escala de motivação

Orientação Intrínseca para Metas ( 5 itens; $\alpha=0,74$ )

Orientação Extrínseca para Metas ( 5 itens; $\alpha=0,62$ )

Valor da Tarefa ( 7 itens; $\alpha=0,90$ );

Crenças de Controle da Aprendizagem (5 itens; $\alpha=0,68)$;

Auto-Eficácia para Aprendizagem e Desempenho (9 itens; $\alpha=0,93$ );

Ansiedade de Avaliação (6 itens; $\alpha=0,80$ );

Escala de Estratégias de Aprendizagem

Repetição ( 5 itens; $\alpha=0,69$ );

Elaboração ( 7 itens; $\alpha=0,76$ );

Organização (5 itens; $\alpha=0,64)$;

Pensamento Crítico ( 6 itens; $\alpha=0,80$ );

Auto-regulação Metacognitiva (13 itens; $\alpha=0,79$ );

Administração de Tempo/Ambiente de Estudo (9 itens; $\alpha=0,76$ );

Regulação de Esforços ( 5 itens; $\alpha=0,69$ );

Aprendizagem entre Pares (4 itens; $\alpha=0,76$ );

Busca por Ajuda ( 5 itens; $\alpha=0,52$ ); 
Tabela 9. Instrumentos destinados à mensuração de estratégias de aprendizagem (continuação).

\begin{tabular}{|c|c|c|}
\hline Autores & Instrumento & Resultados/Fatores obtidos \\
\hline Warr \& Downing (2000) & $\begin{array}{l}\text { Escala de Estratégias } \\
\text { de Aprendizagem }\end{array}$ & $\begin{array}{l}\text { Repetição mental (Amostra 1: } \alpha=0,81 ; \text { Amostra 2: } \\
\alpha=0,77 \text { ); } \\
\text { Reflexão ativa (Amostra } 1: \alpha=0,90 ; \text { Amostra } 2: \\
\alpha=0,83 \text { ); } \\
\text { Busca de ajuda interpessoal (Amostra } 1: \alpha=0,84 ; \\
\text { Amostra } 2: \alpha=0,83 \text { ); } \\
\text { Busca de ajuda no material escrito (Amostra } \\
\text { 1: } \alpha=0,89 ; \text { Amostra 2: } \alpha=0,64 \text { ); } \\
\text { Aplicação prática (Amostra } 1: \alpha=0,78 ; \text { Amostra 2: } \\
\alpha=0,73 \text { ); } \\
\text { Controle da emoção (Amostra } 1: \alpha=0,85 ; \text { Amostra 2: } \\
\alpha=0,75 \text { ); } \\
\text { Controle da motivação (Amostra } 1: \alpha=0,89 ; \text { Amostra } \\
\text { 2: } \alpha=0,88 \text { ); } \\
\text { Monitoramento da compreensão (Amostra } 1: \alpha=0,85 \text {; } \\
\text { Amostra } 2: \alpha=0,84 \text { ); }\end{array}$ \\
\hline Bessa \& Tavares (2001) & $\begin{array}{l}\text { Escala de } \\
\text { Comportamentos } \\
\text { Habituais de Estudo e } \\
\text { Aprendizagem (CHE) }\end{array}$ & $\begin{array}{l}\text { Estratégias cognitivas de transformação e } \\
\text { manipulação da informação (ECTMI, } 7 \text { itens); } \\
\text { Estratégias cognitivas de organização e planeamento } \\
\quad \text { de rotinas (ECOPR, } 5 \text { itens); } \\
\text { Estratégias cognitivas e metacognitivas de gestão e } \\
\text { monitorização (ECMGM, } 7 \text { itens); } \\
\text { Estratégias cognitivas de aquisição e seleção da } \\
\text { informação (ECASI, quatro itens); } \\
\text { Estratégias afetivas de reforço motivacional (EARM, } \\
\quad 2 \text { itens); }\end{array}$ \\
\hline Borges-Ferreira (2004) & $\begin{array}{l}\text { Escala de Estratégias } \\
\text { de Aprendizagem }\end{array}$ & $\begin{array}{l}\text { Busca de ajuda interpessoal ( } 6 \text { itens; } \alpha=0,87 \text { ); } \\
\text { Elaboração e aplicação prática do conteúdo (5 itens; } \\
\quad \alpha=0,76) ; \\
\text { Repetição, organização e ajuda do material ( } 8 \text { itens; } \\
\quad \alpha=0,80) ;\end{array}$ \\
\hline
\end{tabular}

Boruchovitch \& Santos (2004; 2006)
Escala de Estratégias de Aprendizagem para Alunos do Ensino Fundamental (EAEF)
Ausência de utilização de estratégias de aprendizagem (8 itens; $\alpha=0,71)$;

Estratégias cognitivas ( 6 itens; $\alpha=0,59$ );

Estratégias metacognitivas( 6 itens; $\alpha=0,51)$;
Zerbini, Carvalho \& Abbad (2005)
Escala de Estratégias de Aprendizagem
Busca de ajuda interpessoal ( 8 itens, $\alpha=0,85$, cargas fatoriais entre 0,44 e 0,76);

Elaboração e aplicação prática do conteúdo (5 itens, $\alpha=0,75$, cargas fatoriais entre 0,38 e 0,83 );

Repetição, organização e ajuda do material (7 itens, $\alpha=0,78$, cargas fatoriais entre $-0,33$ e $-0,69$ ); 
Tabela 9. Instrumentos destinados à mensuração de estratégias de aprendizagem (conclusão).

\begin{tabular}{lll}
\hline \multicolumn{1}{c}{ Autores } & \multicolumn{1}{c}{ Instrumento } & \multicolumn{1}{c}{ Resultados/Fatores obtidos } \\
\hline \multirow{2}{*}{$\begin{array}{l}\text { Zerbini \& Abbad (2008) } \\
\text { Escala de Estratégias } \\
\text { de Aprendizagem }\end{array}$} & $\begin{array}{l}\text { Controle da emoção, } 5 \text { itens }(\alpha=0,89) ; \\
\text { Busca de ajuda inter pessoal, } 6 \text { itens }(\alpha=0,89) ; \\
\text { Repetição e or ganização, } 5 \text { itens }(\alpha=0,77) ; \\
\text { Controle da motivação, } 4 \text { itens }(\alpha=0,84) ; \\
\text { Elaboração, } 3 \text { itens }(\alpha=0,83) ; \\
\text { Busca de ajuda ao material didático, } 2 \text { itens }(\alpha=0,75) ; \\
\text { Monitoramento da compreensão, } 3 \text { itens }(\alpha=0,82) ;\end{array}$ \\
& & \\
\hline \multirow{3}{*}{$\begin{array}{l}\text { Brandão \& Borges-Andrade } \\
(2011)\end{array}$} & $\begin{array}{l}\text { Escala de estratégias } \\
\text { de aprendizagem no } \\
\text { trabalho }\end{array}$ & $\begin{array}{l}\text { Reflexão ativa, } 9 \text { itens }(\alpha=0,92) ; \\
\text { Busca de ajuda interpessoal, } 5 \text { itens }(\alpha=0,88) ; \\
\text { Busca de ajuda em material escrito, } 5 \text { itens }(\alpha=0,79) ; \\
\text { Reprodução, } 4 \text { itens }(\alpha=0,79) ; \\
\text { Aplicação prática, } 3 \text { itens }(\alpha=0,82) ;\end{array}$ \\
&
\end{tabular}

Tal como é possível verificar, entre os instrumentos destinados à aferição de estratégias de aprendizagem encontram-se tanto escalas desenvolvidas para o cenário escolar, bem como outras ferramentas pensadas para a formação técnica (Pintrich et al., 1991; Santos et al., 2004; Warr \& Downing, 2000; Weinstein \& Palmer, 1987; 1990). Alguns dos instrumentos utilizados em contextos educacionais se diferenciam pela aplicação exclusiva em etapas específicas da preparação escolar formal, tal como o ensino fundamental (Boruchovitch \& Santos, 2004; 2006).

A maior parte das ferramentas construídas corresponde à escalas/questionários que encerram variada gama de estratégias de aprendizagem comportamentais, cognitivas e autorregulatórias. A única exceção diz respeito ao instrumento aberto de autorrelato Selfregulated Learning Interview Schedule (SRLIS); a SRLIS, elaborada por Zimmerman e Martinez-Pons (1986), foi inicialmente testada em 6 diferentes condições de aprendizagem e objetivava avaliar estratégias de aprendizagem autorregulatórias utilizadas por estudantes bem como investigar quais destas eram mais frequentemente utilizadas e possíveis relações entre elas e desempenho acadêmico. O instrumento em questão conta com 15 categorias de estratégias de aprendizagem - autoavaliação, organização e transformação de informações, planejamento e estabelecimento de metas, busca de informação, monitoramento e elaboração de registros, estruturação ambiental, autoconsequências, repetição e memorização, busca de ajuda, revisão de material, e outros - determinadas por pesquisas e teorias situadas no campo da aprendizagem autorregulada; segundo Cobb (2003) o desempenho escolar satisfatório seria fortemente dependente do uso de tais estratégias compreendidas na SRLIS.

Em relação à construção de escalas a serem empregadas em contextos de educação superior, Santos e Boruchovitch (2001) desenvolveram a Escala de Estratégias de 
Aprendizagem para Universitários (EEA-U). O instrumento é composto por 30 itens relativos às práticas de estudo ou preparação para provas costumeiramente utilizadas por alunos do ensino superior. As questões, dispostas em uma escala do tipo Likert, contam com 4 alternativas de respostas - 4: sempre; 3: às vezes; 2: raramente; 1: nunca - e pontuação variando entre 29 a 116 pontos. Segundo Boruchovitch (2006), após a administração da EEAU junto a uma amostra de 434 estudantes universitários e realização de análises fatoriais, foram extraídos 5 fatores aptos a explicar 44\% da variância identificada. Em termos de consistência interna, as escalas atingiram níveis satisfatórios nos Fatores $1(\alpha=0.87)$ e 2 $(\alpha=0.74)$. Todavia, foram encontradas discrepâncias quanto às categorias tradicionais do construto e contradições em relação ao desempenho acadêmico, tomado como critério externo de evidência de validade. A autora sugere a realização de novas pesquisas com tal instrumento, de modo que suas propriedades psicométricas possam vir a ser mais bem apuradas.

Verificam-se também esforços direcionados ao desenvolvimento de instrumentos de medida para uso no cenário laboral. Intentando construir um instrumento de estratégias de aprendizagem no trabalho e avaliar a frequência com que estas eram empregadas por gestores de um banco público, Brandão e Borges-Andrade (2011) realizaram um estudo envolvendo 881 gestores de agências bancárias brasileiras que culminou com a proposição de um questionário composto por 26 itens que expressavam práticas utilizadas para aprender de modo informal no ambiente de trabalho. Tais questões foram ancoradas em uma escala de frequência, que variava de 1 (nunca faço) a 10 (sempre faço). Entre a amostra considerada, as estratégias de aprendizagem denominadas "busca de ajuda interpessoal" e "reflexão" foram as mais utilizadas; além de indicarem as práticas empregadas pelos respondentes, os autores também puderam lançar contribuições teóricas e metodológicas à compreensão da temática estratégias de aprendizagem em ambientes laborais.

De acordo com alguns estudiosos, é possível que todos os estudantes venham a desenvolver técnicas que lhes permitam otimizar o estudo, tal como: destacar aspectos importantes de um texto, gerenciar o entendimento da leitura, utilizar estratégias de memorização, elaborar resumos, ampliar notas de aulas, etc. Considerando a importância das estratégias de aprendizagem para o processo de escolarização, a carência que envolve a elaboração de instrumentos aptos a revelar o repertório do alunado brasileiro quanto a elas e as potencialidades inerentes ao ensino de estratégias de aprendizagem a discentes de desempenho acadêmico deficitário, Boruchovitch et al. (2006) se dedicaram a explicitar as etapas referentes à criação de um escala destinada à avaliação das estratégias de aprendizes 
matriculados no ensino fundamental e revelar a análise prévia a respeito das propriedades psicométricas do instrumento.

Inicialmente, foram colhidos os dados concernentes às estratégias de aprendizagem de 305 estudantes (7 a 18 anos) de duas instituições de ensino fundamental da cidade de Campinas. Para tanto, foram realizadas entrevistas individuais estruturadas que, variando de 45 a 60 minutos, foram fundamentadas na Self-Regulated Learning Structured Interview (Zimmerman \& Martinez-Pons, 1986), traduzida e adaptada por Boruchovitch (1995).

Os itens abertos das entrevistas foram submetidos a análises de conteúdo e validação por juízes. As questões restantes foram convertidas para itens de uma escala, subordinada à aplicação piloto para validação semântica. A princípio, a Escala de Estratégias de Aprendizagem (EAEF) foi elaborada com 40 itens associados a uma escala de 3 pontos do tipo Likert (sempre, algumas vezes e nunca) e uma única questão aberta, tendo por objetivo averiguar se o estudante utilizaria alguma outra estratégia não considerada nos itens definidos. Os itens apresentados retratavam a presença ou a ausência das mais importantes estratégias de aprendizagem cognitivas (ensaio, elaboração e organização) e metacognitivas (planejamento, monitoramento e regulação dos processos cognitivos, motivacionais e afetivos).

Em um momento posterior, a EAEF foi administrada de forma coletiva a 433 estudantes de nível fundamental ( $3^{\mathrm{a}}$ a $8^{\mathrm{a}}$ série) de instituições públicas de ensino em Campinas e Catalão. As orientações e as questões da escala foram registradas em fitas cassete e ouvidas pelos participantes, que assinalavam suas respostas no questionário; o procedimento obteve duração média de 20 minutos.

A avaliação das propriedades psicométricas do instrumento, em matéria de validade e precisão, ocorreu por meio dos métodos da análise fatorial exploratória, estatísticas descritivas e correlação bivariada de Pearson. Em termos de precisão, a escala atingiu um índice total satisfatório, com coeficiente de Cronbach igual a 0,60; três fatores foram obtidos - tendo sido descartados aqueles que apresentaram saturação inferior a 0,35: Fator 1 - 8 itens (28, 30, 31, 32, 35, 37, 38 e 40), cujos conteúdos fazem menção à ausência de utilização de estratégias de aprendizagem; Fator 2 - 6 itens (2, 5, 7, 12, 16 e 25), relacionados a estratégias cognitivas; Fator 3 - 6 itens $(4,6,17,21,26$ e 27) com elementos típicos das estratégias metacognitivas.

Em relação às questões abertas, estas foram respondidas por 8,5\% da amostra e verificou-se a prevalência daquelas cujos conteúdos se assemelhavam aos itens já elencados na escala.

Tais achados se diferenciam dos resultados encontrados por Santos et al. (2004) em investigação efetuada com 434 estudantes universitários que preencheram uma escala cujo 
objetivo era compreender a forma pela qual o aprendiz habitualmente estuda ou se prepara para uma tarefa avaliativa. O instrumento é composto por 30 afirmativas a respeito do uso de estratégias de memorização, administração do tempo, estruturação do ambiente, compreensão de leitura, autoavaliação, entre outras, e estão associadas a uma escala Likert de frequência de 4 pontos. Cinco fatores foram identificados, a saber: Fator 1 - 11 itens $(\alpha=0,87)$ - estratégias cognitivas simples com itens de estratégias metacognitivas; Fator 2 - 8 itens $(\alpha=0,74)-$ estratégias metacognitivas de planejamento e monitoramento; Fator 3 - 5 itens $(\alpha=0,56)$ estratégias metacognitivas de regulação; Fator 4 - 4 itens $(\alpha=0,56)$ - estratégias cognitivas complexas de elaboração e organização; Fator 5 - 2 itens $(\alpha=0,52)$ - estratégias de apoio afetivo.

Considerando a relação estratégias de aprendizagem e faixa etária, Boruchovitch et al. (2006) defendem um possível incremento na complexidade do construto de estratégias de aprendizagem em crianças de maior idade do que em amostras de indivíduos mais jovens. Tais autores admoestam quanto à importância de que estudos futuros venham a avaliar os efeitos que os diferentes estágios de desenvolvimento podem produzir, indicando novos indícios de validade de construto. E propõem que a Escala de Estratégias de Aprendizagem EAEF (anteriormente descrita), apesar de se constituir como tentativa inicial na aferição de estratégias de aprendizagem para estudantes do ensino fundamental, representa uma ferramenta nacional proveitosa para diagnose, intervenção e prevenção em psicologia educacional e escolar.

De acordo com Oliveira et al. (2009), os estudantes que fazem uso de um conjunto variado de estratégias de aprendizagem conservam um desempenho acadêmico superior. Intentando averiguar evidências de validade fatorial no instrumento de Boruchovitch e Santos (2004), as autoras efetuaram um estudo envolvendo tal ferramenta. A amostra utilizada para a validação do questionário foi de 815 estudantes, cujas idades variaram de 7 a 16 anos, da $2^{\mathrm{a}}$ a $8^{\text {a }}$ séries do Ensino Fundamental. A versão da ferramenta de medida utilizada no estudo foi composta por 37 itens associados a uma escala Likert de 3 pontos (sempre, às vezes e nunca). A coleta de dados ocorreu sob administração coletiva em escolas públicas e privadas dos estados de Minas Gerais e São Paulo. Os dados obtidos foram submetidos a exames estatísticos descritivos (média e desvio-padrão) e inferenciais (análise fatorial exploratória e análise de variância - ANOVA). Os achados provenientes dos processos analíticos indicam que a escala $(\alpha=0,83)$ apresenta 3 fatores, a saber: Fator 1: Ausência de estratégias de aprendizagem $(\alpha=0,79)$; Fator 2: Estratégias cognitivas - organizar, armazenar e elaborar as informações, $(\alpha=0,80)$; Fator 3: Estratégias metacognitivas - planejamento, monitoramento, e 
regulação da aprendizagem $(\alpha=0,62)$. Desse modo, os resultados observados revelaram que os aprendizes, de forma geral, admitiram lançar mão de estratégias de aprendizagem durante os momentos de estudo, já que a média de pontos na escala atingiu a marca de 79,3. Depreendese que o emprego de estratégias facilita a aprendizagem, uma vez que possibilita a obtenção e a ulterior retomada e uso da informação, bem como promove o bom desempenho acadêmico.

Em estudo realizado, Testa e Luciano (2010) se propuseram a investigar o papel desempenho pelas estratégias utilizadas pelos aprendizes na regulação de recursos de aprendizagem em ambientes virtuais de ensino. Para tanto, foi utilizada uma versão adaptada do instrumento MSLQ - Motivated Strategies for Learning Questionnaire - empregado por Chen (2002). Os autores efetuaram um estudo de caso com participantes de um curso de capacitação intitulado “Curso de Capacitação de Técnicos dos Núcleos de Tecnologia Educacional (NTE)" oferecido pelo Ministério da Educação, cujo objetivo envolvia a preparação de técnicos em informática para atuarem como profissionais de suporte em instituições de ensino. O curso, ministrado a professores e técnicos de escolas públicas do Paraná, Santa Catarina e Rio Grande do Sul, era composto por cinco distintos módulos Ferramentas de Auditoria da Internet; Instalação e Manutenção de Computadores; Oficina de GNU Linux; Rede de Dados; e Rede Elétrica - e possuía uma duração de 256 horas/aulas, com atividades distribuídas em duas etapas presenciais (totalizando 32 horas/aulas) e duas etapas a distância (somando 224 horas/aula). Dos 179 indivíduos matriculados apenas 73 finalizaram com êxito a ação. A coleta de dados se deu com base na triangulação de seis técnicas diferentes: entrevistas semiestruturadas e abertas; análise de documentos e de registros; observação direta; e pesquisa survey. Dessa feita, foram coletados dados de natureza tanto qualitativa quanto quantitativa.

Os resultados obtidos no estudo indicaram que os estudantes que mais frequentemente estabeleceram interações com seus pares e com os professores, tanto no intuito de esclarecerem dúvidas, como para solicitarem auxílio, foram aqueles que atingiram as mais elevadas médias nos itens interesse, persistência, percepção de autoconfiança e gestão do ambiente social da escala MSLQ. Também foram encontradas correlações significativas entre as elevadas taxas de satisfação com o estudo e desempenho acadêmico e a utilização de estratégias para gestão do tempo e esforço. Os autores, ao concluírem que a negligência para com as estratégias de autorregulação da aprendizagem oferece limitações reais ao desenvolvimento dos processos de ensino-aprendizagem em contextos a distância, propõem práticas didáticas a fim de promovê-las em tais ambientes, como: estabelecer prazos curtos e frequentes para a conclusão das tarefas; fixar nos critérios avaliativos elementos que tratem do 
gerenciamento de tempo; investir em interações viabilizadas pelo recurso do chat ou por meio de videoconferências; sugerir atividades não formais nas quais os estudantes partilhem preferências, opiniões, etc, com a finalidade de desenvolver a percepção de vínculo entre alunos e o engajamento acadêmico do grupo.

Em pesquisa realizada por Donolo et al. (2004), ocorreu a comparação entre estratégias de aprendizagem utilizadas por estudantes tanto em condições de ensino presencial quanto em ambientes virtuais. Nesse estudo, foram investigadas as seguintes estratégias: cognitivas, de revisão, de elaboração, direcionadas ao pensamento crítico, metacognitivas e de gestão de recursos. A amostra foi composta por 99 estudantes inscritos em um curso híbrido, com idade média de 33,8 anos. Os dados necessários ao desenvolvimento da pesquisa foram colhidos mediante a aplicação do questionário Motivated Strategies Learning Questionnaire de Pintrich et al. (1991) que avalia o emprego de distintas estratégias de aprendizagem. A fim de confrontar o uso de estratégias de aprendizagem por estudantes em contextos educacionais diferenciados, o grupo total de participantes foi dividido em dois subconjuntos, de modo que a escala foi administrada em sua versão presencial a 47 alunos e em sua versão virtual aos alunos restantes (52). De acordo com os autores, foram identificadas significativas diferenças no que tange à utilização das estratégias de aprendizagem de gestão de recursos e busca por ajuda. Em relação às demais estratégias, os resultados indicaram um emprego indistinto por parte dos aprendizes nos dois contextos considerados e ganhos efetivos no desempenho acadêmico em ambas as situações de ensino decorrentes da priorização das estratégias de aprendizagem.

Preocupados com o desenvolvimento de uma proposta educacional que contemplasse as especificidades do ensino em contextos face a face e online, Riveiro e Nieto (2004) realizaram um trabalho que averiguou as diversas estratégias de aprendizagem aplicadas por estudantes de duas instituições de ensino superior da Espanha, tanto em contextos de ensino presencial como em ambiente virtual. Foram recrutados para o estudo 298 discentes do curso de Psicologia das duas universidades, sendo 164 alunos (23 anos em média) inscritos na modalidade presencial e 134 na modalidade a distância (idade média de 28 anos). Todos os participantes responderam a escala Motivated Strategies Learning Questionnaire (Pintrich et al., 1991) e as Escalas de Orientación de Meta de Skaalvik (1997), cujos itens consideram os seguintes tipos de metas perseguidas pelos estudantes: metas de tarefa; metas de evitação de esforço; metas de auto-frustração do ego; e, metas de autoengrandecimento do ego. Incialmente, os instrumentos de medida foram submetidos a análises de validade e confiabilidade; os dados obtidos mediante a aplicação das referidas escalas sofreram, então, 
técnicas estatísticas descritivas - diferenças de médias calculadas por meio da prova $t$ de Student para amostras independentes.

Os resultados indicaram consideráveis diferenças envolvendo os dois cenários educacionais contemplados, sendo possível verificar na modalidade de ensino presencial índices mais elevados de uso de estratégias de aprendizagem orientadas à busca de parcerias com os colegas de turma. Já os alunos que realizaram o curso em condições de aprendizagem virtual apresentaram uma significativa elevação nas médias de uso das estratégias de repetição, organização e autorregulação da aprendizagem. Dessa feita, os pesquisadores defendem a necessidade de investimentos em estudos que expandam os conhecimentos a respeito do uso de estratégias de aprendizagem e que sirvam às necessidades e particularidades de ambas as modalidades de ensino.

Avaliar as estratégias de aprendizagem e a motivação dos alunos em condição de ensino a distância, assistida por AVAs, foi o objetivo da investigação empreendida por Chiecher, Danolo e Rinaudo (2008). No estudo em questão, foi oferecido aos participantes 143 estudantes do ensino superior - a oportunidade de realizar três disciplinas de um curso de graduação por meio da modalidade presencial (52 aprendizes) ou através de condições online (91 alunos). O instrumento selecionado para a coleta de dados foi novamente o Motivated Strategies for Learning Questionnaire - MSQL (Pintrich et al., 1991), o qual foi administrado ao fim das disciplinas tencionando avaliar as estratégias cognitivas, metacognitivas e de gestão de recursos utilizadas pelos estudantes. A partir dos achados obtidos, foi possível constatar que os indivíduos que realizaram as disciplinas virtualmente alcançaram menores médias nas estratégias relativas ao gerenciamento do tempo e ambiente e à busca de ajuda. Todavia, esse grupo de alunos atingiu maiores médias, em comparação aos estudantes matriculados em disciplinas face a face, nas seguintes estratégias: elaboração, organização da informação, pensamento crítico, autorregulação, gestão do esforço e aprendizagem com pares.

De acordo com Costa e Boruchovitch (2009), estudiosos e educadores empenham-se na investigação de maneiras apropriadas e eficazes de transmitir estratégias de aprendizagem aos estudantes, principalmente àqueles com dificuldades relacionadas ao aprender. Dessa forma, as autoras efetuaram um trabalho que avaliou a eficiência de uma intervenção em estratégias de aprendizagem para a produção de textos em uma amostra constituída por 35 alunos da $6^{\mathrm{a}}$ série de uma escola pública de Catalão (GO).

Os procedimentos referentes à coleta de dados se deram em três etapas: 1) pré-teste; 2) intervenção (ensino das estratégias de aprendizagem e autorregulação); e 3) pós-teste representando um modelo de aspecto quase experimental, no qual estavam o grupo controle 
( $\mathrm{N}=17)$ e o grupo experimental $(\mathrm{N}=18)$, distribuídos de forma aleatória. As produções escritas dos alunos foram submetidas a uma análise qualitativa sendo classificadas de acordo com os critérios seguintes: caráter estrutural, categorias hierárquicas, quantidade de erros ortográficos e número de linhas produzidas. Os textos elaborados foram apreciados por três avaliadores que conferiram as notas obtidas e verificaram a pontuação alcançada pelos participantes. Os resultados revelaram que os indivíduos do grupo experimental produziram obras de melhor qualidade no pós-teste, representados por uma estrutura narrativa adequada, proposições mais bem encadeadas e maior quantidade de linhas escritas. Por conseguinte, as autoras defendem a importância de se assegurar aos professores vasto conhecimento a respeito das propostas de intervenção em estratégias de aprendizagem e que as ações instrucionais a eles reservadas, os tornem aptos a apreciar, ensinar e promover o correto uso de estratégias de aprendizagem em sala de aula.

O estudo realizado por De Paula e Silva (2004) teve como um de seus objetivos investigar as principais estratégias de aprendizagem e os hábitos de estudos mais relevantes utilizados por uma amostra de estudantes matriculados em um programa educativo semipresencial. O estudo revelou que, em relação aos hábitos de estudo, a maior parcela da amostra prefere estudar sozinho, no período das dezoito horas à meia noite, computando até três horas de estudo na internet e até uma hora de estudo fora do ambiente virtual, por semana, para cada disciplina cursada. Foram encontrados ainda resultados interessantes no tocante à Interface Gráfica, aos Procedimentos Instrucionais e ao Material Didático utilizado no curso: segundo o autor, tais aspectos favorecem a autoinstrução, diminuindo-se a necessidade de solicitar ajuda aos tutores.

Vovides, Sanchez-Alonso, Mitropoulou e Nickmans (2007) buscaram descrever o papel desempenhado pelas estratégias de aprendizagem utilizadas por alunos em ações educacionais transcorridas em ambientes virtuais de ensino. Os autores apregoam que os processos educacionais a distância devem cuidar para que sejam desenvolvidas habilidades de autorregulação da aprendizagem e, para tanto, torna-se imprescindível propiciar ao estudante condições favoráveis à seleção, agrupamento e coordenação de suas estratégias cognitivas e à reflexão, compreensão e monitoramento das mesmas - o que pode levar a um conhecimento mais profundo sobre tais ferramentas metacognitivas. Além disso, os autores advertem quanto a uma subutilização pedagógica das ferramentas e recursos disponibilizados em tais cenários, dado o menosprezo quanto suas propriedades educacionais particulares. Frente a tal fato, Vovides et al. (2007) propõem a adoção de procedimentos didáticos que não só encerrem tais particularidades, mas atuem em consonância com os objetivos instrucionais estabelecidos a 
fim de estimular o uso de estratégias de aprendizagem pelo discente.

Também buscando analisar e explicar as estratégias de aprendizagem metacognitivas utilizadas por estudantes em contextos de e-learning, a partir do desenvolvimento do Model of Strategic e-Learning, Tsai (2009) propôs a realização de dois estudos: um do tipo piloto e outro de caráter oficial. A amostra do estudo foi composta por 536 discentes, sendo 136 alunos do ensino médio (estudo piloto) e 400 estudantes do nível superior (estudo principal). O modelo considerado tinha por objetivo identificar quatro características presentes no processo de aprendizagem de estudantes inscritos em ações instrucionais a distância, a saber: tempo e espaço flexíveis; interações sociais indiretas; recursos de informação abundantes; e interfaces de aprendizagem dinâmicas. Também foram avaliados pelo pesquisador três diferentes domínios referentes às estratégias de aprendizagem em ambientes virtuais: a habilidade de percepção; o afeto; e a autorregulação. O Model of Strategic e-Learning possibilitou a elaboração e validação do instrumento de medida denominado Online Learning Strategies Scale (OLSS), indicado para fins de diagnóstico e aferição de aprendizagem em situações de e-learning. Tal como aponta o autor, essa ferramenta seria de grande utilidade para posteriores e necessárias investigações acerca desse tema.

Já no tocante às implicações sobre as estratégias de aprendizagem decorrentes do nível educacional, Almeida (2001) considera que no ensino superior são requeridas dos alunos frações mais altas de autonomia nos estudos, o que resulta no emprego consciente e ativo de estratégias de aprendizagem. Em decorrência disso, Boruchovitch et al. (2006) intentaram investigar diferenciações quanto ao uso de estratégias autorregulatórias de estudantes universitários em áreas de formação díspares e, ainda, averiguar a ocorrência de modificações nos padrões de utilização dessas estratégias ao longo da permanência desses indivíduos no ensino superior. O estudo contou com a participação de 518 estudantes matriculados na Universidade do Minho, distribuídos em cursos das áreas de humanidades (Português e Relações Internacionais) e ciências (Física, Química e Engenharia Civil) e situados em três níveis: inicial (alunos do $1^{\circ}$ ano), intermediário (alunos do $2^{\circ}$ e $3^{\circ}$ ano), e final (alunos do $4^{\circ}$ ano).

As estratégias de aprendizagem foram mensuradas a partir do instrumento CHE Comportamentos Habituais de Estudo e Aprendizagem (Bessa \& Tavares, 2001) - escala essa elaborada na Universidade de Aveiro e empregada em uma investigação cujo objetivo era o de avaliar o relacionamento entre níveis de ajustamento acadêmico, abordagens e estratégias autorreguladoras da aprendizagem. A referida ferramenta é composta por 25 itens associados a uma escala de concordância do tipo Likert de cinco pontos. Os itens distribuem-se por cinco 
fatores que representam, igualmente, cinco tipos de estratégias de autorregulação, a saber: Fator 1: estratégias cognitivas de modificação e manipulação da informação - diferenciação e escolha da informação e sua junção para interiorização ulterior (7 itens); Fator 2: estratégias cognitivas de ordenação e planejamento de atividades habituais - constância e precisão em relação ao comparecimento às aulas, tempo devotado ao estudo e utilização de registros de apontamentos e dos materiais necessários ao estudo (5 itens); Fator 3: estratégias cognitivas e metacognitivas de gerenciamento e monitorização - gestão e controle da informação, ciência a respeito dos distratores de estudo e busca de condições de trabalho, decisão e estabelecimento de metas e autoavaliação (7 itens); Fator 4: estratégias cognitivas de aquisição e joeiramento da informação - atenção e participação nas aulas e procura de explicações sobre a informação com os professores (4 itens); Fator 5: estratégias afetivas de reforço motivacional - interesse e motivação na frequência às aulas (2 itens). A escala foi administrada de forma coletiva à amostra de universitários atingindo duração aproximada de 20 minutos.

O CHE, que possui coeficiente de consistência interna (Alpha de Cronbach) de 0,85 (Bessa \& Tavares, 2001), na amostra de pesquisa obteve os valores para o nível inicial, nível intermédio e final de 0,83 e 0,82 , respectivamente.

Tal como sugerem os resultados encontrados, não há consideráveis modificações no emprego de estratégias autorregulatórias pelos estudantes em virtude do nível e do campo de formação, apontando que, na população utilizada, os participantes fazem uso de estratégias autorreguladoras da aprendizagem do mesmo tipo. Tais dados contradizem a suposição inicial de que a realização de atividades que exigem o uso apropriado de estratégias de aprendizagem e altos níveis de independência poderia ocasionar, com o passar do tempo, alterações no padrão de estratégias autorregulatórias do indivíduo. Tendo em vista que a escala CHE (Bessa \& Tavares, 2001) foi aplicada somente em dois estudos em território lusitano, há de se considerar a indicação das autoras de que a investigação seja replicada em outras nações de língua portuguesa a fim de comparar os possíveis resultados.

A temática das diferenças em habilidades diversas em função da identidade sexual tem atraído o interesse científico e se tornado objeto de estudo para muitos trabalhos. Nesse sentido, intentando verificar possíveis dissimilitudes quanto à utilização de estratégias de aprendizagem em razão do gênero do alunado, entre outras variáveis, Oliveira, Boruchovitch e Santos (2011) procederam a aplicação da Escala de Estratégias de Aprendizagem (EAEF) (Boruchovitch \& Santos, 2004). A amostra do estudo era composta por 395 indivíduos do sexo masculino $(48,5 \%)$ e 418 do gênero feminino (51,3\%); apenas dois participantes $(0,2 \%)$ 
não informaram a variável investigada. Mediante análises estatísticas, os autores identificaram diferenças estatisticamente significantes entre os gêneros no tocante ao desempenho atingido no instrumento de medida. Dessa forma, verificou-se que os participantes do gênero feminino obtiveram pontuação mais elevada na EAEF do que aqueles do sexo oposto. Apesar dos indícios que levam a reconhecer diferenciações no emprego de estratégias de aprendizagem em virtude do sexo, as próprias autoras advertem quanto a não consideração de aspectos primordiais para o entendimento de tais resultados, tal como "quando" e "como" se deu a escolha das estratégias utilizadas, e quais foram elas - estratégias cognitivas ou metacognitivas.

O papel desempenhado pela variável gênero em relação ao uso de estratégias de aprendizagem ainda se constitui tema inconcluso, com estudos apontando para direções divergentes. Algumas pesquisas corroboram os achados de Oliveira et al. (2011), ou seja, indicam que indivíduos do sexo feminino empregam com maior frequência estratégias de aprendizagem (Alliprandini et al., 2012; Bartalo \& Guimarães, 2008; Boruchovitch et al., 2006; Gomes, 2002). Todavia, outros estudos contestam o perfil mais estratégico das mulheres: ao passo que algumas pesquisas constatam o melhor uso de estratégias de monitoramento por parte dos estudantes homens (Schlieper, 2001; Schlieper \& Boruchovitch, 2001), outros defendem a inexistência de diferenças entre gêneros - nesse caso, estudantes de ambos os sexos recorreriam de forma similar às estratégias de aprendizagem (Cruvinel, 2002).

A discordância de resultados que perpassa as investigações voltadas ao estudo das relações entre estratégias de aprendizagem e gênero talvez seja, em parte, devida à heterogeneidade de métodos e procedimentos de coleta de dados que acompanham tais trabalhos. De qualquer forma, uma compreensão mais apurada deste relacionamento poderá contribuir para a promoção da qualidade do ensino (Allipradini et al., 2012; Oliveira et al., 2011).

Pantoja e Borges-Andrade (2009), apesar de não considerarem a variável gênero para a realização de um mapeamento exploratório acerca das estratégias de aprendizagem utilizadas por indivíduos em contextos de trabalho, verificaram o estabelecimento de distintas configurações de uso de estratégias face aos diferentes postos profissionais ocupados pelos participantes. Ademais, os autores verificaram que as estratégias denominadas "aplicação prática" e "busca de ajuda interpessoal" exerceram papel primordial nos processos de aquisição, retenção e transferência de novos conhecimentos, habilidades e atitudes em âmbito laboral. Logo, a pesquisa em questão fornece substratos a hipótese de que as estratégias de aprendizagem variem entre ambientes e sujeitos, de modo a adquirirem arranjos díspares 
segundo as ocupações de trabalho desempenhadas.

Até o momento, os instrumentos acima apresentados ilustram opções elaboradas para serem administradas em ambientes educacionais e de trabalho. Contudo, outros instrumentos de medida, como o de Warr e Downing (2000), além de serem utilizados no cenário escolar, são destinados particularmente para ações instrucionais de natureza técnica. Tais autores empreenderam uma investigação intentando desenvolver e testar um instrumento de estratégias de aprendizagem que compreendesse as nove dimensões propostas inicialmente por Warr e Allan (1998). A ferramenta, que em sua versão final conta com 45 itens ligados a uma escala de quatro pontos do tipo Likert, foi aplicada a uma amostra de 152 alunos adultos de um curso de mecânica elementar. O instrumento sofreu a redução de um componente, caindo de nove para oito, em decorrência da aglutinação dos dois fatores cognitivos denominados organização e elaboração em um único fator nomeado reflexão ativa. Entre todas as estratégias, apenas busca por ajuda interpessoal e monitoramento da compreensão não foram associadas positivamente a mudanças no conhecimento.

O emprego das estratégias de aprendizagem restantes pode ser assim sintetizado: estudantes que apresentam elevada ansiedade em relação à tarefa de aprendizagem fazem mais uso das estratégias de ensaio, busca de ajuda interpessoal e de material escrito, controle emocional e motivacional; as estratégias de reflexão ativa, controle emocional e monitoramento da compreensão são utilizadas por aqueles com altos níveis de motivação anterior a aprendizagem; aprendizes com trabalhos anteriores relevantes usam com menor frequência as estratégias busca de ajuda interpessoal e de material escrito e controle emocional; e os indivíduos mais velhos fazem uso mais assíduo da estratégia de ensaio.

Tal como declaram Warr e Downing (2000), outros trabalhos já apontavam algumas associações entre estratégias de aprendizagem e obtenção de conhecimento, a saber: o componente elaboração tem sido relacionado a resultados satisfatórios de aprendizagem; ensaio também apresenta resultados positivos de aprendizagem; organização revela-se ligada a desempenho acadêmico superior; o arranjo das estratégias organização e elaboração apresenta resultados semelhantes à análise isolada das mesmas; e as estratégias comportamentais são objeto de poucas pesquisas, de modo que aquelas existentes revelam resultados inconsistentes. Sendo assim, é possível constatar que a maior parte das estratégias de aprendizagem possui condições de associação positiva com resultados de aprendizagem.

Zerbini et al. (2005), baseadas no estudo de Warr e Downing (2000) e guiadas pelas dimensões de Warr e Allan (1998), elaboraram e validaram uma escala de estratégia de aprendizagem. Essa ferramenta, utilizada em pesquisa que objetivou avaliar ações de 
treinamento a distância, possui 20 itens associados a uma escala do tipo Likert de 11 pontos (0-Nunca a 10-Sempre). A amostra composta por 1.860 participantes - indivíduos inscritos em um curso ofertado gratuitamente via web, que pretendia capacitar o aluno a elaborar um plano de negócios - respondeu ao questionário, e os dados obtidos sofreram análises descritivas e exploratórias, bem como análise dos componentes principais e de fatoração dos eixos principais. Após a realização das técnicas analíticas, o instrumento apresentou uma estrutura com três fatores: Busca de Ajuda Interpessoal ( 8 itens, $\alpha=0,85$ ); Elaboração e Aplicação Prática (5 itens, $\alpha=0,75$ ); Repetição, Organização e Ajuda do Material (7 itens, $\alpha=0,78)$.

A fim de também avaliar ações instrucionais ministradas a distância e direcionadas à formação e qualificação de trabalhadores, Borges-Ferreira (2005) adaptou e revalidou o instrumento de estratégias de aprendizagem de Zerbini et al. (2005). Especificamente, o trabalho pretendia avaliar disciplinas de um curso técnico profissionalizante a distância do campo da informática, ministradas pelo Centro de Educação Tecnológica MSD Escola Aberta. Participaram 2.368 indivíduos - com idade média de 19,4 ( $\mathrm{DP}=5,24)$, localizados na região Centro-Oeste $(87,8 \%)$ e a maioria do sexo masculino $(77,1 \%)$ - que responderam virtualmente as escalas. Para o processo de análise das respostas foram efetuadas análises de regressão múltipla padrão. Não foi considerado nenhum fator de estratégias de aprendizagem como variável explicativa dos modelos de regressão múltipla.

À semelhança do estudo realizado por Zerbini et al. (2005), a investigação de BorgesFerreira (2005) não envolveu as estratégias de aprendizagem autorregulatórias presentes nos trabalhos de Warr e Downing (2000) e Warr e Allan (1998).

Considerando a relevância de se atentar para as estratégias de aprendizagem em pesquisas nos contextos de organização e trabalho, Zerbini e Abbad (2008) avaliaram o IPGN (Iniciando um Pequeno Grande Negócio) do SEBRAE, uma ação educacional concebida como programa de qualificação laboral oferecida a distância, que faz uso da internet como principal meio de entrega e detém características de aprendizagem aberta. Uma das metas do estudo foi desenvolver itens concernentes às estratégias de aprendizagem autorregulatórias para validação estatística de um novo instrumento. Uma amostra composta por 4.719 participantes foi apresentada ao instrumento cujos itens encontravam-se associados a uma escala de 11 pontos do tipo Likert que aferia a frequência com que os respondentes utilizavam as estratégias de aprendizagem ao longo do curso. Os sete fatores presentes na escala estão descritos na Tabela 10. 
Tabela 10. Definição dos fatores do instrumento de Zerbini e Abbad (2008).

\begin{tabular}{|c|c|c|}
\hline Fatores & Definição & $\begin{array}{c}\text { Número de itens } \\
(\alpha)\end{array}$ \\
\hline Controle da emoção & $\begin{array}{l}\text { manejo da ansiedade e prevenção de } \\
\text { dispersões de concentração decorrentes de } \\
\text { sentimentos de ansiedade. }\end{array}$ & 5 itens $(\alpha=0,89)$ \\
\hline Busca de ajuda interpessoal & $\begin{array}{l}\text { busca de auxílio de outras pessoas, como } \\
\text { pares e professores, intentando sanar } \\
\text { dúvidas sobre o conteúdo do curso. }\end{array}$ & 6 itens $(\alpha=0,89)$ \\
\hline Repetição e organização & $\begin{array}{l}\text { - } \quad \text { repetição mental da informação na forma } \\
\text { em que foi apresentada ao aluno; } \\
\text { - identificação de pressupostos centrais do } \\
\text { material e criação de esquemas mentais que } \\
\text { agrupam e integram elementos que foram } \\
\text { aprendidos. }\end{array}$ & 5 itens $(\alpha=0,77)$ \\
\hline
\end{tabular}

Controle da motivação

- controle da motivação e da atenção pelo aprendiz durante o processo de

4 itens $(\alpha=0,84)$ aprendizagem, mesmo quando o interesse dele na tarefa a ser aprendida é reduzido.

$\begin{array}{ll}\text { Elaboração } & \text { procedimentos empregados pelo aluno a fim } \quad 3 \text { itens }(\alpha=0,83) \\ & \text { de analisar e refletir sobre implicações e } \\ & \text { conexões possíveis entre o material } \\ & \text { aprendido e os conhecimentos e } \\ & \text { experiências já detidos. }\end{array}$

Busca de ajuda ao material didático
- busca de informações em documentos escritos, manuais de instruções, programas

2 itens $(\alpha=0,75)$ de computador e outras fontes que não envolvam contato interpessoal. Monitoramento da
compreensão
- $\quad$ processo de aquisição de aprendizagem e modificação do comportamento de estudo do indivíduo, quando necessário.
3 itens $(\alpha=0,82)$ 
Não obstante o progressivo desenvolvimento de ações educacionais a distância, as investigações e trabalhos realizados com o escopo de avaliar a utilização das estratégias de aprendizagem tanto no cenário da educação como em contextos de trabalho, conservam sua atenção preponderantemente em ambientes presenciais. Logo, são extremamente necessários estudos que indiquem resultados de eventos instrucionais ofertados não presencialmente, visando delinear um quadro sobre as distintas estratégias que os estudantes lançam mão para se beneficiarem em tais situações. Muitos autores declaram sua inquietação quanto às ações de ensino e pesquisa que, ao negligenciarem as particularidades da educação a distância, robustecem velhas práticas e concepções transvestidas do novo (Beluce \& Oliveira, 2012; Mehlecke \& Guedes, 2006, Silva, 2003; Vovides et al., 2007); nesse sentido, a investigação de possíveis diferenças e especificidades quanto ao emprego de estratégias de aprendizagem na modalidade EAD poderá ser revertida em um uso mais adequado das mesmas em tais contextos. Logo, as ferramentas de medida que buscam reconhecer e mensurar as estratégias de aprendizagem são instrumentos importantes, que possibilitam identificar quais são as estratégias utilizadas na EAD e examinar se sua utilização intervém sobre o aproveitamento e rendimento acadêmico dos discentes.

O breve apanhado de obras dedicadas à variável estratégias de aprendizagem revela a preocupação em compreender as habilidades empregadas pelos alunos a fim de estudarem e aprenderem em diversificadas situações de ensino (Costa \& Boruchovitch, 2004; Gomes \& Boruchovitch, 2005; Joly, Cantalice \& Vendramini, 2004; Machado, 2005; Oliveira et al., 2011). Entre as pesquisas levantadas foi observada preocupação no que tange ao fomento das estratégias de aprendizagem metacognitivas e ligadas à gestão do tempo - tidas como muito relevantes para os processos de autorregulação do conhecimento e do tempo, tão presentes nos AVAs. Por fim, tal como apregoa Beluce e Oliveira (2012), o campo das produções científicas voltado ao estudo das estratégias de aprendizagem em contextos de ensino online vem testemunhando avanços satisfatórios, todavia é necessário reconhecer que tais progressos não se fazem suficientes tendo em vista a seriedade do tema à educação, presencial e a distância. Com isso, faz-se indispensável o desenvolvimento de pesquisas que não somente se detenham nos aspectos já considerados, mas lancem mão de novas contribuições ao estudo desta temática. 


\subsubsection{Fatores relacionados à evasão e à persistência em EAD (variável critério): definições e características}

Apesar das potencialidades e vantagens inerentes à modalidade de ensino a distância, este campo também enfrenta diversos desafios e obstáculos. Talvez, uma das principais e mais preocupantes problemáticas existentes seja os elevados índices de abandono acadêmico observados nesse contexto educacional. As causas da não permanência estudantil são múltiplas, e correspondem tanto a variáveis internas à própria ação instrucional, bem como a elementos externos à mesma. É apontada uma extensa gama de fatores que interferem sobre o avanço e conclusão das ações formais de ensino-aprendizagem a distância. Entre os inúmeros motivos relacionados à desistência e ao insucesso estudantil estão os aspectos relativos à elevada complexidade da vida pessoal, laboral, financeira e familiar. Também é necessário considerar a influência exercida pelas instituições de ensino responsáveis pela oferta de cursos e as políticas sociais mal implementadas, que muitas das vezes não satisfazem as necessidades dos aprendizes e os deixam evadir, sem, contudo, demonstrar interesse em reconhecer os fatores causais e desenvolver medidas que os contenham (Siqueira, 2009).

Powarczuk (2002) ao pesquisar acerca de variáveis relacionadas à motivação e persistência de estudantes inscritos no curso IPGN-SEBRAE, concluiu que o descomprometimento do aprendiz para com o curso poderia ser oriundo de diversas causas, entre elas: a natureza do curso em questão (gratuito e aberto); dificuldades ou falta de habilidade no uso das ferramentas eletrônicas; desinteresse causado por deficiências no curso; perfil psicológico tímido. $\mathrm{O}$ autor também chama a atenção para a aplicabilidade dos conceitos ministrados durante o evento instrucional: segundo ele, ao se valerem de experiências e fatos reais, os tutores otimizam as interações estabelecidas com os aprendizes.

Alguns dos fatores historicamente relacionados à EAD, uma vez que interferem sobre a decisão discente de permanecer ou não no evento instrucional cursado, podem ser classificados em três grandes grupos (Abbad, 2007; Sales, 2009; Shin \& Kim, 1999; Xenos, Pierrakeas, \& Pintelas, 2002), a saber:

(1) conjunto de fatores relativos ao evento instrucional;

(2) conjunto de fatores relacionados a características pessoais dos estudantes; e

(3) conjunto de fatores ligados ao contexto que cerca o aluno a distância. 
Em relação ao primeiro conjunto de variáveis, diversos elementos são por ele contemplados, tal como o desempenho do tutor (questões do exercício profissional e da qualificação do docente em contextos de ensino online.), o desenho instrucional, o ambiente virtual de aprendizagem, a natureza do evento educacional, e o apoio psicossocial entre pares e institucional prestado aos estudantes de cursos a distância. Logo, é possível perceber que os fatores presentes nesse agrupamento contemplam três distintas dimensões - fatores ligados ao tutor; fatores ligados ao curso propriamente dito; e fatores ligados ao suporte prestado aos alunos - tratados a seguir.

\subsubsection{Conjunto de fatores relativos ao evento instrucional}

Alguns dos elementos situados nesse grande conjunto podem estar ligados de maneira mais ou menos intensa à permanência ou abandono estudantil. Sales (2009) pontua uma série de variáveis e possíveis relações (ex. $\uparrow \uparrow:$ fortemente relacionados) entre as mesmas e a evasão/permanência acadêmica, como mostra a Tabela 11.

Tabela 11. Relação de variáveis referentes ao evento instrucional com a evasão ou a persistência de participantes em cursos a distância (Sales, 2009) (Continua).

\begin{tabular}{ll}
\hline \multicolumn{1}{c}{ Variável } & Relação com evasão/persistência \\
\hline Problemas de desempenho do tutor & $\uparrow \uparrow$ \\
\hline Falta de assistência/apoio do tutor & $\uparrow \uparrow$ \\
\hline Falta de feedbacks e acompanhamento dos tutores & $\uparrow \uparrow$ \\
\hline Desenho instrucional inadequado & $\uparrow \uparrow$ \\
\hline Dificuldade em acessar o sistema & $\uparrow \uparrow$ \\
\hline Quantidade/dificuldade de trabalhos escritos exigidos & $\uparrow \uparrow$ \\
\hline Pré-concepções/informações equivocadas sobre o curso & $\uparrow \uparrow$ \\
\hline Cursos longos e difíceis & $\uparrow \uparrow$ \\
\hline Separação física e distância transacional & $\uparrow \uparrow$ \\
\hline Falta de atividades face-a-face & $\uparrow \downarrow$ \\
\hline Falta de suporte de outros alunos & $\uparrow \uparrow$ \\
\hline Falta de suporte da faculdade/Apoio administrativo & $\uparrow \uparrow$ \\
\hline
\end{tabular}


Nos tempos atuais, o campo educacional vem atravessando um momento expressivo de transformações, de modo que o papel do professor, a metodologia de ensino e até mesmo a função das instituições de ensino têm sido objeto de discussão em todo o mundo (Marinho, 2002; Morin, 2001; Perrenoud, 2000; Pretto, 2001; Ramal, 2002; Sarmet \& Abrahão, 2007).

Em relação à atuação do docente em EAD, pode-se afirmar que tal tarefa é desafiadora, complexa e exige aprofundada orientação; a formação especializada da equipe docente envolvida com programas educacionais desta natureza desempenha papel fundamental para uma implementação exitosa (Abreu-e-Lima \& Alves, 2011). Considerando especificamente o contexto da EAD, é possível identificar um constante debate a respeito do papel docente em tais cenários: quais são suas características, por quais atribuições esse profissional responde, o que se modifica no seu fazer, como ele lida com as novas TICs, entre outras questões.

Segundo Belloni (1999), o professor a distância se ocupa com três grandes grupos de tarefas: 1) tarefas de desenvolvimento e implementação dos cursos e materiais didáticos; 2) sistematização da entrega dos materiais e administração acadêmica; e c) acompanhamento do aluno. Logo, o profissional no ensino a distância angaria funções de criação, formação e oferta de cursos/materiais, professor, pesquisador, monitor, e tecnólogo educacional (Belloni, 1999). Dessa feita, a tão utilizada correspondência entre os termos professor e tutor é inapropriada, uma vez que a atividade de tutoria integra o amplo rol de atribuições desse agente de ensino. Tal como propõe Maggio (2001), por ser da alçada do docente a orientação do processo de aprendizagem discente, ele deve desenvolver e implementar atividades pedagógicas que subsidiem a ocorrência de tal fenômeno.

Para Joia e Costa (2007), o papel do professor em programas educacionais a distância pode percorrer um continuum que varia do didático ao facilitativo. Tal como explicitam os autores, o papel didático está relacionado aos tradicionais docentes em salas de aula presenciais, que apresentam conteúdo aos aprendizes. Em eventos instrucionais nos quais a exposição conteudista do professor é uma estratégia instrucional destacada, os demais esforços dispendidos por esse profissional apenas reforçam e estendem as apresentações realizadas. Todavia, quando o docente atua no papel de facilitador, a responsabilidade cognitiva pelo processo de aprendizagem é transferida para os alunos, que passam a responder pelo julgamento das informações obtidas, organização dos dados, elaboração de perspectivas alternativas e aquisição de novos conhecimentos.

No tocante às competências exigidas e necessárias ao docente a distância são mencionadas: habilidades de natureza tecnológica; assiduidade na emissão de feedbacks; 
domínio do conteúdo ministrado; habilidades de comunicação e de mediação; gerenciamento de equipes e gestão de pessoas, entre outras (Maia, 2002). Segundo Galusha (1997), é necessário que os professores a distância se ajustem a essa modalidade educacional e desenvolvam estilos de ensino que os caracterizem enquanto mentores e facilitadores do processo de busca por conhecimento. É fundamental que tais profissionais estejam aptos a identificar necessidades dos aprendizes sem qualquer tipo de contato face a face. Em alguns casos, docentes apresentam sérias lacunas em habilidades básicas que comprometem uma participação plena e eficaz no evento instrucional, e geram dificuldades em responder de forma mais adaptativa aos ambientes virtuais de aprendizagem (Galusha, 1997). Além disso, interesse e motivação não são fatores de sucesso reservados apenas aos estudantes; professores que possuem maior ciência acerca da EAD e se mostram desejosos em dela participar se tornam elementos importantes para a permanência do estudante.

Tendo em vista o elevado número de interações que ocorrem nos ambientes virtuais de aprendizagem e as peculiaridades da atuação docente em contextos a distância, uma das principiais vias de troca estabelecida no processo de ensino-aprendizagem seria a emissão de feedback entre docente e estudante. Segundo Moore e Kearsley (2007), tanto a quantidade como a qualidade dos diálogos, que objetivam a promoção da autonomia de aprendizagem, estabelecidos entre professores e alunos são fatores determinantes para o sucesso da EAD. Neste mesmo sentido, o feedback é visto como parte fundamental do processo de ensino, independente da modalidade adotada (Mory, 2004). O feedback é descrito por Mory (2004) como todo tipo de procedimento ou comunicação efetuado com vistas a informar o indivíduo que aprende acerca da exatidão de sua resposta, comumente relacionada a um questionamento de natureza instrucional. O feedback também fornece ao estudante condições de comparar seu desempenho atual com aquele que é tido como padrão ou é esperado. Em contextos de educação a distância, o feedback é conceitualizado como a informação emitida ao aluno logo após a apresentação de qualquer insumo voltado à modelagem de suas percepções (Abreu-eLima \& Alves, 2011). A noção de feedback formativo é defendida por Shute (2008), segundo a qual trata-se da informação declarada ao estudante com o objetivo de alterar seu comportamento ou seu modo de pensar intentando uma melhoria educacional.

Atualmente, o feedback já não mais apresenta a conotação behaviorista de outrora, ou seja, não é mais compreendido como instrução programada e como reforço ao aprendiz. A informação prestada ao estudante sob a forma de feedback é hoje considerada elemento indispensável para a efetiva instrução, uma vez que ela interage com os conhecimentos prévios do participantes, promovendo a aprendizagem dos mesmos; além disso, esta 
informação orienta o indivíduo quanto ao modo como ele deve se comportar, interagir, expressar, raciocinar e realizar tarefas em um determinado ambiente educacional a fim de cumprir os objetivos instrucionais estabelecidos. Feedbacks insuficientes, ou até mesmo a inexistência destes, prejudicariam o reconhecimento, por parte dos estudantes, de conteúdos e tópicos demandantes de maior atenção, bem como a identificação de competências já bem executadas pelos aprendizes. Para que o feedback produza modificações significativas nos desempenhos do sujeito que aprende, ele deve ser enviado de forma correta em termos de tempo, quantidade de informação e, principalmente, linguagem utilizada (Shute, 2008).

Obviamente, a relevância das interações firmadas entre docente e estudantes não deve ocultar o fato de que esse profissional também deve ser um especialista na área (Lentell, 2003). De forma geral, o docente deve se atentar para o modo como os conteúdos são assimilados pelos alunos e a compreensão é construída, propondo desafios e incentivos que fomentem a superação de dificuldades vivenciadas e o alcance da aprendizagem efetiva (Abreu-e-Lima \& Alves, 2011).

Também é imprescindível ter em mente que o conjunto tecnológico, nos ambientes de ensino a distância, não subsidia apenas a relação docente-discente e docente-tarefas de ensino, mas estrutura de modo medular toda ação do profissional de ensino. Por conta disso, para um desempenho eficiente e satisfatório, o professor deve ser capaz de administrar a todo instante a heterogeneidade e imprevisibilidade inerentes a essa modalidade educacional. Tal habilidade de gerenciamento está intimamente ligada à competência do docente em interpretar demandas instrucionais, desenvolver estratégias para respondê-las, ofertar recursos necessários, acompanhar e avaliar as ações dos aprendizes (Sarmet \& Abrahão, 2007).

Como é possível perceber, ao docente de EAD não é suficiente apenas deter conhecimento acerca dos tópicos a serem tratados e transmitidos; é vital que ele também detenha competências e habilidades pertinentes ao campo de gestão dos processos de ensino e aprendizagem e de equipes, e saiba distinguir as técnicas e os recursos mais apropriados a cada evento educacional. Fica evidente que as novas TICs interferem significativamente nas atribuições docentes, redefinindo a relação dos professores com o trabalho desempenhado e com a clientela atendida. Além disso, Iglesias e Salgado (2012) chamam a atenção para a necessidade de se considerar possíveis diferenciações nas reações exibidas por estudantes em situações de ausência/presença de professores.

Neste momento, outra seara de elementos de interesse passa a ser abordada: propriedades e elementos da ação educacional implementada.

Ao se considerar a influência e importância das TICs sobre a permanência ou evasão 
acadêmica, é quase inevitável se atentar também para o papel diferenciador desempenhado pelos ambientes virtuais de aprendizagem (AVAs). Segundo Almeida (2003), os AVAs representam sistemas computacionais disponíveis na internet, destinados ao subsídio de atividades mediadas pelas TICs. Por meio deles, é possível integrar variadas mídias, linguagens e recursos, expor informações de forma sistemática, proporcionar interações entre indivíduos e objetos de conhecimento, elaborar e compartilhar produções tendo por meta o alcance de objetivos educacionais específicos. Logo, as tarefas e ações de ensino realizadas em tais ambientes se dão no tempo, espaço e ritmo de trabalho de cada participante, e são pautadas por um cuidadoso planejamento preliminar intitulado desenho instrucional, o qual corresponde ao elemento dorsal das ações a serem efetuadas, podendo ser revisto e reestruturado (Almeida, 2003; Paas, 2001).

O termo desenho instrucional (DI), ou design educacional como preferem outros autores, deve representar mais do que a simples criação de formas de apropriação conteudista; o DI deve estar relacionado com a análise da abrangente temática dos problemas de desempenho humano, identificando fatores primários das dificuldades educacionais, testando medidas que as solucionem, e cuidando das consequências imprevistas decorrentes do desenho instrucional (Oliveira, 2010). O DI parte da combinação de três campos do conhecimento: Educação, Psicologia e Comunicação. Da área educacional houve a apropriação de teorias e pressupostos que tratam do fenômeno da aprendizagem em contextos formais ou informais de ensino. A contribuição da ciência psicológica se deu na medida em que postulados e princípios acerca do desenvolvimento e aprendizagem humana foram desenvolvidos. Por fim, o campo da comunicação colabora ao investigar os elementos teóricos e práticos inerentes à veiculação ótima de mensagens e a disposição eficaz das mesmas na tela do computador.

Considera-se que os AVAs são ambientes programados, com interfaces e recursos organizados; tendo em vista que tal sistematização também incide sobre os conteúdos e atividades disponibilizados aos aprendizes, é possível pressupor uma suposta relação entre desenho instrucional e necessidades de interação da clientela atendida (França, 2009).

Os recursos e ferramentas disponíveis nos ambientes virtuais de aprendizagem são, de modo geral, os mesmos presentes na internet - tais como, correio eletrônico, fóruns, salas de bate-papo, conferências, banco de recursos, entre outros - e apresentam como vantagem o gerenciamento de informações trocadas segundo critérios de organização previamente estabelecidos e em consonância com as propriedades de cada software utilizado pelas instituições de ensino. Os AVAs também contam com bancos de informações representados 
por diversas mídias (hipertextos, textos, imagens, vídeos) e interligados por meio de links internos ou externos aos sistemas.

A administração desses ambientes exige atenção a alguns aspectos, como: a gestão das estratégias de comunicação e mobilização empregadas; a gestão da participação e engajamento dos estudantes através do registro das produções, interações e caminhos transcorridos; a gestão do suporte prestado aos alunos; e a gestão dos processos avaliativos (Almeida, 2003). Todos os recursos disponibilizados são fundamentais ao docente, uma vez que permitem a este administrar suas ações - por meio da publicação de atividades, avisos, notícias, materiais didáticos, objetos de aprendizagem, além dos conteúdos de ensino, que promovem as interações e intervenções entre os diferentes agentes de socialização. É importante que os ambientes virtuais de aprendizagem sejam flexíveis e subsidiem a transformação de comportamentos e hábitos de estudo, as trocas entre indivíduos, o registro crítico e a reflexão sobre os percursos cognitivos (França, 2009). De acordo com França (2009), os ambientes virtuais de aprendizagem devem destacar os seguintes aspectos nos projetos de delineamento de cursos em EAD:

1. Flexibilidade do Desenho Instrucional: ligada à compreensão da gama de abordagens e concepções de ensino-aprendizagem vigentes no desenvolvimento de cursos a distância.

2. Gerenciamento de usuários: identificação da presença de usuários com perfis, determinações e acessos diferenciados, que ocasionam ações e funções distintas no uso do AVA.

3. Controle de Atividades: permite ao estudante administrar suas atividades e facilita a realização de intervenções docentes.

4. Mecanismos de Retorno: voltados ao estabelecimento de mecanismos de retorno frente às ações dos usuários.

5. Formas de Produção de Atividades: vias destinadas à oferta de meios e mecanismos de produção e desenvolvimento de atividades múltiplas, que ofereçam aos planejadores uma vasta gama de opções correspondentes a sua proposta pedagógica.

6. Back-up de Arquivos das Produções Colaborativas e Individuais: emprego de mecanismos que, de modo seguro, arquivem os registros das ações empreendidas durante o curso.

7. Eficientes Mecanismos de Acessibilidade e Usabilidade para a Clientela: visam uma navegação de fácil compreensão ao usuário, uma vez que o ambiente é a interface que 
fomenta a aprendizagem.

8. Mecanismos de Colaboração: possibilitam a realização de atividades colaborativas e de integração dos atores envolvidos no processo de ensino-aprendizagem.

9. Interfaces de Comunicação e Criação de Comunidades: observância ao princípio de que os ambientes de aprendizagem devem favorecer a criação de comunidades e de ações conjuntas entre os usuários.

10. Mecanismos de autogerenciamento dos eventos de aprendizagem: fundamentados na lógica de que os ambientes devem contar com interfaces que promovam a autonomia do aprendiz.

Não obstante todo o crescimento e cuidados em garantir a qualidade das ações de ensino a distância, é possível constatar que os ambientes virtuais de aprendizagem ainda revelam deficiências preocupantes relacionadas ao modo com que a clientela é atendida. Tendo em vista que problemas relativos a esse espaço hipermidiático - tais como inadequação nas representações de conhecimento e ruídos de comunicação - podem influenciar a permanência do aluno no curso realizado, as instituições educacionais buscam contornar tais dificuldades por meio da tomada de decisões que incidam de modo semelhante sobre todos os aprendizes envolvidos - aumentando o quadro de docentes, inserindo novas ferramentas colaborativas, ou ainda modificando as interfaces de ensino utilizadas.

E apesar de toda atenção dedicada aos ambientes de aprendizagem que subsidiam programas de EAD, dificilmente os AVAs são capazes de satisfazer as necessidades particulares de cada indivíduo e, consequentemente, não é raro que os estudantes virtuais se queixem de isolamento, falta de atenção ou acompanhamento insatisfatório por parte do corpo institucional (professores, equipe administrativa, entre outros). Por conta disso, a colaboração e o aprendizado virtual colaborativo, ao disponibilizarem formas de interação, cooperação, comunicação, coordenação e controle entre todos os agentes envolvidos, se tornam poderosas armas na luta contra as barreiras impostas pelo distanciamento físico e temporal inerentes ao ensino a distância (Oliveira \& Tedesco, 2010).

Dessa feita, o apoio, de natureza institucional e psicossocial, prestado ao estudante a distância também compõe outro subconjunto de fatores que podem afetar a permanência dos estudantes a distância. O afastamento físico típico da EAD pode interferir negativamente sobre os processos de aprendizagem e, desta feita, variáveis de suporte não devem ser negligenciadas durante o planejamento de ações educacionais nessa modalidade. Para alguns pesquisadores, o senso de comunidade e o auxílio percebido pelo aluno a distância podem 
desempenhar papel mais decisivo sobre a decisão de permanecer ou não no curso quando comparados a algumas variáveis tecnológicas (Galusha, 1997; Holder, 2007).

A variável suporte tem sido compreendida como todos os tipos de intervenções e facilidades que ajudam o aprendiz a distância a contornar dificuldades tecnológicas, problemas de comunicação e sentimentos de isolamento (Tobin, 1995). Nesse sentido, as interações interpessoais devem ser consideradas como um tipo básico de apoio ao aprendiz, independente de sua fonte, recursos mediadores ou status (se formal ou informal).

Alguns princípios básicos e críticos perpassam o suporte oferecido ao estudante, tal como a individualização e diretividade de intervenções realizadas, e a proposição de uma variada gama de contatos humanos - que enfraqueçam o aspecto impessoal de certas ações e materiais empregados nos cursos, e salientem o caráter social da EAD (Garrison, 2003; Robertshaw, 2000; Tait, 1996). Talvez, sem a elaboração de diversificados e individualizados sistemas e componentes de suporte ao aprendiz, a educação a distância seja vista como mais um produto industrializado e impessoal; por outro lado, a consideração das necessidades individuais de cada estudante, por meio de sistemas de apoio, é elemento essencial para o êxito escolar e para o crescimento institucional. O apoio e atenção individualizados ao aprendiz virtual podem ser vistos nas medidas e escolhas tomadas pelas instituições educacionais que enfatizam a cooperação, a conexão, a colaboração e a interação (ao invés da competição) nos ambientes e relações de aprendizagem (Fahy, 2003; Garrison, 2003).

É sabido que para aprendizes de qualquer espécie, tomar parte e se sentir membro de uma comunidade educacional tornam-se aspectos relevantes da esfera social dos mesmos. Segundo alguns autores, o senso de presença social vivenciado por participantes de eventos instrucionais a distância é importante fator para o sucesso de iniciativas educacionais dessa natureza (Leh, 2001; Poole, 2000; Rourke, Anderson, Garrison, \& Archer, 2001). Rovai (2002), ao investigar o papel exercido pelo senso de comunidade em redes de aprendizagem assíncronas identificou ligações entre a qualidade da interação aluno-professor e a persistência nos estudos. De acordo com ele, quanto mais os aprendizes estabelecem contato e conhecem mais profundamente uns aos outros, maior será a probabilidade de que eles desenvolvam confiança, busquem por auxílio e se sintam satisfeitos com o evento cursado. Para Tinto (1975), as interações sociais ocorridas sob a forma de intervenções de suporte estão diretamente relacionadas à permanência do estudante, ao passo que um fraco relacionamento entre estudante e universidade constitui-se em significativo fator para a ocorrência de evasão (Morgan \& McKenzie, 2003).

Entremeado aos elementos docente $\mathrm{x}$ desenho instrucional, é necessário considerar o 
fator ajuda educacional para a obtenção de êxito estudantil e, consequente, permanência acadêmica. Nesse sentido, uma controvérsia aparentemente interminável no campo da educação refere-se à quantidade ótima de orientação instrucional a ser fornecida em ambientes de aprendizagem. Muitos estudiosos questionam se seria mais proveitoso para os estudantes serem informados acerca dos conteúdos que deveriam ser aprendidos ou, ao invés disso, conceder oportunidades para que o conhecimento seja 'descoberto' por eles mesmos (Lee \& Anderson, 2013); ou seja, instituições, docentes e planejadores de cursos enfrentam o chamado "dilema da assistência". Para os autores, tal dilema estaria correlacionado à noção de "dificuldade desejável", segundo a qual condições de aprendizagem que introduzem certas dificuldades ao processo de aquisição do conhecimento, contrariando o senso comum, não prejudicaram os níveis de aprendizagem, mas conduziriam a melhor retenção e transferência de conteúdos.

Na visão de Lee e Anderson (2013), o contraste entre estes dois posicionamentos seria melhor caracterizado enquanto um continuum, apresentando ambos os extremos suas próprias vantagens e fraquezas. Em uma das pontas desse continnum advoga-se em favor da 'minimização' de orientações instrucionais que, por sua vez, favoreceriam a construção ou descoberta do conhecimento pelo próprio indivíduo que aprende - nesta circunstância livre para explorar os materiais/objetos de aprendizagem. Em ambientes orientados por processos de aprendizagem mais autônomos, estudantes são considerados aprendizes ativos - e não meros cumpridores de orientações - e a eles são dadas oportunidades de manipulação de conteúdos. Pesquisas apontam para possíveis benefícios cognitivos e motivacionais oriundos de tais abordagens educacionais, tais como: desenvolvimento de habilidades de pesquisa; aprendizagem por meio de erros; aprimoramento das capacidades de retenção e transferência de conteúdos aprendidos; elevação de atitudes positivas, por parte do aluno, frente ao domínio da aprendizagem. A exploração de objetos do conhecimento, ao conceder ao estudante mais controle sobre as tarefas executadas, também fortaleceria a motivação intrínseca. Ademais, tal abordagem concorre para a aprendizagem de dados adicionais sobre o conteúdo pretendido.

Face aos estudos que defendem as vantagens da 'orientação mínima' em ambientes de aprendizagem, inúmeras pesquisas tratam de demonstrar a superioridade de processos instrucionais mais diretivos em diversos domínios do conhecimento. Encontram-se dispostas na Tabela 12 algumas das vantagens e desvantagens próprias da emissão de orientações instrucionais para indivíduos aprendizes identificadas por Lee e Anderson (2013). 
Tabela 12. Vantagens e desvantagens inerentes à emissão de direcionamento educacional segundo Lee e Anderson (2013).

\begin{tabular}{|c|c|}
\hline Vantagens & Desvantagens \\
\hline Emissão de corretas explicações e resoluções & $\begin{array}{l}\text { Métodos de resolução mecanicamente aprendidos e } \\
\text { pobremente relembrados }\end{array}$ \\
\hline $\begin{array}{l}\text { Orientação de estudantes quanto ao conteúdo a ser } \\
\text { aprendido }\end{array}$ & Desestímulo à aprendizagem que vai além da instrução \\
\hline Identificação de traços críticos nos exemplos dados & $\begin{array}{l}\text { Evita a testagem da aprendizagem por parte dos } \\
\text { próprios alunos }\end{array}$ \\
\hline $\begin{array}{l}\text { Otimização do tempo por meio da diminuição de } \\
\text { buscas ineficientes e erros de aprendizagem }\end{array}$ & $\begin{array}{l}\text { Processamento de instruções verbais interferindo } \\
\text { negativamente na compreensão }\end{array}$ \\
\hline $\begin{array}{l}\text { Redução da memória de trabalho através da } \\
\text { administração de processos envolvendo resolução de } \\
\text { problemas }\end{array}$ & $\begin{array}{l}\text { Perda de atenção quando múltiplas fontes de } \\
\text { informação não são integradas }\end{array}$ \\
\hline
\end{tabular}

Contudo, é importante considerar que a efetividade de ambos os métodos/condutas instrucionais sofre influências de fatores externos as mesmas, tal como o rol de experiências prévias do alunado ou os níveis iniciais de conhecimento apresentados pelos mesmos. Segundo Lee e Anderson (2013), o fenômeno da aprendizagem pode ser incrementado por meio de uma acertada combinação entre ambiente de aprendizagem, medidas de resultados e habilidades cognitivas dos participantes. De acordo com diversas pesquisas, os níveis de conhecimento apresentados pelos aprendizes interagem com os níveis de orientação instrucional fornecidos; pondera-se, desta feita, que estudantes poderiam ser beneficiados se distintos métodos educacionais fossem empregados tendo em vista as experiências anteriores do corpo discente. $\mathrm{O}$ elemento autoexplicação também tem sido considerado em sua interação com as abordagens instrucionais adotadas. Tal fator corresponderia à situação na qual o aluno busca explicar a si mesmo possíveis resoluções para problemas e aprende mais por meio de tal via.

Vale considerar que abordagem/conduta instrucional adotada pode ser danosa ao processo de aquisição de conhecimento e persistência estudantil. Tal fato encontra respaldo em evidências que apontam para a necessidade de que o evento instrucional seja delineado de forma a reduzir cargas cognitivas desnecessárias aos aspectos essenciais das atividades educacionais executadas. Nesse sentido, materiais utilizados no processo de aprendizagem ao serem frequentemente entregues a partir de variadas modalidades (ex. textos e diagramas) principalmente na EAD - podem gerar dificuldades na integração das representações advindas de tais fontes de informação. E dificuldades deste tipo podem conduzir a fragmentações atencionais, e complicações envolvendo a elaboração de úteis esquemas de aprendizagem.

Apesar dos debates travados entre defensores das abordagens educacionais mais 
diretivas e de orientação autônoma, muitas tentativas estão sendo realizadas no sentido de conciliar aspectos positivos de ambas; ou seja, constatam-se inúmeras tentativas de combinar atividades de aprendizagem ativa com orientações educacionais diretas. E resultados de diversas pesquisas atestam a superioridade da junção das duas abordagens em detrimento da adoção de uma única estratégia educacional.

Até o presente momento, foram discutidas algumas das variáveis ligadas à ocorrência de evasão e persistência em ações de EAD pertinentes ao primeiro grande grupo de fatores, ou seja, aqueles relativos ao evento instrucional como um todo. A seguir, apresentar-se-á elementos próprios do segundo conjunto de fatores - características internas dos estudantes também relacionados à permanência/abandono no ensino a distância.

\subsubsection{Conjunto de fatores relacionados a características dos estudantes}

Os fatores referentes às características do público-alvo das ações educacionais a distância além de serem de extrema relevância para o planejamento de cursos em tal modalidade, também são vistos como relacionados à evasão ou à persistência em EAD. Alguns destes fatores dizem respeito a: características demográficas e profissionais; conhecimentos anteriores acerca dos conteúdos tratados no curso; habilidade e experiência no uso de ferramentas e recursos eletrônicos de aprendizagem; disciplina do aluno; motivação para aprender; entre outros.

Especialmente para o estudante a distância, o desenvolvimento e a integração de competências relativas ao amadurecimento pleno do indivíduo, ou o aprender a ser, poderão ser decisivas para seu êxito acadêmico. Entre o conjunto de tais elementos destaca-se a habilidade de administrar o tempo e conciliar as responsabilidades relativas aos inúmeros papéis educacionais, profissionais e sociais assumidos e situações de aprendizagem a distância. Romero e Barberà (2011) propõem que a disponibilidade de tempo é um fator chave para atividades de e-learning. Na maioria das vezes, por serem os estudantes a distância indivíduos adultos responsáveis por compromissos laborais e familiares, o tempo que tal clientela aloca para atividades acadêmicas acaba sendo reduzido - frequentemente, trata-se do tempo restante após a finalização de atividades profissionais, sociais e familiares (Diaz, 2002; Romero \& Barberà, 2011). Song, Singleton, Hill e Koh (2004), após realizarem investigação envolvendo estudantes universitários a distância, identificaram que habilidades no tocante à 
administração do tempo e ao uso das plataformas de ensino beneficiavam a permanência e sucesso do aluno.

O perfil do aprendiz em EAD é caracterizado por um arranjo de habilidades e estratégias metacognitivas complexas, as quais habilitam o indivíduo para automonitorar, autoavaliar e autogerir seu processo de aprendizagem. Nos atuais cenários educacionais, elementos como o estudo autônomo e a autonomia do aprendiz estão sendo cada vez mais preconizados e conceitualizados como essenciais. Estes podem ser definidos enquanto capacidades de: aprender a aprender; automonitorar-se; autocontrolar-se; e administrar o próprio tempo de estudo. Tais competências são dominadas pelos estudantes almejados por instituições de ensino superior a distância. Todavia, é importante reconhecer que esse sujeito que aprende também responde por outros papéis perante a sociedade, que exigem do mesmo atenção e dispêndio de tempo e esforços (Abbad, 2007).

$\mathrm{O}$ perfil do estudante de EAD é importante à medida em que denota tanto suas expectativas e necessidades específicas, bem como sinaliza alguns desafios impostos à efetividade de cursos dessa natureza; a tabela abaixo, formulada por Abbad (2007), indica essa realidade. 
Tabela 13. Perfil da clientela de EAD (Abbad, 2007) (continua).

\begin{tabular}{lccc} 
O Aluno de EAD & $\begin{array}{c}\text { Expectativas e } \\
\text { Demandas }\end{array}$ & Desafios da EAD & $\begin{array}{c}\text { Potencialidades e Limitações } \\
\text { da EAD }\end{array}$ \\
\hline
\end{tabular}

$\begin{array}{ll}\text { É adulto com } & \text { Espera que seus } \\ \text { múltiplas } & \text { conhecimentos e } \\ \text { experiências de } & \text { experiências sejam } \\ \text { vida. } & \text { levados em conta ao } \\ \text { estudar. }\end{array}$
estudar.
Escolher estratégias participativas que favoreçam $o$ aproveitamento dessas experiências de vida no processo de ensinoaprendizagem.
Uso de abordagens e metodologias que facilitem a criação de situações de aplicação prática e resolução de problemas.
Acumula diversos papéis na sociedade.
Espera que as dificuldades de conciliar responsabilidades pessoais, profissionais e de estudo sejam percebidas e consideradas pelos profissionais responsáveis pela concepção e entrega de soluções educacionais
Oportunidades de estudar a qualquer hora e em qualquer lugar.

Horários e tempos de estudo flexíveis, compatíveis com as rotinas profissionais e pessoais.

Interações assíncronas.

Preparação de materiais autoinstrucionais com escolha de mídias compatíveis como contexto e perfil do estudante.

Uso de recursos baseados nas novas tecnologias da informação para armazenagem, acesso on-line a objetos de aprendizagem e comunicação assíncrona entre os atores do processo de ensino-aprendizagem.

Desenho baseado na avaliação do perfil profissional do público-alvo.

Flexibilidade na sequência de apresentação de conteúdos.

Necessita adquirir competências complementares e/ou mais complexas que aquelas que já possui. Espera situações de aprendizagem compatíveis com seu perfil profissional e que tenham impacto favorável sobre a vida profissional.
Necessita de situações de aprendizagem que elevem as suas competências em termos de complexidade e relevância prática. Situações de aprendizagem derivadas da experiência do aluno, que reforcem a sua identidade e carreira profissional.
Pré-teste para ingresso no curso e em cada parte do mesmo.

Possibilidade de orientação e feedback individualizados.

Condições propícias pra a criação de exercícios que requeiram respostas abertas e solução de problemas relacionados às atividades profissionais do aluno.

Esse tipo de estratégia é de difícil implementação para grandes amostras de estudantes. 
Tabela 13. Perfil da clientela de EAD (Abbad, 2007) (conclusão).

\begin{tabular}{lccc} 
O Aluno de EAD & $\begin{array}{c}\text { Expectativas e } \\
\text { Demandas }\end{array}$ & Desafios da EAD & $\begin{array}{c}\text { Potencialidades e Limitações } \\
\text { da EAD }\end{array}$ \\
\hline
\end{tabular}

\begin{tabular}{llll} 
É & $\begin{array}{l}\text { Espera que as mídias de } \\
\text { entrega dos conteúdos e }\end{array}$ & $\begin{array}{l}\text { Utilização de múltiplas } \\
\text { mídias e serviços de }\end{array}$ & $\begin{array}{l}\text { Há mídias mais ou menos } \\
\text { flexíveis e nem todas são } \\
\text { profissionalmente } \\
\text { ativo. }\end{array}$ \\
$\begin{array}{ll}\text { os recursos de apoio } \\
\text { sejam compatíveis e } \\
\text { adequados às rotinas de } \\
\text { trabalho. }\end{array}$ & $\begin{array}{l}\text { compatíveis com } \\
\text { horários de estudo. }\end{array}$ & $\begin{array}{l}\text { adequadas ao tipo de objetivo } \\
\text { educacional do curso. }\end{array}$ \\
\hline
\end{tabular}

\begin{tabular}{|c|c|c|c|}
\hline $\begin{array}{l}\text { É mais qualificado } \\
\text { que estudantes de } \\
\text { cursos presenciais. }\end{array}$ & $\begin{array}{l}\text { Espera não ter que } \\
\text { memorizar informações } \\
\text { pouco complexas e } \\
\text { disponíveis no contexto } \\
\text { de estudo e de trabalho. } \\
\text { Necessita solucionar } \\
\text { problemas reais e } \\
\text { relevantes. }\end{array}$ & $\begin{array}{l}\text { Criar ambientes } \\
\text { interativos de } \\
\text { aprendizagem. } \\
\text { Criar situações em que a } \\
\text { participação ativa o } \\
\text { aluno é decisiva para a } \\
\text { solução de problemas } \\
\text { ligados ao contexto de } \\
\text { estudo. }\end{array}$ & $\begin{array}{l}\text { É possível criar estratégias em } \\
\text { que a interação entre pessoas } \\
\text { (aluno-tutor, aluno-aluno) seja } \\
\text { estimulada. } \\
\text { Uso de simuladores e de } \\
\text { metodologias baseadas em } \\
\text { resolução colaborativa de } \\
\text { problemas, webquests, entre } \\
\text { outros, são possíveis. Porém, } \\
\text { os custos iniciais para o } \\
\text { desenvolvimento desse tipo de } \\
\text { tecnologia são altos. }\end{array}$ \\
\hline $\begin{array}{l}\text { Valoriza o estudo } \\
\text { em função de ciclos } \\
\text { e planos de vida. É } \\
\text { motivado para a } \\
\text { aprendizagem. }\end{array}$ & $\begin{array}{l}\text { Espera ter experiências } \\
\text { de estudo que facilitem o } \\
\text { alcance de objetivos } \\
\text { profissionais e pessoais. }\end{array}$ & $\begin{array}{l}\text { Compatibilizar as } \\
\text { características do curso } \\
\text { ao perfil motivacional do } \\
\text { aluno (produtos e } \\
\text { competências resultantes } \\
\text { do curso valorizadas pela } \\
\text { clientela). }\end{array}$ & $\begin{array}{l}\text { Possibilidade de uso de } \\
\text { inteligência artificial para } \\
\text { adequação do desenho do } \\
\text { curso ao aluno. } \\
\text { Limitação: essas Tecnologias } \\
\text { ainda são pouco acessíveis. }\end{array}$ \\
\hline $\begin{array}{l}\text { Luta contra a } \\
\text { obsolescência } \\
\text { profissional. }\end{array}$ & $\begin{array}{l}\text { Necessita atualizar-se e } \\
\text { se requalificar de modo } \\
\text { contínuo, ao longo de } \\
\text { toda a vida. }\end{array}$ & $\begin{array}{l}\text { Armazenar, indexar e } \\
\text { disponibilizar } \\
\text { informações relevantes, } \\
\text { mecanismos de } \\
\text { orientação profissional e } \\
\text { trilhas de aprendizagem. }\end{array}$ & $\begin{array}{l}\text { Uso de plataformas eletrônicas } \\
\text { de gerenciamento da } \\
\text { aprendizagem. } \\
\text { Acesso a bibliotecas virtuais. } \\
\text { Acesso e estímulo à formação } \\
\text { de comunidades virtuais de } \\
\text { aprendizagem. }\end{array}$ \\
\hline
\end{tabular}

Variáveis cognitivas e motivacionais dos estudantes a distância também são consideradas de grande relevância, de modo que não basta deter recursos autorregulatórios, mas é fundamental conseguir empregá-los constantemente frente a dificuldades, elementos estressantes ou interesses concorrentes (Zimmermam \& Bandura, 1994). Segundo Souza (2010), diversas crenças pessoais interferem no desempenho e motivação dos aprendizes, sejam essas autorreferênciais ou relacionadas ao objeto de conhecimento. Dentre tais fatores, a autoeficácia e locus de controle vêm sendo pesquisados como elementos associados ao 
desempenho acadêmico (Abbad \& Meneses, 2004; Altman \& Arambasich, 1982; Parker, 1995; Zerbini, 2007).

A persistência do aprendiz online depende não apenas de qualidades acadêmicas ou ambientais, mas também de níveis elevados de motivação estudantil (Deimann \& Bastiaens, 2010; Holder, 2007; Morris, Finnegan, \& Wu, 2005). O aspecto motivacional é considerado como fator primário em qualquer modelo ou teoria de aprendizagem. Abbad, Pantoja e Pilati (2001) apontam para uma confusão conceitual que envolve esse constructo, oriunda dos diminutos esforços de pesquisa a fim de saná-la, de modo que essa variável é ora compreendida como causa ora como razão do desempenho humano.

Lacerda e Abbad (2003) trabalham com a noção de motivação para aprender ou motivação para treinar como sendo a direção, esforço, intensidade e persistência com que os treinandos se envolvem nas atividades voltadas para a aprendizagem antes, durante e depois da ação instrucional. Inúmeras pesquisas indicam uma relação diretamente positiva entre motivação e êxito/conclusão do evento instrucional: de acordo com os estudos, discentes com níveis elevados de motivação são aqueles que mais apreciam os cursos e que os finalizam (Bird \& Morgan, 2003; Jamison, 2003; Leasure, Davis \& Thievon, 2000; Visser, Plomp, Amirault \& Kuiper, 2002).

Findada a exposição acerca do segundo grupo de fatores relacionados à permanência ou não do corpo discente em ações de EAD, serão agora consideradas variáveis concernentes ao terceiro e último conjunto de elementos: os fatores contextuais.

\subsubsection{Conjunto de fatores ligados ao contexto que cerca o aluno a distância}

O ambiente de estudo do aluno virtual também pode estar intimamente ligado ao abandono/persistência escolar. É sabido que a clientela atendida por eventos educacionais a distância vivencia situações e dilemas que podem atrapalhar ou até mesmo impedir sua conclusão no curso. Na tabela abaixo, encontram-se listados alguns fatores descritos por Abbad (2007) como comumente vigentes no contexto do estudante de cursos a distância. 
Tabela 14. O contexto da clientela de EAD (Abbad, 2007) (continua).

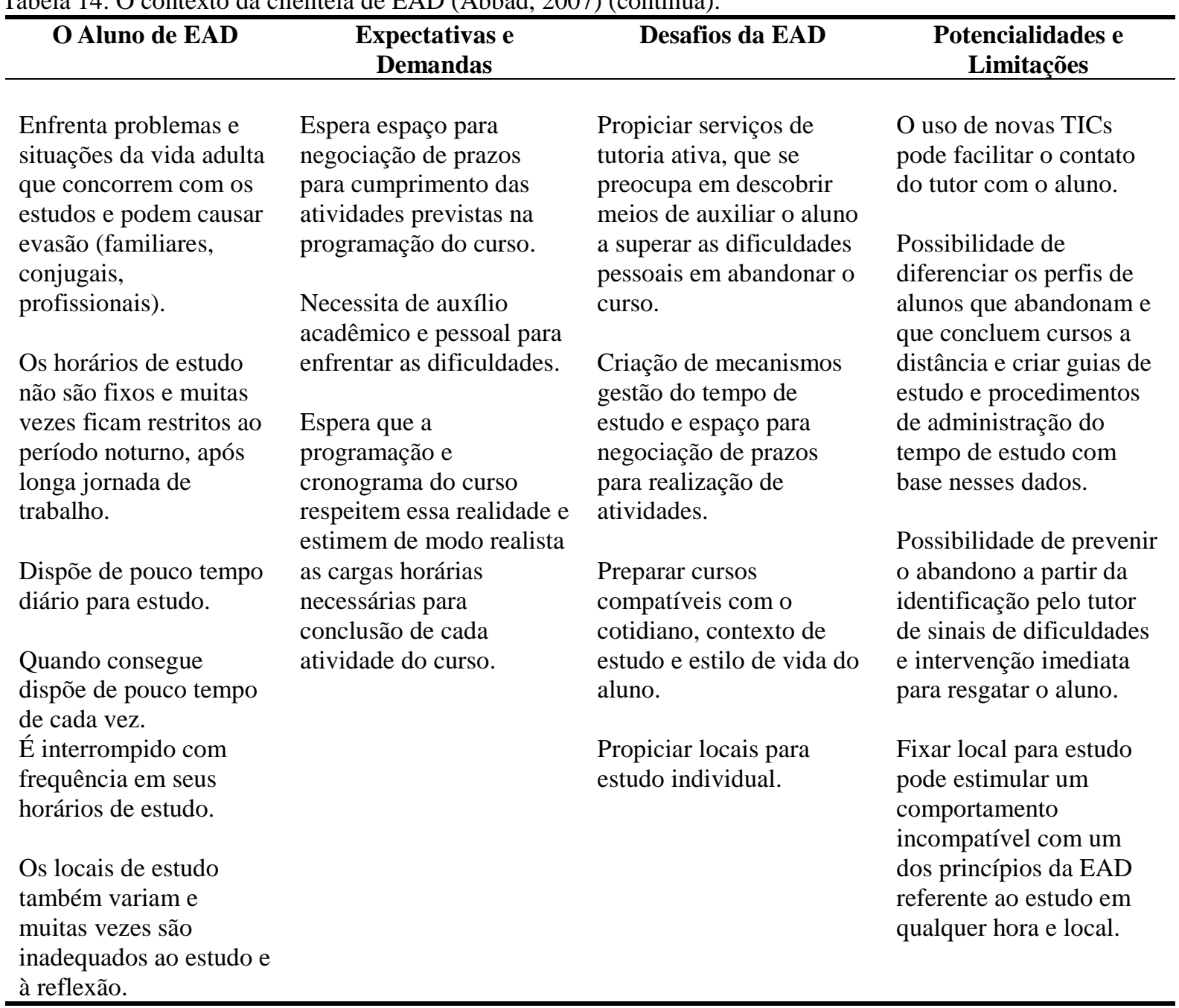

Entre algumas das variáveis ditas do contexto do aluno ligadas a fatores dificultadores da permanência discente, destacam-se: o tempo, ou a falta do mesmo, para o desenvolvimento do curso; as condições de estudo no ambiente familiar; intempéries pessoais; entre outras. Apesar de ser uma alternativa para indivíduos que necessitam e desejam dar continuidade ao processo de aprendizagem, a EAD também estabelece sérios desafios ao seu partícipe. Nesse sentido, ele necessita lidar com diversos ambientes e desenvolver habilidades estratégicas que o possibilite harmonizar o estudo a distância com outras atividades paralelas. A clientela do ensino a distância, por apresentar experiências e estilos de vida característicos - como a necessidade de estudar em locais adversos, mal acomodados e repletos de restrições e interferências - devem ter tais aspectos considerados no planejamento e execução de ações virtuais de ensino (Abbad, 2007).

As considerações até aqui tecidas revelam ser de extrema importância e necessidade a identificação dos elementos relacionados à evasão e à persistência em EAD. Tal 
reconhecimento pode auxiliar planejadores, docentes e corpo administrativo a administrar mais eficazmente os fatores de riscos que ameaçam as iniciativas de educação a distância. Estando cônscios acerca das variáveis que interferem, seja de modo positivo ou negativo, sobre a estada dos aprendizes em seus respectivos eventos instrucionais, os profissionais passam a dispor de melhores recursos na luta pelo progresso do ensino virtual.

Desta feita, discernir quais são as principais problemáticas que minam os esforços de promoção da EAD enquanto meio igualmente hábil para o processo de aprendizagem permite mitigá-las e, consequentemente, robustecer a modalidade. A fim de contribuir para tal conquista, o presente estudo relaciona na Tabela 15 alguns resultados de pesquisas, nacionais e estrangeiras, que tiveram como objetivo investigar variáveis possivelmente ligadas à ocorrência de evasão, ou permanência, de estudantes na educação a distância. 
Tabela 15. Resultados de pesquisas nacionais e internacionais sobre "Fatores Relacionados à Evasão e Persistência em EAD” (continua).

\begin{tabular}{|c|c|c|c|c|c|}
\hline Autores & Objetivo & Amostra/Contexto & $\begin{array}{l}\text { Procedimentos de } \\
\text { coleta de dados }\end{array}$ & $\begin{array}{l}\text { Procedimentos } \\
\text { de análise de } \\
\text { dados }\end{array}$ & Resultados \\
\hline $\begin{array}{l}\text { Shin \& Kim } \\
\text { (1999) }\end{array}$ & $\begin{array}{l}\text { Avaliar uma série de } \\
\text { variáveis, endógenas e } \\
\text { exógenas, ligadas a cursos } \\
\text { não presenciais. }\end{array}$ & $\begin{array}{l}4.668 \text { estudantes da } \\
\text { Universidade } \\
\text { Nacional Aberta da } \\
\text { Coréia }\end{array}$ & $\begin{array}{l}\text { Questionário } \\
\text { composto por } 20 \\
\text { questões referentes às } \\
\text { variáveis endógenas - } \\
\text { (1) tempo dedicado } \\
\text { ao estudo; (2) } \\
\text { planejamento e } \\
\text { organização dos } \\
\text { processos de } \\
\text { aprendizagem; (3) } \\
\text { atividades e contato } \\
\text { pessoal dos alunos - } \\
\text { e exógenas - (1) } \\
\text { carga de trabalho; (2) } \\
\text { incentivo social para } \\
\text { a realização do curso; } \\
\text { (3) desejo de } \\
\text { completar o evento } \\
\text { educacional. }\end{array}$ & $\begin{array}{l}\text { Análises de } \\
\text { regressão } \\
\text { logística; }\end{array}$ & $\begin{array}{l}\text { Os autores chamam a atenção para a } \\
\text { necessidade de se repensar o papel que } \\
\text { encontros presenciais desempenham na } \\
\text { EAD, uma vez que apenas a variável } \\
\text { endógena "atividades e contato pessoal dos } \\
\text { alunos" apresentou relação com o } \\
\text { fenômeno da evasão. }\end{array}$ \\
\hline $\begin{array}{l}\text { Henke \& Hussum } \\
(2000)\end{array}$ & $\begin{array}{l}\text { Identificar fatores diversos } \\
\text { que contribuiriam para a } \\
\text { ocorrência de evasão em } \\
\text { programas corporativos de } \\
\text { EAD. }\end{array}$ & $\begin{array}{l}62 \text { estudantes } \\
\text { evadidos de dois } \\
\text { cursos corporativos } \\
\text { ofertados por meio do } \\
\text { LMS Learning Space } \\
\text { nos continentes } \\
\text { europeu, asiático e } \\
\text { americano }\end{array}$ & $\begin{array}{l}\text { Questionário (12 } \\
\text { perguntas a serem } \\
\text { respondidas em uma } \\
\text { escala Likert de } 5 \\
\text { pontos) relativo a } \\
\text { possíveis causas da } \\
\text { evasão }\end{array}$ & $\begin{array}{l}\text { Análises } \\
\text { correlacionais; }\end{array}$ & $\begin{array}{l}\text { Inexistência de correlações } \\
\text { significativas entre as variáveis analisadas; } \\
\text { A principal razão apontada para a } \\
\text { não finalização do curso foi a dificuldade } \\
\text { em conciliá-lo com outros compromissos } \\
\text { profissionais; }\end{array}$ \\
\hline
\end{tabular}


Tabela 15. Resultados de pesquisas nacionais e internacionais sobre "Fatores Relacionados à Evasão e Persistência em EAD” (continuação).

\begin{tabular}{|c|c|c|c|c|c|}
\hline Autores & Objetivo & Amostra/Contexto & $\begin{array}{l}\text { Procedimentos de } \\
\text { coleta de dados }\end{array}$ & $\begin{array}{l}\text { Procedimentos } \\
\text { de análise de } \\
\text { dados }\end{array}$ & Resultados \\
\hline Tucho (2000) & $\begin{array}{l}\text { Levantar possíveis } \\
\text { fatores dificultadores à } \\
\text { conclusão de programas de } \\
\text { ensino a distância }\end{array}$ & $\begin{array}{l}124 \text { alunos evadidos } \\
\text { da Faculdade } \\
\text { Comunitária da } \\
\text { Filadélfia (EUA) }\end{array}$ & $\begin{array}{l}\text { Questionário, do tipo } \\
\text { Likert, composto por } \\
28 \text { questões (relativas } \\
\text { a barreiras } \\
\text { educacionais de nível } \\
\text { institucional, } \\
\text { situacional e de } \\
\text { predisposição. }\end{array}$ & $\begin{array}{l}\text { Análises } \\
\text { descritivas; } \\
\text { Análises } \\
\text { fatoriais; }\end{array}$ & $\begin{array}{l}\text { Entre os diferentes tipos de barreiras } \\
\text { educacionais considerados, o mais } \\
\text { fortemente relacionado à explicação da } \\
\text { evasão foi aquele denominado situacional. }\end{array}$ \\
\hline $\begin{array}{l}\text { Xenos et al. } \\
(2002)\end{array}$ & $\begin{array}{l}\text { Identificar as mais } \\
\text { importantes causas ligadas } \\
\text { à desistência acadêmica. }\end{array}$ & $\begin{array}{l}\text { Alunos matriculados } \\
\text { no curso da área de } \\
\text { Ciências da } \\
\text { Computação da } \\
\text { Faculdade de Ciência } \\
\text { e Tecnologia da } \\
\text { Universidade Aberta } \\
\text { de Hellenic (Grécia). }\end{array}$ & $\begin{array}{l}\text { Entrevistas; } \\
\text { Registro dos } \\
\text { participantes; } \\
\text { Aplicação de } \\
\text { questionário (relação } \\
\text { aluno-professor; } \\
\text { domínio de recursos } \\
\text { tecnológicos; } \\
\text { impressão acerca da } \\
\text { instituição de ensino); }\end{array}$ & $\begin{array}{l}\text { Análises } \\
\text { multivariadas; }\end{array}$ & $\begin{array}{l}\text { Foram identificados três conjuntos } \\
\text { de fatores ligados à ocorrência da evasão e } \\
\text { determinação de seus índices: } \\
\text { (a) conjunto de fatores relativo às } \\
\text { percepções internas dos estudantes e a } \\
\text { localização do locus de controle (se } \\
\text { externo ou interno ao aluno); } \\
\text { (b) conjunto de fatores pertinente aos } \\
\text { eventos instrucionais e aos tutores } \\
\text { (assistência deficitária prestada pelo } \\
\text { tutor e a quantidade de produções } \\
\text { escritas demandadas); } \\
\text { (c) conjunto de fatores relacionado ao } \\
\text { perfil estudantil, tal como idade e gênero } \\
\text { (indivíduos mais jovens, com } \\
\text { conhecimentos e experiências prévias } \\
\text { envolvendo uso e situações de } \\
\text { aprendizagem com ferramentas } \\
\text { eletrônicas persistiram mais); }\end{array}$ \\
\hline
\end{tabular}


Tabela 15. Resultados de pesquisas nacionais e internacionais sobre "Fatores Relacionados à Evasão e Persistência em EAD” (continuação).

\section{Autores}

Objetivo

Amostra/Contexto

Estudo de caso

envolvendo 37

profissionais

favorecedores da

permanência discente, bem

como fatores

dificultadores, em ações

educacionais ofertadas a

distância via internet participantes

(concluintes ou não)

de um programa de

formação continuada

para professores

universitários
Procedimentos de

coleta de dados

\section{Procedimentos \\ de análise de}

$$
\text { dados }
$$

\section{Resultados}

- $\quad$ Foram identificadas diferenças entre a amostra de participantes concluintes e de evadidos em relação às seguintes variáveis: idade, sexo, formação acadêmica.

- $\quad$ Evadidos e concluintes consideraram como principal variável dificultadora a limitação de tempo para o desenvolvimento do curso.
Questionário de
questões de múltip escolha (identificação pessoal, informações referentes ao curso, razões para a

conclusão/abandono

do curso
Análises descritivas;
- Outros fatores que contribuíram para o abandono acadêmico foram: condições inapropriadas de estudo em casa, local de trabalho sem ambiente adequado para estudo, desorganização pessoal, dificuldades técnicas e falta de correspondência com as expectativas traçadas. 
Tabela 15. Resultados de pesquisas nacionais e internacionais sobre "Fatores Relacionados à Evasão e Persistência em EAD" (continuação).

\section{Autores}

Objetivo
Procedimentos de coleta de dados

\section{Procedimentos \\ de análise de}

$$
\text { dados }
$$

\section{Resultados}

- $\quad$ Fatores que contribuem para a permanência em EAD: motivação pessoal (citada por $73 \%$ dos participantes); interações de aprendizagem satisfatórias $(40 \%)$; políticas organizacionais de conclusão obrigatória $(28.5 \%)$; e,

Refletir acerca das experiências e desafios enfrentados por atuantes no campo da educação a distância em contextos de organizações e trabalho
Wang et al. (2003) profissionais e alunos
388 indivíduos -13 profissionais responsáveis pela gerência de cursos e 375 estudantes - dos

EUA envolvidos com o $e$-learning

\section{Entrevistas;}

Aplicação de questionário (experiências vivenciadas pelos alunos em ações instrucionais a distância);
Análises

descritivas;

Análises de correlação;

Análises de conteúdo; $(16 \%)$;

- $\quad$ Fatores que influenciam os índices de evasão: falta de motivação do aprendiz $(36 \%)$; desenho instrucional e incompatibilidade com os estilos de aprendizagem (36\%); escassez de tempo em virtude de compromissos familiares e laborais (33.1\%); domínio dos conhecimentos e habilidades necessários ao desempenho profissional antes do término do curso (25\%); falta de suporte

organizacional $(25 \%)$ Os resultados indicaram a importância da integração acadêmica do discente, uma vez que os estudantes concluintes se disseram satisfeitos com o
174 alunos do curso de Licenciatura em

Investigar a problemática da evasão acadêmica no

Amidani (2004) contexto brasileiro de ensino superior a distância.
Matemática

ministrado pelo

Centro de Educação

Superior a Distância Janeiro. do Estado do Rio de
Entrevistas (com tutores, alunos concluintes, alunos não concluintes, direção de polo e direção de produção do material didático)

Questionário
Análises qualitativas (de conteúdo);

Análises

quantitativas (Qui-quadrado); transmitido.

- Dificuldades em conciliar atividades discentes e compromissos de outra natureza (familiares, profissionais, sociais), pressões laborais e pouco contato prévio com o ensino a distância também foram considerados como prejudiciais à permanência do estudante. 
Tabela 15. Resultados de pesquisas nacionais e internacionais sobre "Fatores Relacionados à Evasão e Persistência em EAD” (continuação).

\begin{tabular}{|c|c|c|c|c|c|}
\hline Autores & Objetivo & Amostra/Contexto & $\begin{array}{l}\text { Procedimentos de } \\
\text { coleta de dados }\end{array}$ & $\begin{array}{l}\text { Procedimentos } \\
\text { de análise de } \\
\text { dados }\end{array}$ & Resultados \\
\hline $\begin{array}{l}\text { Ngoma et al. } \\
\text { (2004) }\end{array}$ & $\begin{array}{l}\text { Compreender a conjuntura } \\
\text { de variáveis que concorrem } \\
\text { para a evasão no contexto } \\
\text { universitário de ensino }\end{array}$ & $\begin{array}{l}70 \text { tutores do } \\
\text { programa de extensão } \\
\text { da Universidade de } \\
\text { Estudos de Extensão } \\
\text { de Zâmbia }\end{array}$ & $\begin{array}{l}\text { Questionário } \\
\text { semiestruturado ( } 23 \\
\text { questões abertas e } \\
\text { fechadas) versando } \\
\text { sobre informações } \\
\text { pessoais dos tutores, } \\
\text { qualificações } \\
\text { profissionais } \\
\text { possuídas e fatores } \\
\text { considerados como } \\
\text { causadores de evasão }\end{array}$ & $\begin{array}{l}\begin{array}{l}\text { Análises } \\
\text { descritivas; }\end{array} \\
\text { Análises } \\
\text { qualitativas; }\end{array}$ & $\begin{array}{l}\text { Variáveis pouco interferentes nos } \\
\text { índices de evasão: qualificação dos tutores; } \\
\text { conteúdos do curso e custos do evento } \\
\text { educacional; } \\
\text { Variáveis altamente interferentes nos } \\
\text { índices de abando estudantil: compromissos } \\
\text { e tarefas não relacionados ao curso e } \\
\text { dificuldades em contatar os tutores. }\end{array}$ \\
\hline \multirow{4}{*}{$\begin{array}{l}\text { Pierrakeas et al. } \\
(2004)\end{array}$} & \multirow{4}{*}{$\begin{array}{l}\text { Investigar os efeitos da } \\
\text { natureza do evento } \\
\text { instrucional sobre a evasão } \\
\text { ou a persistência em EAD }\end{array}$} & \multirow{4}{*}{$\begin{array}{l}\text { Alunos (evadidos ou } \\
\text { concluintes) de dois } \\
\text { cursos a distância } \\
\text { ofertados - um deles } \\
\text { de bacharelado e o } \\
\text { outro de pós- } \\
\text { graduação - pela } \\
\text { universidade aberta } \\
\text { Hellenic Open } \\
\text { University (Grécia) }\end{array}$} & & \multirow{4}{*}{$\begin{array}{l}\text { Análises } \\
\text { multivariadas; }\end{array}$} & $\begin{array}{l}\text { A subestimação do tempo requerido } \\
\text { para o cumprimento do curso e das demais } \\
\text { atividades paralelas aparece entre as mais } \\
\text { frequentes causas mencionadas para a } \\
\text { desistência discente; }\end{array}$ \\
\hline & & & $\begin{array}{l}\text { Análise documental } \\
\text { (sistema de registro } \\
\text { da instituição); }\end{array}$ & & $\begin{array}{l}\text { Os resultados obtidos apontaram } \\
\text { para uma possível relação positiva entre } \\
\text { idade e índice de evasão. }\end{array}$ \\
\hline & & & $\begin{array}{l}\text { Anotações redigidas } \\
\text { pelos tutores dos } \\
\text { cursos; }\end{array}$ & & $\begin{array}{l}\text { - Nesse estudo, a variável sexo não } \\
\text { esteve significativamente ligada ao } \\
\text { abandono estudantil. }\end{array}$ \\
\hline & & & $\begin{array}{l}\text { Entrevistas junto a } \\
\text { discentes evadidos; }\end{array}$ & & $\begin{array}{l}\text { Índices de evasão mais elevados no } \\
\text { curso de graduação em comparação ao } \\
\text { curso de pós-graduação indicam que } \\
\text { indivíduos ambientados às exigências } \\
\text { próprias do meio educacional apresentam } \\
\text { menor propensão a evadirem-se do que } \\
\text { aqueles inexperientes; }\end{array}$ \\
\hline
\end{tabular}


Tabela 15. Resultados de pesquisas nacionais e internacionais sobre "Fatores Relacionados à Evasão e Persistência em EAD" (continuação).

\begin{tabular}{|c|c|c|c|c|c|}
\hline Autores & Objetivo & Amostra/Contexto & $\begin{array}{l}\text { Procedimentos de } \\
\text { coleta de dados }\end{array}$ & $\begin{array}{c}\begin{array}{c}\text { Procedimentos } \\
\text { de análise de } \\
\text { dados }\end{array} \\
\end{array}$ & Resultados \\
\hline Vargas (2004) & $\begin{array}{l}\text { Avaliar barreiras à } \\
\text { proposição de programas } \\
\text { instrucionais ofertados a } \\
\text { distância }\end{array}$ & $\begin{array}{l}\text { Funcionários de } \\
\text { grande empresa } \\
\text { atuante no ramo } \\
\text { elétrico }\end{array}$ & $\begin{array}{l}\text { Entrevistas } \\
\text { semiestruturadas; } \\
\text { Aplicação de } \\
\text { questionários (MSLQ } \\
\text { e Reações à } \\
\text { Tecnologia); }\end{array}$ & $\begin{array}{l}\text { Análises de } \\
\text { conteúdo; } \\
\text { Análises de } \\
\text { correlação; } \\
\text { Análises de } \\
\text { regressão } \\
\text { logística; } \\
\text { Análises de } \\
\text { regressão linear } \\
\text { padrão; }\end{array}$ & $\begin{array}{l}\text { Análises de regressão logística, } \\
\text { tendo como variáveis antecedentes dados } \\
\text { demográficos, motivacionais e tecnológicos } \\
\text { e a variável critério permanência apontam } \\
\text { para um significativo relacionamento entre } \\
\text { a variável critério e gênero e crenças de } \\
\text { aprendizagem; } \\
\text { - A amostra utilizada considerou } \\
\text { como uma dos principais elementos } \\
\text { dificultadores para a permanência } \\
\text { acadêmica problemas relacionados à } \\
\text { atuação do professor; }\end{array}$ \\
\hline Brauer (2005) & $\begin{array}{l}\text { Verificar o poder } \\
\text { explicativo das variáveis } \\
\text { antecedentes características } \\
\text { da clientela e barreiras } \\
\text { pessoais à conclusão do } \\
\text { curso sobre evasão } \\
\text { em cursos a distância }\end{array}$ & $\begin{array}{l}\text { Indivíduos inscritos } \\
(15889) \text { no curso } \\
\text { Iniciando um } \\
\text { Pequeno Grande } \\
\text { Negócio (IPGN) } \\
\text { ministrado } \\
\text { virtualmente pelo } \\
\text { Sebrae }\end{array}$ & $\begin{array}{l}\text { Escala de "Valor } \\
\text { Instrumental do } \\
\text { Treinamento"; } \\
\text { Escala de "Barreiras } \\
\text { Pessoais à Conclusão } \\
\text { do Curso"; }\end{array}$ & $\begin{array}{l}\text { Análises de } \\
\text { regressões } \\
\text { logísticas; } \\
\text { Análises de } \\
\text { regressão } \\
\text { múltipla padrão } \\
\text { stepwise; }\end{array}$ & $\begin{array}{l}\text { Os modelos testados apresentaram } \\
\text { reduzido poder explicativo, sustentando a } \\
\text { hipótese de que dados demográficos } \\
\text { guardam baixa capacidade preditiva sobre } \\
\text { variáveis de resultados de treinamento. }\end{array}$ \\
\hline
\end{tabular}


Tabela 15. Resultados de pesquisas nacionais e internacionais sobre "Fatores Relacionados à Evasão e Persistência em EAD” (continuação).

\begin{tabular}{|c|c|c|c|c|c|}
\hline Autores & Objetivo & Amostra/Contexto & $\begin{array}{l}\text { Procedimentos de } \\
\text { coleta de dados }\end{array}$ & $\begin{array}{l}\text { Procedimentos } \\
\text { de análise de } \\
\text { dados }\end{array}$ & Resultados \\
\hline
\end{tabular}

\begin{tabular}{|c|c|c|c|c|c|}
\hline $\begin{array}{l}\text { Abbad, Carvalho } \\
\& \text { Zerbini (2006) }\end{array}$ & $\begin{array}{l}\text { Avaliar fatores explicativos } \\
\text { de evasão em uma ação } \\
\text { instrucional gratuita } \\
\text { ofertada totalmente a } \\
\text { distância }\end{array}$ & $\begin{array}{l}\text { População de alunos } \\
(\mathrm{n}=19.849) \text { inscritos } \\
\text { em um curso que } \\
\text { objetivava a } \\
\text { elaboração de um } \\
\text { plano de negócios }\end{array}$ & $\begin{array}{l}\text { Consideração dos três } \\
\text { componentes, (1) } \\
\text { Características } \\
\text { Demográficas da } \\
\text { Clientela; (2) Uso dos } \\
\text { Recursos Eletrônicos } \\
\text { do Curso e (3) } \\
\text { Evasão, presentes no } \\
\text { modelo de pesquisa } \\
\text { proposto }\end{array}$ & $\begin{array}{l}\text { Análises } \\
\text { descritivas; } \\
\text { Análises } \\
\text { exploratórias; }\end{array}$ & $\begin{array}{l}\text { Os participantes que menos } \\
\text { frequentemente acessaram os chats, o mural } \\
\text { de notícias e o ambiente virtual do curso } \\
\text { foram aqueles que mais tenderam à evasão. } \\
\text { Possivelmente, os evadidos, no momento da } \\
\text { realização do curso, não exerciam domínio } \\
\text { sobre o emprego dos recursos baseados nas } \\
\text { novas TICs e/ou não se sentiram } \\
\text { estimulados a utilizá-los; } \\
\text { Os resultados indicam possíveis } \\
\text { relações entre frequência de uso das } \\
\text { ferramentas eletrônicas e evasão em } \\
\text { contextos de e-learning; }\end{array}$ \\
\hline $\begin{array}{l}\text { Favero e Franco } \\
\text { (2006) }\end{array}$ & $\begin{array}{l}\text { Investigar o papel } \\
\text { desempenhado pelas } \\
\text { interações estabelecidas } \\
\text { entre aprendizes em } \\
\text { contextos de aprendizagem } \\
\text { online }\end{array}$ & $\begin{array}{l}\text { Trocas ocorridas } \\
\text { entre os participantes } \\
\text { de curso ofertado } \\
\text { pelo Ambiente } \\
\text { Teleduc, bem como o } \\
\text { AVA e comunidades } \\
\text { virtuais utilizados } \\
\text { pelos mesmos }\end{array}$ & $\begin{array}{l}\text { Análise das } \\
\text { interações ocorridas } \\
\text { entre os alunos } \\
\text { durante a } \\
\text { aprendizagem por } \\
\text { meio do uso das } \\
\text { ferramentas de } \\
\text { comunicação } \\
\text { disponibilizadas } \\
\text { (como fóruns, chats, } \\
e \text {-mails, diários de } \\
\text { bordo e mural) }\end{array}$ & $\begin{array}{l}\text { Análises } \\
\text { descritivas; } \\
\text { Análises } \\
\text { qualitativas; }\end{array}$ & $\begin{array}{l}\text { - No estudo, os estudantes concluintes } \\
\text { foram aqueles que mais se mostraram } \\
\text { solícitos e cooperaram ao longo das } \\
\text { interações estabelecidas no curso e } \\
\text { manifestaram a aquisição de conhecimentos } \\
\text { transmitidos. }\end{array}$ \\
\hline
\end{tabular}


Tabela 15. Resultados de pesquisas nacionais e internacionais sobre "Fatores Relacionados à Evasão e Persistência em EAD” (continuação).

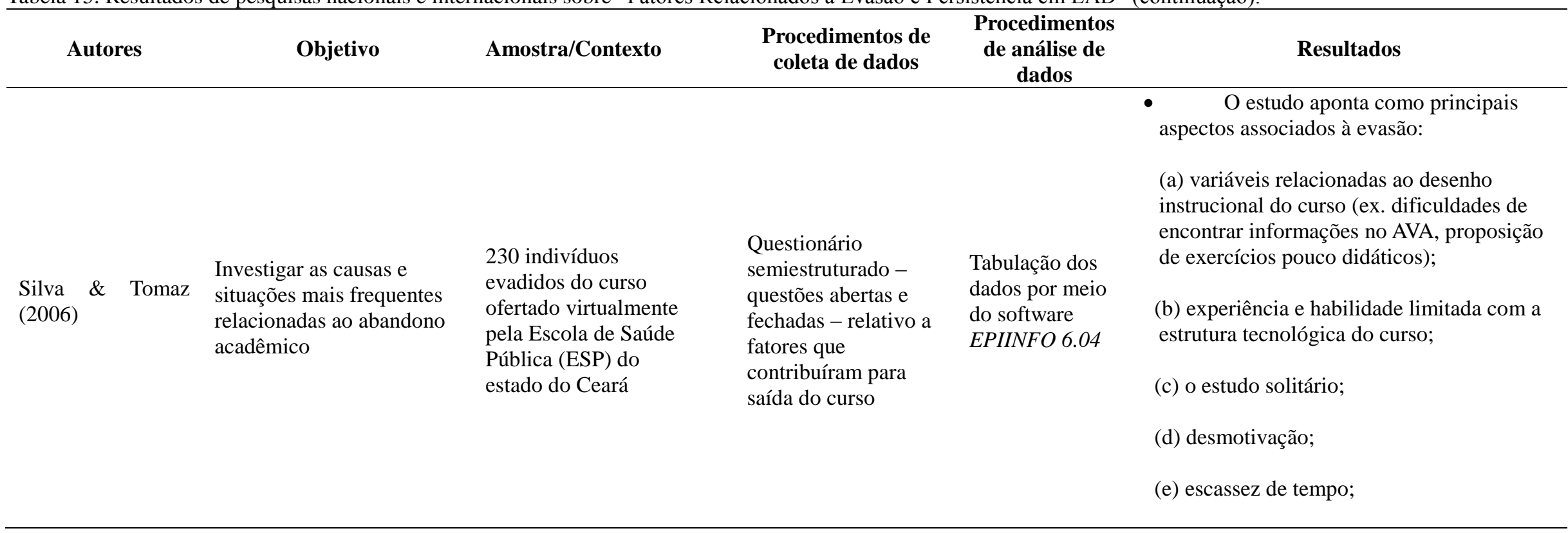


Tabela 15. Resultados de pesquisas nacionais e internacionais sobre "Fatores Relacionados à Evasão e Persistência em EAD" (continuação).

Autores

Objetivo

Amostra/Contexto

coleta de dados

\section{Procedimentos}

de análise de dados

\section{Resultados}

- $\quad$ Elementos favoráveis à conclusão do curso: a criação de um plano de estudo; organização e definição de horários

Análises

estatísticas

Consultores do

Projeto Empreender
1.494 estudantes

(concluintes e

Identificar os elementos preditores

evadidos) dos cursos

de Mediação e

Arbitragem e

Formação de

presenciais
Escala de

"Comportamentos e

Atitudes do Aluno em

Relação a Cursos a

Distância";

exploratórias;

Análises

descritivas;

Análises

inferenciais;

Escala de "Valor

Instrumental do

Treinamento, no

âmbito da Educação a

Distância";

Análises qualitativas (sobre o material específicos para realização das atividades pertinentes ao curso; leitura de materiais a respeito das características do curso; conciliação de compromissos familiares, profissionais e acadêmicos; incentivo e organização familiar para o

desenvolvimento do curso; sentimento favorável ao estudo individual; percepção de apoio do tutor; engajamento em atividades coletivas; didático do curso);

- $\quad$ Elementos desfavoráveis à conclusão do curso: distanciamento físico entre os atores envolvidos; falta de contato visual; não ocorrência de aulas presenciais; complexidade do conteúdo do curso; habilidade de uso dos recursos tecnológicos limitada;

\begin{tabular}{|c|c|c|c|c|c|}
\hline $\begin{array}{l}\text { Yukselturk \& Inan } \\
\text { (2006) }\end{array}$ & $\begin{array}{l}\text { Investigar possíveis fatores } \\
\text { relacionados à evasão em } \\
\text { um programa virtual de } \\
\text { formação superior }\end{array}$ & $\begin{array}{l}98 \text { estudantes } \\
\text { evadidos do } \\
\text { Programa de } \\
\text { Certificação em } \\
\text { Tecnologia da } \\
\text { Informação (Turquia) }\end{array}$ & $\begin{array}{l}\text { Questionário de } \\
\text { concordância do tipo } \\
\text { Likert de } 5 \text { pontos } \\
\text { composto por } 14 \\
\text { questões (tanto de } \\
\text { caráter aberto quanto } \\
\text { fechado) relacionadas } \\
\text { às principais razões } \\
\text { para o abandono } \\
\text { acadêmico }\end{array}$ & $\begin{array}{l}\text { Análises } \\
\text { descritivas; } \\
\text { Análises de } \\
\text { conteúdo; }\end{array}$ & $\begin{array}{l}\text { As principais causas de evasão } \\
\text { foram relacionadas à insuficiência de tempo } \\
\text { para desenvolvimento do curso, problemas } \\
\text { pessoais (doenças, compromissos } \\
\text { profissionais, demandas familiares, etc) e } \\
\text { queda na motivação. }\end{array}$ \\
\hline
\end{tabular}


Tabela 15. Resultados de pesquisas nacionais e internacionais sobre "Fatores Relacionados à Evasão e Persistência em EAD” (continuação).

\begin{tabular}{|c|c|c|c|c|c|}
\hline Autores & Objetivo & Amostra/Contexto & $\begin{array}{l}\text { Procedimentos de } \\
\text { coleta de dados }\end{array}$ & $\begin{array}{c}\text { Procedimentos } \\
\text { de análise de } \\
\text { dados }\end{array}$ & Resultados \\
\hline Almeida (2007) & $\begin{array}{l}\text { Estabelecer as causas de } \\
\text { evasão entre alunos } \\
\text { matriculados em um curso } \\
\text { de especialização }\end{array}$ & $\begin{array}{l}228 \text { alunos evadidos } \\
\text { do curso de } \\
\text { especialização em } \\
\text { Esporte Escolar, } \\
\text { ofertado pelo } \\
\text { Programa Segundo } \\
\text { Tempo do Ministério } \\
\text { do Esporte em } \\
\text { parceria com o } \\
\text { Centro de Educação a } \\
\text { Distância (Cead) da } \\
\text { Universidade de } \\
\text { Brasília }\end{array}$ & $\begin{array}{l}\text { Instrumento } \\
\text { "Comportamentos e } \\
\text { Atitudes do Aluno em } \\
\text { Relação a Cursos a } \\
\text { Distância", } \\
\text { desenvolvido por } \\
\text { Walter (2006) }\end{array}$ & $\begin{array}{l}\begin{array}{l}\text { Análises } \\
\text { descritivas; }\end{array} \\
\text { Análises } \\
\text { inferenciais; } \\
\text { Análises de } \\
\text { conteúdo; }\end{array}$ & $\begin{array}{l}\text { - Identificação de cinco categorias de } \\
\text { fatores relacionados à desistência } \\
\text { acadêmica: } \\
\text { (a) f atores situacionais; } \\
\text { (b) falta de apoio acadêmico; } \\
\text { (c) problemas com a tecnologia; } \\
\text { (d) sobrecarga de trabalho; } \\
\text { (e) falta de apoio administrativo } \\
\text { (dificuldades na distribuição e } \\
\text { recebimento de materiais didáticos, } \\
\text { prazos insuficientes para o envio de } \\
\text { atividades, acumulação de tarefas, etc); }\end{array}$ \\
\hline Holder (2007) & $\begin{array}{l}\text { Avaliar preditores de } \\
\text { persistência em ações } \\
\text { educacionais não } \\
\text { presenciais }\end{array}$ & $\begin{array}{l}259 \text { estudantes } \\
\text { inscritos (evadidos ou } \\
\text { não) em programas } \\
\text { de ensino virtual nos } \\
\text { mais diferentes níveis } \\
\text { (associados, } \\
\text { bacharéis ou } \\
\text { mestrado) e áreas de } \\
\text { formação } \\
\text { (contabilidade, } \\
\text { administração, } \\
\text { enfermagem, direito, } \\
\text { educação, etc) }\end{array}$ & $\begin{array}{l}\text { Instrumento de } \\
\text { medida (composto } \\
\text { por } 60 \text { itens) } \\
\text { versando sobre } \\
\text { variáveis relacionadas } \\
\text { à motivação, ao } \\
\text { ambiente e ao próprio } \\
\text { aluno }\end{array}$ & $\begin{array}{l}\text { Análises } \\
\text { descritivas; } \\
\text { Análises } \\
\text { multivariadas; } \\
\text { Análises de } \\
\text { confiabilidade; }\end{array}$ & $\begin{array}{l}\text { Estudantes não evadidos }(\mathrm{N}=209) \\
\text { obtiveram as taxas mais altas nas medidas } \\
\text { ambientais denominadas Suporte } \\
\text { Emocional; Autoeficácia; e Tempo e } \\
\text { Gerenciamento dos Estudos do instrumento } \\
\text { utilizado. }\end{array}$ \\
\hline
\end{tabular}


$\underline{\text { Tabela 15. Resultados de pesquisas nacionais e internacionais sobre "Fatores Relacionados à Evasão e Persistência em EAD" (continuação). }}$

\begin{tabular}{|c|c|c|c|c|c|}
\hline Autores & Objetivo & Amostra/Contexto & $\begin{array}{l}\text { Procedimentos de } \\
\text { coleta de dados }\end{array}$ & $\begin{array}{c}\text { Procedimentos } \\
\text { de análise de } \\
\text { dados }\end{array}$ & Resultados \\
\hline Walter (2008) & $\begin{array}{l}\text { Analisar relações entre } \\
\text { variáveis relativas às } \\
\text { características da clientela, } \\
\text { características do curso e } \\
\text { comportamentos do } \\
\text { estudante em relação à } \\
\text { EAD com a variável } \\
\text { critério evasão }\end{array}$ & $\begin{array}{l}1.494 \text { estudantes - } \\
615 \text { evadidos e } 879 \\
\text { concluintes - de dois } \\
\text { cursos oferecidos } \\
\text { pelo Centro de } \\
\text { Educação } \\
\text { Tecnológica Escola } \\
\text { Aberta (MSD) em } \\
\text { parceria com a } \\
\text { Confederação das } \\
\text { Associações } \\
\text { Comerciais e } \\
\text { Empresarias do } \\
\text { Brasil (CACB) }\end{array}$ & $\begin{array}{l}\text { Escalas referentes à } \\
\text { idade, gênero, } \\
\text { participações } \\
\text { anteriores em cursos } \\
\text { não presenciais, } \\
\text { pagamento do curso, } \\
\text { valor instrumental do } \\
\text { treinamento, } \\
\text { modalidade cursada } \\
\text { (híbrida ou } \\
\text { totalmente a } \\
\text { distância) e atitudes } \\
\text { do aluno face à EAD }\end{array}$ & $\begin{array}{l}\text { Análises dos } \\
\text { fatores } \\
\text { principais e de } \\
\text { confiabilidade; } \\
\text { Análises de } \\
\text { regressão } \\
\text { logística; }\end{array}$ & $\begin{array}{l}\text { Estudantes com experiência prévia } \\
\text { na modalidade de ensino a distância } \\
\text { evadiram-se em menor frequência dos } \\
\text { cursos; } \\
\quad \text { Alunos que experimentaram o } \\
\text { ensino virtual pela primeira vez } \\
\text { demonstram ser menos autônomos, menos } \\
\text { aptos à administrar o tempo de estudo, } \\
\text { menos confortáveis e confiantes do que } \\
\text { aprendizes que conservavam algum contato } \\
\text { anterior com e-learning; }\end{array}$ \\
\hline Sales (2009) & $\begin{array}{l}\text { Propor e testar um modelo } \\
\text { estatístico de predição da } \\
\text { situação de alunos } \\
\text { (concluintes/evadidos) de } \\
\text { treinamentos a distância, } \\
\text { mediados pela web. }\end{array}$ & $\begin{array}{l}626 \text { estudantes } \\
\text { egressos de } \\
\text { treinamentos } \\
\text { fornecidos pela } \\
\text { Embrapa aos seus } \\
\text { empregados. }\end{array}$ & $\begin{array}{l}\text { Questionário } \\
\text { "Características do } \\
\text { Curso a Distância"; } \\
\text { Questionário } \\
\text { "Características do } \\
\text { Aluno"; } \\
\text { Questionário } \\
\text { "Características do } \\
\text { Contexto do Aluno"; }\end{array}$ & $\begin{array}{l}\text { Análises } \\
\text { exploratórias; } \\
\text { Análises de } \\
\text { confiabilidade } \\
\text { (Alpha de } \\
\text { Cronbach); } \\
\text { Análises de } \\
\text { regressão } \\
\text { logística; } \\
\text { Extração } \\
\text { dos fatores } \\
\text { principais; }\end{array}$ & $\begin{array}{l}\text { Os resultados indicam uma relação } \\
\text { positiva entre domínio de ferramentas } \\
\text { tecnológicas por parte do alunado e a } \\
\text { conclusão de ações educacionais a } \\
\text { distância; } \\
\text { Auto-avaliações favoráveis em } \\
\text { relação às variáveis disciplina/interesse } \\
\text { pelo curso e reações ao desempenho do } \\
\text { tutor apontam para chances mais elevadas } \\
\text { de conclusão dos treinamentos; } \\
\text { - Percepções positivas no tocante às } \\
\text { variáveis tempo disponível para o } \\
\text { curso e questões familiares } \\
\text { encontram-se negativamente ligadas } \\
\text { à evasão; }\end{array}$ \\
\hline
\end{tabular}


Tabela 15. Resultados de pesquisas nacionais e internacionais sobre "Fatores Relacionados à Evasão e Persistência em EAD” (continuação).

\begin{tabular}{|c|c|c|c|c|c|}
\hline Autores & Objetivo & Amostra/Contexto & $\begin{array}{l}\text { Procedimentos de } \\
\text { coleta de dados }\end{array}$ & $\begin{array}{l}\text { Procedimentos } \\
\text { de análise de } \\
\text { dados }\end{array}$ & Resultados \\
\hline $\begin{array}{l}\text { Pacheco, Rissi, } \\
\text { Nakayama, } \\
\text { Silveira \& Spanhol } \\
\text { (2010) }\end{array}$ & $\begin{array}{l}\text { Investigar a desistência } \\
\text { estudantil nos Estados } \\
\text { gerenciados pela } \\
\text { Universidade Federal de } \\
\text { Santa Catarina (UFSC) }\end{array}$ & $\begin{array}{l}\text { Aproximadamente } 15 \\
\text { mil indivíduos } \\
\text { envolvidos } \\
\text { (estudantes, } \\
\text { orientadores, tutores) } \\
\text { no Projeto Aluno } \\
\text { Integrado, âmbito da } \\
\text { UFSC }\end{array}$ & $\begin{array}{l}\text { Análises documentais } \\
\text { (relatórios, banco de } \\
\text { dados do curso, } e \text { - } \\
\text { mails emitidos e } \\
\text { fóruns); } \\
\text { Entrevistas; }\end{array}$ & $\begin{array}{l}\text { Análises de } \\
\text { conteúdo; } \\
\text { Análises } \\
\text { descritivas; }\end{array}$ & $\begin{array}{l}\text { Entre os fatores responsáveis pela } \\
\text { ocorrência de evasão destacam-se: } \\
\text { (a) falhas no planejamento do curso; } \\
\text { (b) problemas de navegabilidade do AVA } \\
\text { (ex. lentidão e dificuldades de acesso; } \\
\text { (c) informações equivocadas acerca da } \\
\text { modalidade EAD; } \\
\text { (d) desmotivação do estudante; } \\
\text { (e) dificuldades do aluno em gerenciar o } \\
\text { tempo de estudo; }\end{array}$ \\
\hline $\begin{array}{l}\text { Varanda et al. } \\
(2010)\end{array}$ & $\begin{array}{l}\text { Avaliar o papel } \\
\text { desempenhado pelas } \\
\text { interações firmadas entre } \\
\text { estudante-professor- } \\
\text { colegas e pela } \\
\text { interatividade do ambiente } \\
\text { de estudo nos processos de } \\
\text { aprendizagem }\end{array}$ & $\begin{array}{l}1.892 \text { inscritos no } \\
\text { curso Iniciando um } \\
\text { Pequeno Grande } \\
\text { Negócio (IPGN) } \\
\text { ofertado via internet } \\
\text { pelo SEBRAE }\end{array}$ & $\begin{array}{l}\text { Escala de "Reações à } \\
\text { Interface Gráfica do } \\
\text { Curso" (15 itens) }\end{array}$ & $\begin{array}{l}\text { Análises } \\
\text { descritivas; } \\
\text { Análise fatorial } \\
\text { exploratória; }\end{array}$ & $\begin{array}{l}\text { Diferenças quanto às características } \\
\text { de uso da interface gráfica entre a amostra } \\
\text { considerada e a população total de } \\
\text { estudantes do IPGN são insípidas. }\end{array}$ \\
\hline
\end{tabular}


Tabela 15. Resultados de pesquisas nacionais e internacionais sobre "Fatores Relacionados à Evasão e Persistência em EAD" (conclusão).

\begin{tabular}{|c|c|c|c|c|c|}
\hline Autores & Objetivo & Amostra/Contexto & $\begin{array}{l}\text { Procedimentos de } \\
\text { coleta de dados }\end{array}$ & $\begin{array}{c}\text { Procedimentos } \\
\text { de análise de } \\
\text { dados }\end{array}$ & Resultados \\
\hline $\begin{array}{l}\text { Iglesias \& Salgado } \\
\text { (2012) }\end{array}$ & $\begin{array}{l}\text { Comparar a efetividade de } \\
\text { duas distintas modalidades } \\
\text { de ensino: treinamento em } \\
\text { sala de aula e treinamento } \\
\text { por videoconferência }\end{array}$ & $\begin{array}{l}561 \text { indivíduos } \\
\text { desempregados } \\
\text { matriculados em } \\
\text { cursos de } \\
\text { empreendedorismo } \\
\text { ofertados pelo } \\
\text { Instituto Gallego para } \\
\text { la Promoción } \\
\text { Económica of the } \\
\text { Xunta de Galicia }\end{array}$ & $\begin{array}{l}\text { Onze escalas do tipo } \\
\text { Likert que } \\
\text { consideravam } \\
\text { aspectos do } \\
\text { treinamento (interesse } \\
\text { e relevância; clima; } \\
\text { qualidade; sala; } \\
\text { informação; } \\
\text { participação; } \\
\text { explicações do } \\
\text { instrutor; estilo do } \\
\text { instrutor; } \\
\text { possibilidades de } \\
\text { interação com o } \\
\text { instrutor; adequação } \\
\text { do instrutor ao curso; } \\
\text { nível de competência } \\
\text { do instrutor }\end{array}$ & $\begin{array}{l}\text { Análises } \\
\text { descritivas; } \\
\text { Análises de } \\
\text { confiabilidade; }\end{array}$ & $\begin{array}{l}\text { Os resultados encontrados indicam } \\
\text { que as modalidades consideradas } \\
\text { apresentaram elevados índices de } \\
\text { efetividade, caracterizando ambas como } \\
\text { valiosas e válidas opções para programas } \\
\text { instrucionais; } \\
\text { - Em circunstâncias nas quais os } \\
\text { conteúdos didáticos são os mesmos, os } \\
\text { participantes não identificam diferenças se } \\
\text { eles são transmitidos face a face ou por } \\
\text { meio de videoconferência; } \\
\text { - Em situações de aprendizagem a } \\
\text { distância, o elemento "tutor" pode } \\
\text { desempenhar papel chave na efetividade de } \\
\text { programas de tal natureza; }\end{array}$ \\
\hline
\end{tabular}


Observando a Tabela 15, é possível verificar o crescente interesse envolvendo a compreensão dos elementos que podem contribuir para a permanência/evasão dos alunos em ações educacionais não presenciais. Esta tendência é refletida na produção de pesquisas, tanto nacionais como estrangeiras, dedicadas ao estudo sistemático dos referidos fatores, focalizando uma multiplicidade de cenários, populações, instrumentais de medida e técnicas analíticas (Abbad et al., 2006; Almeida, 2007; Amidani, 2004; Brauer, 2005; Coelho, 2003; Favero \& Franco, 2006; Henke \& Hussum, 2000; Holder, 2007; Ngoma et al., 2004; Pierrakeas, Xenos, Panagiotakopoulos \& Vergidis, 2004; Sales, 2009; Shin \& Kim, 1999; Silva \& Tomaz, 2006; Tucho, 2000; Varanda et al., 2010; Vargas, 2004; Xenos et al., 2002; Walter, 2006; Walter, 2008; Wang et al., 2003; Yukselturk \& Inan, 2006).

A maior parte das pesquisas voltadas ao estudo das variáveis intervenientes em EAD empregam escalas e questionários digitais administrados virtualmente junto às amostras consideradas. Entre o conjunto de estudos levantados, é possível identificar variações no que tange a abordagem científica utilizada; desta feita, observam-se trabalhos de cunho quanti e qualitativo. Os procedimentos analíticos compreenderam desde técnicas estatísticas descritivas e inferenciais, até análises de conteúdo. De modo geral, os estudos empreendidos buscam angariar dados que evidenciem quais variáveis exercem interferência sobre a decisão do estudante em permanecer ou não no evento instrucional cursado a distância. Em suma, as pesquisas revelam que as variáveis dificultadores à conclusão dos cursos a distância são muitas e de natureza variada, tais como aquelas da ordem do indivíduo que aprende, do próprio curso e do ambiente de estudo do discente.

Em relação aos fatores concernentes ao estudante que desenvolve ações de aprendizagem a distância, a literatura aponta para variáveis como: capacidade de gerenciamento do tempo dedicado ao estudo, experiências educacionais prévias envolvendo a EAD, habilidade com a escrita digital e com as ferramentas tecnológicas utilizadas e dados sociodemográficos.

Para diversos autores, a capacidade do estudante em gerenciar o próprio tempo destinado às atividades educacionais associa-se diretamente à permanência do mesmo no curso (Silva \& Tomaz, 2006; Xenos et al., 2002; Walter, 2008; Wang et al., 2003). Em sentido inverso, a carência de habilidades que tornam o estudante capaz de organizar sua rotina pode levá-lo a abandonar a ação online (Almeida, 2007; Pierrakeas et al., 2004; Coelho, 2003). Autonomia enquanto discente, a autodisciplina e a maturidade foram outros requisitos considerados necessários aos aprendizes virtuais (Palloff \& Pratt, 2004; Silva \&Tomaz, 2006). 
Diversas pesquisas indicaram que habilidades, experiências e frequência de uso dos recursos e instrumentais tecnológicos disponibilizados nos AVAs podem atuar sobre a decisão de abandonar ou não um curso virtual (Abbad et al., 2006; Almeida, 2007; Abbad et al., 2006; Carvalho, 2003; Coelho, 2003; Palloff \& Pratt, 2004; Vargas, 2004; Xenos et al, 2002). Possivelmente, a falta de contato prévio e de habilidade com o uso das estruturas tecnológicas dos cursos são um dos principais fatores que influenciam os participantes a desistirem do mesmo (Silva \& Tomaz, 2006). A literatura também menciona deficiências no repertório acadêmico e contato limitado com o ensino a distância como fatores ligados a não permanência de discentes em ações virtuais de ensino (Amidani, 2004; Sales, 2009; Walter, 2008).

Tal como mencionado, aspectos sociodemográficos dos alunos a distância também foram considerados nas investigações acerca dos fatores ligados à persistência e desistência em EAD. Resultados de pesquisa considerando as variáveis idade e gênero são pouco conclusivos e consistentes (Brauer, 2005; Coelho, 2003; Pierrakeas et al., 2004; Xenos et al., 2002; Wang et al., 2003); por outro lado, foram identificadas correlações positivas envolvendo o nível de escolaridade do aprendiz, motivação e permanência em cursos a distância (Almeida, 2007; Brauer, 2005; Curless, 2004; Nesler, 1999; Petty, Johnston \& Shafer, 2004; Wang et al., 2003). Nesse sentido, torna-se importante que os profissionais responsáveis pelo desenho instrucional e pela ministração de cursos a distância cuidem para que as estratégias e recursos utilizados captem a atenção do aprendiz, façam-os perceber a instrução como relevante, satisfaçam-os com os cursos realizados e desenvolvam confiança no alcance de resultados de aprendizagem positivos (Curless, 2004). Outros fatores, como dificuldades financeiras associadas ao custeamento dos cursos (ABRAEAD, 2007; Yukselturk \& Inan, 2006), não correspondência do curso às expectativas iniciais dos aprendizes (Coelho, 2003) e receio de não ser aprovado (Smith, 1987, citado por Ngoma et al., 2004), também influenciariam a continuidade ou não na modalidade EAD.

No tocante aos fatores relativos ao meio que circunda o aluno, as pesquisas desenvolvidas convergem para o ajustamento do ambiente familiar e laboral e demais aspectos que, se fazendo presentes no cotidiano do estudante, podem exercer influência sobre seus estudos. Alguns estudiosos propõem que compromissos e eventos domésticos/profissionais devem contribuir e estar, consequentemente, associados à escassez de tempo reservado ao estudo e cumprimento de atividades escolares (Pierrakeas et al., 2004; Wang et al., 2003). Sobre uma perspectiva distinta, outros pesquisadores consideram que o 
problema reside não na falta de horários, mas sim na incapacidade do estudante a distância de conceder primazia às tarefas e eventos necessários ao desenvolvimento do curso - relegar a segundo plano as atividades acadêmicas possibilita que outros compromissos ou responsabilidades do indivíduo sejam destacados, resultando em não comparecimentos, demoras na participação em tarefas colaborativas, falta de engajamento à rotina do curso, entre outros (Silva \& Tomaz, 2006).

Segundo alguns trabalhos levantados, a frequente menção à falta de tempo para se dedicar ao curso pode ser, na verdade, produto de outras complicações enfrentadas pelos aprendizes, tais como: dificuldades de adaptação à nova realidade instrucional, desorganização pessoal, más condições de estudo em casa, falta de ambiente apropriado no local de trabalho, problemas técnicos e não atendimento das expectativas pessoais. Ainda é possível associar a questão da falta de tempo ao fator novidade, uma vez que a movimentação no novo espaço educacional e o ajuste à nova temporalidade advinda do ambiente virtual requer aprendizado e organização pessoal (Coelho, 2003).

A precariedade de condições para o estudo no lar, somada ao surgimento de imprevistos familiares, nascimentos/gestações não planejadas, separações, mortes/enfermidades, entre outros, intensifica as pressões domésticas vivenciadas pelo aluno e o torna mais suscetível à decisão de interromper seu programa educacional (Yukselturk \& Inan, 2006; Coelho, 2003; Xenos et al., 2002; Tucho, 2000). Em relação aos fatores situados no ambiente laboral dos estudantes a distância ligados à permanência em cursos de tal natureza, a literatura menciona o excesso de tarefas, pressões constantes, condições físicas e materiais (Almeida, 2007; Vargas, 2004; Coelho, 2003; Tucho, 2000; Xenos et al., 2002). Neste sentido, alunos que apenas se dedicam aos estudos, em comparação àqueles que desempenham atividades profissionais, apresentam chances mais elevadas de permanecerem nos cursos iniciados (Tucho, 2000).

Por fim, os resultados de pesquisa descrevem uma série de elementos próprios aos cursos a distância associados, em maior ou menor grau, ao abandono/permanência do estudante. São eles: desempenho do tutor; desenho instrucional do curso; estilos de aprendizagem; complexidade das tarefas demandas pelo curso; suporte psicossocial e institucional prestado ao estudante e ao professor; entre outros (Almeida, 2007; Frankola, 2001; Holder, 2007; Ihamaki \& Vilapola, 2004; Maia, 2003; Silva \& Tomaz, 2006; Simpson, 2004; Tyler-Smith, 2006; Xenos et al., 2002; Wang et al., 2003).

Em relação ao fator suporte ao estudante, Rovai (2002), em ensaio teórico versando 
sobre a persistência de indivíduos no e-learning, elegeu a noção de pertencimento ao grupo como um dos elementos que contribuem para a sua estadia em cursos nesta modalidade. Para o autor, essa percepção opõe-se ao distanciamento físico próprio da EAD que, por sua vez, favorece a não permanência do aluno. Neste sentido, Fávero e Franco (2006) defendem a relevância de um AVA interativo, uma vez que grande parte da clientela de EAD experimenta como sensação comum a solidão, ou seja, uma impressão de desamparo que se estende durante todo o curso e se intensifica em situações de pouca ou nenhuma interação entre os agentes desse processo.

Em resumo, o levantamento bibliográfico acerca de fatores relacionados à evasão e à persistência em ações educacionais ofertadas a distância apresenta indicativos do relevante papel desempenhado por variáveis presentes no curso, no próprio aluno e no ambiente de estudo para a compreensão das razões que podem levar os indivíduos a malograrem em suas investidas educacionais. Todavia, o número de investigações dedicadas ao esclarecimento de tais relações ainda se faz insuficiente. São necessários maiores esforços de pesquisa para o desenvolvimento e validação de instrumentos de medida aptos à identificar e mensurar elementos preditores de tais variáveis em ações de e-learning. As preocupações também se estendem às ferramentas já elaboradas, que não só carecem de adaptações propostas pelos respectivos autores, como também necessitam ser revistas em termos de quantidade, redação e fatores contemplados.

Apesar desses e de outros achados, os estudos empíricos na área ainda são pouco extensos e conclusivos, de modo que é justificável a realização de investigações que se proponham a avaliar mais detidamente variáveis preditivas dos fatores relacionados à evasão e persistência discente no ensino não presencial. De acordo com Ngoma et al. (2004) o campo de estudos de EAD ainda não conta com um número satisfatório de modelos teóricos ou conceituais que apresentem suficiente validade preditiva para os fenômenos que se fazem presentes e afetam tal cenário. Dessa forma, fica clara a necessidade de desenvolvimento de novos trabalhos que não se detenham apenas na identificação de variáveis preditoras de elementos relacionados à evasão e à permanência em EAD, mas que proponham modelos teóricos para avaliação desta modalidade de ensino que tanto padece com os agravos já mencionados. 


\section{CAPÍTULO 4. CARACTERÍSTICAS METODOLÓGICAS DA PESQUISA}

\section{Objetivo do capítulo 4}

O presente capítulo se propõe a descrever a delimitação do problema, a justificativa e os objetivos da pesquisa, retratar o modelo de investigação, e apresentar as características das instituições de ensino superior participantes, os cursos e disciplinas avaliados, da população e amostras, dos instrumentos de medida, assim como, dos procedimentos de coleta e análise estatística dos dados.

\subsection{Delimitação do problema, objetivos de pesquisa e modelo de investigação}

A partir da apreciação das questões empíricas que permeiam o campo literário nacional e estrangeiro em treinamento, desenvolvimento e educação, com foco no subsistema de avaliação de treinamento e em agendas de pesquisas de investigações anteriores que se voltaram a essa temática, o problema de pesquisa deste estudo foi delimitado.

A partir da revisão de literatura, percebe-se que apesar dos benefícios e do crescimento experimentado pelos programas de $\mathrm{EAD}$, ainda são poucos os estudos que se dedicam a investigar de forma sistemática a efetividade de treinamentos a distância. Constata-se a urgente necessidade de refinamento da modalidade no que tange ao desenvolvimento dos docentes, à adaptação dos cursos ao ambiente de estudo dos alunos, ao emprego adequado das novas ferramentas disponíveis, às estratégias de aprendizagem e hábitos de estudo do aprendiz. Todos esses elementos possivelmente se encontram relacionados aos desafios instrucionais registrados e dificultam os retornos aos altos investimentos na implementação dessa modalidade de ensino. Nesse sentido, o presente estudo pretende fornecer elementos que auxiliem na compreensão dos fatores que historicamente vêm sendo ligados ao abandono/persistência acadêmica no ensino não presencial, sendo analisadas, para tanto, as possíveis relações existentes entre a variável critério fatores relacionados à evasão e persistência em EAD (contexto de estudo, desenho do treinamento e características internas do estudante) e as variáveis antecedentes pertencentes às características da clientela (dados sociodemográficos e estratégias de aprendizagem), como mostra a Figura 11. 
1. Características da Clientela

1.1. Estratégias de Aprendizagem

1.2. Dados Sociodemográficos

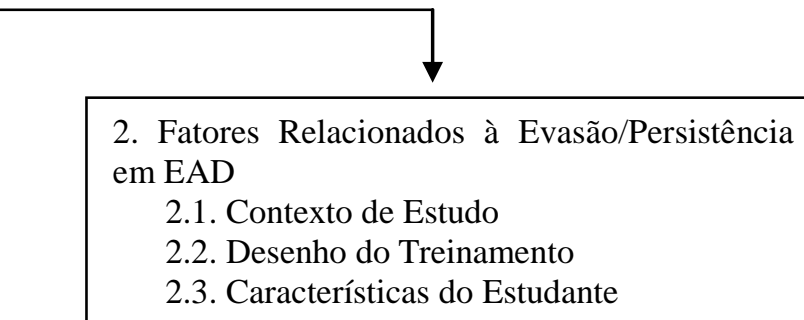

2. Fatores Relacionados à Evasão/Persistência em EAD

2.1. Contexto de Estudo

2.2. Desenho do Treinamento

2.3. Características do Estudante

Figura 11. Modelo de investigação proposto.

Em decorrência do modelo ora apresentado, são propostos os seguintes problemas de pesquisa:

1. Qual é o perfil da clientela em EAD quanto aos dados sociodemográficos?

2. Quais são as estratégias de aprendizagem utilizadas pelos alunos em cursos desta natureza?

3. Em que medida tais variáveis se relacionam a fatores dificultadores/favorecedores da permanência discente no curso?

Com o intento de responder às questões empíricas acima elencadas, foram estabelecidos os objetivos da pesquisa, apresentados a seguir.

\section{Objetivo Geral}

Propor e testar um modelo de avaliação de ações educacionais ofertadas a distância, objetivando identificar variáveis preditoras de fatores relacionados à evasão e persistência em EAD (contexto de estudo, desenho do treinamento e o próprio estudante) relacionadas às características da clientela (dados sociodemográficos e estratégias de aprendizagem).

\section{Objetivos Específicos}

- Adaptar e verificar evidências de validade na Escala de Fatores Relacionados à Evasão e à Persistência em EAD (Sales, 2009).

- Verificar evidências de validade na Escala de Estratégias de Aprendizagem de Martins (2012).

- Identificar as estratégias de aprendizagem utilizadas pelos alunos ao longo da ação 
educacional.

- Identificar o contexto de estudo do aluno do curso a distância, analisando potenciais elementos dificultadores/favorecedores de sua permanência no mesmo.

- Analisar o perfil da clientela de ações educacionais a distância.

\subsection{Características das instituições de ensino superior}

Em razão das dificuldades vivenciadas no processo de captação de parcerias de pesquisa, houve a necessidade de se contar com a associação de três diferentes organismos educacionais. A primeira instituição partícipe da presente pesquisa é uma universidade de caráter privado ofertante de cursos de graduação na modalidade a distância no Estado de São Paulo. Tal estabelecimento encontra-se situado na região de Ribeirão Preto e apresenta uma considerável história no ensino de nível superior, além de ministrar cursos superiores em EAD. Após deliberação do corpo profissional responsável, a instituição parceira optou por ter sua identidade preservada, de modo que no estudo não serão prestadas informações que transgridam tal determinação. A fim de ter sua identificação facilitada, esta universidade passará a ser tratada como instituição parceira A.

O contato com a mesma se deu por meio de sua coordenadora pedagógica e foi agendada uma reunião, na qual foram detalhados os objetivos da pesquisa e os procedimentos que seriam empregados. O material utilizado para tal apresentação, juntamente com o projeto de pesquisa, foi encaminhado à referida profissional, a qual concordou com a realização do estudo.

O desenvolvimento do trabalho e das ações de pesquisa foi principiado a partir da celebração de um convênio acadêmico entre a Universidade de São Paulo e a instituição parceira A. Tal documento visa a cooperação acadêmica na área de pesquisa, tendo por objetivo o partilhamento de esforços entre os compartes mediante a utilização de seus recursos humanos, tecnológicos, científicos e materiais disponíveis para a execução da presente investigação, e na permissão para o levantamento e emprego de dados relacionados a cursos a distância via internet ofertados pela instituição parceira, e seus efeitos sobre evasão e permanência acadêmica.

Nesta instituição são ofertados os seguintes cursos de graduação na modalidade a 
distância: Administração, Análise e Desenvolvimento de Sistemas, Ciências Contábeis, Ciências Sociais, Gestão Ambiental, Gestão Financeira, Gestão Pública, Gestão de Recursos Humanos, Logística, Marketing, Processos Gerenciais, Letras, Pedagogia, Sistema de Informação, Teologia e também o Programa de Integralização de Créditos em Teologia. Todos os cursos mencionados preveem semanalmente a ministração de teleaulas presenciais transmitidas, via satélite, sempre no período matutino ou noturno, pelo estúdio da universidade localizado na cidade de São Paulo.

A segunda universidade parceira cooptada consiste na própria Universidade de São Paulo - USP. A proposta de trabalhar em âmbito da instituição de ensino superior da qual deriva o presente trabalho partiu de uma profissional que integra o corpo docente do departamento de Psicologia da Faculdade de Filosofia, Ciências e Letras - FFCLRP-USP. A referida docente, por ter uma atuação intensa no curso "Licenciatura em Ciências" da USP, teceu a sugestão de que esta ação instrucional fosse também investigada. Dessa feita, foi solicitada ao corpo administrativo competente permissão para coleta e utilização de dados advindos do referido curso. Após o deferimento do pedido, foram iniciadas as ações metodológicas necessárias.

O curso "Licenciatura em Ciências", de feitio semipresencial, passou a ser ministrado pela USP visando satisfazer uma demanda de aperfeiçoamento nas etapas do Ensino Fundamental e Médio paulistas, e está incluso no Programa Universidade Virtual do Estado de São Paulo (UNIVESP). Por meio de tal iniciativa, a universidade em questão pretende fomentar a preparação de recursos humanos altamente qualificados que, consequentemente, concorrerão para o desenvolvimento da coletividade. Segundo informações constantes no site do referido curso, pelo fato de os modelos tradicionais de ensino superior presencial guardarem limitações no tocante a uma formação mais personalizada e flexível, a USP compreende que ações instrucionais ofertadas a partir das modalidades a distância ou semipresencial operam como alternativas factíveis e, neste sentido, não só contribuem para o processo de democratização do ensino nacional, bem como suplementam medidas governamentais de capacitação e qualificação dos professores do Ensino Fundamental.

O curso Licenciatura em Ciências destina-se ao preparo de indivíduos que desejam se tornar aptos à prática do magistério no Ensino Fundamental ou de docentes atuantes na Educação Básica. Atualmente, são oferecidas 360 vagas distribuídas entre polos estabelecidos em diversas cidades do estado de São Paulo, tais como: São Paulo, São Carlos, Ribeirão Preto, Piracicaba, Jaú, Lorena e Santos. Vale mencionar que a forma de ingresso no curso 
ocorre por meio de concurso vestibular efetivado pela Fundação Universitária para o Vestibular (FUVEST). A fim de cumprir as deliberações previstas na Resolução CoG n ${ }^{\circ}$ $5539 / 2009$, bônus são adicionados nas notas da $1^{\mathrm{a}}$ e $2^{\mathrm{a}}$ fases de candidatos com o seguinte perfil:

- Professores sem curso superior completo, atuando em docência na Educação Básica nas redes públicas há pelo menos 2 anos - bônus: 12 \%;

- Portadores de diploma de conclusão de curso superior (público ou reconhecido), com experiência docente comprovada de, no mínimo, 2 anos na Educação Básica nas redes públicas, em qualquer área, e que não possuam licenciatura - bônus: 9 \%;

- Licenciados que, necessariamente, tenham experiência docente de pelo menos 2 anos em escolas das redes públicas - bônus: $6 \%$;

- Egressos do ensino médio, sem formação universitária, formados há, no mínimo, 10 anos - bônus: $3 \%$.

Por fim, a terceira instituição parceira é denominada Instituto de Ensino e Pesquisa em Administração - INEPAD, e encontra-se situada no sistema educacional privado. Tal entidade, criada no ano de 2003 a partir da conjugação de esforços entre professores, pesquisadores e profissionais do campo da Administração, opera em três distintos níveis de atuação: ensino, pesquisa e extensão organizacional. O contato com esta instituição também se deu por meio de uma docente do Departamento de Psicologia da FFCLRP-USP que detinha conhecimento acerca dos programas de formação oferecidos pelo INEPAD.

A parceria de pesquisa com tal organismo teve início com uma reunião agendada entre o Gerente de Ensino e o Supervisor de Desenvolvimento, PPCP e Produção do instituto, a pesquisadora e a docente que intermediou este contato. $\mathrm{O}$ encontro objetivou apresentar o estudo em questão, propor a associação no campo da pesquisa e estruturar um plano de trabalho a fim de orientar os procedimentos de coleta de dados.

O curso ministrado pelo instituto e considerado neste estudo corresponde a uma ação educacional de especialização, ou seja, trata-se de um MBA, e é denominado Gestão Estratégica. Curiosamente, a oferta deste curso se dá em parceria com a USP, uma vez que o INEPAD é contratado pela Fundação para Pesquisa e Desenvolvimento da Administração, Contabilidade e Economia - Fundace - como parceiro EAD para a oferta de MBAs a distância específicos.

Esta ação instrucional encontra-se voltada a profissionais detentores de diplomas em 
cursos de graduação, licenciatura e tecnólogos em diversificadas áreas, como: Estratégia, Finanças e Gestão de pessoas.

Na sequência são descritos os principais aspectos desses cursos, objetivando descrevelas em termos de seus elementos formais.

\subsection{Características dos cursos}

Intentando viabilizar a pesquisa ora apresentada, foram estabelecidas associações com todas as instituições de ensino ofertantes de cursos em EAD receptivas ao convite feito pela pesquisadora. Tendo em vista que cada instituição partícipe apresenta distintos perfis, foram convidados a participar do referido estudo indivíduos com características igualmente díspares. Tal dado torna-se digno de nota uma vez que o mesmo pode influir sobre os achados advindos dos processos analíticos empreendidos; desta forma, é ressaltada a importância de que as apreciações a serem tecidas levem em conta as propriedades singulares de cada estabelecimento educacional, bem como sua clientela ordinária.

Tal como já exposto, os cursos ministrados durante o desenvolvimento deste estudo e considerados pelo mesmo foram: Administração, Análise e Desenvolvimento de Sistemas, Ciências Contábeis, Ciências Sociais, Gestão Ambiental, Gestão Financeira, Gestão Pública, Gestão de Recursos Humanos, Logística, Marketing, Processos Gerenciais, Letras, Pedagogia, Sistema de Informação, Teologia (todos ofertados pela instituição parceira A), Licenciatura em Ciências (oferecido pela USP) e Gestão Estratégica (de responsabilidade do INEPAD em associação com a USP).

A Tabela 16 mostra algumas características específicas dos cursos investigados. 
Tabela 16. Características dos cursos oferecidos pelas instituições parceiras e avaliados na pesquisa (continua).

\begin{tabular}{|c|c|c|c|c|c|}
\hline Instituição Ofertante & Curso & Objetivo geral & Duração & Estrutura & Conteúdos \\
\hline \multirow{5}{*}{ Instituição parceira $A$} & Administração & $\begin{array}{l}\text { Formar profissionais habilitados à } \\
\text { empreender, atuar e gerir organizações e } \\
\text { negócios por meio de suas habilidades } \\
\text { interpessoais/comunicação e visão sócio- } \\
\text { política }\end{array}$ & 48 meses & 8 períodos & \multirow{5}{*}{$\begin{array}{l}\text { Administração por } \\
\text { meio de módulos } \\
\text { integrados de estudo }\end{array}$} \\
\hline & $\begin{array}{l}\text { Análise e } \\
\text { Desenvolvimento de } \\
\text { Sistemas }\end{array}$ & $\begin{array}{l}\text { Fundamentar o domínio das tecnologias } \\
\text { pertinentes ao campo da Ciência da } \\
\text { Computação (programação de } \\
\text { computadores/desenvolvimento de sistemas; } \\
\text { programação baseada em componentes; } \\
\text { desenvolvimento de sistemas para Web; } \\
\text { computação móvel; sistemas em rede; banco } \\
\text { de dados; programação gráfica 3D. }\end{array}$ & 24 meses & $\begin{array}{l}3 \text { módulos } \\
5 \text { períodos }\end{array}$ & \\
\hline & Ciências Contábeis & $\begin{array}{l}\text { Desenvolvimento de competências próprias à } \\
\text { área de conhecimento, tais como: legislações } \\
\text { tributárias e trabalhistas; mercado de capitais; } \\
\text { processos decisórios. }\end{array}$ & 48 meses & 8 períodos & \\
\hline & Ciências Sociais & $\begin{array}{l}\text { Fomentar a capacidade crítica de pesquisa e } \\
\text { reflexão do profissional apto a operar nas } \\
\text { diversas áreas sociais. }\end{array}$ & 36 meses & 6 períodos & \\
\hline & Gestão Ambiental & $\begin{array}{l}\text { Preparar o indivíduo para análises e } \\
\text { apreciações de laudos acerca da qualidade } \\
\text { ambiental; gerenciamento de riscos } \\
\text { ambientais; orientação quanto ao uso de } \\
\text { tecnologias limpas na resolução de problemas } \\
\text { com emissão de poluentes; elaborar projetos a } \\
\text { fim de recuperar áreas degradadas. }\end{array}$ & 24 meses & 15 módulos & \\
\hline
\end{tabular}


Tabela 16. Características dos cursos avaliados (continuação).

\begin{tabular}{|c|c|c|c|c|c|}
\hline Instituição Ofertante & Curso & Objetivo geral & Duração & Estrutura & Conteúdos \\
\hline \multirow{5}{*}{ Instituição parceira $A$} & Gestão Financeira & $\begin{array}{l}\text { Preparar profissionais para aturem no } \\
\text { planejamento financeiro, organização, } \\
\text { direçãa, captação e investimentos de recursos } \\
\text { de instituições empresariais, assim como } \\
\text { cuidar da análise de créditos/demonstrativos } \\
\text { contábeis, da manutenção de estoques, e do } \\
\text { acompanhamento dos fluxos de caixa. }\end{array}$ & 24 meses & 4 períodos & \multirow{5}{*}{$\begin{array}{l}\text { Administração por } \\
\text { meio de módulos } \\
\text { integrados de estudo }\end{array}$} \\
\hline & Gestão Pública & $\begin{array}{l}\text { Promover a formação de gestores capacitados } \\
\text { à integrarem equipes multidisciplinares em } \\
\text { distintos campos de atuação, tal como } \\
\text { governos, terceiro setor, movimentos sociais } \\
\text { e empresas privadas que mantenham relações } \\
\text { com o poder público. }\end{array}$ & 24 meses & $\begin{array}{l}16 \text { módulos } \\
4 \text { eixos }\end{array}$ & \\
\hline & $\begin{array}{l}\text { Gestão de Recursos } \\
\text { Humanos }\end{array}$ & $\begin{array}{l}\text { Propiciar condições à atuação em } \\
\text { organizações empresariais, bem como } \\
\text { instrumentalizar o aluno para a realização de } \\
\text { consultorias/desenvolvimento do próprio } \\
\text { negócio. }\end{array}$ & 24 meses & 4 períodos & \\
\hline & Letras & $\begin{array}{l}\text { Formar indivíduos aptos à realização de } \\
\text { atividades próprias ao ensino da língua } \\
\text { portuguesa em variados cenários (Ensino } \\
\text { Fundamental e Médio, cursinhos, escolas de } \\
\text { idiomas, campo de editoração) }\end{array}$ & 48 meses & 6 períodos & \\
\hline & Logística & $\begin{array}{l}\text { Desenvolver no aluno o domínio de conceitos } \\
\text { práticos do campo, por meio de uma visão } \\
\text { sistêmica de seus principais processos aliada } \\
\text { às estratégias de mercado, dentro de uma } \\
\text { política global de negócios. }\end{array}$ & 24 meses & 4 períodos & \\
\hline
\end{tabular}


Tabela 16. Características dos cursos avaliados (continuação).

\begin{tabular}{|c|c|c|c|c|c|}
\hline Instituição Ofertante & Curso & Objetivo geral & Duração & Estrutura & Conteúdos \\
\hline \multirow{4}{*}{ Instituição parceira A } & Marketing & $\begin{array}{l}\text { Formar profissionais aptos a responder as } \\
\text { demandas dos atuais cenários de mercado por } \\
\text { meio de capacidades de: } \\
\text { interpretação/operacionalização de } \\
\text { estratégias; planejamento e implantação de } \\
\text { sistemas de informação; elaboração de } \\
\text { projetos de comunicação integrada; } \\
\text { lançamento de novos produtos, entre outras. }\end{array}$ & 24 meses & 4 períodos & \multirow{4}{*}{$\begin{array}{l}\text { Administração por } \\
\text { meio de módulos } \\
\text { integrados de estudo }\end{array}$} \\
\hline & Pedagogia & $\begin{array}{l}\text { Habilitar o indivíduo para o exercício da } \\
\text { docência na Educação Infantil e nas Séries } \\
\text { Iniciais do Ensino Fundamental, bem como } \\
\text { para a gestão e avaliação dos sistemas de } \\
\text { ensino, escolas e demais espaços educativos. }\end{array}$ & 48 meses & 8 períodos & \\
\hline & Processos Gerenciais & $\begin{array}{l}\text { Preparar indivíduos para o gerenciamento de } \\
\text { micro, pequenas e médias empresas por meio } \\
\text { da estruturação de projetos/estratégias de } \\
\text { mercado. }\end{array}$ & 24 meses & 4 períodos & \\
\hline & Sistema de Informação & $\begin{array}{l}\text { Fornecer preparo para a atuação em cargos } \\
\text { gerenciais nas áreas de gestão de sistemas de } \\
\text { informação, desenvolvimento de software e } \\
\text { infraestrutura de Tecnologia da Informação. }\end{array}$ & 48 meses & 8 períodos & \\
\hline
\end{tabular}


Tabela 16. Características dos cursos avaliados (conclusão).

\begin{tabular}{|c|c|c|c|c|c|}
\hline Instituição Ofertante & Curso & Objetivo geral & Duração & Estrutura & Conteúdos \\
\hline Instituição parceira $A$ & Teologia & $\begin{array}{l}\text { Capacitar o aluno para o ministério pastoral, } \\
\text { o ensino e a pesquisa teológica. }\end{array}$ & 48 meses & 8 períodos & $\begin{array}{l}\text { Administração por } \\
\text { meio de módulos } \\
\text { integrados de estudo }\end{array}$ \\
\hline $\begin{array}{c}\text { Universidade de São } \\
\text { Paulo }\end{array}$ & $\begin{array}{l}\text { Licenciatura em } \\
\text { Ciências }\end{array}$ & $\begin{array}{l}\text { Habilitar professores atuantes na área de } \\
\text { Ciências na etapa do Ensino Fundamental. } \\
\text { Tal preparação a compreensão abrangente e } \\
\text { integrada das Ciências da Natureza e, ao } \\
\text { mesmo tempo, a postura como intelectual } \\
\text { crítico e reflexivo, apto a orientar e } \\
\text { estimular os alunos para o aprendizado } \\
\text { significativo das ciências. }\end{array}$ & 48 meses & 8 módulos & $\begin{array}{l}\text { Atividades formativas } \\
\text { são desenvolvidas } \\
\text { durante os módulos } \\
\text { estabelecidos, um por } \\
\text { semestre. }\end{array}$ \\
\hline INEPAD & Gestão Estratégica & $\begin{array}{l}\text { Desenvolver competências estratégicas e } \\
\text { oferecer repertório qualificado de } \\
\text { conhecimentos para profissionais que atuam } \\
\text { como gestores em organizações públicas e } \\
\text { privadas. }\end{array}$ & 18 meses & 7 módulos & $\begin{array}{l}\text { Conteúdos aplicados } \\
\text { desenvolvidos no } \\
\text { decorrer de cada ciclo } \\
\text { de aula previsto. }\end{array}$ \\
\hline
\end{tabular}


A partir da análise da tabela anterior apresentada é possível verificar grande heterogeneidade no que tange aos campos de conhecimento científico nos quais se encontram dispostos os cursos avaliados, bem como às características próprias aos mesmos, tal como tempo de duração, número de módulos e eixos temáticos trabalhados. De modo geral, os cursos considerados pelo presente estudo podem ser alocados em 4 grandes campos de concentração, a saber: Humanidades; Ciências; Tecnologia; e Gestão e Negócios.

Apesar de não ter sido exposto na Tabela 16, é importante mencionar alguns aspectos que subjazem as ações educacionais comentadas e, em vista disso, são relevantes ao entendimento das mesmas. Todas as informações a seguir foram retiradas dos sites das agências de ensino parceiras (licenciaturaciencias.usp.br; www.inepad.org.br).

No tocante aos cursos ofertados pela instituição parceira A convém dizer que os processos avaliativos que sustêm todos os mesmos se dão de modo presencial e ocorrem em datas previamente estabelecidas no calendário acadêmico, após aprovação dos colegiados competentes. As atividades avaliativas se dão ao longo de cada um dos módulos previstos para o curso em questão. Também são efetuadas ao término de cada período (semestre) avaliações que objetivam aferir e integrar todos os módulos estudados.

Tal como já foi explicitado, o evento instrucional ministrado pela USP, Licenciatura em Ciências, encontra-se organizado em 8 módulos, sendo que cada um deles apresenta duração de 1 semestre e é constituído por disciplinas ou temas de interesse. Há a possibilidade de que uma ou mais disciplinas/temas sejam ofertadas concomitantemente. As atividades formativas previstas - atividades web, leitura e encontros presenciais - contabilizam uma carga horária total de 2.835 horas, compreendendo:

- 405 horas presenciais dedicadas às Práticas como Componente Curricular;

- 403 horas ao Estágio Curricular Supervisionado;

- 210 horas destinadas às Atividades Acadêmico-Científico-Culturais;

- 1800 horas de atividades relacionadas com os Conteúdos Curriculares de Natureza Científico-Cultural, sendo 1470 horas desenvolvidas a distância.

A tabela abaixo apresenta de forma mais detalhada as temáticas desenvolvidas em cada módulo, assim como as respectivas cargas horárias. 
Tabela 17. Curso "Licenciatura em Ciências": estrutura e organização (continua).

Atividade

Capacitação Tutor

Capacitação Tutor/Disciplina

Capacitação Alunos

Capacitação dos alunos no Ambiente AVA;

Fundamentações matemáticas - Revisão e Cálculo;

Dinâmica do movimento dos corpos;

Módulo/Semestre 1: Terra e Universo

Matéria: organização e transformações;

Luz e ondas eletromagnéticas;

Céu;

Estrelas;

Evolução das Ciências: natureza dos conhecimentos científico, filosófico e do senso comum;

Laboratório Didático I;

$-$

$-$

$-$

Carga Horária 
Tabela 17. Curso "Licenciatura em Ciências": estrutura e organização (continuação).

Atividade

Módulo/Semestre 2: Ambiente na Terra

Módulo/Semestre 3: Vida e Meio Ambiente
Atmosfera: composição e propriedades; ar e vida; perturbações e ação humana;

Hidrosfera: Composição e propriedades; fonte de recursos; perturbações e ação humana; ciclos; modelos físicos. Geosfera: composição e propriedades; Solo e vida;

A Terra: clima e tempo; dias e estações do ano; determinantes geofísicos da organização da vida;

Fundamentações matemáticas; estudo de modelos; fundamentos de Estatística e Probabilidade;

Evolução das Ciências: Construção histórica e individual do conhecimento científico

Ser vivo características gerais: biomoléculas e funções vitais

Diversidade dos organismos: grupos de animais e plantas;

Fungos, bactérias e vírus;

Ciclos da natureza; Fotossíntese e cadeia alimentar;

História da vida no planeta;

A distribuição da vida no planeta; biomas; biodiversidade;

Bioenergética: transformações de energia nos seres vivos;

Estudo de modelos matemáticos pertinentes aos assuntos tratados neste módulo;

Fundamentos de Estatística Descritiva;

Introdução aos Estudos da Educação; 
Tabela 17. Curso "Licenciatura em Ciências": estrutura e organização (continuação).

Atividade

Tema

O Ser Humano e o Meio Ambiente: Introdução à Ecologia Humana;

Do indivíduo à comunidade: Conceitos ecológicos de população, comunidade, ecossistemas e biomas;

A homeostasia e o organismo humano;

Interações do ser humano com o meio ambiente;

Módulo/Semestre 4: Ser Humano e

Meio Ambiente sistema endócrino e sistema imunitário;

O Ser Humano e a Ontogênese: reprodução, desenvolvimento, crescimento, manutenção, envelhecimento e morte;

Alimentação e nutrição;

Atividade física e suas consequências sobre a saúde;

Estudo de modelos matemáticos e estatísticos vinculados a assuntos tratados neste Módulo;

Política e Organização da Educação Brasileira;

Introdução aos Estudos da Educação em Ciências; 
Tabela 17. Curso "Licenciatura em Ciências": estrutura e organização (continuação).

Atividade

Distribuição de doenças e de seus condicionantes em populações humanas;

A intervenção humana sobre o ambiente e suas consequências;

Módulo/Semestre 5: Ser Humano, Fenômenos sociais universais como cultura, socialização e organização social; Saúde e Sociedade

Métodos estatísticos: aplicações nas pesquisas em saúde pública, controle de doenças e epidemias;

Educação em Ciências: diferentes abordagens da ciência na prática docente;

Psicologia da Educação: desenvolvimento físico, psicológico, cognitivo e social

O ser humano e a transformação da Natureza;

Módulo/Semestre 6

Trabalho Humano, Tecnologia e

Sociedade

Ciência, Sociedade e Tecnologia;

Apropriação e transformação de recursos minerais, animais, vegetais pela sociedade, causas e consequências;

Perspectivas tecnológicas: engenharia genética, células tronco, nanotecnologia;

Educação em Ciências: diferentes abordagens da ciência na prática docente;

Didática: Organização do trabalho pedagógico/didático na escola; planejamento de ensino;
Módulo/Semestre 7: Estágio e

Trabalho de Conclusão de Curso

\section{Metodologia do Ensino de Ciências;}

Primeira fase de elaboração de um projeto de ensino em ciências: discussão, escolha e justificativa do tema do projeto; 
Tabela 17. Curso "Licenciatura em Ciências": estrutura e organização (conclusão)

Atividade

\section{Tema}

Carga Horária

Metodologia do Ensino de Ciências: teorias, abordagens e concepções pedagógicas relacionadas ao ensino de Ciências;

Segunda fase de elaboração de um projeto de ensino em ciências, estudo e discussão das bases teóricas; elaboração do projeto de ensino; análise e discussão dos resultados; redação e apresentação do trabalho;

: Estágio e

Apropriação e transformação de recursos minerais, animais, vegetais pela sociedade, causas e consequências;

Perspectivas tecnológicas: engenharia genética, células tronco, nanotecnologia;

Educação em Ciências: diferentes abordagens da ciência na prática docente;

Didática: Organização do trabalho pedagógico/didático na escola; planejamento de ensino; 
Segundo informações constantes no site do referido curso (licenciaturaciencias.usp.br) são necessárias, no mínimo, 10 horas semanais ( 2 horas por dia) para o cumprimento das tarefas online. Aos sábados são realizadas aulas presenciais (8-12h e 13h30-17h30) acerca dos temas/disciplinas previamente estabelecidos em calendário escolar; em tais momentos, educadores e docentes contam com a possibilidade de adotarem diferentes estratégias metodológicas tendo em vista as turmas e os conteúdos a serem trabalhos, exemplo: apresentação de nova temática durante aula presencial que antecede o estudo da mesma, ou revisão e síntese do objeto de interesse após a semana de estudos online. Ao final de cada um dos módulos estão previstas aulas laboratoriais (cerca de 7), nas quais são efetuadas experiências relativas aos tópicos considerados.

Por fim, no que diz respeito às atividades avaliativas - produtos/resultados de ações efetuadas no AVA (fóruns, tarefas discursivas, relatórios, exercícios) e produções derivadas de trabalhos presenciais postados após o desenvolvimento dos mesmos - estas podem ser consideradas pelo tutor válidas ou não dentro do prazo de dois dias a contar do momento da entrega. Neste processo de atribuição de "status" às atividades discentes o tutor deverá se atentar para os seguintes aspectos: a coerência das respostas emitidas frente à questão formulada e respeito aos prazos de entrega estabelecidos; sob algumas outras condições as produções podem ser consideradas inválidas, tais como: atividades em branco e conteúdos que encerrem materiais ilícitos.

Quanto à ação de MBA denominada "Gestão Estratégica", oferecida pelo INEPAD, esta possui uma carga horária total de 360 horas distribuídas entre atividades de leitura do material didático (aproximadamente 12 horas semanais), tarefas online, pesquisas e acompanhamento das aulas ao vivo (2 horas de duração) intituladas como "e-Aula @o Vivo". A entrega de tal produto se dá por meio da tecnologia de aula ao vivo via internet. Aos alunos, que participam do chat ao vivo, por meio do qual podem tecer perguntas aos docentes que os assistem e tê-las respondidas em tempo real, é requerido uso de computador com acesso à internet (banda larga, $512 \mathrm{kbps)} \mathrm{conectado} \mathrm{unicamente} \mathrm{à} \mathrm{aula} \mathrm{no} \mathrm{momento} \mathrm{de} \mathrm{sua}$ exibição. Os conteúdos ministrados ficam disponíveis para posteriores apreciações por meio de streamming na Midiateca (biblioteca de mídias digitais) institucional; é consentido ao discente assistir a $25 \%$ do curso em formato gravado, como forma de recuperação de frequência.

Considerando as necessidades específicas de sua clientela, o INEPAD adota alguns estímulos pedagógicos congregados em um modelo ilustrado pela figura a seguir: 


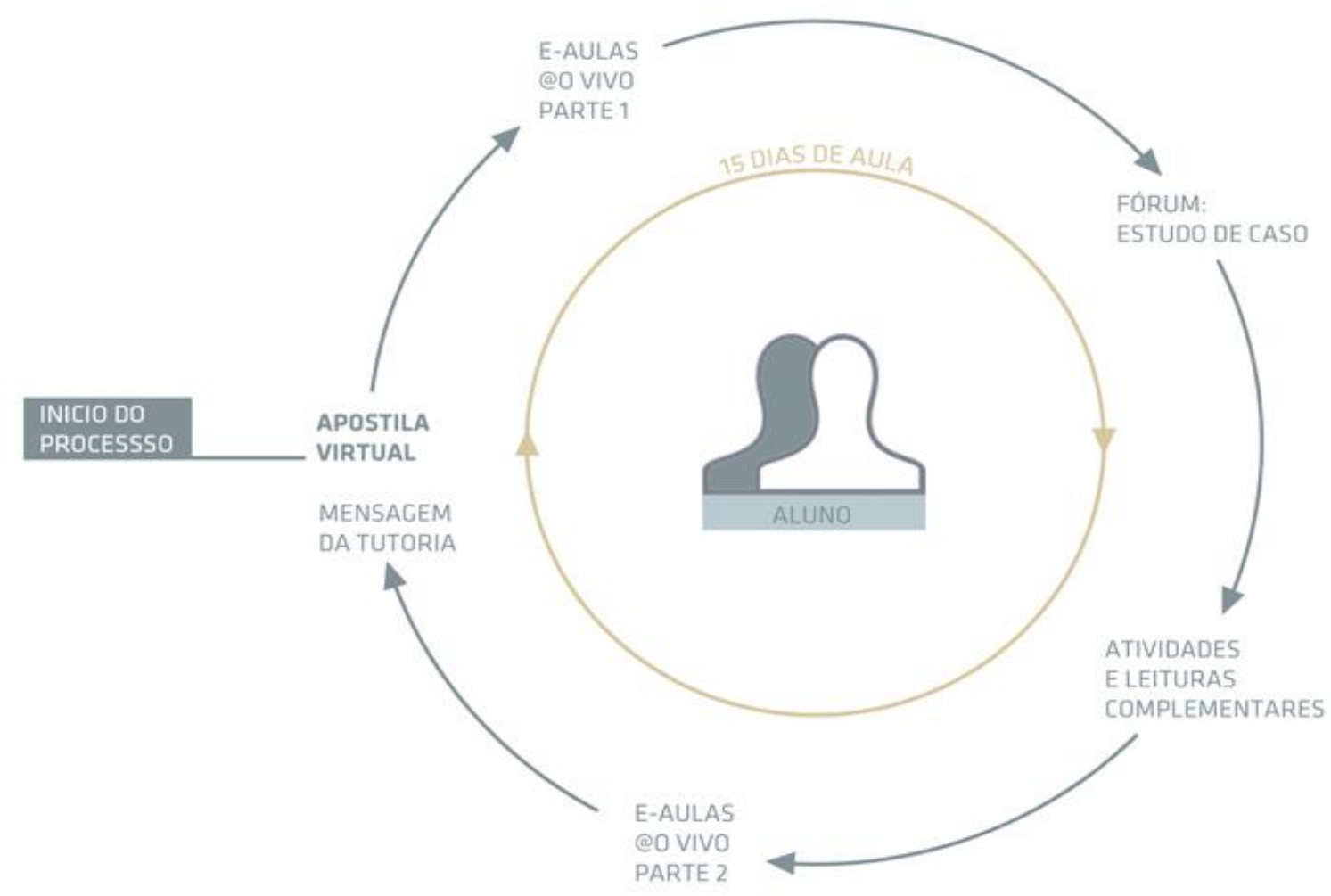

Figura 12: Esquema de organização didático-pedagógica do curso "Gestão Estratégica".

De acordo com o esquema adotado, todas as ações realizadas se estruturam dentro de um período de 15 dias, ou seja, espera-se que na primeira semana de cada um dos ciclos de aula o discente se ocupe com a leitura da apostila virtual (que traz informações indispensáveis ao entendimento dos conteúdos considerados e indica medidas alternativas que auxiliam os aprendizes na tarefa educacional) e acompanhe a $e$-Aula @o Vivo. O estudante deve ao término da semana elaborar uma questão a respeito dos conteúdos vistos e encaminhá-la ao docente contribuindo, desta forma, para a estruturação do próximo encontro. A conclusão dos ciclos se dá com a leitura, por parte do corpo discente, da Mensagem da Tutoria (postagem da tutoria que consolida todo o aprendizado) e conseguinte apreciação da qualidade da mesma.

Situações de interação presencial não são previstas durante o desenrolar das atividades supracitadas; somente para a realização das avaliações são previstos encontros face a face neste caso, o estudante se dirige até seu polo correspondente em data prevista no cronograma regular do curso. Considerando mais detidamente os conteúdos estudados durante o evento instrucional, pontua-se que as primeiras duas aulas são dedicadas à apresentação do sistema de ensino a distância, suas ferramentas e recursos, bem como do próprio curso. Subsequentemente, são ministradas as disciplinas de conteúdo aplicado. A sequência de 
módulos e disciplinas/aulas previstas em cada um deles é expressa na Tabela 18.

Tabela 18. Curso "Gestão Estratégica": estrutura e organização.

\begin{tabular}{|c|c|}
\hline Módulo & Disciplina/Aula \\
\hline Ambientação & Ambientação Partes 1 e 2; \\
\hline Administração e Contemporaneidade & $\begin{array}{l}\text { Perspectivas da Administração; } \\
\text { Perspectivas de Processo na Administração ; } \\
\text { Administração de Projetos; } \\
\text { Indicadores Como Instrumento de Tomada de } \\
\text { Decisão; } \\
\text { Ética e Sustentabilidade nas Organizações; } \\
\text { Inovação nas Organizações; } \\
\text { Empreendedorismo; }\end{array}$ \\
\hline Gestão de Pessoas & $\begin{array}{l}\text { Clima e Cultura; } \\
\text { Comportamento Organizacional; } \\
\text { Aprendizado e Gestão do Conhecimento; } \\
\text { Organizações em Rede; } \\
\text { Equipes de Alta Performance; }\end{array}$ \\
\hline Controladoria & $\begin{array}{l}\text { Matemática Financeira e Contabilidade Gerencial; } \\
\text { Orçamento Empresarial; } \\
\text { Planejamento e Controle Financeiro; }\end{array}$ \\
\hline Finanças de curto e longo prazo & $\begin{array}{l}\text { Administração de Custos e Alavancagem; } \\
\text { Administração do Capital de Giro; } \\
\text { Estratégias Financeiras de Curto e Longo Prazo; } \\
\text { Avaliação de Investimento e de Desempenho } \\
\text { Organizacional; } \\
\text { Análise de projetos; }\end{array}$ \\
\hline Finanças Estratégicas & $\begin{array}{l}\text { Gestão de Valor; } \\
\text { Gestão de Riscos (Operacional, Mercado e Crédito); } \\
\text { Valuation, Aquisições e fusões; } \\
\text { Visão Estratégica de Longo Prazo; } \\
\text { Competitividade e Sustentabilidade Financeira; }\end{array}$ \\
\hline Estratégia & $\begin{array}{l}\text { Marketing Estratégico e Branding; } \\
\text { Decisões estratégicas: preço, produto, distribuição e } \\
\text { comunicação; } \\
\text { Marketing de Relacionamento e Comportamento do } \\
\text { Consumidor; } \\
\text { Planejamento Estratégico Contemporâneo; } \\
\text { Balanced Scorecard; }\end{array}$ \\
\hline
\end{tabular}


A instituição mantém em seu ambiente virtual de aprendizagem os recursos midiáticos utilizados no processo de ensino-aprendizagem, além de disponibilizar por tal meio os conteúdos programáticos do curso. Desta forma, por intermédio do espaço web os estudantes podem obter acesso a diversos expedientes para aprendizagem, comunicação e avaliação, tais como:

- Materiais: correspondendo a todos os conteúdos transmitidos, os materiais podem ser documentos arquivados no servidor, páginas criadas por meio de editor de textos ou arquivos advindos de outros sites visualizados no AVA. Todos os materiais empregados a cada ciclo de aula encontram-se disponíveis, de modo cumulativo, na biblioteca virtual;

- Tarefas: descrições/enunciados de atividades (redações, projetos, relatórios, etc) a serem executadas pelo aluno;

- Chat: possibilita a ocorrência de discussões textuais via web em modalidade síncrona;

- Fóruns: cenário destinado à elaboração de discussões que visam o esclarecimento de dúvidas, reflexões aprofundadas envolvendo os objetos de estudo e aprimoramento do conhecimento; fóruns e chats são elementos que contam com a mediação de profissionais tutores que servirão como canais de ligação e para ponderações coletivas;

- Networking: expediente criado com vistas a favorecer o processo de integração do AVA e das redes sociais comumente utilizadas pelos estudantes, e por meio do qual docentes e alunos podem disponibilizar em seus perfis dados academicamente importantes e empreender buscas por interesse, localização, palavras-chave e interesse;

- Glossário: encerra listas de definições em feitio de dicionário ou como uma $F A Q$ (Frequently Asked Questions);

- Trabalhos em grupo a distância: estratégia pedagógica que fomenta a construção do conhecimento grupal, bem como o desenvolvimento de habilidades intra e interpessoais;

- Estudo de Caso (modalidade PBL - Problem Based Learning): visa à entrega e reflexão dos conteúdos de aprendizagem. As situações a serem consideradas são entregues no início do ciclo e discutidas, com o auxílio do tutor, ao longo dos 15 dias conseguintes.

- Mensagem da Tutoria: recurso utilizado pela tutoria para postagem de comentários ao término de cada ciclo de aula, finalizando, desta forma, o tópico estudado. Por meio da "mensagem da tutoria" é possível que os aprendizes tenham seus desempenhos comentados; que as melhores e mais fracas respostas do alunado sejam comentadas; sejam identificados os pontos fortes e fracos observados ao longo do ciclo; e que o tutor tenha 
seu desempenho avaliado - através da apreciação da qualidade da mensagem por ele emitida;

- Envio de Pergunta Preparatória: se dá na primeira semana de cada ciclo de estudo e por meio de tal questão os alunos devem expressar suas principais expectativas e conhecimentos quanto à temática que será trabalhada;

- Avaliação de Reação: indaga-se aos alunos aspectos como: atuação do professor de $e$ Aula@o Vivo, qualidade do material didático, desempenho da tutoria e condução da temática, entre outros;

- Atividades dos Finais de Semana: as tarefas perdidas no decorrer da semana podem ser recuperadas no final de semana imediatamente posterior ao período em que as mesmas ocorreram;

- Avaliações do Curso: são fundamentadas por meio da realização de atividades online (atividades ao longo do ciclo de aula e provas a distância) e provas presenciais. Para obtenção do certificado no curso é exigido que o aluno seja: aprovado nas disciplinas com média final igual ou maior a sete (7); aprovado nas disciplinas com frequência online igual ou maior a 85\%; e aprovado na defesa presencial do TCC.

\subsection{População e amostras}

Em relação aos dados sociodemográficos da população discente atendida pelas instituições partícipes foi possível delinear um perfil a partir das respostas ao questionário disponibilizado aos respondentes.

A amostra ora considerada é composta pelos estudantes inscritos em todos os cursos supracitados, que responderam ao questionário sociodemográfico totalizando $126^{2}$ alunos. Tais dados captados estão descritos na Tabela 19.

\footnotetext{
2 Vale pontuar que alguns questionários apresentaram preenchimento parcial, de modo tal que algumas informações relativas ao perfil sociodemográfico dos respondentes encontram-se não declaradas.
} 
Tabela 19. Perfil da amostra de alunos que estudam a distância nas universidades parceiras.

\begin{tabular}{|c|c|c|c|c|c|}
\hline Variável & $\mathbf{F}$ & $\%$ & Variável & $\mathbf{F}$ & $\%$ \\
\hline Sexo & & & Renda* & & \\
\hline Feminino & 60 & 49,2 & Até 1 & 9 & 8,6 \\
\hline Masculino & 62 & 50,8 & 2 a 3 & 28 & 26,7 \\
\hline Região geográfica & & & 4 a 5 & 17 & 16,2 \\
\hline Norte & 5 & 4,1 & 6 a 7 & 5 & 4,8 \\
\hline Nordeste & 5 & 4,1 & Acima de 7 & 46 & 43,8 \\
\hline Centro-Oeste & 4 & 3,3 & Estado civil & & \\
\hline Sudeste & 102 & 84,3 & Solteiro & 44 & 36,7 \\
\hline Sul & 5 & 4,1 & Casado & 76 & 63,3 \\
\hline Escolaridade & & & Idade & & \\
\hline Superior Incompleto & 47 & 38,8 & 19 a 24 & 6 & 5 \\
\hline Superior Completo & 74 & 61,2 & 25 a 30 & 26 & 21,8 \\
\hline Composição familiar & & & 31 a 36 & 33 & 27,7 \\
\hline Não tem fillhos & 53 & 43,4 & 37 a 42 & 24 & 20,2 \\
\hline Tem filhos & 69 & 56,6 & 43 a 48 & 19 & 16 \\
\hline Área de atuação laboral & & & 49 a 54 & 8 & 6,7 \\
\hline Humanas & 22 & 19,5 & Acima de 55 & 3 & 2,5 \\
\hline Exatas e Tecnologia & 17 & 15 & & & \\
\hline Gestão e Negócios & 31 & 27,4 & Média & 36,5 & \\
\hline Comércio e Autônomo & 32 & 28,3 & Desvio-padrão & 8,53 & \\
\hline Outros & 11 & 9,7 & Moda & 32 & \\
\hline Experiência anterior no & & & Mínimo & 19 & \\
\hline uso da internet & & & Máximo & 58 & \\
\hline Sim & 105 & 87,5 & & & \\
\hline Não & 15 & 12,5 & & & \\
\hline
\end{tabular}

$\mathrm{F}=$ Frequência absoluta e \%=Porcentagem

* Renda em salários mínimos

Apreciando os dados colhidos é possível verificar que a amostra é composta predominantemente por indivíduos do sexo masculino (50,8\%), casados $(63,3 \%)$, com filhos $(56,6 \%)$ e residentes na região sudeste $(84,3 \%)$. Em média, a amostra considerada possui 36,5 anos de idade ( $\mathrm{DP}=8,53)$, sendo 32 anos a idade que com mais frequência apareceu, 58 anos a máxima e 19 anos a mínima.

No tocante à formação educacional, a maior parcela de participantes declarou contar com o Ensino Superior Completo $(61,2 \%)$ - este dado permite pensar em um novo perfil de pessoas que ingressam em cursos educacionais a distância, ou seja, cada vez mais profissionais já graduados buscam novas formações como meio de incrementar ou atualizar suas competências laborais, e nesse cenário a EAD torna-se um estratégico expediente para tal clientela já responsável por diversas atribuições e responsabilidades.

Majoritariamente, todos os respondentes relataram possuir experiência prévia no uso da internet, denotando domínio das ferramentas e instrumentais utilizados nos ambientes virtuais. Vale ressaltar que a maioria dos respondentes $(43,8 \%)$ declararam contar com uma renda financeira de mais de 7 salários mínimos.

Vale pontuar que em vista da elevada heterogeneidade que perpassou as respostas dos 
participantes referentes à ocupação/profissão exercida pelos mesmos, optou-se pela definição e classificação de tais dados a partir de cinco grandes áreas de atuação laboral, a saber: Humanas (pedagogia, relações públicas, publicidade, direito, etc); Exatas e Tecnologia (engenharia, estatística, contabilidade, entre outros); Gestão e Negócios (administração, coordenação financeira, gerência, etc); Comércio e Autônomo (vendedor, bancário, representante comercial, etc); e, Outros. $\mathrm{Na}$ última categoria proposta foram inclusas atividades que não se encaixaram nos demais campos, tais como trabalhos temporários, de natureza informal, bem como aquelas relativas ao trabalho em casa (donas-de-casa) e ao estudo (estudantes). A maior parte da amostra relatou exercer atribuições ligadas ao comércio ou de caráter autônomo (28,3\%); todavia, o desempenho de funções pertinentes à gestão e negócios também figurou como expressivo $(27,4 \%)$.

Considerar a exiguidade da amostra participante torna-se deveras importante para a identificação das limitações da pesquisa ora apresentada. Infelizmente, a receptividade das instituições de ensino envolvidas com a educação a distância foi prejudicialmente reduzida. Apesar das diversas tentativas voltadas ao estabelecimento de parcerias de pesquisa, somente as instituições ora caracterizadas mostraram-se solícitas a cooperar e conjugar esforços visando a implementação do presente trabalho. Não obstante a prestimosa colaboração de pesquisa fornecida pelas universidades parceiras, é necessário ter em conta que se tratam de instituições/cursos de dimensões mais restritas na região de desenvolvimento do estudo. Somado a isso, as dificuldades em obter taxas de retorno significativas, já tão conhecidas e que obstaculizam os procedimentos de coleta de dados a distância, certamente contribuíram para a constituição de uma amostra relativamente representativa.

\subsection{Instrumentos de medida}

Os instrumentos de medida empregados na investigação são: 1) Estratégias de Aprendizagem (Martins, 2012); 2) Escala de Fatores Relacionados à Evasão e à Persistência em EAD (Sales, 2009). Tais instrumentos foram desenvolvidos e validados em pesquisas precedentes. A seguir, são apresentadas as informações referentes às estruturas empíricas de cada uma dessas escalas obtidas nos estudos correspondentes (Tabela 20). 
Tabela 20. Resumo das informações sobre os instrumentos utilizados na pesquisa.

\begin{tabular}{llcccc}
\hline \multicolumn{1}{c}{ Instrumento } & \multicolumn{1}{c}{ Escalas obtidas } & $\begin{array}{c}\mathbf{N}^{\mathbf{o}} \\
\text { itens }\end{array}$ & Alfa & $\begin{array}{c}\text { Cargas fatoriais } \\
\text { Mín. }\end{array}$ & Máx. \\
\hline & Desempenho do Tutor & 14 & 0,96 & 0,61 & 0,91 \\
& Desenho do Curso & 19 & 0,90 & 0,34 & 0,76 \\
Escala de Fatores & Disciplina e Interesse do Aluno & 9 & 0,89 & 0,41 & 0,86 \\
Relacionados à Evasão e à & Experiências e Habilidades & & & & \\
Persistência em EAD & Importantes para os Cursos a & 5 & 0,75 & 0,42 & 0,86 \\
(Sales, 2009) & Distância & & & & \\
& Tempo Disponível & 6 & 0,85 & 0,38 & 0,88 \\
& Apoio no Trabalho & 5 & 0,84 & 0,43 & 0,9 \\
& Questões Familiares & 5 & 0,72 & 0,38 & 0,77 \\
\hline \multirow{2}{*}{ Estratégias de } & Estratégias cognitivas & 15 & 0,90 & 0,33 & 0,72 \\
Aprendizagem (Martins, & Controle da emoção & 4 & 0,77 & 0,46 & 0,76 \\
$2012)$ & Estratégias autorregulatórias & 7 & 0,86 & $-0,50$ & $-0,69$ \\
& Busca de ajuda interpessoal & 3 & 0,68 & 0,45 & 0,69 \\
\hline
\end{tabular}

Uma vez que no estudo de Sales (2009) a ferramenta de medida correspondente aos fatores ligados à evasão e à persistência em EAD foi aplicada a uma amostra de sujeitos inscritos em ações instrucionais profissionalizantes gratuitas, tal questionário sofreu alterações tendo em vista seu ajustamento a contextos de formação superior a distância, detidamente, cursos de graduação. O instrumento de Martins (2012) foi derivado da escala proposta por Zerbini et al. (2005). A autora efetuou modificações na referida ferramenta a fim de também adaptá-la a cenários educacionais de nível superior.

O processo de adaptação e revalidação do instrumento de medida de Sales (2009) envolveu a aplicação da referida escala em uma amostra de estudantes a distância, atividade esta que ocorreu em um único momento - na quarta semana do mês de maio de 2012. Para tanto, a pesquisadora estruturou um encontro presencial com os respondentes na própria universidade parceira cuja duração foi de, aproximadamente, 20 minutos.

A fim de que os discentes avaliassem a precisão, clareza e objetividade, bem como a adequação das instruções da escala, estes foram orientados a realizarem a leitura e julgamento de cada item elencado. Todas as modificações sugeridas pelos participantes foram inseridas em um arquivo desenvolvido para este intento. As alterações propostas foram avaliadas por meio de análise e comparação com a versão do questionário aplicado e, quando consideradas alternativas mais adequadas para o aperfeiçoamento da escala, os itens sofreram a reelaboração necessária.

Após realizarem a leitura de cada item, os participantes da validação semântica julgaram e indicaram a substituição de palavras ou acréscimo de expressões que complementassem as variáveis expressas; foram apontadas dúvidas ou incertezas que se manifestaram no momento de responder à escala devido aos aspectos dúbios de alguns itens. 
No Capítulo 5, os resultados das adaptações dos instrumentos, bem como os processos de validação semântica e por juízes são apresentados.

\subsection{Considerações Éticas}

No que tange aos aspectos éticos para a realização de pesquisa, pontua-se que o projeto foi submetido à aprovação do Comitê de Ética em Pesquisa da Faculdade de Filosofia, Ciências e Letras de Ribeirão Preto (FFCLRP-USP). Obtido o consentimento necessário, deuse início aos procedimentos cabíveis à coleta de dados.

Previamente à aplicação dos questionários, os participantes receberam esclarecidos sobre os objetivos do estudo e seus procedimentos. Ademais, mediante assinatura de um Termo de Consentimento Livre e Esclarecido, aprovado pelo Comitê de Ética em questão, foi requerida ao respondente autorização quanto ao uso de suas informações no estudo, bem como lhe foi garantido a manutenção de sigilo e anonimato acerca de sua identidade e o caráter voluntário de sua participação.

\subsection{Procedimentos de coleta de dados}

O desenvolvimento do presente trabalho inclui a apresentação e a testagem de um modelo de avaliação de ações educacionais ofertadas a distância, objetivando identificar variáveis preditoras de fatores ligados à evasão e persistência em EAD relacionadas às características da clientela. Para o cumprimento de tais propósitos procedeu-se à administração de questionários a estudantes inscritos em variados programas de EAD das instituições de ensino superior parceiras. Tais ferramentas de medida eram destinadas ao levantamento das características sociodemográficas dos discentes, das estratégias de aprendizagem por eles empregadas durante o desenvolvimento do curso e dos possíveis fatores ligados à decisão de permanecer ou não no evento instrucional cursado.

Tendo em vista a participação de distintos agentes de ensino no presente estudo, não foi possível empreender a coleta de dados em um único momento - em virtude das diferenças 
entre calendários institucionais que marcaram o encerramento das atividades dos cursos. Em relação à instituição parceria A, as informações foram colhidas no período de 26 de novembro de 2012 a 15 de dezembro de 2012. Já a aplicação dos questionários entre os estudantes do curso "Licenciatura em Ciências - USP" ocorreu durante os dias 29 de junho a 10 de julho de 2013. Por fim, as ferramentas de medida utilizadas foram disponibilizadas aos discentes do curso de "Gestão Estratégica" do INEPAD no espaço de tempo de 23 de julho a 04 de agosto de 2013; nesta última instituição houve o prolongamento de tal processo em mais duas semanas, de forma que o mesmo veio a se encerrar definitivamente no dia 18 do mesmo mês e ano. A partir da Tabela 21 é possível verificar o índice de retorno dos instrumentais de pesquisa por instituição de ensino.

Tabela 21. Frequência e porcentagem de respostas dos alunos por instituição de ensino a cada questionário.

\begin{tabular}{lccc}
\hline \multicolumn{1}{c}{ QUESTIONÁRIO } & INSTITUIÇÃO PARCEIRA A & USP & INEPAD \\
\hline Sociodemográfico & 17 & 74 & 60 \\
\hline Estratégias de Aprendizagem & 17 & 74 & 60 \\
\hline $\begin{array}{l}\text { Fatores Relacionados à Evasão e à } \\
\text { Persistência em EAD }\end{array}$ & 17 & 74 & 60 \\
\hline
\end{tabular}

O procedimento de coleta de dados foi realizado totalmente a distância, pela internet, por meio da qual os instrumentos uma vez digitalizados foram disponibilizados em formato de questionário para serem administrados via e-mail/link de pesquisa aos estudantes dos programas de EAD das instituições de ensino superior. Em relação ao processo de digitalização das ferramentas de medida, este esteve a cargo da pesquisadora que converteu para o formato digital as versões originais dos questionários utilizados.

Primando pela elevação dos índices de retorno descritos na literatura, foram empregados esforços para aprimorar os procedimentos de coleta de dados pela internet. Neste sentido, houve investimento nos contatos com as instituições de ensino superior, os quais tornaram claros os procedimentos da pesquisa, bem como intensificaram a importância da divulgação e incentivo à participação no estudo. Precedendo à aplicação dos questionários, aos tutores foram enviadas cartas (Anexo A) que esclareciam os objetivo da pesquisa, os procedimentos de coleta, e a relevância de sua colaboração para que os estudantes respondessem aos questionários no período estabelecido; aos discentes, tal como já mencionado, foram encaminhados e-mails (Anexo B) ou disponibilizados no ambiente virtual de aprendizagem banners que explicitavam os procedimentos e objetivos da pesquisa, bem como solicitava ao participante o preenchimento dos questionários hospedados em endereço da internet, indicado em link específico. 
Dessa feita, para o preenchimento dos instrumentos de medida era necessário apenas clicar sobre o link indicado e este redirecionava o estudante diretamente aos questionários $-1^{\text {a }}$ Etapa: Questionário 1 "Estratégias de Aprendizagem"; 2a Etapa: Questionário 2 "Fatores Relacionados à Evasão e à Persistência em EAD”; $3^{\text {a }}$ Etapa: Questionário 3 "Sociodemográfico".

Considerando o número de respostas às escalas de medida, obteve-se a entrega de 151 questionários que contemplavam as escalas de estratégias de aprendizagem, fatores relacionados à evasão e à persistência em EAD, além das informações sociodemográficas. Destes, 126 questionários estavam aptos à utilização (preenchidos de forma integral ou parcial).

As respostas aos instrumentos de medida foram digitalizadas e integradas ao banco de dados. Uma vez findado o processo de coleta de dados, e obtida uma amostra estatisticamente significativa, as informações foram enviadas para o SPSS (Statistical Package for the Social Science) versão 16.0 - software que viabilizou as análises do material coletado.

As ações relativas à análise de dados, descrita a seguir, foram iniciadas após a finalização do procedimento de pareamento das respostas de cada discente aos distintos questionários.

\subsection{Procedimentos de análise de dados}

Precedendo a realização das análises ligadas ao cumprimento dos objetivos estabelecidos neste estudo, foram efetuadas análises descritivas (média, desvio-padrão, moda, mínimo e máximo) e exploratórias a fim de examinar a exatidão da entrada dos dados, a presença de casos extremos, a distribuição dos casos omissos, a distribuição de frequência e o tamanho das amostras. Na sequência, são descritos os procedimentos que subsidiaram as análises executadas nas duas etapas do presente trabalho ${ }^{3}$. No Capítulo 5 encontram-se detalhados os resultados e discussões oriundos de tais processos analíticos.

\footnotetext{
${ }^{3}$ Para a descrição de todas as recomendações e autores considerados nesta seção foram efetuadas consultas a Zerbini (2007), que descreve detalhadamente as medidas a serem tomadas a fim de orientar cada fase do procedimento de análise de dados, dotando de rigor as ações empreendidas.
} 


\subsubsection{Procedimentos de análises exploratórias das estruturas empíricas dos questionários}

Para a efetuação de todas as análises previstas na Etapa 1 (validação dos instrumentos) foi empregado o software SPSS versão 16.0. Análises exploratórias foram executadas intentando identificar casos omissos; casos extremos univariados e multivariados, multicolinearidade, singularidade e linearidade, segundo as recomendações de Tabachnick e Fidell (2001). Considerando as proposições tecidas por Pasquali (2004), não se procedeu a testes de normalidade das distribuições de frequência nesta etapa do estudo, uma vez que a normalidade não é considerada problema grave na análise fatorial exploratória, pois essa técnica mostra-se robusta à violação desse pressuposto, suportando desvios da normalidade.

$\mathrm{Na}$ hipótese de identificação de casos omissos, Tabachnick e Fidell (2001) recomendam três possíveis soluções: substituí-los pela média; suprimi-los em uma ou duas variáveis, nas situações em que os mesmos são tomados aos pares (pairwise); considerar somente os casos que encerram dados válidos em todos os indicadores/variáveis (listwise). Antes que o pesquisador decida-se por um dos procedimentos, é necessário averiguar a quantia e a aleatoriedade de dados ausentes, em razão do possível reconhecimento de subgrupos amostrais. Todavia, quando o índice de dados omissos for inferior a $5 \%$ dos casos a análise em questão passa a não ser essencial. Dessa feita, uma vez verificada a ocorrência dos casos omissos, sendo que as variáveis apresentaram mais do que 5\% dos mesmos, optouse pela utilização do método listwise.

Segundo Tabachnick e Fidell (2001) casos extremos univariados referem-se a respostas dissonantes do conjunto de assertivas em uma única variável; por outro lado, casos extremos multivariados são valores decorrentes de um arranjo anormal de escores em duas ou mais variáveis. A identificação dos casos extremos univariados compreendeu a transformação de todas as variáveis em escores Z. As respostas cujos escores padronizados eram iguais ou superiores a 3,29 ( $\mathrm{p}<0,001$, two-tailed $)$ foram retiradas. A distância Mahalanobis conceitualizada como a distância de um caso do centro do restante dos casos, quando o centro é o ponto criado pelas médias de todas as variáveis - foi utilizada para a identificação dos casos extremos multivariados. A partir do estabelecimento de um nível de significância de 99\% $(\alpha=0,01)$ e a determinação do número de graus de liberdade (número de variáveis consideradas), chegou-se a um valor de referência a partir do exame da tabela de distribuição 
qui-quadrado. Cifras acima do valor de referência são tidas como extremos (Tabachnick e Fidell, 2001), e, consequentemente, foram excluídas.

Logo após, deu-se início às análises fatoriais exploratórias dos três instrumentos seguindo, para tanto, as proposições de Pasquali (2004), a saber: a) coleta da informação por meio de pesquisa empírica (exposta na seção 4.7); b) construção da matriz de covariância; c) análise da matriz de covariância no que diz respeito à fatorabilidade e ao número de fatores; d) extração inicial dos fatores; e) rotação dos fatores para uma estrutura final; f) interpretação dos fatores; g) determinação dos escores fatoriais para uso em análises ulteriores.

A elaboração da matriz de covariância obedeceu aos seguintes pressupostos destacados por Pasquali (2004):

a) Tipos de coeficientes de correlação: empregou-se o tipo mais ajustado de matriz de covariâncias para análise fatorial, ou seja, aquele baseado nas correlações bivariadas paramétricas de Pearson;

b) Tamanho da amostra: foi adotado o critério que aventa cerca de 10 casos para cada variável observável;

c) Normalidade e Linearidade: sendo a análise fatorial exploratória robusta contra possíveis desvios da normalidade, não foram empreendidos testes de normalidade das distribuições de frequência. A linearidade, por sua vez, interfere na análise fatorial, dado que as correlações são fundamentadas em medidas de relações lineares. Para a análise da linearidade foram produzidas correlações bivariadas e o parâmetro adotado foi o coeficiente de correlação produto-momento de Pearson (valores diferentes de zero e significativos sinalizam a existência de uma relação linear, considerada forte quanto mais próxima de 1 for o coeficiente obtido);

d) Multicolinearidade e Singularidade: no caso de variáveis com multicolinearidade as mesmas apresentam-se tão correlacionadas que parecem sinônimos; em tal situação uma das variáveis deve ser retirada da análise. Variáveis com singularidade são a combinação de duas ou mais variáveis, ou seja, são redundantes. Para análise da multicolinearidade e singularidade verificou-se a presença de correlações superiores a 0,80 a 0,90 , tal como sugerido por Pasquali (2004) e Tabachnick e Fidell (2001) respectivamente; 
A análise da matriz de covariância em termos de fatorabilidade (constatação da real presença de covariâncias na matriz) e do número de fatores considerou os seguintes aspectos: a) análise do tamanho das correlações - foram consideradas importantes as correlações cujos valores estavam acima de 0,30 , positivo ou negativo. Uma vez que os valores de correlações acima de 0,30 ultrapassavam 50\% dos casos, a matriz podia ser fatorizável; b) teste de adequação da amostra de Kaiser-Meyer-Olkin (KMO) - examina as correlações parciais das variáveis; a matriz será mais fatorável quanto mais próxima do valor 1 for esta estatística, visto que isso indica que as variáveis guardam muita variância em comum.

A extração inicial dos fatores foi obtida por meio da análise dos componentes principais (Principal Components - PC). A PC objetiva reduzir o número de variáveis em componentes que expliquem a maior parte da variância original das variáveis. Tal técnica, tida como de simplificação e ortogonalização, analisa os mais importantes componentes e determina o número mínimo de fatores a serem inicialmente extraídos. Intentando definir o número de componentes, foram empregados na PC três tipos de critérios, a saber:

a) Critérios convencionais: apenas foram considerados os valores próprios (eigenvalues) superiores a 1 (um), sendo também analisada a distribuição visual dos mesmos através do scree plot (o formato do gráfico resultante é tomado para determinar o ponto de corte; os ângulos de inclinação que representam os componentes passam de uma inclinação acentuada para uma de feitio quase horizontal; o ponto no qual a curva começa a ficar plana é considerado indicativo do número de componentes a serem retidos);

b) Critérios estatísticos (testes de significância): foi efetuada a análise paralela de Horn, que coteja valores próprios empíricos, resultantes da análise da PC, com valores próprios aleatórios, obtidos por intermédio do software RanEign, em função da quantidade de variáveis e do tamanho da amostra. Retira-se da estrutura os fatores que apresentam valor próprio empírico igual ou menor que os valores aleatórios - de acordo com Laros (2004), tal procedimento apresenta índice de precisão de $92 \%$ de indicação correta do número de fatores, constituindo-se como o melhor método para estabelecimento de número de fatores de uma matriz de respostas a questionários;

c) Critérios de relevância do fator: efetuaram-se análises de interpretabilidade, importância e consistência dos fatores após a rotação dos mesmos. A 
importância do fator é determinada pela variância que consegue explicar após a rotação da matriz fatorial; de acordo com o critério de Harman considera-se como irrelevante aquele fator que explica menos do que 3\% da variância total das variáveis. O tamanho das cargas fatoriais expressa a validade do fator, ou seja, quanto maiores eles forem, mais a variável é representativa do fator. Todavia, um fator pode ser válido, mas não consistente, por isso, executou-se também análises de consistência dos fatores, por meio da análise de Alfa de Cronbach.

O próximo passo foi obter confirmação das estruturas fatoriais, por meio de análises fatoriais e utilizando o método de fatoração dos eixos principais (Principal Axis Factoring $P A F)$. A $P A F$ analisa as covariâncias entre as variáveis e possui um modelo teórico que subsidia as suas análises, ou seja, a $P A F$ assume que a covariância entre as variáveis é produto de uma causa comum entre elas: os fatores comuns. O aspecto vantajoso de se executar a PC antes da PAF, com todos os seus critérios, reside na definição do número mínimo de fatores a serem inicialmente extraídos. Para a $P A F$ foi adotado o método de rotação oblíqua (direct oblimin), que oportuniza o aparecimento de fatores ortogonais quando estes existem, sem forçar a dependência entre os fatores, enquanto que a rotação ortogonal só permite fatores independentes. Por fim, findada a extração dos fatores, verificou-se a estabilidade e interpretabilidade dos mesmos, bem como foram gerados os escores fatoriais.

Para a análise da estabilidade levou-se em conta o quanto os itens eram bons representantes do fator, por meio do tamanho da carga fatorial, que é a correlação entre o item com o conjunto dos outros itens do fator - quão mais próxima de 1 for esta carga, melhor representará o fator. $\mathrm{Na}$ análise da interpretabilidade, o traço latente, considerado a causa do agrupamento das variáveis, foi identificado através da análise da literatura da área. A média dos escores das variáveis originais que pertencem ao fator foi utilizada para a produção dos escores fatoriais.

\subsubsection{Procedimentos de análise dos testes de regressão múltipla}

Concluídas as análises fatoriais exploratórias, foram gerados os escores fatoriais a partir da média das variáveis originais dos fatores. O produto gerado por tal técnica foi 
utilizado nas análises de regressão múltipla padrão empreendidas com o intento de investigar e identificar os principais preditores da variável Fatores Relacionados à Evasão e à Persistência, medida em termos da média das respostas dos participantes aos itens que compõem a escala de elementos ligados à permanência ou saída discente de cursos em EAD.

Para a referida fase de investigação de resultados, foi considerado o arquivo de dados completo, contendo o modelo multivariado pareado com as seguintes variáveis: estratégias de aprendizagem, fatores relacionados à evasão e permanência em EAD e dados sociodemográficos dos respondentes. Análises exploratórias foram efetuadas no arquivo completo a fim de identificar casos omissos, casos extremos - univariados e multivariados bem como a presença de normalidade univariada, multicolinearidade, singularidade e linearidade, em observância as recomendações de Tabachnick e Fidell (2001), Miles e Shevlin (2001) e Hair, Anderson, Tatham e Black (2005). Apenas diferiram-se dos critérios adotados nas análises fatoriais exploratórias aqueles pertinentes à normalidade univariada e cálculos para definição do tamanho amostral. As análises multivariadas, em oposição à análise fatorial exploratória, são afetadas pelo pressuposto da normalidade, que necessita ser apreciada por meio de índices estatísticos ou recursos gráficos (frequências com histogramas e curva normal), sendo a assimetria (skewness) e a curtose (kurtosis) os dois principais elementos de análise. De acordo com Hair et al. (2005), a assimetria corresponde a medida de simetria de uma distribuição quando comparada com uma distribuição normal, em outros termos, uma variável cuja média não é o centro da distribuição possui assimetria. Já a curtose faz referência à medida da elevação ou do achatamento de uma distribuição quando comparada com uma distribuição normal: uma variável que apresenta distribuição muito achatada ou muito alongada possui curtose. Logo, é possível afirmar que quando a variável possui uma distribuição normal, os valores de assimetria e curtose são zero; vale ressaltar que a ocorrência de distribuições normais com valores zero de assimetria e curtose é inabitual, mormente em pesquisas de ciências sociais. Há a recomendação de que variáveis com assimetria e curtose devem sofrer transformações (Tabachnick \& Fidell, 2001), objetivando a aproximação de uma distribuição normal, tais como: raiz quadrada para assimetria leve; logaritmo para assimetria substancial; e inversa para assimetria severa (Sant'anna, 2002). Outro importante ponto a ser considerado refere-se à violação da premissa da normalidade, a qual não inviabiliza a análise multivariada, mas pode enfraquecê-la.

Uma vez que não foram identificadas diferenças nas análises com e sem transformação das variáveis com assimetria/curtose em algumas investigações (Carvalho \& Abbad, 2006; 
Lacerda \& Abbad, 2003; Meneses \& Abbad, 2003; Sant'anna, 2002; Tamayo, 2002; Zerbini \& Abbad, 2005), decidiu-se por não proceder à transformação das mesmas.

Em conformidade com os mesmos critérios elencados na seção precedente, os casos omissos foram tratados por meio do método listwise, foram identificadas relações lineares entre as variáveis consideradas nas regressões (linearidade), e não houve singularidade e multicolinearidade entre elas. Segundo critérios formulados por Tabachnick e Fidell (2001), é recomendável que as análises de regressão respeitem os seguintes critérios de inclusão para análise: amostra maior ou igual a 50 casos mais oito vezes o número de variáveis antecedentes $(\mathrm{N} \geq 50+8 \mathrm{~m})$ para testes de correlações múltiplas e $\mathrm{N} \geq 104+\mathrm{m}$, para testar preditores individuais.

No capítulo a seguir são descritos os resultados de adaptação e validação das ferramentas de medida, análises descritivas, exploratórias fatoriais e de relacionamento entre as variáveis. 


\section{CAPÍTULO 5. RESULTADOS}

\section{Objetivo do capítulo 5}

Este capítulo tem como objetivo apresentar os resultados alcançados pelo presente estudo, relacionando-os com os objetivos estabelecidos.

\subsection{Adaptação e validação dos instrumentos de medida}

O instrumento "Escala de Fatores Relacionados à Evasão e à Persistência em EAD" (Sales, 2009) foi submetido a modificações para se ajustar às características dos contextos de formação educacional de nível superior em EAD. Com o propósito de realizar a adaptação e revalidação do instrumento, foi adotada uma abordagem qualitativa e consultas a trabalhos de cunho científico na literatura da área foram feitas, de modo a favorecer a construção de novos itens que evidenciam fatores relacionados à evasão e persistência em educação a distância, observando as admoestações de estudos recentes que sugerem a possibilidade de que os participantes de ações educacionais ministradas a distância, via internet, estão sujeitos a diversas variáveis externas e/ou endógenas a eles mesmos que influenciam a decisão de permanecer ou não no curso. Também foram analisadas as especificidades dos cursos avaliados, assim como as terminologias e expressões utilizadas no ambiente virtual de aprendizagem e pelos agentes envolvidos com os cursos (estudantes, professores, coordenação, etc.). Por fim, foi utilizado o instrumento construído por Martins (2012) para coleta de dados pessoais dos participantes da pesquisa, com o propósito de contextualizar e definir um perfil da amostra de discentes que participam de cursos de graduação a distância (Anexo C).

O instrumento de Sales (2009), com 63 itens após validação estatística, sofreu modificações na redação de alguns itens, novos foram incluídos e outros eliminados e uma versão de 45 itens - melhor ajustados à aplicação em cursos de ensino superior ofertados a distância - foi submetida à validação semântica e por juízes.

\section{Validação semântica e por juízes}

Para que os itens do instrumento fossem submetidos à validação semântica, um grupo de alunos de graduação foi orientado a realizar a leitura e julgamento de cada item elencado, 
avaliando-os quanto à precisão, clareza e objetividade apresentada pelos mesmos, bem como a adequação das instruções constantes na escala. Todas as modificações sugeridas pelos participantes foram inseridas em um arquivo desenvolvido para este intento. As alterações propostas foram avaliadas por meio de análise e comparação com a versão do questionário aplicado e, quando consideradas alternativas mais adequadas para o aperfeiçoamento da escala, os itens sofreram a reelaboração necessária.

O conjunto final de itens relacionados à evasão e à persistência em EAD foi submetido à validação por juízes, processo esse que compreendeu a avaliação, por especialistas da área, da adequação do instrumento elaborado - em termos da representatividade, precisão, clareza e apontamento do fator correspondente a cada item existente.

$\mathrm{Na}$ sequência, são apresentados os resultados frutos da validação semântica e por juízes por fator presente na escala, pertencente a cada conjunto de variáveis: 1) características do curso - variáveis relacionadas ao tutor, variáveis do curso propriamente dito e variáveis de suporte; 2) características do aluno - habilidades de gerenciamento do tempo de estudo, locus de controle, habilidades na escrita digital, experiências educacionais anteriores e dados demográficos; 3) características do contexto de estudo - adequação do ambiente de estudo familiar e laboral, carga de atividades profissionais, compromissos paralelos ao curso.

\section{Características do curso}

No fator "desempenho do tutor", o item de número 1, cuja grafia original era "O apoio do tutor à interação entre os participantes", foi alterado para "O apoio fornecido pelo tutor à interação entre os participantes do curso". Considerou-se que a nova escrita do item melhor contextualiza e descreve a situação considerada.

O termo 'participantes' presente no item de número 6 - "A qualidade gramatical das mensagens trocadas pelo tutor com os participantes" - foi substituído pela expressão 'alunos', uma vez que o instrumento em questão não é destinado a uma população de aprendizes do contexto corporativo e sim do ensino superior. Logo, o referido item passou a seguinte grafia: "A qualidade gramatical das mensagens trocadas pelo tutor com os alunos".

O item de número 11, "A relação afetiva do tutor com os participantes", foi alterado para "O vínculo estabelecido entre tutor e alunos”. Considera-se que o termo 'vínculo' é mais apropriado, pois compreende os aspectos afetivos considerados e não possibilita interpretações de caráter mais subjetivo que fujam do aspecto avaliado. Além disso, também se optou pela substituição da expressão 'participantes' por 'tutor e alunos' uma vez que esta 
última clarifica de forma mais adequada quais são os agentes compreendidos no item.

No item de número 15 foi inserido o termo 'fornecidos pelo' e também optou-se por adotar a expressão 'à minha participação' no plural. Logo, o item anteriormente grafado como "A qualidade do feedback/orientações do tutor em relação à minha participação" passou a ser redigido como "A qualidade do feedback/orientações fornecidos pelo tutor em relação às minhas participações".

Tendo por objetivo especificar e ampliar o repertório considerado no item 28, "A qualidade das respostas fornecidas pelo tutor às dúvidas dos participantes", o referido item recebeu o termo 'questões', revelando a seguinte escrita "A qualidade das respostas fornecidas pelo tutor às dúvidas/questões dos alunos".

Pressupondo que toda ação educativa, inclusive aquelas ministradas à distância, envolvem algum tipo de interação, considerou-se conveniente acrescentar a palavra 'qualidade' ao item 29, de modo que se torna possível avaliar mais detidamente tal aspecto. Também houve a substituição do termo 'participantes' por 'alunos'. Dessa feita, a escrita "As interações de aprendizagem (entre participantes e entre participantes e tutor) ao longo do curso" passou a ser "A qualidade das interações de aprendizagem (entre alunos e entre alunos e tutor) ao longo do curso".

O item 30 "A qualidade da condução das discussões pelo tutor" foi excluído por já estar contemplado no item 1 "O apoio do tutor à interação entre os participantes". O item 34, “A qualidade da participação do tutor nas discussões em fóruns e ROL-Reunião on-line", foi retirado por estar compreendido no item 26, "A qualidade das interações de aprendizagem (entre alunos e entre alunos e tutor) ao longo do curso".

No item 35, "O grau de conhecimento do tutor sobre os temas relacionados ao curso", ocorreu a substituição da expressão 'sobre os temas' para 'a respeito dos temas'.

Em relação ao item 38, além da modificação do termo 'à exposição' por 'frente à manifestação' mais uma vez a expressão 'participantes' deu lugar a 'alunos'.

Por fim, os itens 44, "A prontidão (rapidez) de resposta do tutor às minhas consultas", 48, "A habilidade do tutor para utilizar os recursos de interação disponibilizados no curso", e 53, "A habilidade didática do tutor ao abordar os conteúdos", não foram mantidos por estarem contemplados nos itens 14, "A qualidade do feedback/orientações fornecidos pelo tutor em relação às minhas participações", 26, "A qualidade das interações de aprendizagem (entre alunos e entre alunos e tutor) ao longo do curso", e 30 "O grau de conhecimento do tutor a respeito dos temas relacionados ao curso", respectivamente. 
No fator "desenho do curso", seguindo as recomendações atuais feitas pelo campo científico, foi acrescido o adjetivo 'virtual' junto à expressão 'ambiente' presente no item de número 9 "O acesso ao sistema do curso", pois dessa forma buscou-se especificar o elemento que estava sendo considerado. $\mathrm{O}$ item passou a exibir a seguinte escrita: "O acesso ao sistema virtual do curso".

O item 12, "Disponibilização pela Empresa de infraestrutura tecnológica para a realização do curso", foi retirado por estar relacionado à acessibilidade ao curso fornecida pela organização de trabalho, não se ajustando, portanto, ao contexto de ensino universitário considerado pela pesquisa.

Houve o acréscimo da palavra 'utilizado' ao item de número 14, "O acesso ao material didático do curso", recebendo o mesmo a seguinte escrita "O acesso ao material didático utilizado no curso".

O item 19, "Fornecimento de informações precisas acerca do curso antes de seu início", foi alterado para "Acesso às informações acerca do curso antes de seu início".

No item 20, "A quantidade de atividades propostas no curso", houve a retirada do artigo 'A' e acréscimo da palavra 'durante o', apresentando o item a grafia "Quantidade de atividades propostas durante o curso".

O item de número 21 "A distância física entre os participantes" foi substituído por "Separação física entre tutores e alunos na maior parte do tempo do curso", dado que a nova redação, além de denotar os contatos pessoais mais diminutos, também melhor descreve os agentes envolvidos, ou seja, os discentes e tutores.

Optou-se pela redação do item 23, “A complexidade das atividades propostas pelo curso", como sendo "O grau de dificuldade das atividades propostas pelo curso", pois esta adota uma linguagem menos técnica e de mais facilitada compreensão à população-alvo.

A frase "O apoio dos outros participantes ao longo do curso", item 25, foi alterada para "A cooperação entre os alunos ao longo do curso", uma vez que a nova grafia melhor representa o tipo de auxílio vigente em situações de educação a distância, bem como os indivíduos envolvidos em tal interação.

O item 31 sofreu a retirada dos termos '(exemplo de fóruns, ROL-Reunião on-line, entre outros)' passando à seguinte redação 'Disponibilidade de ferramentas eletrônicas no ambiente do curso para interação com os outros participantes". Os itens 37, "A qualidade de interações no ambiente de aprendizagem com os outros participantes e com o tutor", e 59 "Quantidade de interações com os outros participantes prevista no curso", foram excluídos 
por já estarem contemplados no item 26, “A qualidade das interações de aprendizagem (entre alunos e entre alunos e tutor) ao longo do curso".

O termo 'aplicação' presente no item 41 foi substituído por 'empregar' por se considerar que tal mudança melhor se adequa ao contexto normalmente circundante do indivíduo discente.

\section{Características do aluno}

No fator "disciplina e interesse do aluno", o segundo item da escala "Minha capacidade de administrar o meu tempo para me dedicar aos estudos" sofreu a seguinte reformulação "Minha habilidade em administrar o tempo para me dedicar aos estudos". A substituição do termo 'capacidade' pela expressão 'habilidade' foi considerada mais apropriada em virtude desta última denotar de forma mais abrangente a possibilidade do indivíduo utilizar seus recursos pessoais a fim de gerenciar seus momentos dedicados ao estudo.

O item de número 8, "Minha habilidade de conciliar o curso com outras atividades", recebeu o acréscimo da expressão 'pessoais' tendo por objetivo complementar e tornar mais explícito o fato de que o item considerava outras atividades de caráter não acadêmicas e sim de cunho pessoais, podendo, dessa feita, compreender tarefas laborais, compromissos familiares entre outros. A redação adotava foi "Minha habilidade de conciliar o curso com outras atividades pessoais".

Seguindo a lógica adotada na avaliação do primeiro item, o item de número 10 "Minha capacidade de elaborar um plano de estudo" foi alterado para "Minha habilidade em elaborar um plano de estudo que oriente minhas atividades", pois expressa de forma mais clara a finalidade do mesmo.

A fim de tornar o item 24 "A frequência com que utilizei espontaneamente as ferramentas da web (tira dúvidas, mural de notícias, ROL-Reunião on-line, etc.) durante o curso", mais conciso foram retiradas as seguintes expressões '(tira dúvidas, mural de notícias, ROL-Reunião on-line, etc.)', passando o mesmo a apresentar a seguinte grafia "A frequência com que utilizei espontaneamente as ferramentas da web durante o curso".

No item de número 32 foi acrescentada a expressão 'a realização do'. Logo, a escrita observada foi a de "Minha motivação para a realização do curso ao longo de sua ocorrência" e já não mais "Minha motivação para o curso ao longo de sua realização".

A redação do item 39, "Meu esforço para permanecer no curso ao encontrar dificuldades", foi alterada para "Meu esforço para permanecer no curso durante momentos de 
dificuldades".

O item 40, "O fato de as atividades do curso suprirem minhas necessidades de capacitação", foi retirado por estar dirigido para o ambiente de trabalho e, logo, não se aplicar ao contexto do estudo.

O item 42 "Minha disciplina para realizar as tarefas propostas para o curso dentro do prazo estabelecido" foi alterado para "Minha disciplina para cumprir as tarefas propostas para o curso no prazo fixado".

Os itens 54, "Minha familiaridade com o uso do computador", e 55, "Minha habilidade de escrita", também foram desconsiderados por já estarem compreendidos no item 16, "Minha habilidade em utilizar recursos e ferramentas tecnológicas do curso".

\section{Características do contexto de estudo}

No fator "tempo disponível para o curso", O item de número 4, originalmente elaborado como "Mudança na rotina de trabalho no período do curso", passou a figurar como "Alterações em minha rotina de trabalho ocorridas durante a realização do curso".

O item 13 "A quantidade de compromissos familiares" sofreu a retirada das expressões 'a quantidade', sob a justificativa de que o mesmo tornar-se-ia mais conciso e não sofreria prejuízos em seu sentido, e 'compromissos', substituído por 'eventos' devido o caráter mais neutro do novo vocábulo. Também foi adotado o termo 'durante a realização do curso' a fim de tornar mais claro o momento exato de ocorrência de tais eventos. $\mathrm{O}$ item passou a seguinte redação "Eventos familiares durante a realização do curso".

No fator "questões familiares", objetivando a concisão dos termos, o item de número 16 "O incentivo da minha família para a realização do curso" sofreu a reformulação "O incentivo familiar para a realização do curso". Tendo em vista o mesmo aspecto, foram retirados as expressões '(Internet, correio eletrônico, ROL-Reunião on-line, fórum, ferramentas de áudio e vídeo, entre outros)' do item 16, "Minha habilidade em utilizar os recursos tecnológicos do curso (Internet, correio eletrônico, ROL-Reunião on-line, fórum, ferramentas de áudio e vídeo, entre outros)", apresentando a seguinte redação "Minha habilidade em utilizar recursos e ferramentas tecnológicas do curso".

O item 22 do instrumento, "As condições de estudo em casa", sofreu a retirada do artigo 'As' bem como recebeu o termo especificador 'ambiente de estudo'. A redação final passou a ser "Condições do ambiente de estudo em casa".

O item 62, "Mudanças na rotina familiar no período de realização do curso", passou a 
seguinte escrita "Mudanças na rotina familiar no período de desenvolvimento do curso".

Os itens 17 "A quantidade de compromissos/atividades no meu trabalho", 36, "O apoio fornecido pela Empresa na qual trabalho para realizar o curso", 47, "As condições de estudo no local de trabalho", 52, "O reconhecimento pela minha Empresa em decorrência da realização do curso", 57, "O apoio fornecido pela chefia para realizar o curso", e 58, "O apoio fornecido pelos colegas de trabalho para realizar o curso", foram todos excluídos por estarem relacionados com o cenário de trabalho.

As alterações propostas no processo de validação semântica e por juízes, possibilitaram o aprimoramento e a adaptação da escala de medida em questão, que ficou com 45 itens (Anexo D).

Devido à recenticidade do estudo de Martins (2012), o qual adaptou e verificou evidências de validade no instrumento de medida "Estratégias de aprendizagem" (Zerbini \& Abbad, 2008), em contexto de IES, considera-se conveniente descrever tal processo que culminou com a proposição de uma das ferramentas de medida por esta pesquisa utilizada. A adaptação da referida escala envolveu a construção de novos itens referentes às estratégias de aprendizagem autorregulatórias, bem como a modificação dos demais itens. Para a elaboração de novos itens relativos a tais estratégias, Martins (2012) avaliou e considerou publicações científicas na literatura. O questionário, que contava com 28 itens após validação estatística, sofreu a incorporação de novos itens e a exclusão de outros, bem como foi submetido a mudanças de grafia. Um novo instrumento composto por 41 itens foi validado semanticamente e por juízes.

Os resultados advindos da validação semântica e por juízes se encontram dispostos de acordo com os fatores presentes no instrumento, pertencentes a cada tipo de estratégia: 1) estratégias autorregulatórias - controle da emoção, controle da motivação, monitoramento da compreensão; 2) estratégias comportamentais - busca de ajuda interpessoal, busca de ajuda ao material didático, aplicação prática; 3) estratégias cognitivas - repetição e organização, elaboração. Em relação ao primeiro conjunto de estratégias, denominadas autorregulatórias, 3 itens sofreram modificações em sua grafia e três foram retirados do instrumento. Quanto ao grupo de estratégias comportamentais 8 itens foram eliminados da escala e 3 passaram por reformulações de escrita. Por fim, no último conjunto, correspondente às estratégias cognitivas, 4 itens foram alterados e apenas 1 excluído da ferramenta de medida. Tais alterações se devem a esforços visando a adequação do instrumento às especificidades dos 
contextos de ensino superior em EAD; dessa forma, as reelaborações sofridas por alguns itens, assim como a exclusão de outros, objetivaram ajustar e aclarar a escrita de algumas afirmativas, bem como eliminar redundâncias de itens identificadas. Após a validação semântica e por juízes, o instrumento em questão que ficou com 31 itens (Anexo E).

\subsection{Análises descritivas}

São expostos nesta seção os resultados descritivos de cada variável presente no modelo de investigação. Debate-se o valor das médias, desvios-padrão, modas, mínimo, máximo e concentração das respostas emitidas pelos respondentes às variáveis pesquisadas.

\subsubsection{Estratégias de aprendizagem}

Os resultados descritivos referentes aos itens do questionário de Estratégias de Aprendizagem encontram-se descritos na Tabela 22; tais elementos intentam aferir a frequência de uso, ao longo do desenvolvimento da ação instrucional, de habilidades comportamentais, capacidades cognitivas, monitoramento da compreensão e controle da ansiedade e da motivação empregadas pelo estudante a fim de gerenciar os próprios processos psicológicos de aprendizagem, tais como atenção, aquisição, memorização e transferência. Os referidos itens encontram-se associados a uma escala de frequência de comportamento de 11 pontos que varia de 0 (Nunca) a 10 (Sempre).

Tabela 22 - Resultados descritivos de Estratégias de Aprendizagem (continua).

\begin{tabular}{|c|c|c|c|c|c|c|c|}
\hline \multirow{2}{*}{ Itens } & \multirow{2}{*}{$\begin{array}{c}\text { Casos } \\
\text { omissos }\end{array}$} & \multirow{2}{*}{ Média } & \multirow{2}{*}{$\begin{array}{l}\text { Desvio } \\
\text { Padrão }\end{array}$} & \multirow{2}{*}{ Moda } & \multirow{2}{*}{ Min } & \multirow{2}{*}{ Máx } & $\begin{array}{l}\text { Concentração de } \\
\text { Respostas (\%)* }\end{array}$ \\
\hline & & & & & & & $8-10$ \\
\hline
\end{tabular}

29.Associei os conteúdos do curso aos meus
conhecimentos anteriores. 3 8,63 1,75

10

3

10
2,4

22,8 74,8 15.Busquei compreender melhor os conteúdos ao estudá-los nas apostilas do

1

10

5,8 curso.

14.Busquei solucionar minhas dúvidas ao consultar as apostilas do 4 8,27

2,07

10

0

10 
Tabela 22 - Resultados descritivos de Estratégias de Aprendizagem (continua).

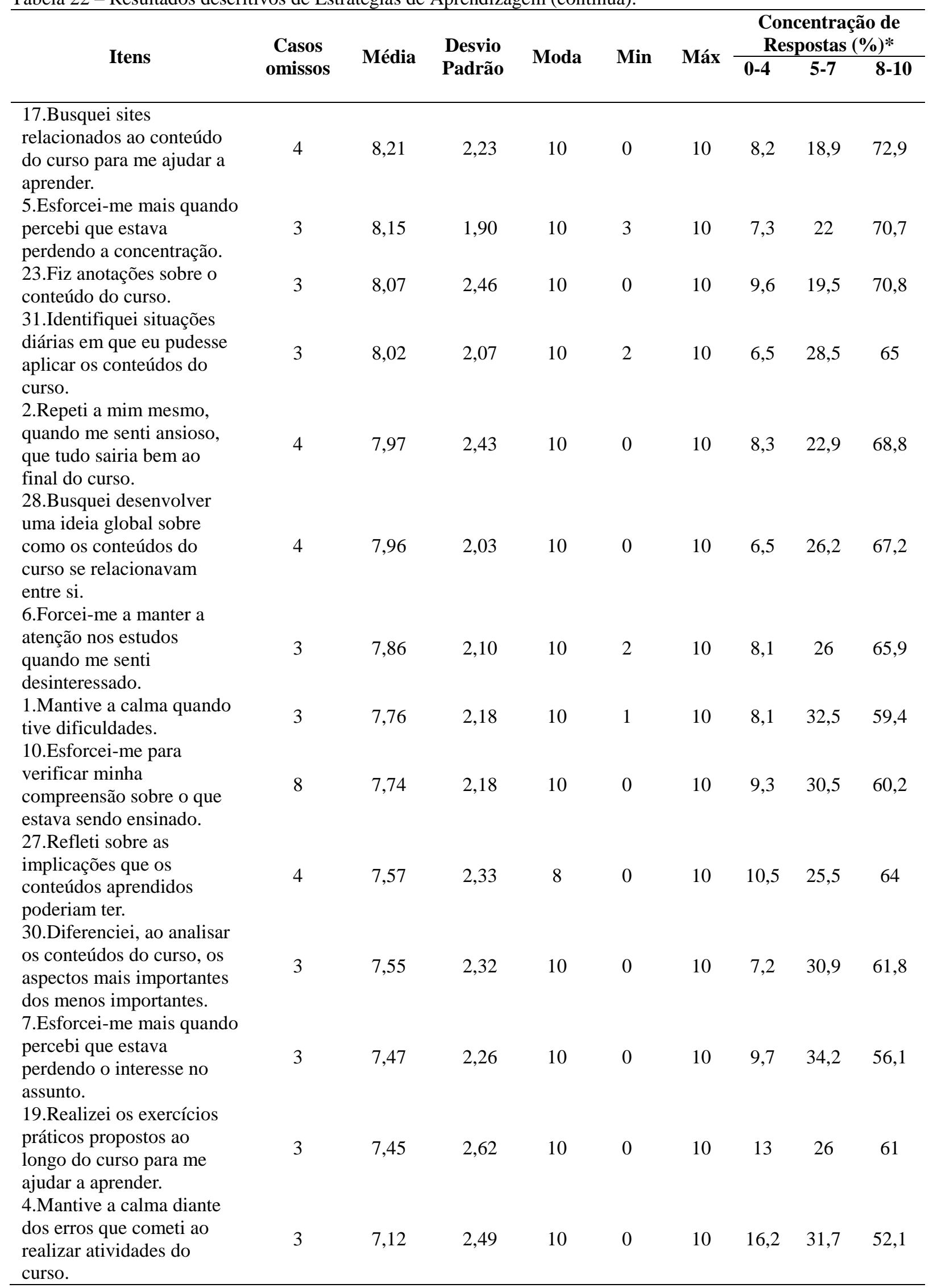


Tabela 22 - Resultados descritivos de Estratégias de Aprendizagem (continuação).

\begin{tabular}{|c|c|c|c|c|c|c|c|c|c|}
\hline \multirow{2}{*}{ Itens } & \multirow{2}{*}{$\begin{array}{c}\text { Casos } \\
\text { omissos }\end{array}$} & \multirow{2}{*}{ Média } & \multirow{2}{*}{$\begin{array}{l}\text { Desvio } \\
\text { Padrão }\end{array}$} & \multirow{2}{*}{ Moda } & \multirow{2}{*}{ Min } & \multirow{2}{*}{ Máx } & \multicolumn{3}{|c|}{$\begin{array}{l}\text { Concentração de } \\
\text { Respostas }(\%)^{*}\end{array}$} \\
\hline & & & & & & & $0-4$ & $5-7$ & 8-10 \\
\hline $\begin{array}{l}\text { 16.Busquei outras fontes } \\
\text { de pesquisa, fora da } \\
\text { internet, relacionadas ao } \\
\text { curso para me ajudar a } \\
\text { aprender. }\end{array}$ & 4 & 7,05 & 3,15 & 10 & 0 & 10 & 21,3 & 20,4 & 58,2 \\
\hline $\begin{array}{l}\text { 3. Mantive a calma com a } \\
\text { possibilidade de ter um } \\
\text { rendimento abaixo do } \\
\text { esperado. }\end{array}$ & 3 & 6,75 & 2,68 & 10 & 0 & 10 & 18 & 35,7 & 46,3 \\
\hline $\begin{array}{l}\text { 24.Fiz resumos do } \\
\text { conteúdo do curso. }\end{array}$ & 4 & 6,66 & 3,25 & 10 & 0 & 10 & 23,6 & 24,6 & 51,7 \\
\hline $\begin{array}{l}\text { 20.Revisei os conteúdos } \\
\text { relativos aos exercícios em } \\
\text { que cometi erros. }\end{array}$ & 3 & 6,53 & 2,78 & 8 & 0 & 10 & 20,3 & 33,3 & 46,4 \\
\hline $\begin{array}{l}\text { 9.Revisei a matéria para } \\
\text { verificar o quanto eu } \\
\text { dominava o conteúdo. }\end{array}$ & 5 & 6,28 & 2,82 & 8 & 0 & 10 & 23,2 & 36,3 & 40,5 \\
\hline $\begin{array}{l}\text { 25.Li o conteúdo do curso } \\
\text { várias vezes como método } \\
\text { para aprender. }\end{array}$ & 4 & 6,06 & 3,01 & 7 & 0 & 10 & 26,3 & 36 & 37,7 \\
\hline $\begin{array}{l}\text { 18.Tentei entender o } \\
\text { conteúdo ao aplicá-lo na } \\
\text { prática, ao invés de dedicar } \\
\text { tempo lendo ou pedindo } \\
\text { ajuda a alguém. }\end{array}$ & 4 & 5,98 & 2,83 & 5 & 0 & 10 & 23,9 & 41 & 35,1 \\
\hline $\begin{array}{l}\text { 8.Elaborei perguntas para } \\
\text { testar minha compreensão } \\
\text { sobre os conteúdos do } \\
\text { curso. }\end{array}$ & 5 & 5,95 & 3,00 & 10 & 0 & 10 & 28,2 & 36,3 & 35,5 \\
\hline $\begin{array}{l}\text { 26.Fiz esquemas do } \\
\text { conteúdo do curso como } \\
\text { método para aprender. }\end{array}$ & 4 & 5,92 & 3,28 & 8 & 0 & 10 & 29,6 & 27,9 & 42,7 \\
\hline $\begin{array}{l}\text { 22.Repeti mentalmente os } \\
\text { conteúdos do curso que } \\
\text { gostaria de aprender. }\end{array}$ & 5 & 5,71 & 3,28 & 10 & 0 & 10 & 33,1 & 29,7 & 37,2 \\
\hline $\begin{array}{l}\text { 21.Aprendi conteúdos ao } \\
\text { mentalizá-los } \\
\text { repetidamente até perceber } \\
\text { que havia entendido. }\end{array}$ & 3 & 5,48 & 3,20 & 3 & 0 & 10 & 38,2 & 28,5 & 33,3 \\
\hline $\begin{array}{l}\text { 11.Busquei auxílio do tutor } \\
\text { para esclarecer minhas } \\
\text { dúvidas sobre o conteúdo. }\end{array}$ & 3 & 5,47 & 3,11 & 5 & 0 & 10 & 35,7 & 32,4 & 31,7 \\
\hline
\end{tabular}


Tabela 22 - Resultados descritivos de Estratégias de Aprendizagem (conclusão).

\begin{tabular}{|c|c|c|c|c|c|c|c|c|c|}
\hline \multirow{2}{*}{ Itens } & \multirow{2}{*}{$\begin{array}{c}\text { Casos } \\
\text { omissos }\end{array}$} & \multirow{2}{*}{ Média } & \multirow{2}{*}{$\begin{array}{l}\text { Desvio } \\
\text { Padrão }\end{array}$} & \multirow{2}{*}{ Moda } & \multirow{2}{*}{ Min } & \multirow{2}{*}{ Máx } & \multicolumn{3}{|c|}{$\begin{array}{c}\text { Concentração de } \\
\text { Respostas (\%)* }\end{array}$} \\
\hline & & & & & & & $0-4$ & $5-7$ & 8-10 \\
\hline $\begin{array}{l}\text { 13.Troquei mensagens } \\
\text { com os colegas para } \\
\text { esclarecer dúvidas } \\
\text { sobre o conteúdo do } \\
\text { curso. }\end{array}$ & 4 & 4,75 & 3,60 & 0 & 0 & 10 & 46 & 25,4 & 28,6 \\
\hline $\begin{array}{l}\text { 12.Busquei auxílio de } \\
\text { colegas nos fóruns } \\
\text { para esclarecer minhas } \\
\text { dúvidas. }\end{array}$ & 3 & 4,45 & 3,38 & 0 & 0 & 10 & 50,3 & 26 & 23,6 \\
\hline
\end{tabular}

Em relação a este instrumento, observa-se que dos 31 itens, 19 apresentaram concentração de respostas superior a $50 \%$ nos pontos mais altos da escala, e apenas 1 item apresentou uma concentração de respostas superior a 50\% nos pontos mais baixos da escala. Os 11 itens restantes apresentaram concentração de respostas similar nos três grupos de concentração. A média de emprego das estratégias de aprendizagem retratadas nos itens variou de 4,45 a 8,63 , revelando que os discentes se comportaram com muita frequência em determinados aspectos e com baixa frequência em outros, ou seja, determinadas estratégias de aprendizagem foram empregadas inúmeras vezes, ao passo que outras o foram poucas vezes; tal achado é corroborado pelos valores das modas, que manifestaram acentuadas alterações de um conjunto de itens para outro - foram encontrados valores de 10 para um grupo de itens e de 0 para outro conjunto.

Os valores dos desvios-padrão foram altos na maior parte dos itens, algo já previsto, uma vez que houve elevada heterogeneidade de uso das estratégias de aprendizagem entre os participantes ao longo do curso. Tal diversidade de uso também pode ser constatada por meio da análise dos valores mínimos e máximos, que oscilaram de 0 a 10 . Foram encontrados poucos casos omissos na amostra de 126 participantes. De modo geral, a inconsonância observada nas concentrações de respostas, valores das médias e modas, possivelmente, decorre do fato do instrumento de medida considerado congregar distintos tipos de estratégias de aprendizagem, que poderão ser utilizadas em maior ou menor frequência pelos participantes ao longo de um mesmo evento instrucional; ademais, tal divergência pode sinalizar o padrão diferenciado de uso de tais estratégias por estudantes não presenciais. 
As dez médias mais altas - $29(\mathrm{M}=8,63$ e $\mathrm{DP}=1,75) ; 15(\mathrm{M}=8,29$ e $\mathrm{DP}=2,03) ; 14$ $(\mathrm{M}=8,27$ e $\mathrm{DP}=2,07) ; 17(\mathrm{M}=8,21$ e $\mathrm{DP}=2,23) ; 5(\mathrm{M}=8,15$ e $\mathrm{DP}=1,90) ; 23 \quad(\mathrm{M}=8,07$ e $\mathrm{DP}=2,46) ; 31(\mathrm{M}=8,02$ e $\mathrm{DP}=2,07) ; 2(\mathrm{M}=7,97$ e $\mathrm{DP}=2,43) ; 28(\mathrm{M}=7,96$ e $\mathrm{DP}=2,03)$; e 6 $(\mathrm{M}=7,86$ e $\mathrm{DP}=2,10)$ - agrupam os 5 itens do fator "Estratégias Cognitivas" encontrado por Martins (2012) (Itens 17, 23, 28, 29 e 31). Este fator diz respeito a estratégias de reflexão ativa (repetição, organização e elaboração mental da informação que foi apresentada), bem como de estratégias comportamentais (busca de ajuda no material didático e aplicação prática). Os cinco itens restantes correspondem a estratégias do tipo "Autorregulatórias" (Itens 2, 5, 6, 14 e 15), que fazem menção a estratégias ligadas ao controle da motivação e ao monitoramento da compreensão, ambas auxiliando na autorregulação dos processos de aprendizagem.

As oito médias mais baixas - $12(\mathrm{M}=4,45$ e $\mathrm{DP}=3,38) ; 13(\mathrm{M}=4,75$ e $\mathrm{DP}=3,60) ; 11$ $(\mathrm{M}=5,47$ e $\mathrm{DP}=3,11) ; 21(\mathrm{M}=5,48$ e $\mathrm{DP}=3,20) ; 22(\mathrm{M}=5,71$ e $\mathrm{DP}=3,28) ; 26(\mathrm{M}=5,92$ e $\mathrm{DP}=3,28) ; 8(\mathrm{M}=5,95$ e $\mathrm{DP}=3,00)$; e $18(\mathrm{M}=5,98$ e $\mathrm{DP}=2,83)$ - agrupam 4 itens do fator "Estratégias Cognitivas", acima referidas, e 3 itens do fator "Busca de Ajuda Interpessoal", que, segundo Martins (2012), avalia uma estratégia de aprendizagem comportamental do aluno referente à busca ativa por auxílio de outras pessoas, como pares e professores, a fim de sanar dúvidas a respeito do conteúdo do curso. Dos 13 itens que apresentaram valores situados entre as dez médias mais altas e as oito médias mais baixas, 6 pertencem ao fator "Estratégias Cognitivas" de Martins (2012). Os outros 7 itens estão relacionados, inicialmente, às estratégias de aprendizagem "Autorregulatórias" e de "Controle da Emoção" - que favorecem o controle da ansiedade e a prevenção de dispersões de concentração ocasionadas por sentimentos de ansiedade no momento de estudo.

Avaliando os resultados descritivos do questionário de Estratégias de Aprendizagem, é possível perceber que a maior ocorrência de médias altas concentra-se nos itens do fator 1, 2 e 3 obtidos nesta pesquisa, que encerram estratégias de aquisição de conhecimentos, controle emocional e esquematização mental de conteúdos, respectivamente, indicando que tal arranjo de estratégias foi o mais frequentemente empregado pela amostra. É cabível considerar que estas estratégias compõem o conjunto usual de medidas e práticas acadêmicas adotadas pelos discentes ao longo de sua trajetória de formação tencionando melhorar os desempenhos instrucionais obtidos pelos mesmos. 


\subsubsection{Fatores relacionados à evasão e à persistência em EAD}

$\mathrm{Na}$ Tabela 23 são apresentados os resultados descritivos referentes aos itens do questionário de Fatores Relacionados à Evasão e à Persistência em EAD, que objetivam mensurar fatores dificultadores e favorecedores da permanência discente em cursos de tal natureza. Os alunos avaliaram as variáveis ligadas ao abandono e à permanência acadêmica utilizando uma escala de intensidade que variava de -5 (Dificultou muito) a +5 (Facilitou muito).

Tabela 23 - Resultados descritivos de Fatores relacionados à evasão e à persistência em EAD (continua).

\section{Concentração de}

Itens $\begin{gathered}\text { Casos } \\ \text { omissos }\end{gathered} \quad$ Média $\begin{gathered}\text { Desvio } \\ \text { Padrão }\end{gathered} \quad$ Moda Mín. Máx. $\frac{\text { Respostas (\%)* }}{-5 \text { a }-2 \quad-1 \text { a +1 }+2 \text { a +5 }}$

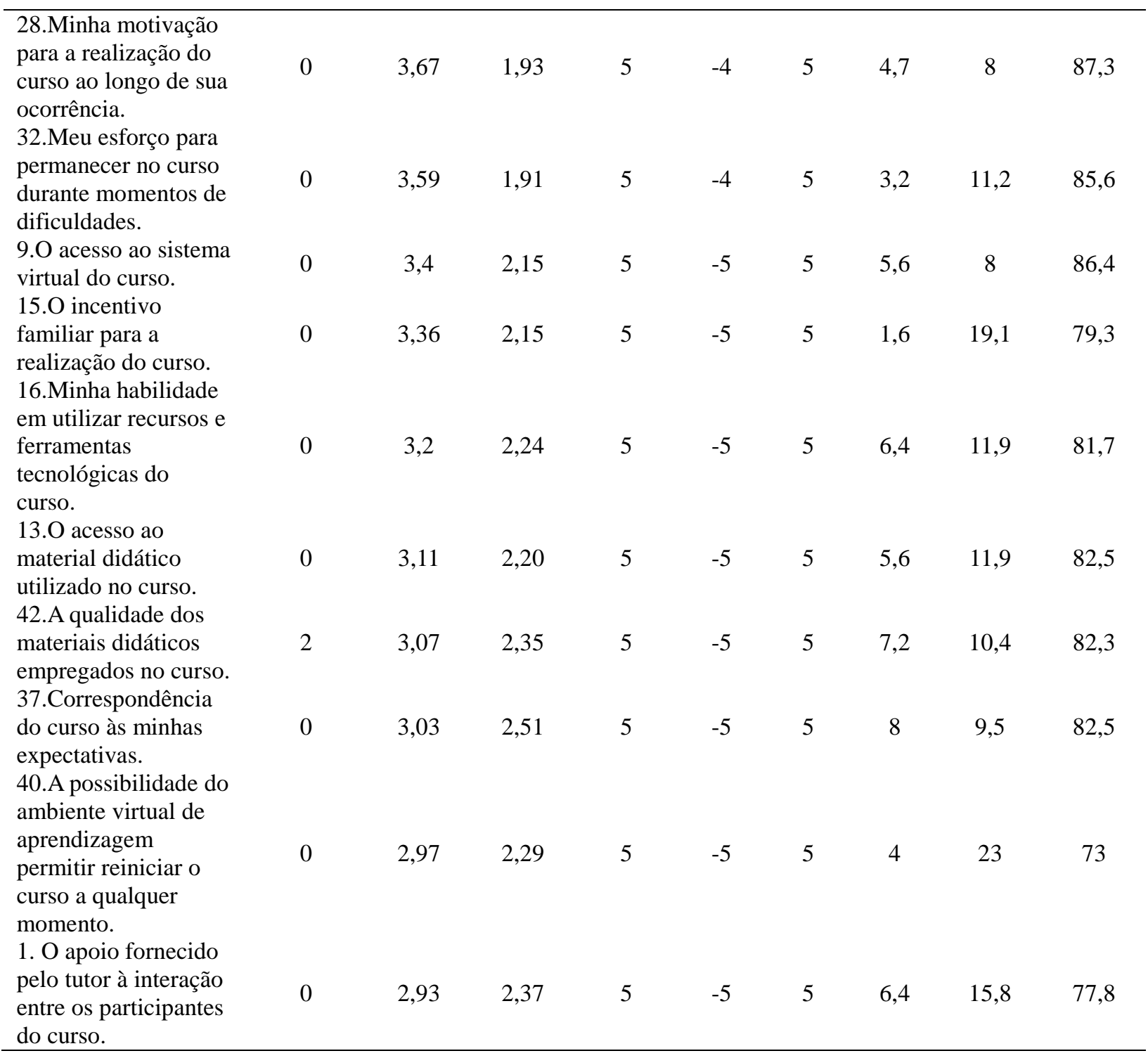


Tabela 23 - Resultados descritivos de Fatores relacionados à evasão e à persistência em EAD (continuação).

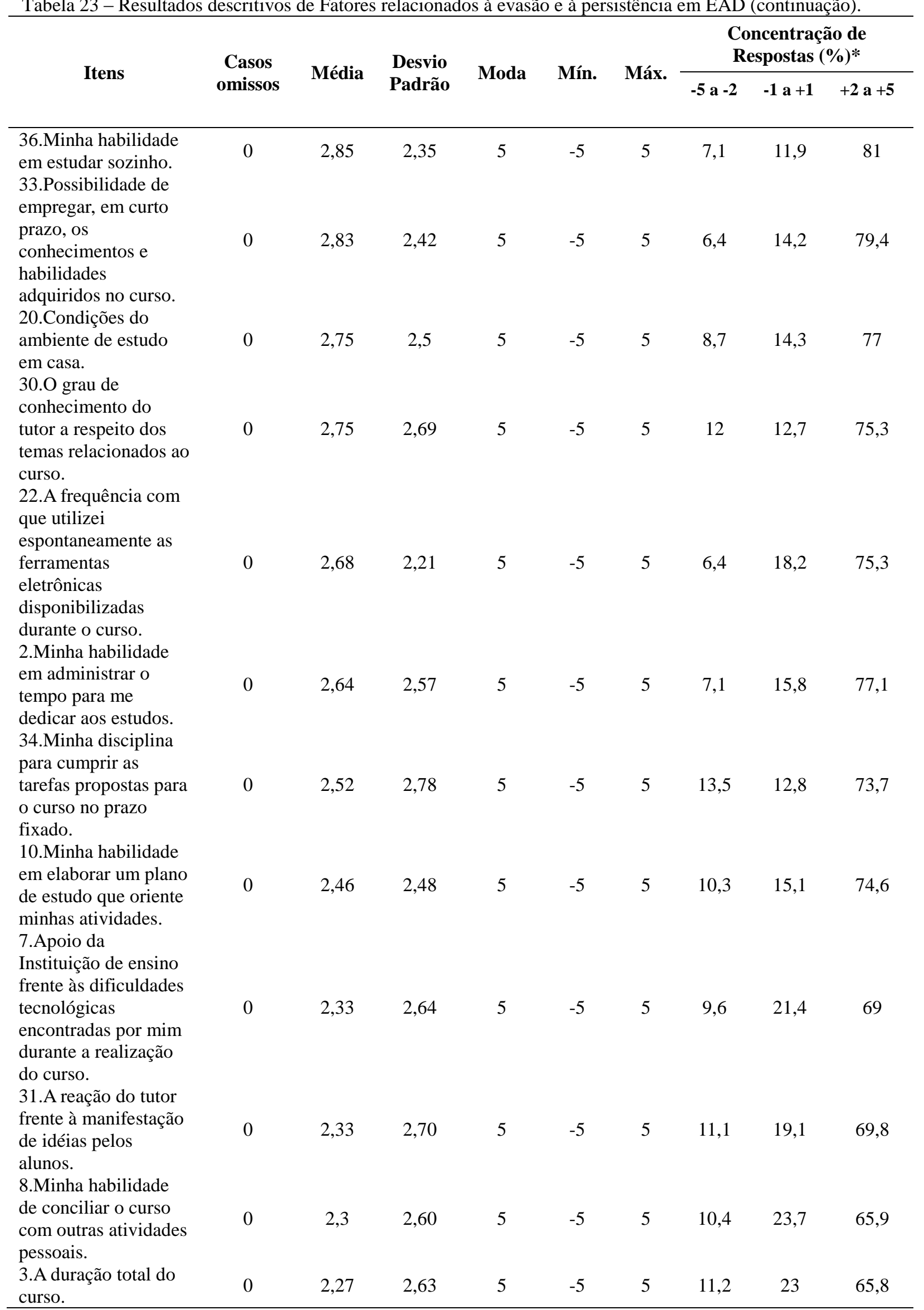


Tabela 23 - Resultados descritivos de Fatores relacionados à evasão e à persistência em EAD (continuação).

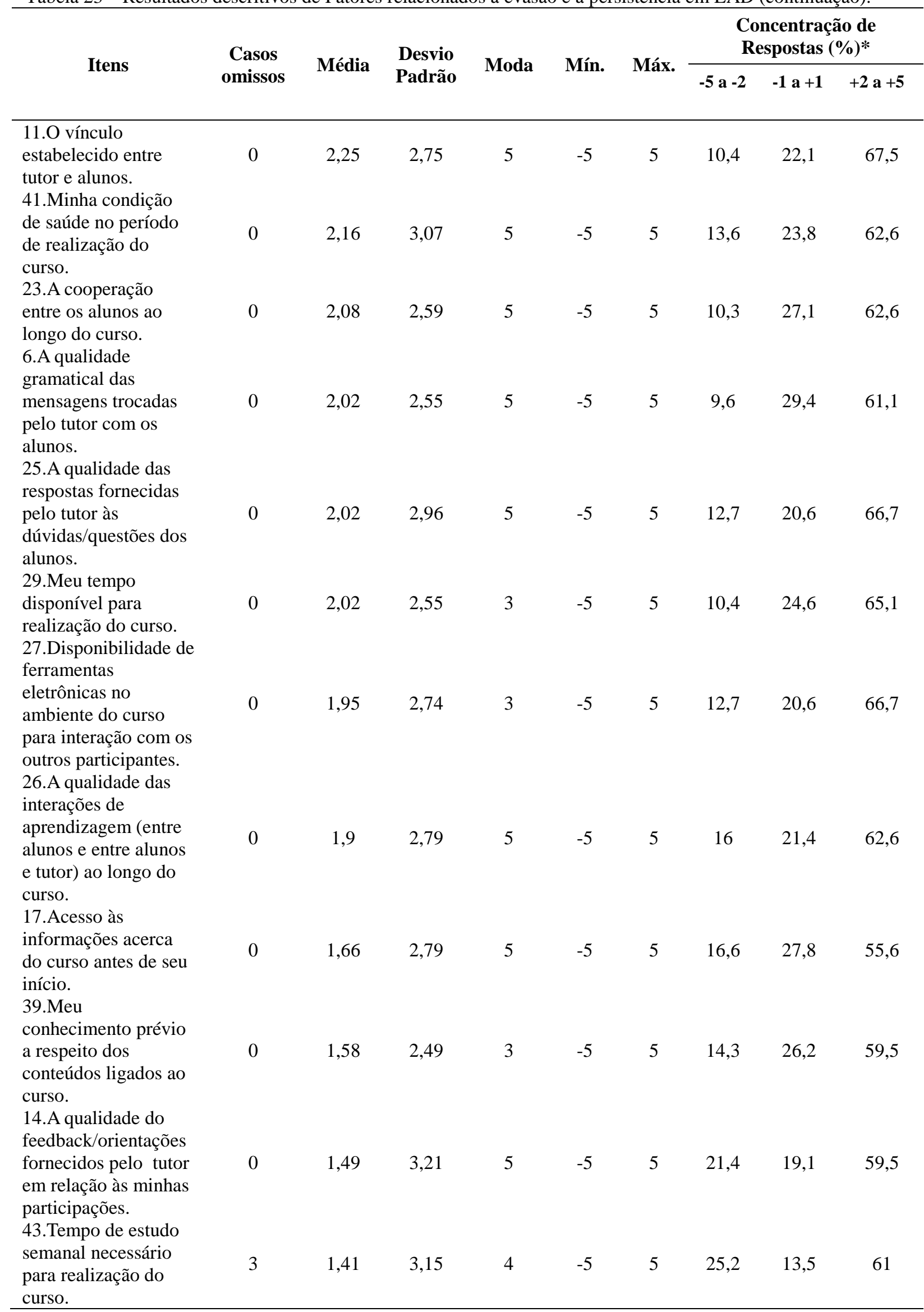


Tabela 23 - Resultados descritivos de Fatores relacionados à evasão e à persistência em EAD (conclusão).

\begin{tabular}{|c|c|c|c|c|c|c|c|}
\hline \multirow{2}{*}{ Itens } & \multirow{2}{*}{$\begin{array}{c}\text { Casos } \\
\text { omissos }\end{array}$} & \multirow{2}{*}{ Média } & \multirow{2}{*}{$\begin{array}{l}\text { Desvio } \\
\text { Padrão }\end{array}$} & \multirow{2}{*}{ Moda } & \multirow{2}{*}{ Mín. } & \multirow{2}{*}{ Máx. } & $\begin{array}{l}\text { Concentração de } \\
\text { Respostas }(\%)^{*}\end{array}$ \\
\hline & & & & & & & $-1 a+1$ \\
\hline
\end{tabular}

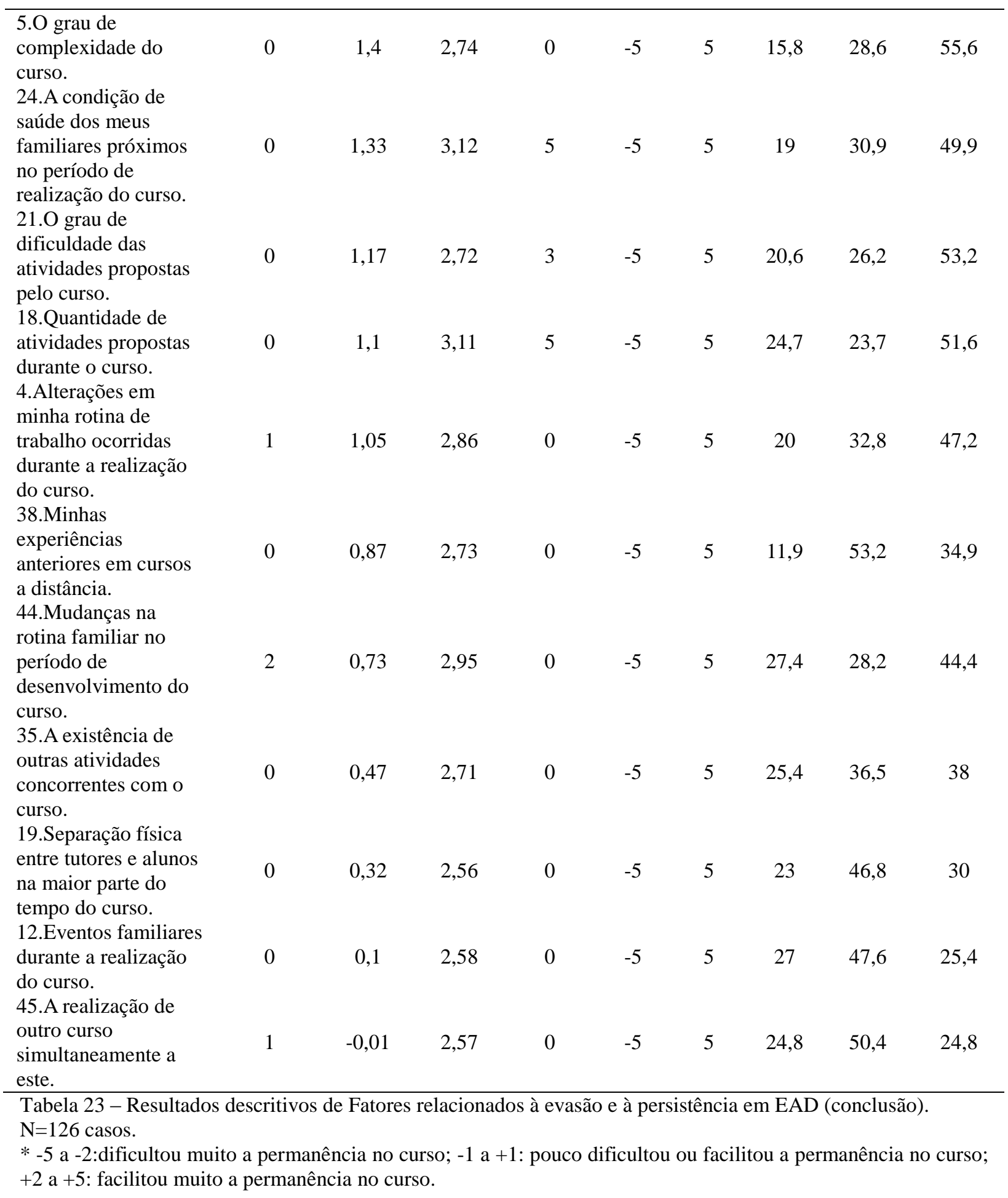

É possível verificar que dos 45 itens que compõem a ferramenta de medida ora apresentada, 38 manifestaram concentração de respostas superior a 50\% nos pontos mais altos 
da escala, e nenhum item apresentou uma concentração de respostas superior a $50 \%$ nos pontos mais baixos da escala. Os 7 itens restantes apresentaram concentração de respostas predominante nos pontos médios da escala. Tais resultados indicam que a maioria dos participantes considera as variáveis descritas, referentes aos fatores ligados à evasão e à persistência em EAD, facilitadores de sua permanência na ação instrucional e, tão logo, contribuem para a não ocorrência da desistência acadêmica. Outro dado que ratifica tal afirmação são os valores das modas, os quais variaram de $0,3,4$ e 5.

A média da influência das variáveis ligadas à evasão e à persistência em EAD variou de -0,01 a 3,67, indicando razoável dificuldade encontrada. Os valores correspondentes aos desvios-padrão são altos em alguns itens e medianos em outros; este indício de heterogeneidade entre as respostas dos participantes já é algo esperado, uma vez que a amostra considerada é composta por uma diversidade de cursos, com distintos níveis de complexidade e objetivos instrucionais. A diversidade de opiniões entre os respondentes também pode ser constatada a partir da análise dos valores mínimos e máximos, que apresentaram uma variação de -5 a +5 . Semelhantemente ao instrumento anterior, foram encontrados poucos casos omissos na amostra de 126 participantes.

Os itens que atingiram as médias mais altas foram: item $28(\mathrm{M}=3,67$ e $\mathrm{DP}=1,93) ; 32$ $(\mathrm{M}=3,59$ e $\mathrm{DP}=1,91) ; 9$ ( $\mathrm{M}=3,4$ e $\mathrm{DP}=2,15) ; 15$ ( $\mathrm{M}=3,36$ e $\mathrm{DP}=2,15) ; 16$ (M=3,2 e $\mathrm{DP}=2,24)$; $13(\mathrm{M}=3,11$ e $\mathrm{DP}=2,20) ; 42(\mathrm{M}=3,07$ e $\mathrm{DP}=2,35) ; 37(\mathrm{M}=3,03$ e $\mathrm{DP}=2,51) ; 40(\mathrm{M}=2,97$ e $\mathrm{DP}=2,29)$; e $1(\mathrm{M}=2,93$ e $\mathrm{DP}=2,37)$. Os itens que menos dificultaram a permanência do aluno no curso referem-se às percepções dos participantes sobre os conhecimentos, habilidades e atitudes manifestadas pelo tutor ao longo do curso; o desenho do curso, sua acessibilidade e o apoio oferecido; as habilidades discentes relativas ao gerenciamento do tempo, elaboração de planos de estudo, respeito a prazos, esforço diante das dificuldades encontradas e relevância do curso; as experiências prévias envolvendo uso de computadores e outros recursos tecnológicos de informação e comunicação, empregados nos cursos a distância via web; e, a condição da própria saúde e de familiares durante o período de realização do curso, as condições de estudo em casa ou mudanças na rotina familiar e o incentivo familiar (Sales, 2009).

No tocante aos itens que apresentaram as médias mais baixas, têm-se os seguintes elementos: $45(\mathrm{M}=-0,01$ e $\mathrm{DP}=2,57) ; 13(\mathrm{M}=0,1$ e $\mathrm{DP}=2,58) ; 19(\mathrm{M}=0,32$ e $\mathrm{DP}=2,56) ; 35$ $(\mathrm{M}=0,47$ e $\mathrm{DP}=2,71) ; 44(\mathrm{M}=0,73$ e $\mathrm{DP}=2,95) ; 38(\mathrm{M}=0,87$ e $\mathrm{DP}=2,73)$; e $4(\mathrm{M}=1,05$ e $\mathrm{DP}=2,86)$; e $18(\mathrm{M}=1,1$ e $\mathrm{DP}=3,11)$. A maior parte dos itens descritos pertence ao fator 
“Tempo Disponível” obtido no estudo de Sales (2009); os demais fazem referência aos fatores "Desenho do Curso", "Questões Familiares" e "Experiências e Habilidades Importantes para Cursos a Distância".

Vale ressaltar que das oito médias mais baixas evidenciadas no parágrafo anterior, quatro estão relacionadas aos compromissos concorrentes à realização do evento instrucional. Frente a este fato, é possível iniciar a discussão de que os aspectos que menos favoreceram a permanência do aluno no curso foram aqueles relacionados ao tempo livre para a execução do mesmo; tendo em vista que mais da metade da amostra considerada $(61,2 \%)$ declarou possuir ensino superior completo - ou seja, muito possivelmente já se encontra ou busca se inserir no mercado de trabalho - ser casada $(63,3 \%)$ e com filhos $(56,6 \%)$, é provável que tal arranjo circunstancial possa comprometer os momentos destinados às atividades educacionais tornando, dessa forma, os eventos ligados a esse aspecto dificultadores à permanência estudantil.

\subsection{Análises exploratórias fatoriais das estruturas empíricas dos questionários}

Esta seção descreve os resultados das análises exploratórias fatoriais das estruturas empíricas dos questionários de Estratégias de aprendizagem e Fatores relacionados à evasão e à persistência em EAD. Estas análises se ligam ao alcance dos objetivos específicos de adaptação e verificação de evidências de validade das ferramentas de medida mencionadas em contextos de IES.

\subsubsection{Estratégias de aprendizagem}

O questionário de Estratégias de aprendizagem conta com 126 respostas válidas em seus 31 itens e valores omissos variando entre 0,7 e 3,9\% - a opção adotada foi a de não estimar valores para substituir os mesmos. Foram identificados 11 casos extremos univariados e nenhum caso extremo multivariado, os quais foram mantidos no arquivo de dados.

Após a elaboração e exame da matriz de covariância verificou-se a presença de poucos relacionamentos lineares entre as variáveis; foi identificado apenas 1 par de itens altamente correlacionados entre si: 
- Par 1: 21 "Aprendi conteúdos ao mentalizá-los repetidamente até perceber que havia entendido" e 22 "Repeti mentalmente os conteúdos do curso que gostaria de aprender" $(r=0,81, p<0,01)$;

Em relação ao par encontrado, constatou-se que realmente os conteúdos medidos por esses itens eram similares quanto aos desempenhos, os quais consistem na repetição mental dos conteúdos ministrados no curso, entretanto, os mesmos se distinguem já que o primeiro item diz respeito ao produto ou consequência da ação considerada. Já o segundo trata da causa que desencadeou o referido comportamento - no caso, o desejo de aprender determinado conteúdo instrucional.

Para a análise da matriz de covariância em termos de fatorabilidade, foram avaliados o tamanho das correlações e a adequação da amostra. Foram identificados em mais de $50 \%$ dos casos valores de correlação superiores a 0,30 , indicando que a matriz provavelmente é fatorizável. No tocante ao teste de Kaiser-Meyer-Olkin (KMO), foi obtido um valor de 0,79, considerado por Pasquali (2004), um bom índice de adequação da amostra.

A extração inicial dos fatores ocorreu por meio da análise dos componentes principais, observando os critérios convencionais anteriormente elencados. A análise dos componentes principais, com tratamento listwise para os casos omissos, indica uma estrutura empírica com 8 componentes que explicam, em conjunto, 67,90\% da variância total das respostas dos participantes aos itens do questionário. Para tal análise foi seguido o critério dos eigenvalues (valores próprios) maiores ou iguais a 1 (um), bem como o critério de Harman, segundo o qual cada componente deveria explicar, no mínimo, 3\% da variância total. Assim, poderiam ser extraídos oito fatores, no máximo. Em contraposição, pela análise do scree plot, foi identificada a presença de 3 ou 4 componentes, como pode ser observado na Figura 13. 


\section{Scree Plot}

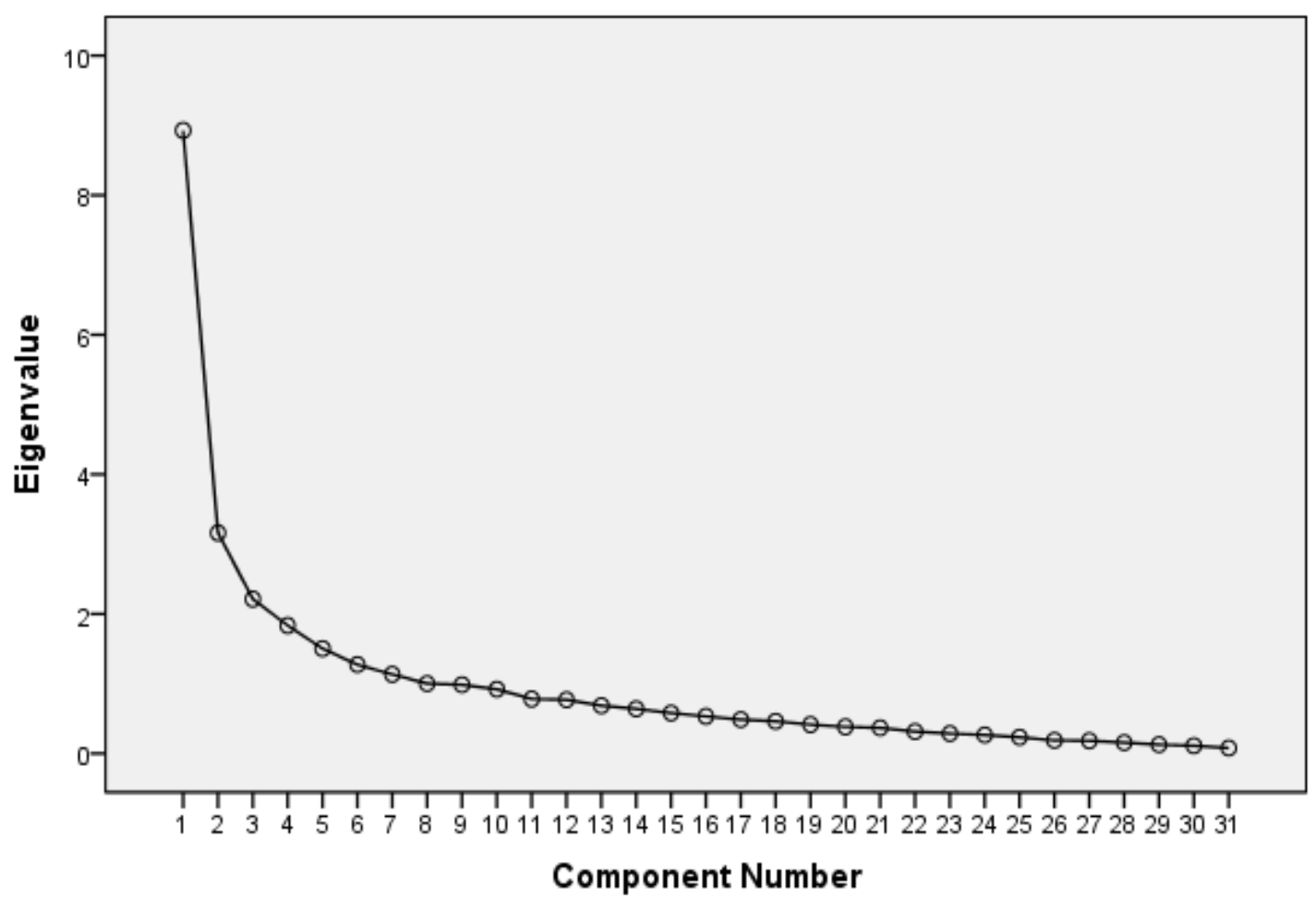

Figura 13. Distribuição dos valores próprios (scree plot) da escala de Estratégias de aprendizagem.

A análise paralela de Horn possibilita a retenção de componentes cujos autovalores empíricos são superiores àqueles encontrados através de matrizes de variáveis randômicas não correlacionadas, com tamanho análogo de amostra e número de variáveis (Laros, 2004). A interpretação da análise paralela propõe a existência de 4 fatores para a ferramenta, cujos valores próprios empíricos e valores aleatórios são expostos na Tabela 24.

Tabela 24. Valores próprios empíricos e aleatórios dos primeiros dez componentes de Estratégias de aprendizagem.

\begin{tabular}{lcccccccccc}
\hline $\begin{array}{l}\text { Valores } \\
\text { Próprios }\end{array}$ & 1 & 2 & 3 & 4 & 5 & 6 & 7 & 8 & 9 & 10 \\
\hline Empírico & $\mathbf{8 , 9 2}$ & $\mathbf{3 , 1 6}$ & $\mathbf{2 , 2 1}$ & $\mathbf{1 , 8 3}$ & 1,50 & 1,27 & 1,13 & 1,00 & 0,98 & 0,92 \\
\hline Aleatório & $\mathbf{2 , 0 7}$ & $\mathbf{1 , 9 1}$ & $\mathbf{1 , 7 9}$ & $\mathbf{1 , 6 9}$ & 1,60 & 1,52 & 1,44 & 1,37 & 1,31 & 1,24 \\
\hline
\end{tabular}

$\mathrm{N}^{\circ}$ de itens (31); $\mathrm{N}=126$ 
Tal como pode ser constatado na Tabela 24, os 4 primeiros fatores da estrutura explicam maior variância do que os correlativos nos dados aleatórios. Dessa feita, a análise paralela de Horn admite uma estrutura composta por 4 fatores.

A confirmação da estrutura fatorial final da ferramenta se deu por meio da $P A F$, com método de rotação oblíqua e tratamento listwise para casos omissos. Na escala foram inclusos apenas os itens com conteúdos semânticos similares e cargas fatoriais superiores ou iguais a 0,30. A partir dessa técnica foram extraídos 4 fatores que explicam, respectivamente, $28,80 \%$, $10,19 \%, 7,13 \%$ e 5,91\%. A escolha por esta solução apresenta sentido tanto teórico como técnico.

A Tabela 25 exibe a estrutura empírica da ferramenta, as cargas fatoriais, as comunalidades $\left(\mathrm{h}^{2}\right)$ dos itens, as médias e desvios-padrão, os índices de consistência interna das escalas e os valores próprios e percentuais de variância explicada de cada fator.

Tabela 25. Estrutura empírica da Escala de Estratégias de aprendizagem (Continua).

\begin{tabular}{|c|c|c|c|c|c|c|c|}
\hline \multirow{2}{*}{ Descrição dos Itens } & \multicolumn{4}{|c|}{ Cargas Fatoriais } & \multirow{2}{*}{$\mathbf{h}^{2}$} & \multirow{2}{*}{$\mathbf{X}$} & \multirow{2}{*}{ DP } \\
\hline & 1 & 2 & 3 & 4 & & & \\
\hline 1.Mantive a calma quando tive dificuldades. & & 0,71 & & & 0,55 & 7,92 & 2,01 \\
\hline $\begin{array}{l}\text { 2. Repeti a mim mesmo, quando me senti ansioso, } \\
\text { que tudo sairia bem ao final do curso. }\end{array}$ & & 0,55 & & & 0,53 & 7,96 & 2,39 \\
\hline $\begin{array}{l}\text { 3. Mantive a calma com a possibilidade de ter um } \\
\text { rendimento abaixo do esperado. }\end{array}$ & & 0,81 & & & 0,77 & 6,71 & 2,56 \\
\hline $\begin{array}{l}\text { 4. Mantive a calma diante dos erros que cometi ao } \\
\text { realizar atividades do curso. }\end{array}$ & & 0,69 & & & 0,75 & 7,11 & 2,42 \\
\hline $\begin{array}{l}\text { 5.Esforcei-me mais quando percebi que estava } \\
\text { perdendo a concentração. }\end{array}$ & 0,36 & 0,46 & & & 0,70 & 8,08 & 1,84 \\
\hline $\begin{array}{l}\text { 6.Forcei-me a manter a atenção nos estudos } \\
\text { quando me senti desinteressado. }\end{array}$ & 0,36 & 0,47 & & & 0,73 & 7,85 & 2,04 \\
\hline $\begin{array}{l}\text { 7.Esforcei-me mais quando percebi que estava } \\
\text { perdendo o interesse no assunto. }\end{array}$ & & 0,35 & 0,43 & & 0,78 & 7,37 & 2,25 \\
\hline $\begin{array}{l}\text { 8.Elaborei perguntas para testar minha } \\
\text { compreensão sobre os conteúdos do curso. }\end{array}$ & 0,47 & & & & 0,60 & 5,8 & 3,02 \\
\hline $\begin{array}{l}\text { 9. Revisei a matéria para verificar o quanto eu } \\
\text { dominava o conteúdo. }\end{array}$ & 0,48 & & & & 0,69 & 6,25 & 2,85 \\
\hline $\begin{array}{l}\text { 10.Esforcei-me para verificar minha compreensão } \\
\text { sobre o que estava sendo ensinado. }\end{array}$ & 0,32 & 0,30 & & 0,37 & 0,74 & 7,75 & 2,20 \\
\hline $\begin{array}{l}\text { 11.Busquei auxílio do tutor para esclarecer } \\
\text { minhas dúvidas sobre o conteúdo. }\end{array}$ & & & 0,63 & & 0,55 & 5,27 & 3,05 \\
\hline $\begin{array}{l}\text { 12.Busquei auxílio de colegas nos fóruns para } \\
\text { esclarecer minhas dúvidas. }\end{array}$ & & & 0,72 & & 0,80 & 4,22 & 3,21 \\
\hline $\begin{array}{l}\text { 13.Troquei mensagens com os colegas para } \\
\text { esclarecer dúvidas sobre o conteúdo do curso. }\end{array}$ & & & 0,67 & & 0,71 & 4,6 & 3,48 \\
\hline $\begin{array}{l}\text { 14.Busquei solucionar minhas dúvidas ao } \\
\text { consultar as apostilas do curso. }\end{array}$ & & & & 0,46 & 0,67 & 8,17 & 2,15 \\
\hline $\begin{array}{l}\text { 15.Busquei compreender melhor os conteúdos ao } \\
\text { estudá-los nas apostilas do curso. }\end{array}$ & & 0,37 & & 0,43 & 0,71 & 8,22 & 2,10 \\
\hline
\end{tabular}


Tabela 25. Estrutura empírica da Escala de Estratégias de aprendizagem (conclusão).

\begin{tabular}{|c|c|c|c|c|c|c|c|}
\hline \multirow{2}{*}{ Descrição dos Itens } & \multicolumn{4}{|c|}{ Cargas Fatoriais } & \multirow{2}{*}{$\mathbf{h}^{2}$} & \multirow{2}{*}{$\mathbf{X}$} & \multirow{2}{*}{ DP } \\
\hline & 1 & 2 & 3 & 4 & & & \\
\hline $\begin{array}{l}\text { 16.Busquei outras fontes de pesquisa, fora da } \\
\text { internet, relacionadas ao curso para me ajudar a } \\
\text { aprender. }\end{array}$ & & & & & 0,53 & 7,14 & 3,04 \\
\hline $\begin{array}{l}\text { 17.Busquei sites relacionados ao conteúdo do } \\
\text { curso para me ajudar a aprender. }\end{array}$ & 0,33 & & & & 0,54 & 8,3 & 2,16 \\
\hline $\begin{array}{l}\text { 18.Tentei entender o conteúdo ao aplicá-lo na } \\
\text { prática, ao invés de dedicar tempo lendo ou } \\
\text { pedindo ajuda a alguém. }\end{array}$ & 0,64 & & & & 0,47 & 5,89 & 2,87 \\
\hline $\begin{array}{l}\text { 19.Realizei os exercícios práticos propostos ao } \\
\text { longo do curso para me ajudar a aprender. }\end{array}$ & 0,67 & & & & 0,55 & 7,66 & 2,44 \\
\hline $\begin{array}{l}\text { 20. Revisei os conteúdos relativos aos exercícios } \\
\text { em que cometi erros. }\end{array}$ & 0,61 & & & & 0,63 & 6,56 & 2,85 \\
\hline $\begin{array}{l}\text { 21.Aprendi conteúdos ao mentalizá-los } \\
\text { repetidamente até perceber que havia entendido. }\end{array}$ & 0,65 & & & & 0,84 & 5,44 & 3,22 \\
\hline $\begin{array}{l}\text { 22.Repeti mentalmente os conteúdos do curso que } \\
\text { gostaria de aprender. }\end{array}$ & 0,70 & & & & 0,83 & 5,77 & 3,26 \\
\hline 23.Fiz anotações sobre o conteúdo do curso. & & & & 0,75 & 0,60 & 7,94 & 2,51 \\
\hline 24.Fiz resumos do conteúdo do curso. & & & & 0,80 & 0,64 & 6,57 & 3,27 \\
\hline $\begin{array}{l}\text { 25.Li o conteúdo do curso várias vezes como } \\
\text { método para aprender. }\end{array}$ & & & & 0,41 & 0,56 & 6,01 & 3,02 \\
\hline $\begin{array}{l}\text { 26.Fiz esquemas do conteúdo do curso como } \\
\text { método para aprender. }\end{array}$ & & & & 0,43 & 0,60 & 5,97 & 3,24 \\
\hline $\begin{array}{l}\text { 27.Refleti sobre as implicações que os conteúdos } \\
\text { aprendidos poderiam ter. }\end{array}$ & 0,47 & & & 0,39 & 0,70 & 7,61 & 2,34 \\
\hline $\begin{array}{l}\text { 28.Busquei desenvolver uma ideia global sobre } \\
\text { como os conteúdos do curso se relacionavam } \\
\text { entre si. }\end{array}$ & 0,38 & & & 0,38 & 0,60 & 7,93 & 2,07 \\
\hline $\begin{array}{l}\text { 29.Associei os conteúdos do curso aos meus } \\
\text { conhecimentos anteriores. }\end{array}$ & & & & 0,38 & 0,49 & 8,69 & 1,67 \\
\hline $\begin{array}{l}\text { 30.Diferenciei, ao analisar os conteúdos do curso, } \\
\text { os aspectos mais importantes dos menos } \\
\text { importantes. }\end{array}$ & 0,30 & & & & 0,42 & 7,51 & 2,33 \\
\hline $\begin{array}{l}\text { 31.Identifiquei situações diárias em que eu } \\
\text { pudesse aplicar os conteúdos do curso. }\end{array}$ & & & & & 0,44 & 7,97 & 2,08 \\
\hline $\mathrm{N}$ & 105 & 105 & 105 & 105 & & & \\
\hline Eigenvalue (Valor próprio) & 9,38 & 3,07 & 2,17 & 1,84 & & & \\
\hline \% da Variância Explicada & 30,26 & 9,92 & 7,01 & 5,96 & & & \\
\hline No. de itens & 14 & 9 & 4 & 10 & & & \\
\hline Alfa $(\alpha)$ & 0,87 & 0,80 & 0,82 & 0,78 & & & \\
\hline
\end{tabular}

A escala de Estratégias de aprendizagem é formada por 31 itens e possui 4 fatores nomeados: Fator 1 "Monitoramento da Compreensão", Fator 2 "Estratégias Autorregulatórias", Fator 3 "Busca de Ajuda Interpessoal" e Fator 4 "Estratégias CognitivoComportamentais".

O Fator 1, Monitoramento da Compreensão, apresentou um total de 12 itens (5, 6, 8, 9, 10 e 17 a 30, com exceção dos itens 23, 24, 25, 26 e 29) e possui um bom índice de consistência interna $(\alpha=0,87)$, com cargas fatoriais variando entre 0,30 e 0,70 . Dos 14 itens 
que compõem esse fator, 9 correspondem às estratégias cognitivas e três itens provêm das estratégias autorregulatórias, segundo Martins (2012). No trabalho da referida autora, o fator de estratégias cognitivas é composto por variáveis ligadas à repetição, organização e elaboração do material didático juntamente com um item de aplicação prática e dois itens relativos a estratégias comportamentais de busca de ajuda ao material didático, tal como propõem Warr e Allan (1998). No caso das estratégias autorregulatórias, estas compreendem elementos destinados ao gerenciamento da motivação e monitoramento da compreensão. Neste estudo, algumas das estratégias cognitivas e autorregulatórias verificadas por Martins (2012) se agruparam em um mesmo fator. Tendo em vista o perfil dos cursos considerados na presente investigação, a amostra conta com diminutos encontros presenciais; dessa feita, é bastante coerente o agrupamento de itens que contribuam para o processo de aprendizagem e modificação do comportamento de estudo do discente quando necessário, já que o mesmo responde majoritariamente pelas ações instrucionais efetuadas. $\mathrm{O}$ fator 1 apresentou compartilhamento de cargas em três itens com os fatores de estratégias autorregulatórias (fator 2) e cognitivo-comportamentais (fator 4). O item 10, "Esforcei-me para verificar minha compreensão sobre o que estava sendo ensinado", que revelou cargas compartilhadas entre os fatores 2 e 4 , alude a ações responsáveis pela verificação da tomada de conhecimento e gestão do comportamento discente.

Já os itens 27 e 28, "Refleti sobre as implicações que os conteúdos aprendidos poderiam ter" e "Busquei desenvolver uma ideia global sobre como os conteúdos do curso se relacionavam entre si" respectivamente, obtiveram partilhamento de cargas o fator 4. A decisão por manter tais itens no fator de monitoramento da compreensão fundamenta-se no entendimento de que os mesmos expressam meios utilizados a fim de gerenciar o processo de aquisição de conhecimento sendo, neste caso, a consulta ao material do curso apenas mero expediente utilizado para isso. Ademais, sobre a tomada dessa escolha também pesou o tamanho das cargas fatoriais.

O Fator 2, Estratégias Autorregulatórias, apresentou um total de 7 itens (1 a 7) que correspondem à definição de estratégias de controle da emoção e estratégias autorregulatórias, propostas por Martins (2012). De acordo com a definição estabelecida por Warr e Allan (1998), tais itens corresponderiam à definição de estratégias de aprendizagem autorregulatórias no que tange ao controle da emoção - essas estratégias representariam o controle da ansiedade e prevenção de dispersões de concentração ocasionadas por sentimentos de ansiedade. Novamente, em virtude do feitio da amostra tida em conta, é esperado e 
necessário que aprendizes, cujas atividades acadêmicas são marcadas pelo distanciamento físico e isolamento social, desenvolvam recursos hábeis ao domínio emocional e motivacional. Este fator apresentou um bom índice de consistência interna $(\alpha=0,80)$, com cargas fatoriais variando entre 0,35 e 0,81 .

Dentro do fator 2, dois itens de estratégias autorregulatórias compartilharam cargas com itens de monitoramento da compreensão (fator 1), e um item teve carga compartilhada com o fator 3 - busca de ajuda interpessoal. Em relação ao primeiro caso (compartilhamento de cargas entre os fatores 2 e 1), apesar dos itens se referirem, em um primeiro momento, a ações que favorecem o processo de acompanhamento da compreensão, e consequente conquista da aprendizagem, entendeu-se que os mesmos evidenciam e se relacionam em maior intensidade a expedientes voltados à regulação ótima dos níveis de concentração e interesse discente. No tocante à segunda situação, cargas compartilhadas entre os fatores $2 \mathrm{e}$ 3 , observou-se que, apesar do tamanho das cargas fatoriais, o item claramente se vincula às estratégias autorregulatórias, não guardando manifesta relação com habilidades que visem a busca por ajuda de outros indivíduos. Dessa forma, a decisão por manter tais itens $(5,6$ e 7$)$ no fator 1, encontra respaldo na definição conceitual presente na literatura para tais estratégias.

O Fator 3, Busca de Ajuda Interpessoal, contou com um total de 3 itens (11, 12 e 13) que denotam estratégias voltadas à obtenção de auxílio de outras pessoas, como colegas e tutores, a fim de solucionar dúvidas a respeito do conteúdo do curso. Esse fator retrata um comportamento proativo do aprendiz de procurar por ajuda, ao contrário de obter instruções a partir do próprio material do curso (Warr \& Allan, 1998). Houve correspondência entre o fator em questão e aquele obtido por Martins (2012). O índice de consistência interna para o mesmo é considerado bom $(\alpha=0,82)$, com cargas fatoriais variando entre 0,63 e 0,72 .

O Fator 4, Estratégias Cognitivo-Comportamentais, é formado por 7 itens (14, 15, 23 a 26 e 29), possui um índice de consistência interna razoável $(\alpha=0,78)$ e itens com cargas fatoriais variando entre 0,38 a 0,80. As estratégias de busca de ajuda ao material didático e repetição, organização e elaboração, na proposta de Warr e Allan (1998), uniram-se em um mesmo fator. A obtenção de informações por meio de fontes que não pressuponham contato social parece funcionar como recurso auxiliar às estratégias de reflexão ativa acerca dos conteúdos ministrados ao longo das ações instrucionais. Dado que o nível de complexidade de diversos cursos pode ser considerado alto, é razoável ponderar que estratégias responsáveis apenas pela consecução do dado de informação 'bruto' não atuem como imprescindíveis à 
amostra; ao contrário, apesar de fazerem referência aos materiais didáticos empregados, estes são tomados a fim de favorecerem os processos de seleção, decodificação, armazenamento e recuperação de informações.

No fator 4 houve compartilhamento de cargas com um item de estratégias autorregulatórias (fator 2) que se refere à consulta nas apostilas a fim de melhor compreender os conteúdos transmitidos. A opção por manter esse item (15) no fator 4 justifica-se pelo tamanho da carga fatorial e pela proposição teórica identificada no campo científico.

Do total dos 31 itens analisados, 2 não se agruparam em fator algum, a saber: 16, "Busquei outras fontes de pesquisa, fora da internet, relacionadas ao curso para me ajudar a aprender", e 31, "Identifiquei situações diárias em que eu pudesse aplicar os conteúdos do curso", referentes às estratégias cognitivas, tal como proposto por Martins (2012).

\subsubsection{Fatores relacionados à evasão e à persistência em EAD}

As respostas dos 126 participantes aos 45 itens do questionário apresentaram 11 casos extremos univariados e nenhum caso extremo multivariado, os quais não foram retirados do arquivo de dados. Foram identificados valores omissos entre $0,79 \%$ e 2,38\%, não sendo necessário estimar valores para substituir os mesmos.

Precedendo a realização da análise de componentes principais, observaram-se algumas características sobre a elaboração da matriz de covariância e foi identificado 1 par de itens altamente correlacionados entre si, sendo ele:

- Par 1: 25 “A qualidade das respostas fornecidas pelo tutor às dúvidas/questões dos alunos" e 26 "A qualidade das interações de aprendizagem (entre alunos e entre alunos e tutor) ao longo do curso" $(r=0,83, p<0,01)$;

No tocante ao referido par de itens, verificou-se que os conteúdos avaliados pelos mesmos eram similares. O item 25 avalia as propriedades inerentes às orientações e feedbacks emitidos pelo tutor em face de questionamentos e solicitações discentes. No caso do item 26 , é aferida a natureza e condições das comunicações estabelecidas entre todos os possíveis agentes participantes da ação instrucional. Avaliando as duas afirmativas, conclui-se que, apesar de uma aparente e inicial redundância de conteúdo, tais itens se propõem a apreciar 
distintos tipos de interações tecidas entre profissionais e estudantes. Anui-se que o item 25 aparenta ser um elemento derivado da sentença 26 , ou seja, o primeiro corresponderia às propriedades de um tipo de contato específico (a qualidade das respostas dadas pelo tutor) enquanto que a segunda afirmativa retrataria um aspecto de caráter mais generalista (a qualidade de toda e qualquer troca interpessoal efetuada); logo, entendeu-se que tais itens estimam diferentes variáveis que podem ser generalizadas sob o termo 'intercomunicabilidade instrucional'. Assim estabelecida a diferença, poder-se-ia dizer que a qualidade das interações de aprendizagem é o gênero do qual a qualidade das respostas emitidas pelo tutor é espécie.

Por esta razão, e tendo em vista a relevância das competências de tutoria para o êxito de práticas educativas em EAD, optou-se por manter os itens em questão no instrumento de fatores relacionados à evasão e à persistência em EAD.

A análise da matriz de covariância em termos de fatorabilidade se deu com base no tamanho das correlações obtidas e a adequação da amostra. Foram encontrados em mais de $50 \%$ dos casos valores de correlação superiores a 0,30 , sugerindo que a matriz provavelmente é fatorizável. No tocante ao teste de KMO, obteve-se um valor de 0,81, tido como um bom índice de adequação da amostra.

Para a extração inicial de fatores foi empregada a técnica de análise dos componentes principais, respeitando os critérios convencionais já descritos anteriormente. A análise dos componentes principais, com tratamento listwise para os casos omissos, indica uma estrutura empírica composta por 7 componentes que explicam, em conjunto, 59,44\% da variância total das respostas dos participantes aos itens do questionário. Tal exame considerou o critério dos eigenvalues (valores próprios) maiores ou iguais a um. Em relação à importância do fator, cada componente deveria explicar, no mínimo, 3\% da variância total. Portanto, poderiam ser extraídos sete fatores, no máximo. A análise do scree plot, sugeriu a existência de 3 ou 4 componentes, como pode ser observado na Figura 14. 


\section{Scree Plot}

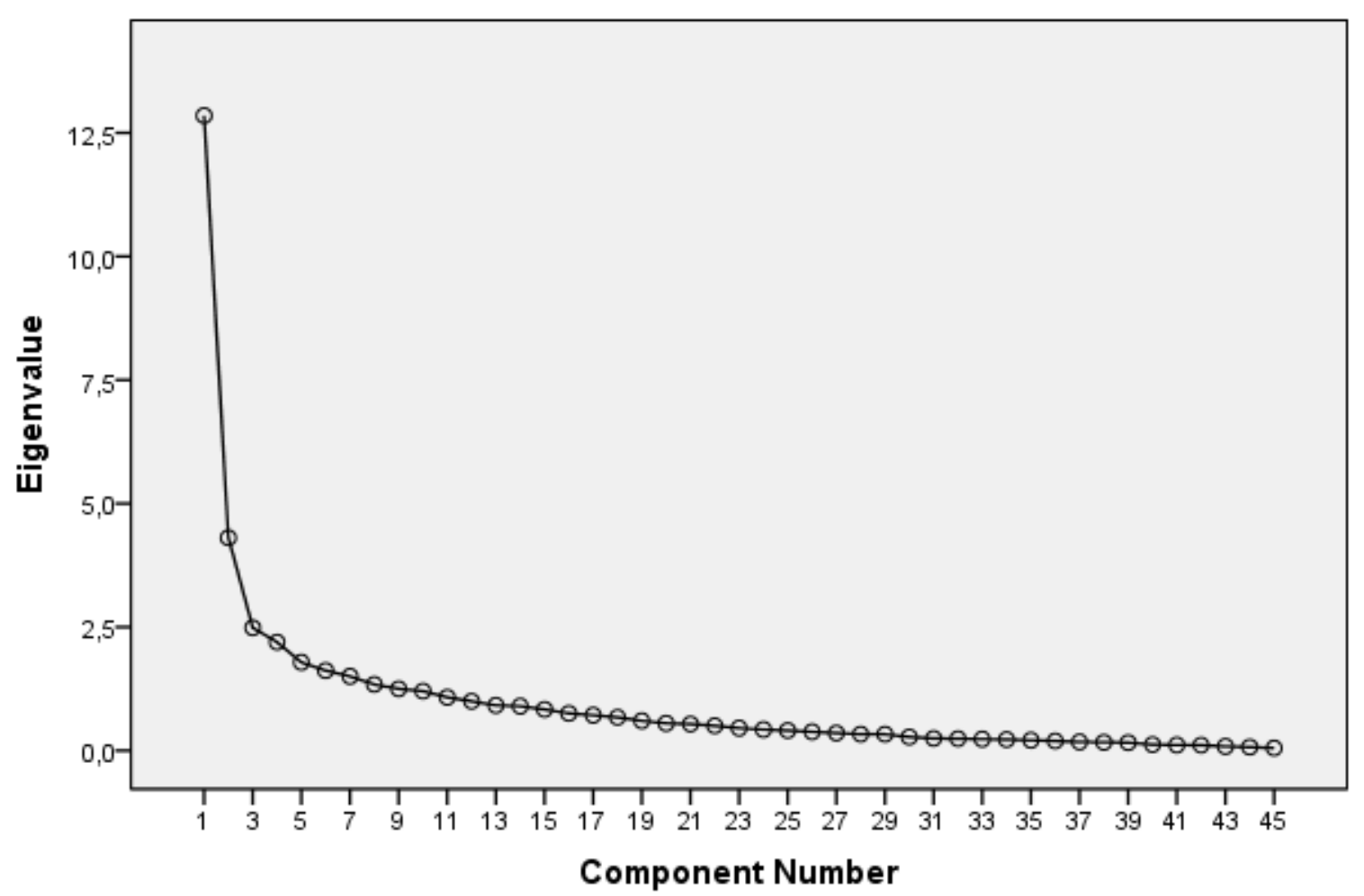

Figura 14. Distribuição dos valores próprios (scree plot) da escala de Fatores relacionados à evasão e à persistência em EAD.

Já a análise paralela de Horn apontou para uma solução com 4 fatores para o instrumento em questão. A Tabela 26 descreve os valores próprios empíricos e os valores aleatórios obtidos a partir de tal técnica.

Tabela 26. Valores próprios empíricos e aleatórios dos primeiros dez componentes de Fatores relacionados à evasão e à persistência em EAD.

\begin{tabular}{lcccccccccc}
\hline $\begin{array}{l}\text { Valores } \\
\text { Próprios }\end{array}$ & 1 & 2 & 3 & 4 & 5 & 6 & 7 & 8 & 9 & 10 \\
\hline Empírico & $\mathbf{1 2 , 8 4}$ & $\mathbf{4 , 3 0}$ & $\mathbf{2 , 4 8}$ & $\mathbf{2 , 1 9}$ & 1,78 & 1,61 & 1,50 & 1,33 & 1,25 & 1,20 \\
\hline Aleatório & $\mathbf{2 , 3 8}$ & $\mathbf{2 , 2 2}$ & $\mathbf{2 , 0 9}$ & $\mathbf{1 , 9 9}$ & 1,90 & 1,81 & 1,73 & 1,66 & 1,59 & 1,53 \\
\hline
\end{tabular}

$\mathrm{N}^{\circ}$. de itens (45); $\mathrm{N}=126$

É possível verificar que apenas os quatro primeiros componentes apresentam valor próprio empírico maior que o gerado pela análise paralela, indicando uma estrutura formada por 4 fatores. $\mathrm{Na}$ análise dos valores próprios e variância explicada foram obtidos o máximo de 7 componentes, na análise do scree plot verificou-se maior ênfase para uma estrutura com 
três ou quatro componentes e na análise paralela obteve-se 4 fatores. Mediante isso, foram efetuadas análises para a extração final dos fatores com 3 e 4 fatores para comparação. A solução com quatro fatores revelou maior sentido empírico e teórico.

A Tabela 27 apresenta a estrutura empírica da escala, as cargas fatoriais, as comunalidades $\left(\mathrm{h}^{2}\right)$ dos itens, as médias e desvios-padrão, os índices de consistência interna e os valores próprios e percentuais de variância explicada de cada fator.

Tabela 27. Estrutura empírica de Fatores relacionados à evasão e à persistência em EAD (Continua).

\begin{tabular}{|c|c|c|c|c|c|c|c|}
\hline \multirow{2}{*}{ Descrição dos Itens } & \multicolumn{4}{|c|}{ Cargas Fatoriais } & \multirow{2}{*}{$\mathbf{h}^{2}$} & \multirow{2}{*}{$\mathbf{X}$} & \multirow{2}{*}{ DP } \\
\hline & 1 & 2 & 3 & 4 & & & \\
\hline $\begin{array}{l}\text { 1. O apoio fornecido pelo tutor à interação entre } \\
\text { os participantes do curso. }\end{array}$ & 0,81 & & & & 0,78 & 2,88 & 2,40 \\
\hline $\begin{array}{l}\text { 2.Minha habilidade em administrar o tempo para } \\
\text { me dedicar aos estudos. }\end{array}$ & & & 0,72 & & 0,73 & 2,64 & 2,60 \\
\hline 3.A duração total do curso. & & 0,43 & & & 0,62 & 2,27 & 2,66 \\
\hline $\begin{array}{l}\text { 4.Alterações em minha rotina de trabalho } \\
\text { ocorridas durante a realização do curso. }\end{array}$ & & 0,55 & & & 0,72 & 1,09 & 2,88 \\
\hline 5.O grau de complexidade do curso. & & & & $-0,64$ & 0,80 & 1,38 & 2,71 \\
\hline $\begin{array}{l}\text { 6.A qualidade gramatical das mensagens trocadas } \\
\text { pelo tutor com os alunos. }\end{array}$ & 0,47 & & & & 0,69 & 2,02 & 2,56 \\
\hline $\begin{array}{l}\text { 7. Apoio da Instituição de ensino frente às } \\
\text { dificuldades tecnológicas encontradas por mim } \\
\text { durante a realização do curso. }\end{array}$ & 0,44 & & & & 0,66 & 2,29 & 2,68 \\
\hline $\begin{array}{l}\text { 8. Minha habilidade de conciliar o curso com } \\
\text { outras atividades pessoais. }\end{array}$ & & & 0,65 & & 0,72 & 2,28 & 2,65 \\
\hline 9.0 acesso ao sistema virtual do curso. & 0,40 & & & & 0,61 & 3,38 & 2,19 \\
\hline $\begin{array}{l}\text { 10.Minha habilidade em elaborar um plano de } \\
\text { estudo que oriente minhas atividades. }\end{array}$ & & & 0,74 & & 0,72 & 2,45 & 2,53 \\
\hline 11.0 vínculo estabelecido entre tutor e alunos. & 0,81 & & & & 0,79 & 2,22 & 2,80 \\
\hline $\begin{array}{l}\text { 12.Eventos familiares durante a realização do } \\
\text { curso. }\end{array}$ & & 0,62 & & & 0,62 & 0,1 & 2,59 \\
\hline $\begin{array}{l}13 . \mathrm{O} \text { acesso ao material didático utilizado no } \\
\text { curso. }\end{array}$ & 0,47 & & & & 0,66 & 3,08 & 2,24 \\
\hline $\begin{array}{l}\text { 14.A qualidade do feedback/orientações } \\
\text { fornecidos pelo tutor em relação às minhas } \\
\text { participações. }\end{array}$ & 0,77 & & & & 0,77 & 1,45 & 3,22 \\
\hline $\begin{array}{l}\text { 15.O incentivo familiar para a realização do } \\
\text { curso. }\end{array}$ & & & & & 0,49 & 3,34 & 2,17 \\
\hline $\begin{array}{l}\text { 16. Minha habilidade em utilizar recursos e } \\
\text { ferramentas tecnológicas do curso. }\end{array}$ & & & 0,58 & & 0,69 & 3,18 & 2,27 \\
\hline $\begin{array}{l}\text { 17.Acesso às informações acerca do curso antes } \\
\text { de seu início }\end{array}$ & & & & & 0,65 & 1,61 & 2,82 \\
\hline
\end{tabular}


Tabela 27. Estrutura empírica de Fatores relacionados à evasão e à persistência em EAD (continuação).

\begin{tabular}{|c|c|c|c|c|c|c|c|}
\hline \multirow{2}{*}{ Descrição dos Itens } & \multicolumn{4}{|c|}{ Cargas Fatoriais } & \multirow{2}{*}{$\mathbf{h}^{2}$} & \multirow{2}{*}{$\mathbf{X}$} & \multirow{2}{*}{ DP } \\
\hline & 1 & 2 & 3 & 4 & & & \\
\hline $\begin{array}{l}\text { 18. Quantidade de atividades propostas durante o } \\
\text { curso. }\end{array}$ & & & & $-0,51$ & 0,72 & 1,04 & 3,12 \\
\hline $\begin{array}{l}\text { 19.Separação física entre tutores e alunos na } \\
\text { maior parte do tempo do curso. }\end{array}$ & 0,49 & & & & 0,53 & 0,36 & 2,54 \\
\hline 20.Condições do ambiente de estudo em casa. & & 0,30 & & & 0,48 & 2,73 & 2,54 \\
\hline $\begin{array}{l}\text { 21.O grau de dificuldade das atividades propostas } \\
\text { pelo curso. }\end{array}$ & & & & $-0,52$ & 0,79 & 1,24 & 2,70 \\
\hline $\begin{array}{l}\text { 22. A frequência com que utilizei } \\
\text { espontaneamente as ferramentas eletrônicas } \\
\text { disponibilizadas durante o curso. }\end{array}$ & & & 0,41 & & 0,71 & 2,63 & 2,24 \\
\hline $\begin{array}{l}\text { 23.A cooperação entre os alunos ao longo do } \\
\text { curso. }\end{array}$ & 0,48 & & & 0,33 & 0,63 & 2,1 & 2,64 \\
\hline $\begin{array}{l}\text { 24.A condição de saúde dos meus familiares } \\
\text { próximos no período de realização do curso. }\end{array}$ & & 0,45 & & & 0,65 & 1,32 & 3,14 \\
\hline $\begin{array}{l}\text { 25.A qualidade das respostas fornecidas pelo tutor } \\
\text { às dúvidas/questões dos alunos. }\end{array}$ & 0,93 & & & & 0,89 & 2,03 & 2,97 \\
\hline $\begin{array}{l}\text { 26. A qualidade das interações de aprendizagem } \\
\text { (entre alunos e entre alunos e tutor) ao longo do } \\
\text { curso. }\end{array}$ & 0,87 & & & & 0,86 & 1,9 & 2,79 \\
\hline $\begin{array}{l}\text { 27.Disponibilidade de ferramentas eletrônicas no } \\
\text { ambiente do curso para interação com os outros } \\
\text { participantes. }\end{array}$ & 0,60 & & & & 0,73 & 1,98 & 2,77 \\
\hline $\begin{array}{l}\text { 28.Minha motivação para a realização do curso ao } \\
\text { longo de sua ocorrência. }\end{array}$ & 0,46 & & & & 0,66 & 3,65 & 1,96 \\
\hline $\begin{array}{l}\text { 29.Meu tempo disponível para realização do } \\
\text { curso. }\end{array}$ & & 0,37 & 0,35 & & 0,71 & 2,08 & 2,55 \\
\hline $\begin{array}{l}30.0 \text { grau de conhecimento do tutor a respeito } \\
\text { dos temas relacionados ao curso. }\end{array}$ & 0,80 & & & & 0,86 & 2,78 & 2,68 \\
\hline $\begin{array}{l}\text { 31.A reação do tutor frente à manifestação de } \\
\text { idéias pelos alunos. }\end{array}$ & 0,78 & & & & 0,86 & 2,34 & 2,69 \\
\hline $\begin{array}{l}\text { 32.Meu esforço para permanecer no curso durante } \\
\text { momentos de dificuldades. }\end{array}$ & & & 0,45 & & 0,57 & 3,56 & 1,92 \\
\hline $\begin{array}{l}\text { 33.Possibilidade de empregar, em curto prazo, os } \\
\text { conhecimentos e habilidades adquiridos no curso. }\end{array}$ & & & & $-0,36$ & 0,59 & 2,83 & 2,45 \\
\hline $\begin{array}{l}\text { 34.Minha disciplina para cumprir as tarefas } \\
\text { propostas para o curso no prazo fixado. }\end{array}$ & & & 0,71 & & 0,79 & 2,48 & 2,837 \\
\hline $\begin{array}{l}\text { 35. A existência de outras atividades concorrentes } \\
\text { com o curso. }\end{array}$ & & 0,67 & & & 0,65 & 0,47 & 2,72 \\
\hline 36.Minha habilidade em estudar sozinho. & & & 0,61 & & 0,70 & 2,88 & 2,32 \\
\hline $\begin{array}{l}\text { 37.Correspondência do curso às minhas } \\
\text { expectativas. }\end{array}$ & 0,67 & & & $-0,32$ & 0,74 & 3,00 & 2,55 \\
\hline $\begin{array}{l}\text { 38.Minhas experiências anteriores em cursos a } \\
\text { distância. }\end{array}$ & & & & & 0,38 & 0,94 & 2,74 \\
\hline $\begin{array}{l}\text { 39.Meu conhecimento prévio a respeito dos } \\
\text { conteúdos ligados ao curso. }\end{array}$ & & & & & 0,52 & 1,69 & 2,44 \\
\hline $\begin{array}{l}\text { 40.A possibilidade do ambiente virtual de } \\
\text { aprendizagem permitir reiniciar o curso a } \\
\text { qualquer momento. }\end{array}$ & 0,43 & & & & 0,62 & 3,00 & 2,30 \\
\hline $\begin{array}{l}\text { 41.Minha condição de saúde no período de } \\
\text { realização do curso. }\end{array}$ & & 0,37 & & & 0,66 & 2,22 & 3,03 \\
\hline 42.A qualidade dos materiais didáticos & 0,63 & & & & 0,74 & 3,04 & 2,385 \\
\hline
\end{tabular}

empregados no curso. 
Tabela 27. Estrutura empírica de Fatores relacionados à evasão e à persistência em EAD (conclusão).

\begin{tabular}{|c|c|c|c|c|c|c|c|}
\hline \multirow{2}{*}{ Descrição dos Itens } & \multicolumn{4}{|c|}{ Cargas Fatoriais } & \multirow{2}{*}{$\mathbf{h}^{2}$} & \multirow{2}{*}{$\mathbf{X}$} & \multirow{2}{*}{ DP } \\
\hline & 1 & 2 & 3 & 4 & & & \\
\hline $\begin{array}{l}\text { 43.Tempo de estudo semanal necessário para } \\
\text { realização do curso. }\end{array}$ & & 0,52 & & & 0,78 & 1,43 & 3,17 \\
\hline $\begin{array}{l}\text { 44.Mudanças na rotina familiar no período de } \\
\text { desenvolvimento do curso. }\end{array}$ & & 0,78 & & & 0,72 & 0,78 & 2,95 \\
\hline $\begin{array}{l}\text { 45.A realização de outro curso simultaneamente a } \\
\text { este. }\end{array}$ & & 0,66 & & & 0,54 & 0,03 & 2,56 \\
\hline $\mathrm{N}$ & 120 & 120 & 120 & 120 & & & \\
\hline Eigenvalue (Valor próprio) & 13,2 & 4,21 & 2,50 & 2,13 & & & \\
\hline \% da Variância Explicada & 29,34 & 9,36 & 5,55 & 4,75 & & & \\
\hline No. de itens & 18 & 11 & 8 & 4 & & & \\
\hline $\operatorname{Alfa}(\alpha)$ & 0,93 & 0,84 & 0,86 & 0,75 & & & \\
\hline
\end{tabular}

Para análise da estabilidade, verificou-se o quanto os itens eram bons representantes do fator, por meio do tamanho das cargas fatoriais. Para analisar a interpretabilidade, ao denominar os fatores e associá-los ao agrupamento de itens, recorreu-se ao exame do material didático e literatura pertinente. Também foram realizadas análises de consistência interna. Por último, foram produzidos os escores fatoriais pela média dos escores das variáveis originais que pertencem ao fator. Nenhum item foi excluído da estrutura proposta.

O Fator 1, denominado Suporte Tecnológico e de Tutoria, é composto por 18 itens (1, $6,7,9,11,13,14,19,23,25,26,27,28,30,31,37,40$ e 42) que avaliam o quanto aspectos relacionados às competências demonstradas pelo tutor ao longo do curso; à acessibilidade dos materiais e o suporte institucional e social recebido pelo estudante; e às ferramentas virtuais de acesso facilitaram a permanência do aluno no curso. Este fator apresentou um alto índice de consistência interna $(\alpha=0,93)$ e itens com cargas fatoriais variando entre 0,40 e 0,93. Os itens pertencentes ao fator 1 são decorrentes da escala intitulada Influência das Características do Curso a Distância na Permanência do Aluno (ICCP), por Sales (2009), que comporta dois fatores (Desempenho do Tutor e Desenho do Curso). Os itens 23, "A cooperação entre os alunos ao longo do curso", e 37, "Correspondência do curso às minhas expectativas", apresentaram cargas compartilhadas com o fator 4 (Desenho do Curso). No tocante ao item 23, após avaliação conceitual e tendo em vista a congruência semântica, optou-se por mantêlo no fator 1; já em relação à afirmativa 37, após exame da mesma e consulta à literatura pertinente, chegou-se a conclusão de que a adequação do evento instrucional às expectações discentes (elemento retratado pelo item) pode decorrer das ações e apoio prestado ao estudante por parte das instituições de ensino e profissionais envolvidos. Considerando que o item 37 conta com certo nível de abstração (não expressar um comportamento e sim um 
construto intangível), talvez seja interessante que posteriores estudos se atentam para o aperfeiçoamento da redação do mesmo, de forma que elementos observáveis mais específicos possam ser representados.

O Fator 2, Características Exógenas ao Curso, formado por 11 itens (3, 4, 12, 20, 24, $29,35,41,43,44$ e 45), aprecia o quanto variáveis ligadas à conciliação do curso com outras atividades de estudos, profissionais e compromissos familiares; à disponibilidade de tempo; e a problemas de saúde dificultaram a persistência do estudante no evento. Este fator apresentou um bom índice de consistência interna $(\alpha=0,93)$, com itens cujas cargas fatoriais variaram entre 0,30 e 0,78. Os fatores Tempo Disponível e Questões Familiares, oriundas da escala Influência do Contexto do Aluno na sua Permanência nos Cursos a Distância (ICOP) (Sales, 2009), uniram-se em um mesmo fator no presente trabalho. Dentro do fator 2, o item 29, "Meu tempo disponível para realização do curso", compartilhou carga com o fator 3 (Características do Aluno). Em virtude da coerência conceitual e teórica encontrada para tal assertiva, além da relevância das cargas fatoriais, esse item foi mantido no fator ora considerado.

O Fator 3, nomeado Características do Aluno, é constituído pelos itens 2, 8, 10, 16, 22, 32,34 e 36 que averiguam o quanto elementos concernentes às habilidades e atributos discentes (administrar o tempo de estudo, elaborar planos de estudo, respeitar e cumprir prazos, perseverar frente a contratempos e experiências prévias com os recursos tecnológicos) interferiram sobre a permanência do mesmo na ação educativa. Este fator apresentou um bom índice de consistência interna $(\alpha=0,86)$ e itens com cargas fatoriais variando entre 0,35 e 0,71 . Os fatores presentes na escala de Sales (2009) Influência das Características do Aluno na sua Permanência em Cursos a Distância (ICAP) - composta pelos fatores Disciplina e Interesse do Aluno e Experiências e Habilidades Importantes para os Cursos a Distância - foram agregados em um único fator.

Por fim, o Fator 4, Desenho do Curso, integrado pelos itens 5, 18, 21 e 33, considera em que medida os aspectos relativos ao planejamento instrucional (objetivos propostos, planejamento de conteúdos, sequência de conteúdos, avaliações de aprendizagem, carga horária, linguagem empregada e complexidade do curso) contribuem para a saída/permanência do aluno do evento educativo. O presente fator apresentou um índice de consistência interna razoável $(\alpha=0,75)$, com itens cujas cargas fatoriais variaram entre $-0,64$ e 0,33. As afirmativas que compõem este fator decorrem unicamente da escala ICCP, mais especificadamente do fator Desenho do Curso, de Sales (2009). 


\subsubsection{Síntese dos resultados: verificação de evidências de validade dos instrumentos}

A Tabela 28 expõe uma síntese acerca dos dados das ferramentas de medida utilizadas na presente investigação e que foram alvo de análises exploratórias, apresentadas na seção anterior, a fim de verificar evidências de validade das mesmas.

Tabela 28: Resumo das informações sobre os instrumentos de pesquisa.

\begin{tabular}{llcccc}
\hline \multirow{2}{*}{ Instrumento } & \multicolumn{1}{c}{ Escalas obtidas } & No de & \multirow{2}{*}{ Alfa } & \multicolumn{2}{c}{ Cargas fatoriais } \\
\cline { 5 - 7 } & & itens & Min. & Max. \\
\hline \multirow{2}{*}{ Estratégias de } & Monitoramento da compreensão & 14 & 0,87 & 0,30 & 0,70 \\
Aprendizagem & Estratégias autorregulatórias & 9 & 0,80 & 0,35 & 0,81 \\
& Busca de ajuda interpessoal & 4 & 0,82 & 0,63 & 0,72 \\
& Estratégias cognitivo-comportamentais & 10 & 0,78 & 0,38 & 0,80 \\
\hline \multirow{2}{*}{ Fatores Relacionados } & Suporte tecnológico e de tutoria & 18 & 0,93 & 0,40 & 0,93 \\
à Evasão è̀ & Características exógenas ao curso & 11 & 0,84 & 0,30 & 0,78 \\
Persistência eme EAD & Características do aluno & 8 & 0,86 & 0,35 & 0,71 \\
& Desenho do curso & 4 & 0,75 & $-0,64$ & 0,33 \\
\hline
\end{tabular}

Tal como é possível observar, os índices de confiabilidade oscilaram entre 0,75 a 0,93, sugerindo a presença de consistência interna nas escalas obtidas. $\mathrm{O}$ tamanho das cargas fatoriais variou de $-0,64$ a 0,93, revelando que as escalas, além de consistentes, também são válidas e agregam itens representativos de cada fator.

\subsection{Análises de regressão múltipla}

As análises de regressão múltipla foram efetuadas intentando cumprir o objetivo de testagem do modelo proposto. As variáveis que compõem o modelo sofreram análises exploratórias, de acordo com os critérios de Tabachnick e Fidell (2001). Segundo tais autores, as análises de regressão devem respeitar os seguintes critérios de inclusão: amostra maior ou igual a 50 casos mais oito vezes o número de variáveis antecedentes $(\mathrm{N} \geq 50+8 \mathrm{~m})$ para testagem de correlações múltiplas e $\mathrm{N} \geq 104+\mathrm{m}$ para testagem de preditores individuais. $\mathrm{Na}$ análise stepwise, uma amostra maior é necessária (razão de 40 casos para cada variável antecedente). Portanto, para testar o modelo completo, com 8 variáveis antecedentes, foi possível realizar apenas a regressão padrão $(\mathrm{N} \geq 50+8.8=\mathrm{N} \geq 126)$.

Em virtude da obtenção dos 4 fatores, "Suporte tecnológico e de tutoria", 
"Características exógenas ao curso", "Características do aluno" e "Desenho do curso", relativos à variável critério, foram testados diferentes modelos preditivos correlatos a cada um dos fatores extraídos.

Dessa feita, no Modelo A, foram inseridas nas análises as seguintes variáveis antecedentes: média das respostas aos itens dos quatro fatores do instrumento Estratégias de aprendizagem: est1 (monitoramento da compreensão), est2 (estratégias autorregulatórias), est3 (busca de ajuda interpessoal), est4 (estratégias cognitivo-comportamentais); média das respostas aos itens do instrumento de variáveis sociodemográficas (idade, sexo, composição familiar e estado civil). Tomando em consideração os achados e indicações provenientes da literatura especializada, não foram inclusas aquelas variáveis que pouca contribuição ofertam ao entendimento do objeto de estudo aqui considerado. A variável critério estudada foi a média das respostas dos participantes aos itens que compõem o fator Suporte tecnológico e de tutoria, medida em termos das respostas dos participantes à escala de intensidade da influência das variáveis ligadas ao abandono e à permanência acadêmica. Na Figura 15 é possível visualizar o Modelo A. 


\section{ESTRATÉGIAS DE APRENDIZAGEM}

Monitoramento da compreensão - est1

Estratégias autorregulatórias - est2

Busca de ajuda interpessoal - est3

Estratégias cognitivo-comportamentais - est4

\section{DADOS SOCIODEMOGRÁFICOS}

Sexo - Sex

Idade - Idd

Estado Civil - EstCiv

Composição Familiar - Fam

Figura 15. Modelo A de análise de predição de Suporte tecnológico e de tutoria.

Encontram-se dispostas na Tabela 29 as correlações entre as variáveis, os coeficientes de regressão não padronizados $(\mathrm{B})$, os coeficientes de regressão padronizados $(\beta)$, a contribuição individual de cada variável $\left(\mathrm{Sr}^{2}\right)$, as médias das variáveis $(\mathrm{X})$, os desvios-padrão (DP), a constante, o $\mathrm{R}^{2}$ (correlação entre todas as variáveis antecedentes com a variável critério - variância individual e compartilhada das variáveis antecedentes em relação à variável critério), o $\mathrm{R}^{2}$ ajustado (estimativa do $\mathrm{R}^{2}$ da população) e o $\mathrm{R}$ (correlação entre a variável critério e as variáveis antecedentes). 
Tabela 29. Regressão múltipla padrão para o Modelo A.

\begin{tabular}{|c|c|c|c|c|c|c|c|c|c|}
\hline Var. & $\begin{array}{l}\text { Eva1 } \\
\text { (VD) }\end{array}$ & Sex & Idd & EstCiv & Fam & Est1 & Est2 & Est3 & Est4 \\
\hline Sex & 0,02 & & & & & & & & \\
\hline Idd & $0,13^{*}$ & 0,03 & & & & & & & \\
\hline EstCiv & $0,15^{*}$ & $0,24^{*}$ & $0,42 *$ & & & & & & \\
\hline Fam & $-0,00$ & $0,13^{*}$ & $-0,50$ & $-0,24$ & & & & & \\
\hline Est1 & $0,36 *$ & $-0,06$ & $0,14^{*}$ & $0,13 *$ & $-0,15$ & & & & \\
\hline Est2 & $0,28^{*}$ & 0,04 & $0,17 *$ & 0,03 & $-0,00$ & $0,36^{*}$ & & & \\
\hline Est3 & $0,39 *$ & $-0,32$ & 0,03 & $-0,13$ & $-0,23$ & $0,48^{*}$ & $0,15^{*}$ & & \\
\hline Est4 & $0,31 *$ & $-0,34$ & $0,21 *$ & 0,03 & $-0,09$ & $0,60 *$ & $0,22 *$ & $0,42 *$ & \\
\hline $\mathrm{B}$ & & 5,77 & 0,64 & 12,69 & 8,52 & $0,06^{*}$ & 0,57 & $1,74^{*}$ & 0,31 \\
\hline$\beta$ & & 0,09 & 0,02 & 0,19 & 0,13 & 0,04 & 0,17 & 0,36 & 0,11 \\
\hline $\mathrm{Sr}^{2}$ & & 0,00 & 0,00 & 0,01 & 0,00 & 0,00 & 0,01 & 0,05 & 0,00 \\
\hline $\mathrm{X}$ & 38,55 & 1,52 & 3,47 & 1,63 & 1,41 & 74,29 & 46,56 & 11,05 & 43,76 \\
\hline DP & 31,60 & 0,50 & 1,41 & 0,48 & 0,49 & 20,57 & 9,68 & 6,63 & 11,86 \\
\hline Constante & $-70,28$ & $\mathrm{R}^{2}=$ & & $\mathrm{R}^{2}$ (ajustad & $=0,20^{*}$ & &, $52 *$ & & \\
\hline
\end{tabular}

$\mathrm{O}$ coeficiente de regressão múltipla $\mathrm{R}$ foi significativamente diferente de zero, $\mathrm{F}(8$, 126) $=3,99<0,001$, sendo considerados limites de confiança de 95\%. Duas variáveis antecedentes contribuíram significativamente para a explicação de suporte tecnológico e de tutoria, a saber: Est1 ( $\beta=0,04$ e IC de 95\%) e Est3 ( $\beta=0,36$ e IC de 95\%). Agrupadas, as 8 variáveis iniciais, explicam 27\% (20\% ajustado) da variabilidade de suporte tecnológico e de tutoria; já em relação às variáveis que contribuíram significativamente com a explicação da variável critério estas explicam cerca de $4 \%$ da variabilidade de suporte tecnológico e de tutoria. A Figura 16 ilustra o relacionamento identificado entre as variáveis que indicaram maior poder preditivo com a variável critério. 


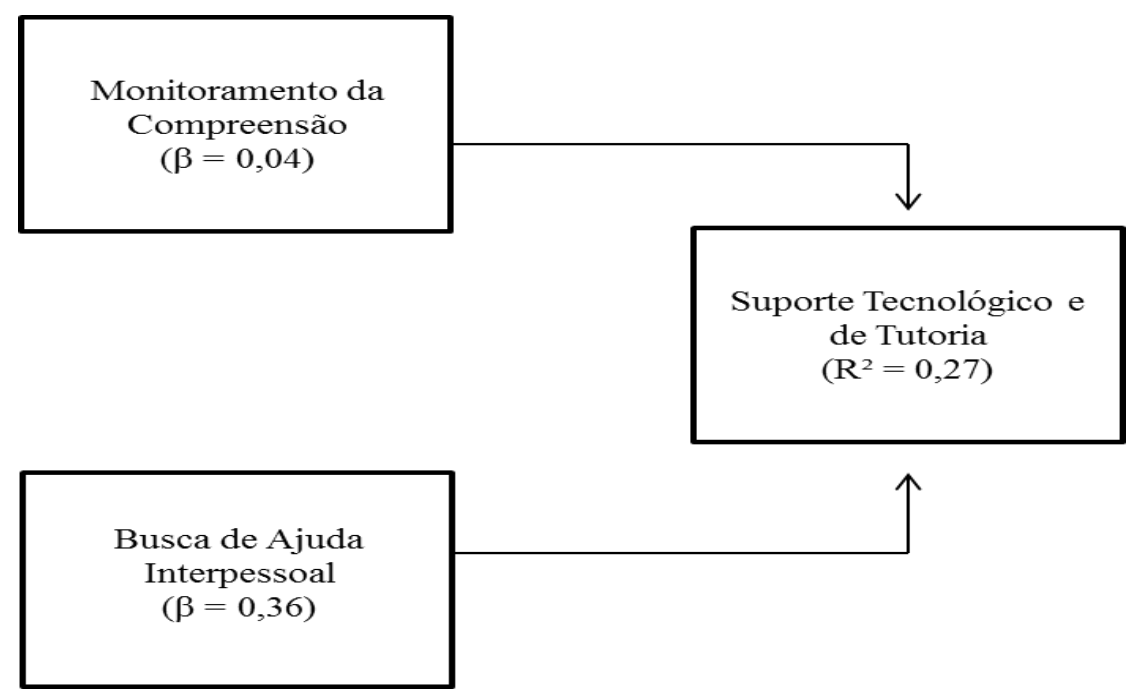

Figura 16. Representação do modelo de regressão múltipla para Suporte tecnológico e de tutoria como variável critério.

De modo geral, os estudantes que relataram empregar com mais frequência as estratégias de aprendizagem de monitoramento da compreensão e de busca de ajuda interpessoal foram aqueles que mais consideraram o suporte tecnológico e de tutoria fornecido como relevante para sua continuidade no curso desenvolvido. Tal relação parece muito razoável quando se considera a relevância que o apoio prestado aos discentes pelos profissionais e instituição educativa teria para os indivíduos que mais recorrem a obtenção de orientações e auxílio de seus pares a fim de mitigar dúvidas sobre os conteúdos transmitidos. Ou seja, o emprego exitoso da estratégia de procura de ajuda interpessoal dependeria em grande parte da qualidade do suporte ofertado, bem como dos recursos tecnológicos subsidiários ao mesmo. Ademais, em situações de aprendizagem nas quais o aprendiz torna-se o principal responsável pelo ganho efetivo de conhecimento (tal como ocorre na educação a distância), é esperado e desejável o desenvolvimento de habilidades que o auxiliem a inspecionar os processos cognitivos que geram tal ganho.

Para testagem do Modelo B, foram consideradas as seguintes variáveis antecedentes: média das respostas aos itens dos quatro fatores do instrumento Estratégias de aprendizagem: est1 (monitoramento da compreensão), est2 (estratégias autorregulatórias), est3 (busca de ajuda interpessoal), est4 (estratégias cognitivo-comportamentais); média das respostas aos itens do instrumento de variáveis sociodemográficas (idade, sexo, composição familiar e estado civil). A variável critério investigada foi a média das respostas dos participantes aos itens que compõem o fator Características exógenas ao curso, medida em termos das respostas dos participantes à escala de intensidade da influência das variáveis relacionadas ao abandono e à permanência acadêmica. Na Figura 17 é possível visualizar o Modelo B. 


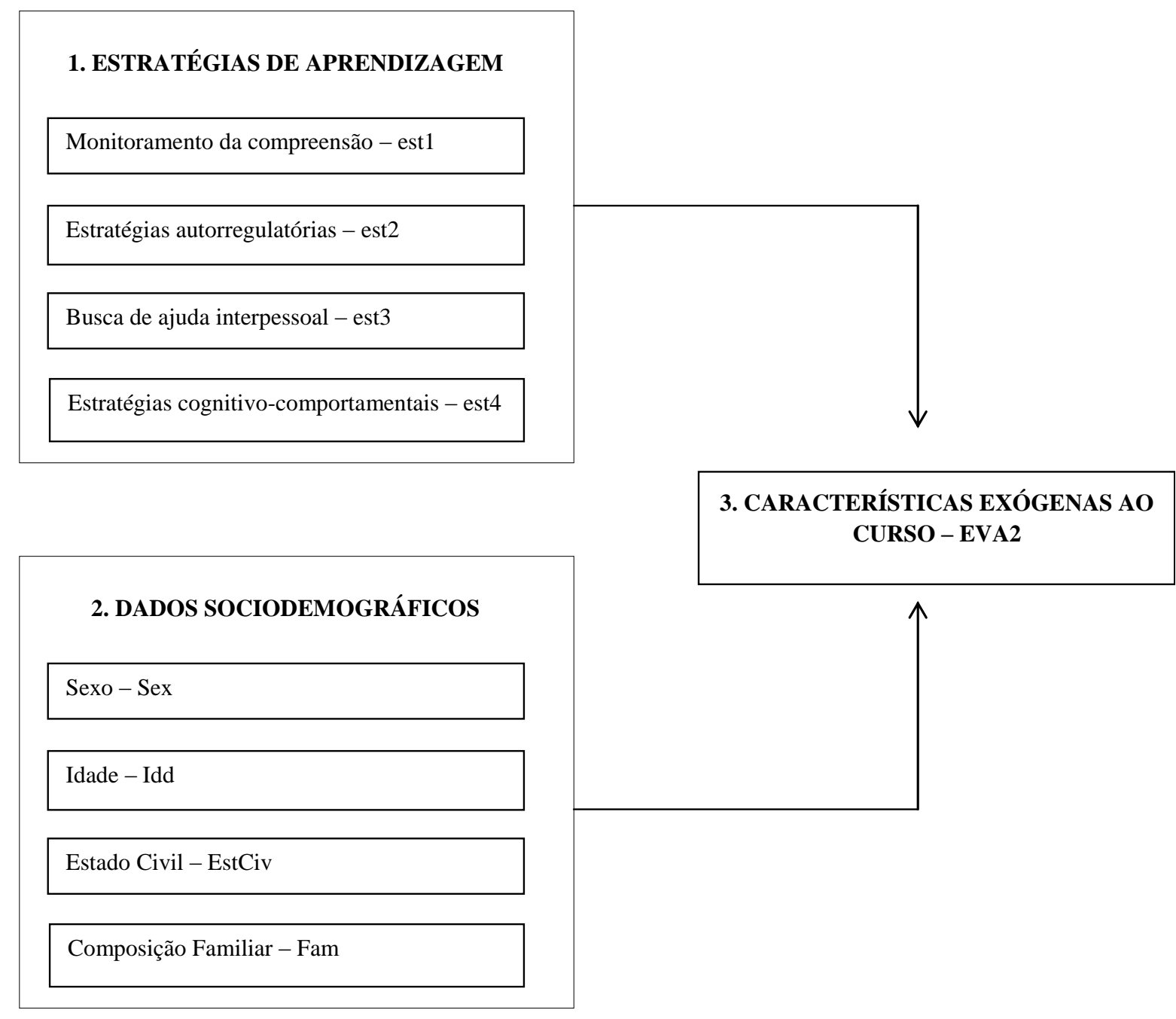

Figura 17. Modelo B de análise de predição de Características exógenas ao curso.

Na Tabela 30 são apresentadas as correlações entre as variáveis, os coeficientes de regressão não padronizados $(B)$, os coeficientes de regressão padronizados $(\beta)$, a contribuição individual de cada variável $\left(\mathrm{Sr}^{2}\right)$, as médias das variáveis $(\mathrm{X})$, os desvios-padrão (DP), a constante, o $\mathrm{R}^{\mathbf{2}}$ (correlação entre todas as variáveis antecedentes com a variável critério variância individual e compartilhada das variáveis antecedentes em relação à variável critério), o $\mathrm{R}^{2}$ ajustado (estimativa do $\mathrm{R}^{2}$ da população) e o $\mathrm{R}$ (correlação entre a variável critério e as variáveis antecedentes). 
Tabela 30: Regressão múltipla padrão para o Modelo B.

\begin{tabular}{|c|c|c|c|c|c|c|c|c|c|}
\hline Var. & $\begin{array}{l}\text { Eva2 } \\
\text { (VD) }\end{array}$ & $\operatorname{Sex}$ & Idd & EstCiv & Fam & Est1 & Est2 & Est3 & Est4 \\
\hline Sex & $-0,04$ & & & & & & & & \\
\hline Idade & 0,09 & 0,03 & & & & & & & \\
\hline Est.Civil & 0,02 & $0,24 *$ & $0,42 *$ & & & & & & \\
\hline Comp.Fam. & $-0,17$ & $0,13^{*}$ & $-0,50$ & $-0,24$ & & & & & \\
\hline Est1 & $0,47 *$ & $-0,06$ & $0,14^{*}$ & 0,13 & $-0,15$ & & & & \\
\hline Est2 & $0,24^{*}$ & 0,04 & $0,17 *$ & 0,03 & $-0,00$ & $0,36^{*}$ & & & \\
\hline Est3 & $0,44^{*}$ & $-0,32$ & 0,03 & $-0,13$ & $-0,23$ & $0,48^{*}$ & $0,15^{*}$ & & \\
\hline Est4 & $0,28 *$ & $-0,34$ & $0,21 *$ & 0,03 & $-0,09$ & $0,60 *$ & $0,22 *$ & $0,42 *$ & \\
\hline $\mathrm{B}$ & & 2,30 & $-0,22$ & $-0,28$ & $-3,25$ & $0,27 *$ & 0,18 & $0,81 *$ & $-0,04$ \\
\hline$\beta$ & & 0,06 & $-0,01$ & $-0,00$ & $-0,08$ & $\mathbf{0 , 3 1}$ & 0,09 & 0,28 & $-0,03$ \\
\hline $\mathrm{Sr}^{2}$ & & 0,00 & 0,00 & 0,00 & 0,00 & $\mathbf{0 , 0 3}$ & 0,00 & $\mathbf{0 , 0 3}$ & 0,00 \\
\hline $\mathrm{X}$ & 12,92 & 1,54 & 3,48 & 1,61 & 1,43 & 74,71 & 46,44 & 11,22 & 43,94 \\
\hline DP & 18,61 & 0,50 & 1,41 & 0,48 & 0,49 & 20,91 & 9,69 & 6,58 & 11,93 \\
\hline Constante $=-21,16$ & & $\mathrm{R}^{2}=0,30^{*}$ & & $\mathrm{R}^{2}$ (ajustad & $=0,23 *$ & & $0,54 *$ & & \\
\hline
\end{tabular}

Foi significativamente diferente de zero o coeficiente de regressão múltipla $R, F(8$, 126) $=4,47<0,001$, sendo considerados limites de confiança de 95\%. Três variáveis antecedentes contribuíram significativamente para a explicação de características exógenas ao curso, a saber: Est1 ( $\beta=0,31$ e IC de 95\%), Est3 ( $\beta=0,28$ e IC de 95\%) e Est4 ( $\beta=-0,03$ e IC de 95\%). Agrupadas, as 8 variáveis iniciais explicam 30\% (23\% ajustado) da variabilidade de características exógenas ao curso; as variáveis que contribuíram significativamente com a explicação da variável critério explicam cerca de 6,2\% da variabilidade de características exógenas ao curso. A Figura 18 esquematiza o relacionamento identificado entre as variáveis que indicaram maior poder preditivo com a variável critério. 


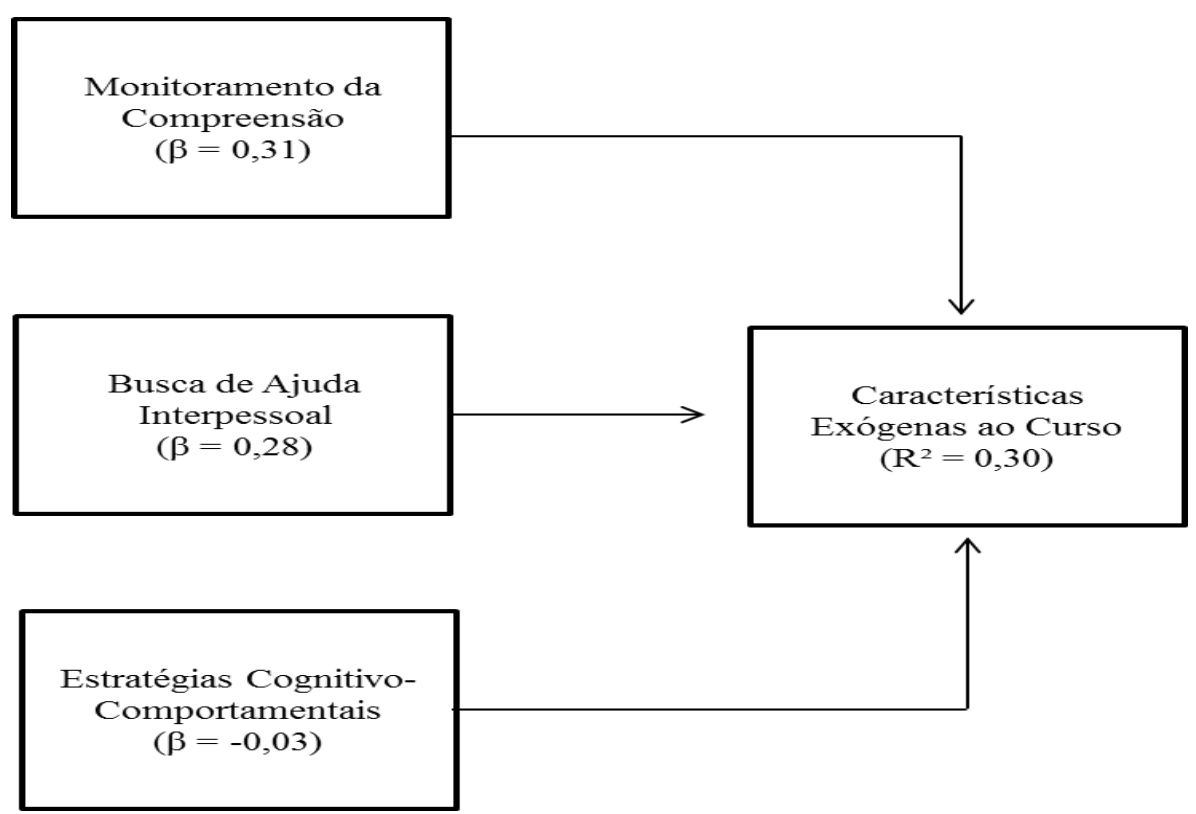

Figura 18. Representação do modelo de regressão múltipla para Características exógenas ao curso como variável critério.

Em suma, os discentes que consideraram as variáveis relativas às características exógenas ao curso como sendo de considerável importância para a não permanência dos mesmos no evento instrucional foram aqueles que afirmaram recorrer repetidas vezes às estratégias de monitoramento da compreensão, busca de ajuda interpessoal e estratégias cognitivo-comportamentais. Tendo em vista que os aprendizes a distância estão sujeitos a um maior número de distratores e respondem por uma extensa gama de afazeres, que caracterizam a complexa realidade atual, é possível que para tais indivíduos, cujas intempéries situacionais podem dificultar sobremaneira a realização de uma ação educativa em EAD, o auxílio prestado por terceiros figure como elemento-chave para uma resolução de problemas de aprendizagem mais imediata e diretiva - que, provavelmente, seria mais custosa se buscada de modo solitário. Além disso, na presença de eventos concorrentes, não é possível afirmar que o aprendiz se sentirá disperso ou desmotivado, mas certamente ele deverá dedicar mais esforços a fim de que seu processo de aprendizagem seja eficaz; nesse sentido, as estratégias voltadas à organização e controle dos fenômenos psíquicos que subsidiam o aprender atuarão como prestimosos recursos para superação de distratores ambientais.

No Modelo C testado, foram consideradas as seguintes variáveis antecedentes: média das respostas aos itens dos quatro fatores do instrumento Estratégias de aprendizagem: est1 (monitoramento da compreensão), est2 (estratégias autorregulatórias), est3 (busca de ajuda interpessoal), est4 (estratégias cognitivo-comportamentais); média das respostas aos itens do instrumento de variáveis sociodemográficas (idade, sexo, composição familiar e estado civil). 
A variável critério estabelecida foi a média das respostas dos participantes aos itens que compõem o fator Características do aluno, medida em termos das respostas dos participantes à escala de intensidade da influência das variáveis relacionadas ao abandono e à permanência acadêmica. Na Figura 19 é possível visualizar o Modelo C.

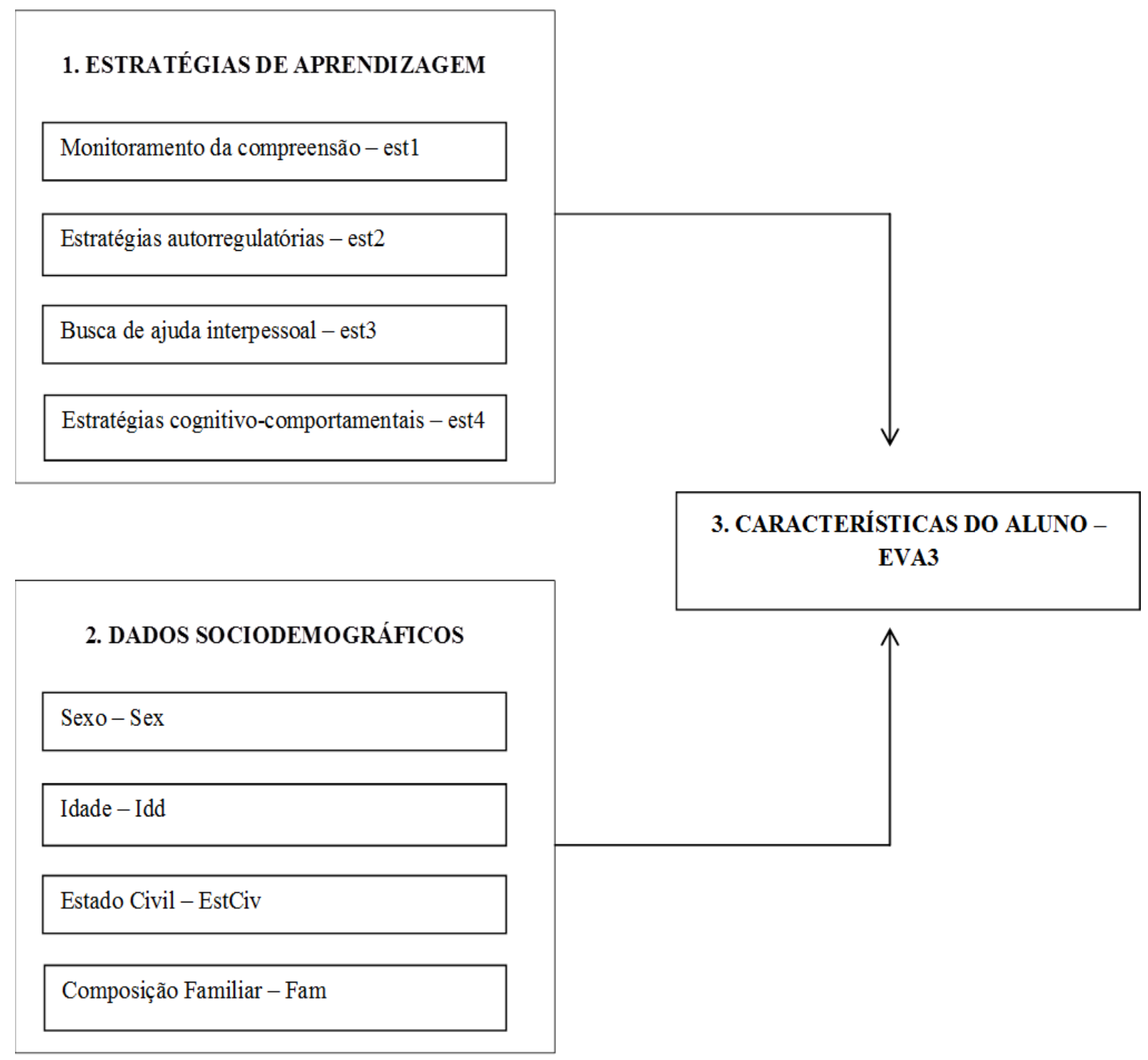

Figura 19. Modelo C de análise de predição de Características do aluno.

Na Tabela 31 encontram-se descritas as correlações entre as variáveis, os coeficientes de regressão não padronizados $(B)$, os coeficientes de regressão padronizados $(\beta)$, a contribuição individual de cada variável $\left(\mathrm{Sr}^{2}\right)$, as médias das variáveis $(\mathrm{X})$, os desvios-padrão (DP), a constante, o $\mathrm{R}^{2}$ (correlação entre todas as variáveis antecedentes com a variável critério - variância individual e compartilhada das variáveis antecedentes em relação à variável critério), o $R^{2}$ ajustado (estimativa do $R^{2}$ da população) e o $R$ (correlação entre a 
variável critério e as variáveis antecedentes).

Tabela 31: Regressão múltipla padrão para o Modelo C.

\begin{tabular}{|c|c|c|c|c|c|c|c|c|c|}
\hline Var. & $\begin{array}{l}\text { Eva1 } \\
\text { (VD) }\end{array}$ & Sex & Idd & EstCiv & Fam & Est1 & Est2 & Est3 & Est4 \\
\hline Sex & 0,05 & & & & & & & & \\
\hline Idd & 0,07 & 0,03 & & & & & & & \\
\hline EstCiv & $0,18^{*}$ & $0,24 *$ & $0,42 *$ & & & & & & \\
\hline Fam & 0,05 & $0,13 *$ & $-0,50$ & $-0,24$ & & & & & \\
\hline Est1 & $0,52^{*}$ & $-0,06$ & $0,14^{*}$ & $0,13 *$ & $-0,15$ & & & & \\
\hline Est2 & $0,42^{*}$ & 0,04 & $0,17 *$ & 0,03 & $-0,00$ & $0,36^{*}$ & & & \\
\hline Est3 & $0,36^{*}$ & $-0,32$ & 0,03 & $-0,13$ & $-0,23$ & $0,48^{*}$ & $0,15^{*}$ & & \\
\hline Est4 & $0,28^{*}$ & $-0,34$ & $0,21 *$ & 0,03 & $-0,09$ & 0,60 & $0,22 *$ & $0,42 *$ & \\
\hline $\mathrm{B}$ & & 1,09 & $-0,11$ & $6,26^{*}$ & $5,63^{*}$ & $0,22 *$ & $0,38^{*}$ & $0,55^{*}$ & $-0,07^{*}$ \\
\hline$\beta$ & & 0,04 & $-0,01$ & 0,22 & 0,20 & 0,34 & 0,27 & 0,27 & $-0,06$ \\
\hline $\mathrm{Sr}^{2}$ & & 0,00 & 0,02 & 0,00 & 0,03 & 0,04 & 0,04 & $\mathbf{0 , 0 3}$ & $\mathbf{0 , 0 0}$ \\
\hline $\mathrm{X}$ & 18,77 & 1,53 & 3,47 & 1,62 & 1,42 & 74,61 & 46,56 & 11,10 & 43,91 \\
\hline DP & 13,46 & 0,50 & 1,40 & 0,48 & 0,49 & 20,70 & 9,63 & 6,61 & 11,88 \\
\hline \multicolumn{2}{|c|}{ Constante $=-38,05$} & \multicolumn{2}{|c|}{$\mathrm{R}^{2}=0,42^{*}$} & $\mathrm{R}^{2}$ (ajustac & $=0,37^{*}$ & \multicolumn{2}{|c|}{$\mathrm{R}=0,65^{*}$} & & \\
\hline
\end{tabular}

$\mathrm{O}$ coeficiente de regressão múltipla $\mathrm{R}$ foi significativamente diferente de zero, $\mathrm{F}(8$, 126) $=7,99<0,001$, sendo considerados limites de confiança de $95 \%$. As variáveis antecedentes que contribuíram significativamente para a explicação de características do aluno foram: Composição familiar ( $\beta=0,20$ e IC de $95 \%)$, Estado civil $(\beta=0,22$ e IC de 95\%), Est1 ( $\beta=0,34$ e IC de 95\%), Est2 ( $\beta=0,27$ e IC de 95\%), Est3 ( $\beta=0,27$ e IC de 95\%) e Est4 $(\beta=-0,06$ e IC de $95 \%)$. Agrupadas, as 8 variáveis iniciais, explicam $42 \%$ (37\% ajustado) da variabilidade de características do aluno; as variáveis que contribuíram significativamente com a explicação da variável critério explicam cerca de $13,6 \%$ da variabilidade de características do aluno. A Figura 20 demonstra o relacionamento identificado entre as variáveis que revelaram maior poder preditivo com a variável critério. 


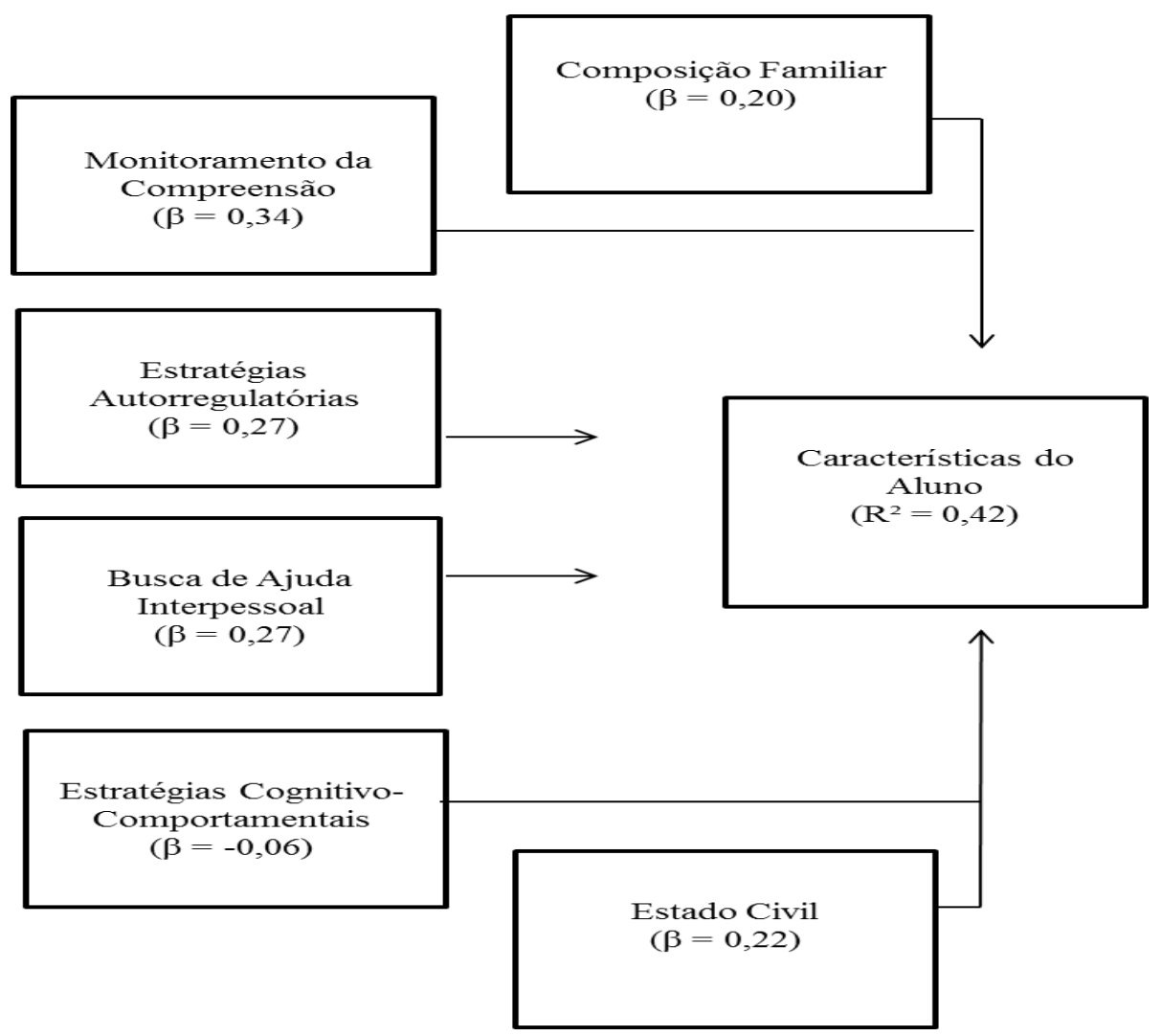

Figura 20. Representação do modelo de regressão múltipla para Características do aluno como variável critério.

Em síntese, os alunos que fizeram uso recorrente das estratégias de monitoramento da compreensão, autorregulatórias, busca de ajuda interpessoal e cognitivo-comportamentais ao longo do evento instrucional foram os mesmos que consideraram as características pessoais do alunado como interferentes sobre a decisão de abandonar o evento. Considerando a própria definição teórica apresentada pelas estratégias de aprendizagem ora referidas, constata-se que as mesmas decorrem de um complexo conjunto de capacidades cognitivas desenvolvidas pelo sujeito ao longo de sua vida; portanto, sendo derivadas de características pessoais do indivíduo que aprende, é razoável que estudantes que se servem das mesmas também compreenderão seus atributos psíquicos como relevantes para a execução do curso e sua finalização. Depreende-se também que para os participantes casados e com filhos os atributos internos do sujeito que aprende são de grande relevância para sua permanência no curso. É provável que para tais indivíduos esse específico arranjo familiar (presença de filhos e cônjuge) implique em numerosos compromissos que, para não dificultarem a continuidade da ação instrucional, dependerão das características pessoais dos mesmos - em termos de persistência e comprometimento com suas incumbências acadêmicas.

Por fim, para o Modelo D, foram estabelecidas como variáveis antecedentes: a média das respostas aos itens dos quatro fatores do instrumento Estratégias de aprendizagem: est1 
(monitoramento da compreensão), est2 (estratégias autorregulatórias), est3 (busca de ajuda interpessoal), est4 (estratégias cognitivo-comportamentais); e a média das respostas aos itens do instrumento de variáveis sociodemográficas (idade, sexo, composição familiar e estado civil). A variável critério estimada foi a média das respostas dos participantes aos itens que compõem o fator Desenho do curso, medida em termos das respostas dos participantes à escala de intensidade da influência das variáveis relacionadas ao abandono e à permanência acadêmica. Na Figura 21 é possível visualizar o Modelo D.

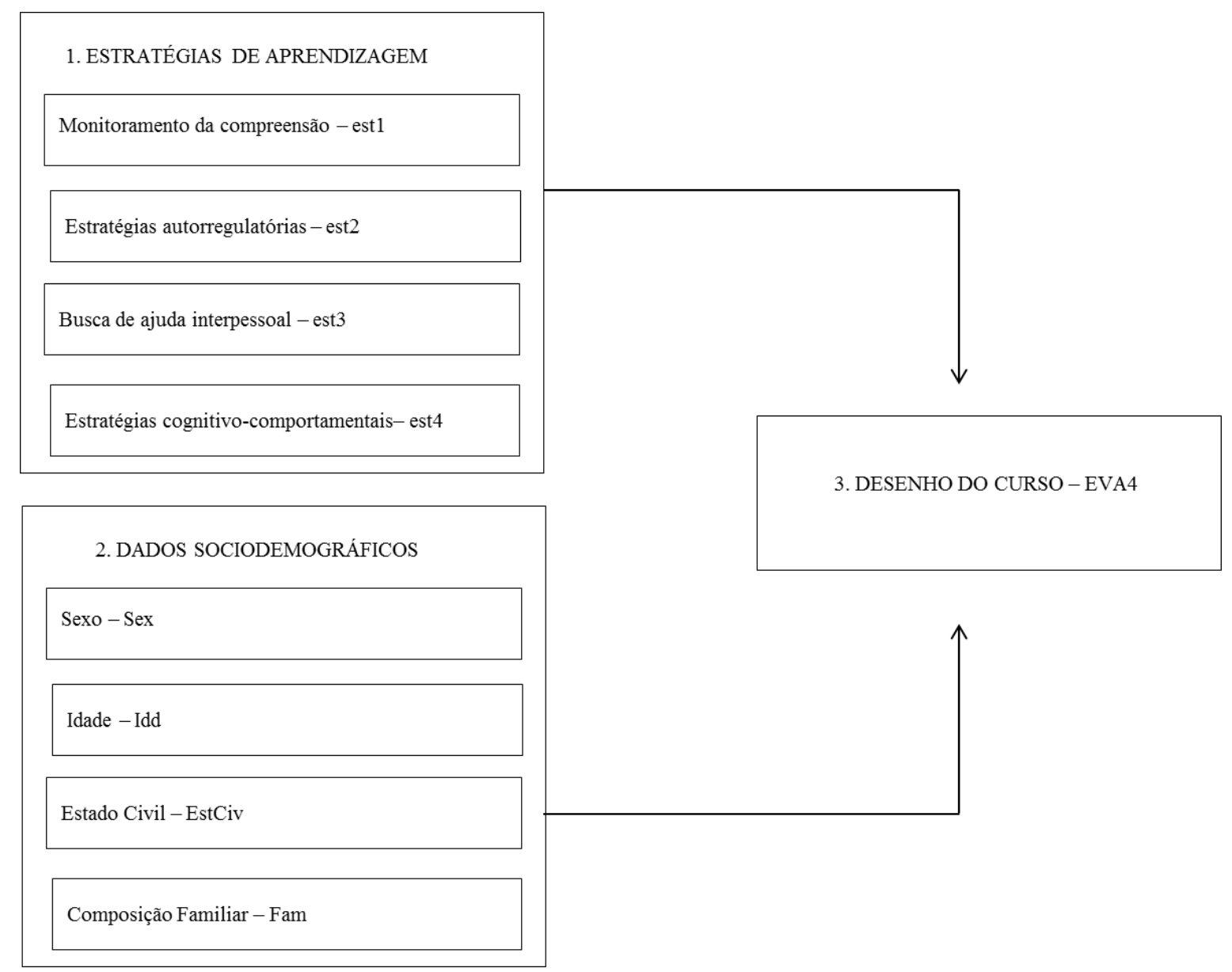

Figura 21. Modelo D de análise de predição de Desenho do curso.

São apresentadas na Tabela 32 as correlações entre as variáveis, os coeficientes de regressão não padronizados $(\mathrm{B})$, os coeficientes de regressão padronizados $(\beta)$, a contribuição individual de cada variável $\left(\mathrm{Sr}^{2}\right)$, as médias das variáveis $(\mathrm{X})$, os desvios-padrão (DP), a constante, o $\mathrm{R}^{2}$ (correlação entre todas as variáveis antecedentes com a variável critério variância individual e compartilhada das variáveis antecedentes em relação à variável critério), o $R^{2}$ ajustado (estimativa do $R^{2}$ da população) e o $R$ (correlação entre a variável critério e as variáveis antecedentes). 
Tabela 32. Regressão múltipla padrão para o Modelo D.

\begin{tabular}{|c|c|c|c|c|c|c|c|c|c|}
\hline Var. & $\begin{array}{l}\text { Eva4 } \\
\text { (VD) }\end{array}$ & Sex & Idd & EstCiv & Fam & Est1 & Est2 & Est3 & Est4 \\
\hline Sex & 0,09 & & & & & & & & \\
\hline Idd & $-0,00$ & 0,03 & & & & & & & \\
\hline EstCiv & $0,14^{*}$ & $0,24^{*}$ & $0,42 *$ & & & & & & \\
\hline Fam & $-0,02$ & $0,13^{*}$ & $-0,50$ & $-0,24$ & & & & & \\
\hline Est1 & $0,37 *$ & $-0,06$ & $0,14 *$ & $0,13^{*}$ & $-0,15$ & & & & \\
\hline Est2 & $0,33^{*}$ & 0,04 & $0,17^{*}$ & 0,03 & $-0,00$ & $0,36^{*}$ & & & \\
\hline Est3 & $0,27 *$ & $-0,32$ & 0,03 & $-0,13$ & $-0,23$ & $0,48^{*}$ & $0,15^{*}$ & & \\
\hline Est4 & $0,23 *$ & $-0,34$ & $0,21 *$ & 0,03 & $-0,09$ & $0,60 *$ & $0,22 *$ & $0,42 *$ & \\
\hline B & & 2,92 & $-1,39$ & 3,63 & $-0,46$ & $0,07 *$ & $0,26 *$ & 0,28 & $0,05^{*}$ \\
\hline$\beta$ & & 0,14 & $-0,19$ & 0,17 & $-0,02$ & $\mathbf{0 , 1 5}$ & 0,25 & 0,19 & $\mathbf{0 , 0 7}$ \\
\hline $\mathrm{Sr}^{2}$ & & 0,01 & 0,01 & 0,01 & 0,00 & 0,00 & $\mathbf{0 , 0 3}$ & 0,01 & $\mathbf{0 , 0 0}$ \\
\hline$X$ & 8,14 & 1,53 & 3,47 & 1,62 & 1,42 & 74,61 & 46,56 & 11,10 & 43,91 \\
\hline DP & 9,89 & 0,50 & 1,40 & 0,48 & 0,49 & 20,70 & 9,63 & 6,61 & 11,88 \\
\hline \multicolumn{2}{|c|}{ Constante $=-20,11$} & \multicolumn{2}{|c|}{$\mathrm{R}^{2}=0,24 *$} & \multicolumn{3}{|c|}{$\mathrm{R}^{2}($ ajustado $)=0,17^{*}$} & \multicolumn{2}{|c|}{$\mathrm{R}=0,49 *$} & \\
\hline
\end{tabular}

O coeficiente de regressão múltipla $\mathrm{R}$ foi significativamente diferente de zero, $\mathrm{F}(8$, 126) $=3,43<0,001$, sendo considerados limites de confiança de 95\%. As variáveis antecedentes que contribuíram significativamente para a explicação de desenho do curso foram Est1 ( $\beta=0,15$ e IC de 95\%), Est2 ( $\beta=0,25$ e IC de 95\%) e Est4 ( $\beta=0,07$ e IC de 95\%). Agrupadas, as 8 variáveis iniciais, explicam 24\% (17\% ajustado) da variabilidade de desenho do curso; as variáveis que contribuíram significativamente com a explicação da variável critério explicam cerca de $5 \%$ da variabilidade de características do curso. A Figura 22 exemplifica o relacionamento identificado entre as variáveis que apresentaram maior poder preditivo com a variável critério. 


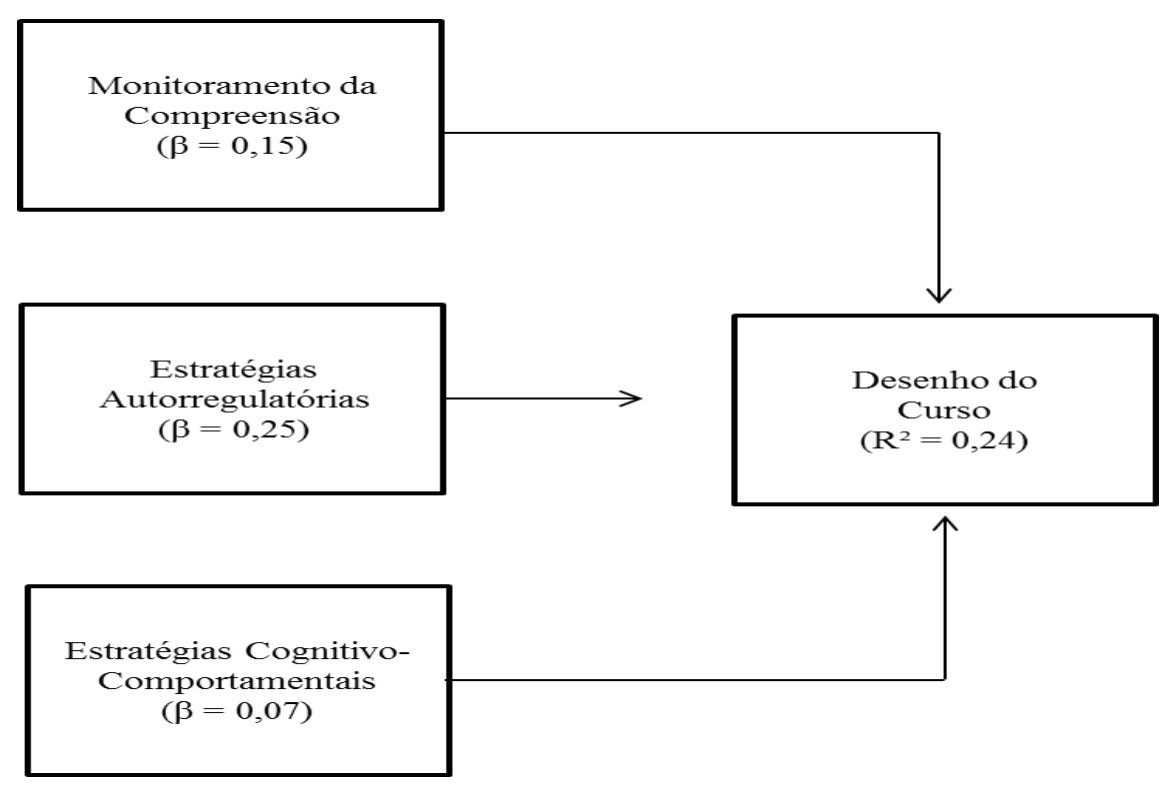

Figura 22. Representação do modelo de regressão múltipla para Desenho do curso como variável critério.

Depreende-se que os discentes que relataram empregar com constância as estratégias de aprendizagem denominadas monitoramento da compreensão, autorregulatórias e cognitivocomportamentais foram aqueles que declararam ser vital para a permanência do aprendiz no evento a distância o desenho apresentado pelo curso. Tendo em vista que a literatura em EAD define a estrutura da ação educativa como elemento medular, quiçá preponderante, para o bom desempenho acadêmico, é cabível considerar que indivíduos que devotam elevada importância ao papel desempenhado pelas propriedades do curso deverão ser aqueles que fazem dos recursos voltados ao controle do processo de aprendizagem e do aspecto emocional dispositivos habituais para sua estadia no mesmo. Ou seja, em determinadas circunstâncias, as estratégias autorregulatórias e primárias poderão atuar no sentido de amparar o discente frente a possíveis falhas de estruturação do evento educacional. 


\section{CAPÍTULO 6. DISCUSSÕES}

\section{Objetivo do capítulo 6}

O objetivo do presente capítulo é discutir os resultados encontrados, relacionando-os com os objetivos estabelecidos e com resultados apresentados pelas pesquisas consideradas na revisão de literatura.

\subsection{Discussões dos resultados de análises exploratórias fatoriais dos instrumentos}

Os objetivos específicos envolvendo a adaptação e verificação de evidências de validade das ferramentas de medida utilizadas, "Estratégias de aprendizagem" e "Fatores relacionados à evasão e à persistência em EAD”, em âmbito de IES foram alcançados. As escalas revelaram índices de confiabilidade que variaram de 0,75 a 0,93 , o que indica a presença de consistência interna nas mesmas. Ademais, as cargas fatoriais variaram de $-0,64$ a 0,93, indicando que as escalas, além de consistentes, são também válidas e agregam itens representativos de cada fator. As discussões a serem tecidas respeitarão a ordem de apresentação de cada instrumento mencionado.

\section{$\underline{\text { Estratégias de aprendizagem }}$}

Tendo em vista os esforços empreendidos por Martins (2012) a fim de elaborar componentes que contemplassem as estratégias de aprendizagem autorregulatórias presentes na escala de Warr e Downing (2000) - que não figuraram nos trabalhos de Borges-Ferreira (2005) e Zerbini et al. (2005) - considerou-se necessário averiguar como os elementos pertencentes a essa dimensão se portariam e, bem como, aferir a relevância e a contribuição das demais estratégias cognitivas e comportamentais para o desenvolvimento das práticas de estudo dos alunos do nível superior de ensino. Tal como bem apregoa Zerbini (2007), a atenção dedicada a itens relativos às estratégias de aprendizagem autorregulatórias é justificada com base no pressuposto de que, em cursos a distância via internet, os aprendizes devem demonstrar maior controle emocional, motivacional e um mais acentuado monitoramento da compreensão para persistir no curso, do que em ações face a face. 
Em relação às ferramentas disponíveis na literatura nacional e internacional para ajuizar estratégias de aprendizagem, conta-se com instrumentos destinados ao cenário escolar, com destaque para as séries iniciais de preparação (Boruchovitch \& Santos, 2004; Boruchovitch et al., 2006; Costa \& Boruchovitch, 2009), bem como para o ensino profissionalizante técnico e contextos laborais (Borges-Ferreira, 2005; Pintrich et al., 1991; Ribeiro \& Silva, 2007; Santos et al., 2004; Warr \& Downing, 2000; Weinstein \& Palmer, 1987; 1990; Zerbini \& Abbad, 2008), entre outros.

Os resultados advindos das análises exploratórias das escalas não indicaram itens altamente correlacionados entre si. Obtiveram-se quatro fatores de estratégias de aprendizagem - os quais apresentam maiores similaridades com as dimensões teóricas propostas por Warr e Allan (1998), do que com as dimensões e estruturas obtidas nos estudos de Borges-Ferreira (2004), De Paula e Silva (2004), Martins (2012), Warr e Downing (2000), Zerbini, Carvalho e Abbad (2005) e Zerbini e Abbad (2008).

No fator Monitoramento da compreensão (12 itens, $\alpha=0,87$, cargas fatoriais entre 0,30 a 0,70) as estratégias de aquisição de aprendizagem propostas por Warr e Allan (1998) foram agregadas em um único fator. Tal estrutura difere da obtida por Martins (2012), cujas estratégias de monitoramento da compreensão associaram-se a itens de controle da motivação e de busca de ajuda ao material didático - compondo o fator denominado Estratégias autorregulatórias, com 7 itens, $\alpha=0,86$ e cargas fatoriais entre $-0,50$ e - -0,69. A extração de um fator unicamente composto por estratégias voltadas ao monitoramento da compreensão revela que frente às singularidades dos cursos (encontros presenciais esparsos delegando ao aluno a inspeção primária dos processos de estudo), os participantes devem não somente recorrer, mas desenvolver competências hábeis de gerenciamento que lhes permitam automonitorar e autoavaliar seus processos de aprendizagem. Especialmente em cenários educacionais a distância, recursos favorecedores do estudo autônomo do aprendiz estão sendo cada vez mais retratados como cruciais à 'sobrevivência' do estudante em situações nas quais ele é o principal responsável pelo exame minucioso e sistemático das atividades que alicerçam sua progressão no evento instrucional não presencial.

O segundo fator Estratégias autorregulatórias ( 7 itens, $\alpha=0,80$, cargas fatoriais entre 0,35 a 0,81) guarda correspondências com os fatores obtidos por Martins (2012), Warr e Downing (2000) e Zerbini e Abbad (2008). Tais estratégias vinculam-se ao controle da ansiedade, atenção e motivação. Neste estudo, o fator é formado por itens derivados das estratégias Controle da emoção e Controle da motivação presentes na clássica definição de 
Warr e Allan (1998). Considerando que o êxito estudantil não depende unicamente de atributos acadêmicos, mas também do emprego de adequados recursos controladores dos estados emocionais do sujeito que aprende face a dificuldades, elementos estressantes ou interesses concorrentes, é possível pensar que para a amostra considerada é fundamental a utilização de tais variáveis, que a auxiliará a responder a desafios de seleção, focalização e processamento de estímulos.

O fator Busca de ajuda interpessoal ( 3 itens, $\alpha=0,82$, cargas fatoriais entre 0,63 a 0,72 ) congrega estratégias que exprimem a busca ativa por auxílio de outros indivíduos, como pares e tutores, para sanar dúvidas sobre o conteúdo do curso (Warr \& Allan, 1998). Esse fator se fez presente nos estudos conduzidos por Martins (2012), Warr e Downing (2000) e Zerbini e Abbad (2008) - cujas propriedades foram, respectivamente: 3 itens, $\alpha=0,68$, cargas fatoriais entre 0,45 a 0,$69 ; 5$ itens, $\alpha=0,84$, cargas fatoriais entre 0,54 a 0,$68 ; 6$ itens, $\alpha=0,89$, cargas fatoriais entre 0,66 a 0,83 .

O quarto fator Estratégias cognitivo-comportamentais ( 7 itens, $\alpha=0$,78, cargas fatoriais entre 0,38 a 0,80) agrupa itens pertencentes a duas estratégias primárias, a saber: repetição, elaboração e organização e busca de ajuda ao material didático. De acordo com Warr e Allan (1998), as estratégias cognitivas de repetição consistem na repetição mental da informação na forma em que foi apresentada ao aluno; as estratégias de organização se referem à identificação de ideias centrais do material e criação de esquemas mentais que agrupam e relacionam elementos que foram aprendidos; e as estratégias de elaboração correspondem aos procedimentos de análise e reflexão acerca de implicações e conexões existentes entre o material aprendido e o arcabouço de informações já existentes. Já a estratégia de busca de ajuda ao material didático implica a obtenção de orientações a partir de consultas a fontes que não envolvam contato social. $O$ arranjo desse fator se difere do encontrado por Martins (2012), Warr e Downing (2000) e Zerbini e Abbad (2008).

Observando as definições conceituais atribuídas às estratégias que compõem o último fator extraído, estas se coadunam às dimensões teóricas propostas por Warr e Allan (1998). Além de se originariam a partir de um radical comum (o grande grupo das estratégias de aprendizagem primárias), o agrupamento encontrado indica que a busca de informações por meio de materiais educativos parece atuar como forma de aprimorar os processos de reflexão ativa dos objetos de aprendizagem vistos. Ademais, considerando as propriedades da amostra deste estudo, torna-se possível que as estratégias relativas a consultas ao material didático tenham sido compreendidas como demasiadamente simples para ações educativas que exibem 
objetivos instrucionais de níveis mais complexos. Dessa feita, tais estratégias não ensejaram o surgimento de um fator distinto para as mesmas.

Os resultados encontrados fornecem contribuições para investigações acerca do planejamento instrucional, visto que sinalizam quais são as estratégias de aprendizagem mais empregadas pelos estudantes para executar tarefas de aprendizagem quando mediadas pelas TICs. O entendimento a respeito dos padrões de uso e preferências das estratégias de aprendizagem possibilita cotejar o ajustamento e conformidade das estratégias de ensino utilizadas às estratégias mais adotadas pelos alunos; dessa feita, deve haver consonância entre ambas. É necessário, por conseguinte, que planejadores instrucionais, tutores e instituições educativas cuidem das: (1) Estratégias primárias - a elaboração e oferta de materiais completos, com redação e exposição de conteúdos precisas; emissão de exemplos que permitam os estudantes vincular conhecimentos transmitidos aos já sedimentados; incentivar a leitura, resumo e identificação de pontos nodais dos tópicos analisados; (2) Estratégias autorregulatórias - além de cuidar para que os discentes examinem sua atenção, concentração e motivação durante os estudos, é importante que os mesmos controlem seu processo de aquisição de aprendizagem. O emprego dessas estratégias exerceu influência na explicação dos fatores ligados à conclusão ou abandono de ações educativas a distância.

\section{Fatores relacionados à evasão e à persistência em EAD}

$\mathrm{O}$ instrumento de Fatores relacionados à evasão e à persistência em EAD sofreu alterações de grafia e exclusão de alguns itens para se ajustar ao contexto e à amostra de aplicação. A escala foi readministrada em contextos de ensino a distância, pois gera informações relevantes acerca das variáveis que de alguma forma interferem sobre a decisão discente de finalizar ou não o evento instrucional iniciado - neste caso, diferentemente da aplicação original, cursos de graduação e especialização. Há de se considerar o fato de que, em cursos a distância os aspectos relativos ao planejamento instrucional, ao comportamento do tutor, aos atributos cognitivos do aprendiz e aos acontecimentos situacionais exercem inegável influência sobre a estadia do alunado.

Entre as ferramentas de medida disponíveis na literatura nacional e estrangeira para aferir as variáveis ligadas ao abandono e permanência dos participantes em cursos em EAD estão as propostas por Brauer (2005), Holder (2007), Sales (2009) e Walter (2006).

Nas análises exploratórias não foram identificados itens altamente correlacionados entre si. Obtiveram-se quatro fatores de variáveis relacionadas à evasão e à persistência em 
EAD que se distinguem daqueles verificados por Sales (2009) em sua pesquisa. Neste trabalho, foram encontrados, quatro fatores compondo a estrutura da presente escala, ao contrário de Sales (2009), que obtive 7 fatores em suas análises.

O primeiro fator obtido é denominado Suporte tecnológico e de tutoria, com 18 itens, $\alpha=0,93$, e cargas fatoriais variando de 0,40 e 0,93 , que avaliam o quanto aspectos relacionados às competências demonstradas pelo tutor ao longo do curso; à acessibilidade dos materiais e o suporte institucional e social recebido pelo estudante; e às ferramentas eletrônicas de acesso dificultaram a permanência do aluno no curso. Este fator congregou em sua estrutura os dois fatores obtidos por Sales (2009), Desempenho do tutor e Desenho do curso, ambos originários da escala de Influência das Características do Curso a Distância na Permanência do Aluno (ICCP). Avaliando a composição do fator em questão, nota-se que o mesmo agrupou elementos/recursos que viabilizam a consecução dos cursos, não se referindo, portanto, a variáveis relativas ao desenho estrutural da ação educativa. Tal dado é importante à medida que fornece indicativos, ainda que de modo tênue, sobre quais seriam os aspectos acessórios aos cursos (que serviriam a sua execução) e quais configurariam como genuínos aos mesmos.

O segundo fator, Características Exógenas ao Curso, com 11 itens, $\alpha=0,93$, com cargas fatoriais entre 0,30 a 0,77 , avalia o quanto variáveis concernentes à conciliação do curso com outras atividades de estudos, profissionais e compromissos familiares; à disponibilidade de tempo; e a problemas de saúde dificultaram a persistência do estudante no evento. Os fatores Tempo Disponível e Questões Familiares, provenientes da escala Influência do Contexto do Aluno na sua Permanência nos Cursos a Distância (ICOP) (Sales, 2009), uniram-se no fator considerado. Tomando as indicações e tratamentos dispensados pelo campo de estudo aos itens que estruturam o fator características exógenas ao curso, parece ser mais coerente e lógico que esses viessem a se reunir um mesmo grupo, ou seja, o grande conjunto de elementos externos aos cursos a distância.

O fator Características do Aluno, composto por 8 itens, $\alpha=0,86$, cargas fatoriais entre 0,35 a 0,71 , averigua em que medida elementos ligados às habilidades e atributos discentes (capacidade de administração do tempo de estudo, elaboração de planos de estudo, respeito e cumprimento de prazos, perseverança frente a dificuldades e experiências prévias com as TICs) contribuíram para a permanência ou saída do estudante da ação educativa. Os fatores Disciplina e Interesse do Aluno e Experiências e Habilidades Importantes para os Cursos a Distância - presentes na escala Influência das Características do Aluno na sua Permanência em Cursos a Distância (ICAP) (Sales, 2009) - convergiram para um único fator. A razão da 
junção dessas variáveis em um mesmo fator encontra justificativa no aspecto comum tratado por elas: disposições internas do sujeito que aprende e estuda.

O último fator, Desenho do Curso, constituído por 4 itens, $\alpha=0,75$ e cargas fatoriais entre $-0,64$ e 0,33 , avalia o grau em que aspectos atinentes ao planejamento instrucional (objetivos propostos, planejamento de conteúdos, sequência de conteúdos, avaliações de aprendizagem, carga horária, linguagem empregada e complexidade do curso) contribuem para a saída do aluno do evento educativo. Os itens presentes neste fator decorrem unicamente da escala ICCP, mais especificadamente do fator Desenho do Curso, de Sales (2009). É cabível que em ações educacionais a distância as propriedades do desenho do curso se sobressaiam, corroborando os achados de literatura que as consideram elementos medulares em programas de EAD. Provavelmente, para discentes cujos processos de aprendizagem são modelados pela estrutura e organização dos cursos, estes elementos assumem conotação capital.

Os achados obtidos auxiliam na compreensão das variáveis relacionadas ao abandono e permanência discente em programas a distância. Dessa feita, aos agentes envolvidos em tais ações são fornecidas indicações acerca dos principais aspectos comprometedores do sucesso educacional - tanto para instituições de ensino, bem como para profissionais atuantes e alunos envolvidos. Tal como anteriormente pontuado, os elementos ligados à permanência e saída do estudante a distância apresentam natureza diversificada, sendo necessário cuidar para que atributos do curso, do próprio aluno e do ambiente externo que o envolve não façam fracassar os esforços educacionais despendidos. Logo, o instrumento de Fatores relacionados à evasão e à persistência em EAD pode ser aplicado em situações de ensino não presencial como ferramenta fidedigna e válida ao propósito de aferir a influência de distintas variáveis (pertinentes ao curso realizado; ao ambiente que circunda o estudante; e às características psicológicas do mesmo) sobre a decisão do aluno de permanecer ou interromper seus estudos.

\subsection{Discussões dos resultados das análises de regressão}

Foi alcançado o objetivo geral do presente estudo - propor e testar um modelo de avaliação de ações educacionais a distância, intentando identificar variáveis preditoras de fatores relacionados ao fenômeno da evasão e da persistência estudantil em contextos de 
EAD.

Da mesma forma, foram cumpridos os objetivos específicos, a saber: A) identificar e analisar variáveis preditoras de elementos ligados à permanência ou não do discente em cursos a distância, medidas em termos das respostas dos participantes à escala de Fatores relacionados à evasão e à persistência em EAD; B) relacionar as medidas de fatores ligados à evasão e à permanência estudantil com as medidas das variáveis preditivas referentes às características da clientela (estratégias de aprendizagem e dados sociodemográficos).

O modelo de avaliação de ações educacionais a distância proposto e testado foi composto por variáveis individuais e sociodemográficas, visando reconhecer quais variáveis apresentavam maior poder preditivo e mensurar aquelas que contribuíram significativamente para a explicação da variável critério: fatores ligados à evasão e à persistência em EAD. Dessa feita, para exame do modelo foram consideradas as seguintes variáveis antecedentes: média das respostas aos itens dos quatro fatores da ferramenta de Estratégias de aprendizagem (monitoramento da compreensão; estratégias autorregulatórias; busca de ajuda interpessoal; e estratégias cognitivo-comportamentais) e média das respostas aos itens da escala de dados sociodemográficos (sexo; idade; estado civil e composição familiar).

Nos quatro modelos de predição de Fatores relacionados à evasão e à persistência estudantil em EAD (Modelo A - Suporte tecnológico e de tutoria, Modelo B - Características exógenas ao curso, Modelo C - Características do aluno e Modelo D - Desenho do curso), diferentes variáveis apresentaram contribuição significativa na explicação das variáveis critérios. Em todos os modelos as variáveis antecedentes anteriormente descritas foram incluídas nas análises empreendidas.

No Modelo A, as variáveis que revelaram relação de predição com fatores ligados à evasão e à persistência foram Monitoramento da compreensão $(\beta=0,04)$ e Busca de ajuda interpessoal $(\beta=0,36)$. A variância compartilhada e individual das variáveis antecedentes agrupadas, em relação à variável critério, foi de $\mathrm{R}^{2}=36 \%$. Os participantes que perceberam considerável interferência da variável suporte tecnológico e de tutoria sobre a decisão de permanecer ou não no evento instrucional foram aqueles que empregaram com mais frequência as estratégias de aprendizagem monitoramento da compreensão e busca de ajuda interpessoal.

É sabido que para o contingente de estudantes a distância o conjunto de agentes e instrumentais envolvidos, direta ou indiretamente, no desenvolvimento das ações educacionais implementadas não atua apenas como fragmento acessório e secundário, mas 
subsidia de forma fundamental toda ação ou decisão a ser tomada em cenários de EAD (Almeida, 2007; Holder, 2007; Sales, 2009; Vargas, 2004). Em contextos de EAD, torna-se imprescindível cuidar para que o corpo discente tenha acesso, de qualidade, aos aspectos operacionais e de suporte ao longo das ações instrutivas (Walter, 2006). Foi observado que em cursos a distância os níveis de abandono discente são influenciados por fatores ligados à qualidade e quantidade de apoio fornecido ao aprendiz, além do tipo e meios selecionados para estabelecimento de contato com os mesmos (Abbad, Carvalho \& Zerbini, 2006; Xenos et al., 2002).

Dessa forma, frente a deficiências ou falhas nos sistemas responsáveis pela integração e acesso discente aos serviços e expedientes disponibilizados, é provável que tais indivíduos devam recorrer com mais veemência às competências voltadas à inspeção do progresso pessoal ao longo do evento educacional, pois, de outra sorte, seu desempenho acadêmico poderia não atingir a excelência pretendida. Em sentido inverso, alunos a distância que pouco empregam habilidades metacognitivas necessitariam usufruir de experiências mais facilitadoras e satisfatórias com instituições de ensino, profissionais tutores e dispositivos tecnológicos a fim de que se mantivessem nos cursos. A utilização de estratégias de monitoramento da compreensão seria fundamental em situações nas quais o apoio, de natureza psicossocial e tecnológica, não cumpre seu papel, ou seja, tais estratégias auxiliariam o aprendiz a manter em nível ótimo seu ganho de conhecimento mesmo em face a desajustes e desamparo acadêmico.

A estratégia de busca de ajuda interpessoal também se revelou preditora de suporte tecnológico e de tutoria. Assim como já foi dito, esse grupo de estratégias de aprendizagem representa a busca proativa do indivíduo por ajuda advinda de outras pessoas a fim de solucionar dúvidas referentes aos conteúdos transmitidos. Mediante a falhas nos elementos de suporte, é cabível que os alunos recorram àqueles que também fazem uso de tais variáveis subsidiadoras das ações de EAD - como seus pares. Considerando que a colaboração e o aprendizado virtual colaborativo, ao disponibilizarem formas de comunicação, orientação e controle entre todos os aprendizes envolvidos, se tornam imprescindíveis armas contra as limitações impostas por serviços de suporte defectivos, esta categoria de estratégias seria mais empregada por aqueles que vivenciam dificuldades no tocante ao suporte tecnológico e de tutoria (Leh, 2001; Galusha, 1997; Holder, 2007; Oliveira \& Tedesco, 2010; Poole, 2000; Rourke et al., 2001).

Admite-se que as estratégias de monitoramento da compreensão e busca de ajuda 
interpessoal são relevantes para a predição de variáveis ligadas ao suporte institucional, tecnológico e tutorial. Vale ressaltar que tal gama de fatores ligados à evasão ou permanência de alunos em eventos de EAD contempla elementos deveras importantes, uma vez que os mesmos possibilitam o contato direto com o aluno, o incentivo a sua participação nas atividades propostas, a orientação frente a situações de dúvidas, entre outros. A investigação de tal conjunto de variáveis torna-se fundamental para a compreensão das causas da persistência e abandono estudantil no ensino não presencial (Borges-Ferreira, 2005; Brauer, 2005; Holder, 2007; Sales, 2009; Walter, 2006; Zerbini 2003, 2005, 2007).

As variáveis no Modelo B que apresentaram relação de predição com características exógenas ao curso, na ordem de magnitude das contribuições individuais foram: Monitoramento da compreensão $(\beta=0,31)$, Busca de ajuda interpessoal $(\beta=0,28)$ e Estratégias cognitivo-comportamentais $(\beta=-0,03)$. A variância compartilhada e individual das variáveis antecedentes agrupadas, em relação à variável critério, foi de $\mathrm{R}^{2}=30 \%$. Tais dados indicam que os discentes que definiram as variáveis ambientais como muito influentes na decisão de dar continuidade ou não ao curso, foram os mesmos cujos padrões de uso de estratégias voltadas ao gerenciamento dos processos de ensino-aprendizagem, à procura por ajuda externa e à estruturação cognitiva dos conteúdos acadêmicos se mostram elevados.

$\mathrm{Na}$ literatura, as variáveis relacionadas ao meio circundante do aluno a distância aparecem diretamente relacionadas à interrupção dos cursos, ou seja, quanto mais os alunos percebem tais elementos como dificultadores de sua permanência, mais chances eles terão de se evadirem (Almeida, 2007; Coelho, 2003; Sales, 2009; Silva \& Tomaz, 2006; Tucho, 2000; Xenos et al., 2002; Walter, 2006; Yukselturk \& Inan, 2006). Em modelos testados por tais autores, variáveis dessa natureza foram consideradas preditoras de evasão; a influência desse conjunto de fatores sobre a permanência estudantil é quase uma unanimidade entre os pesquisadores do campo. É interessante mencionar que na investigação conduzida por Sales (2009), apesar das variáveis relativas ao contexto de estudo do aluno terem se comportado como preditoras da situação do indivíduo ao final do curso (concluinte/evadido), estas apareceram apenas de forma residual nos resultados, revelando uma relação baixa com o fenômeno do abandono acadêmico. Este dado chama a atenção para a necessidade de se empreender estudos comparativos entre cursos a distância de diversos feitios - profissionais, de especialização, de graduação, semipresenciais, totalmente a distância, etc - a fim de verificar se o grau da influência exercida pelo ambiente externo na decisão de evadir-se ou não do evento depende das propriedades deste último. 
Contextualizando o resultado obtido ao perfil da amostra analisada, constata-se que a maior parte dos participantes se declarou mantenedora de relação matrimonial estável, com filhos, além de executores de atividades profissionais paralelas. Logo, é possível concluir que se trata de um conjunto de pessoas que respondem por inúmeros compromissos e, consequentemente, enfrentam sérias adversidades contextuais. Destaca-se, neste ponto, a influência dos aspectos autogerenciadores da informação/compreensão e de resolução proativa de conflitos de aprendizagem para a não desistência do aluno a distância. As iniciativas instrucionais não presenciais representam uma profunda transformação no processo de ensino contemporâneo, contribuindo para a constituição de uma realidade educacional nunca concebida; todavia, é preciso que todos os agentes envolvidos com esta modalidade (planejadores instrucionais, coordenadores de curso, tutores, instituições educacionais, entre outros) se atentem para os elementos cuja presença poderia contribuir para a evasão estudantil em situações de EAD - tal como as já citadas circunstâncias provenientes do meio social que envolve os alunos. Deve-se prezar o papel desempenhado pelas estratégias de aprendizagem ora comentadas - monitoramento da compreensão, busca de ajuda interpessoal e estratégias cognitivo-comportamentais - para a proposição e desenvolvimento de ações educativas efetivas, mesmo frente ao surgimento de negativas variáveis exógenas ao curso.

Destaca-se, mais uma vez, a importância das estratégias de monitoramento da compreensão para os aprendizes em EAD. Tais habilidades revelam-se decisórias em momentos nos quais o compromisso do indivíduo para com o curso é prejudicado pelo aparecimento de contratempos circunstanciais. Estar atento ao progresso e êxito de suas atividades acadêmicas garante ao aprendiz maiores chances de identificar lapsos de comprometimento e, com isso, prevenir possíveis desistências. A literatura pontua o papel preponderante das competências voltadas ao controle eficiente da informação e dos processos de pensamento para o sucesso acadêmico do aluno (Badia \& Monereo, 2010; Oliveira Boruchovitch \& Santos, 2009; Ribeiro, 2003; Xenos et al., 2002). Outros achados científicos também retratam as inegáveis contribuições das estratégias de busca por auxílio interpessoal não só para a resolução efetiva de dificuldades de aprendizagem, mas para a superação do próprio conceito de distância transacional - espaço psicológico e de interação entre estudantes e demais atores instrucionais envolvidos (Walter, 2006) - que, certamente, tende a se acentuar em momentos de atividades e eventos concorrentes ao curso ministrado. Dessa feita, medidas envolvendo a cooperação entre aprendizes para solução de problemas parecem atuar como apropriadas alternativas para o sobrepujamento de barreiras à conclusão do curso ocasionadas 
por causas externas ao mesmo. Estudos sobre relações de ensino colaborativas revelam que medidas envolvendo a cooperação, a conexão e as trocas não competitivas entre alunos podem funcionar como aspectos decisivos para o enfraquecimento da magnitude de certos acontecimentos alheios à ação educativa e favorecer a retenção do corpo discente (Fahy, 2003; Holder, 2007; Garrison, 2003).

Inegavelmente, habilidades que possibilitam aos aprendizes selecionar pontos-chave dos conteúdos estudados e armazená-los mentalmente se tornam indispensáveis durante momentos em que o tempo disponível e o interesse dedicado às atividades escolares são reduzidos. Inúmeros resultados decorrentes de pesquisas realizadas corroboram com os indícios de associação positiva dessas estratégias de aprendizagem e o sucesso acadêmico (Oliveira, Boruchovitch \& Santos, 2009; Warr \& Downing, 2000; Zerbini \& Abbad, 2008). Tão logo, vale aferir de que forma e em que medida tais competências favorecem e otimizam os esforços pessoais de estudo em meio a contratempos e barreiras circunstanciais.

Na testagem do Modelo $\mathrm{C}$, as variáveis que apresentaram relação de predição com características do aluno, segundo a ordem de magnitude das contribuições individuais foram: Monitoramento da compreensão $(\beta=0,34)$, Estratégias autorregulatórias $(\beta=0,27)$, Busca de ajuda interpessoal $(\beta=0,27)$, Estado civil $(\beta=0,22)$, Composição familiar $(\beta=0,20)$ e Estratégias cognitivo-comportamentais $(\beta=-0,06)$.

A variância compartilhada e individual das variáveis antecedentes agrupadas, em relação à variável critério, foi de $\mathrm{R}^{2}=42 \%$. Tais dados sinalizam que alunos que empregaram com frequência estratégias de aprendizagem voltadas à autogestão dos processos de aquisição de aprendizagem, ao controle do aspecto emocional, à solicitação por ajuda externa e ao armazenamento cognitivo dos objetos de estudo consideraram os atributos psicológicos do estudante como importantes para a decisão de interromper a ação educativa empreendida. As variáveis sociodemográficas correlatas à constituição familiar (com ou sem filhos) e à condição marital (solteiro ou casado) também se mostraram preditoras da variável critério.

Curiosamente, todos os fatores de estratégias de aprendizagem obtidos por este estudo compuseram o rol de elementos preditores do modelo avaliado. Para indivíduos que consideram as características disposicionais do sujeito que estuda - como disciplina e interesse pelo curso; capacidade de administrar o tempo; e organização pessoal, entre outros altamente influentes na decisão de perseverar no evento educativo, o conjunto total das estratégias de aprendizagem elencadas figura como altamente profícuo para o cumprimento das atividades escolares exigidas a tais estudantes. 
Pesquisas revelam que as características internas do alunado são importantes para o entendimento da presença de tais indivíduos ao longo das ações instrucionais; nesse sentido, tais variáveis vêm sendo amplamente discutidas e tendo seu papel de 'facilitadores à permanência estudantil em EAD' esquadrinhado (Brauer, 2005; Chyung, Winiecki \& Fenner, 1999; Coelho, 2003; Curless, 2004; Palloff \& Pratt, 2004; Pierrakeas et al., 2004; Silva \& Tomaz, 2006; Simwanza \& Makunka, 2004; Xenos et al., 2002; Walter, 2006; Wang et al., 2003). Levando em conta os trabalhos que investigam a importância do locus de controle para o sucesso acadêmico, é conveniente considerar que para este estudo a aplicação de variadas estratégias de aprendizagem indica os participantes que, possivelmente, se mantém constantes no curso graças as suas próprias capacidades psíquicas. Avaliações direcionadas à compreensão de tal constructo no ensino não presencial poderão ser elucidativas (Meneses, 2002; Pilati, 2004; Walter, 2006).

Ademais, considerando que toda a gama de estratégias de aprendizagem compartilha a mesma gênese (ou seja, é fruto dos atributos e esforços empreendidos pela pessoa que estuda), é coerente que para aprendizes que valorizam e fazem uso das mesmas, as disposições internas do indivíduo (neste caso, a fonte dessas habilidades) também serão vistas como necessárias, e interferentes, para a continuidade ao longo do evento educativo. O fato das estratégias de aprendizagem se comportarem como preditoras do conjunto de características do aluno alude à importância de os cursos coadunarem-se ao perfil da clientela atendida. Nesse sentido, práticas relativas a análises de necessidades de treinamento (ANT) poderiam beneficiar a adequação do evento ao seu público alvo, uma vez que orientariam todas as ações instrucionais de planejamento e ministração com base nos predicados discentes (Abbad, 2009; Borges-Andrade, 2006; Sales, 2009).

Assim como afirmam Abbad, Carvalho e Zerbini (2006), entre os pesquisadores da área de TD\&E comumente ocorre a coleta de dados demográficos a fim de avaliar treinamentos realizados. Porém, as autoras salientam que essas variáveis apresentam efeitos estatisticamente controlados e não são parte integrante de modelos estatísticos multivariados de investigação. Neste estudo, as variáveis sociodemográficas composição familiar e estado civil tiveram contribuição significativa na explicação do fator características do aluno. É cabível que estudantes com arranjos pessoais mais complexos e requerentes de maior dedicação (como quando na presença de filhos e companheiros conjugais) venham a valorizar e presumir que o abandono acadêmico não se efetua graças às suas competências e disposições de caráter interno. Tendo em vista que inúmeras pesquisas detêm-se sobre os 
dados sociodemográficos da clientela em EAD, é recomendável que estas e outras variáveis sociodemográficas continuem a ser exploradas para que maior consistência teórica seja atribuída a esse exato tema (Brauer, 2005; Sales, 2009; Shea, Motiwalla \& Lewis, 2001; Vargas, 2004; Xenos et al., 2002; Walter, 2006).

No Modelo D, as variáveis que apresentaram relação de predição com fatores ligados à evasão e à persistência foram Monitoramento da compreensão $(\beta=-0,15)$, Estratégias autorregulatórias $(\beta=0,25)$ e Estratégias cognitivo-comportamentais $(\beta=0,07)$. A variância compartilhada e individual das variáveis antecedentes agrupadas, em relação à variável critério, foi de $\mathrm{R}^{2}=24 \%$. Os participantes que empregaram com mais frequência as estratégias de aprendizagem monitoramento da compreensão, autorregulatórias e cognitivocomportamentais foram aqueles para quem a variável desenho do curso exerceu forte atuação sobre a decisão de permanecer ou não evento instrucional.

Achados da literatura apontam para a relevância da estruturação instrucional para a saída ou permanência do estudante em contextos de EAD. Segundo tais estudos, o fenômeno do abandono estudantil estaria intrinsecamente ligado a inadequações na forma como a ação educativa é delineada e ministrada - neste caso, mencionam-se desajustes quanto ao estabelecimento de objetivos instrucionais, escolha de estratégias de ensino, complexidade dos conteúdos de aprendizagem, natureza dos exercícios propostos, qualidade das atividades face a face programadas para momentos específicos do curso, volume de trabalhos requeridos entre outros (Silva \& Tomaz, 2006; Shin \& Kim, 1999; Xenos et al., 2002; Wang et al., 2003; Walter, 2006). Curiosamente, em estudo conduzido por Sales (2009), a variável desenho do curso não influenciou significativamente a situação final do estudante (evadido/concluinte). A autora sugere que este fato poderia ser explicado pela alta correlação identificada entre a variável critério e os preditores Disciplina e interesse ( $\mathrm{r}=0,734$, $\mathrm{sig}=0,01)$ e Desempenho do tutor $(r=710$, sig=0,01); dessa feita, Sales considera que tais correlações podem ter implicado na exclusão da variável desenho do curso por redundância.

$\mathrm{Na}$ presente pesquisa, há de se considerar que a inclusão de diversos cursos manifestamente heterogêneos pode ter contribuído para que o fator referente ao delineamento da ação educacional se mostrasse ligado à evasão acadêmica. Investigar tal elemento em contextos outros - especialmente naqueles em que haja maior similaridade em termos de desenho instrucional - talvez favoreça a compreensão aprofundada deste aspecto para a retenção de alunos em ações de ensino a distância. À semelhança desta pressuposição, distintos trabalhos vêm avaliando elementos variados para a não persistência em EAD a 
depender da natureza dos cursos considerados, por exemplo: se pertinentes à área de humanas, exatas, se são cursos de graduação ou especialização, se totalmente a distância ou semipresenciais, etc (Carr \& Ledwith, 2000; Pierrakeas et al., 2004; Walter, 2006). Os resultados do estudo de Vargas (2000), que discorre sobre a implantação e avaliação de um curso a distância através de videoconferência, apontaram para a importância do tipo de modalidade de ensino para um processo de aprendizado mais efetivo entre o alunado.

Tal como bem propõem Hall, Watkins e Eller (2003), o desenho de uma ação educacional via web deve combinar os dois extremos: a simplicidade e a complexidade. Dessa forma, é necessário garantir ao estudante a apresentação de objetos de aprendizagem progressivamente mais complexos. A complexidade almejada seria composta por três dimensões, a saber: A) interatividade - esforços, por meio do desenho instrucional, em incentivar uma participação ativa do estudante nas tarefas propostas, ao invés de coloca-lo em uma posição passiva de escuta ou leitura; B) multimodalidade - emprego de estratégias, como a apresentação de conteúdos por meio de múltiplas modalidades e formatos, tendo em vista o aumento da motivação para aprender, da aprendizagem e da retenção de conteúdos complexos; C) adaptabilidade - flexibilidade do desenho em se ajustar aos distintos perfis de clientelas e estilos de aprendizagem.

Considerando tais propriedades fundamentais ao delineamento instrucional, bem como sua relevância para a retenção do estudante no curso, o emprego das estratégias de aprendizagem vistas como preditoras do fator desenho do curso certamente possibilita ao aluno conservar seu processo de aprendizagem, mesmo em face a inadequações do próprio evento. Pode-se depreender que para indivíduos cujas falhas ou inconformidades na organização e ministração do curso teriam acentuado peso, o uso constante em suas produções acadêmicas das estratégias de monitoramento da compreensão, autorregulatórias e cognitivocomportamentais poderia abrandar os efeitos negativos exercidos por tais incorreções.

Em resumo, os modelos avaliativos testados neste estudo assinalaram significativas relações entre variáveis e aspectos essenciais à presença e ao êxito do estudante em ações educacionais a distância. Os resultados encontrados indicaram que quanto mais facilitadores são percebidos os elementos referentes ao suporte tecnológico e de tutoria prestado ao discente; aos eventos do meio externo/social que envolvem o aluno; às características e atributos internos do aprendiz; e, ao arranjo instrucional do curso, mais expressiva será a possibilidade da clientela de tais eventos finalizarem os mesmos. Além disto, constatou-se o papel primordial exercido pelas estratégias de aprendizagem empregadas pelos estudantes ao 
longo da ação instrucional para a predição dos fatores ligados à ocorrência de evasão em contextos de EAD. Tais dados guardam correspondência e apoio nos resultados empíricos obtidos por estudos anteriores, ou seja, atesta-se a significância do emprego de um variado repertório de estratégias de aprendizagem para a excelência acadêmica (Badia \& Monereo, 2010; Oliveira, Boruchovitch \& Santos, 2009; Zabalza, 2005; Warr \& Downing, 2000).

A depender dos desarranjos ou variáveis considerados negativos a sua permanência em cursos a distância, o indivíduo pode fazer uso de distintas estratégias de aprendizagem a fim de superar tais elementos dificultadores. Assim como revela a literatura especializada, o emprego de estratégias de aprendizagem facilita o processo de ensino, uma vez que propicia meios à aquisição, recuperação e uso dos conteúdos de aprendizagem. Ademais, a utilização e aprimoramento de tais estratégias fomenta o desenvolvimento de graus mais acentuados de autorregulação de conhecimento, considerada uma das principais componentes do aprender efetivo na EAD. Com todos estes indicativos em mente, é crível que a observância quanto aos padrões de uso e frequência das estratégias de aprendizagem por parte dos alunos viabilize o reconhecimento daqueles fatores que exercerão forte influência sobre a decisão discente de abandonar ou não a ação instrucional. Desse modo, profissionais e instituições de ensino responsáveis por esforços no campo da educação não presencial poderão recorrer ao perfil de sua clientela quanto ao emprego de estratégias de aprendizagem para a identificação, e consequente prevenção, de variáveis nocivas à retenção de seu alunado; a avaliação acurada acerca das estratégias de aprendizagem em ambientes virtuais de ensino poderá fornecer valorosas contribuições para o aperfeiçoamento de tais cenários educativos, bem como para o cumprimento positivo das ações iniciadas.

Por fim, vale ressaltar que o fato dos participantes serem casados e possuírem filhos também comportou-se como fator preditivo para um dos conjuntos de elementos ligados à evasão em EAD (Características do aluno). Seguindo a mesma linha de pensamento, ao considerarem o arranjo familiar de sua clientela, os agentes envolvidos com a ministração de cursos a distância poderão ter em mãos importantes indicativos sobre quais aspectos deverão ser melhor cuidados e, nesse caso, incentivados entre seus alunos - como a administração adequada do tempo dedicado ao estudo, a elaboração de planos que orientem as tarefas instrucionais, a disciplina frente a possíveis distratores, entre outros.

A seguir, são discutidas as principais contribuições e limitações do estudo, bem como propõe-se uma agenda de pesquisa. 


\section{CAPÍTULO 7. CONSIDERAÇÕES FINAIS}

Entre as principais contribuições do presente estudo encontram-se o aprimoramento e a revalidação das ferramentas de medida utilizadas. As escalas avaliadas neste estudo apresentaram bons índices psicométricos de validade e consistência interna. Sugere-se a replicação das mesmas em outros contextos, bem como a realização de análises fatoriais confirmatórias nas mesmas.

O campo da educação não presencial sofre consideravelmente com a perda expressiva de sua clientela, apesar dos constantes esforços em identificar variáveis responsáveis ou ligadas à ocorrência desse fenômeno. Frente a isso, os achados obtidos neste trabalho podem favorecer a compreensão dos elementos influenciadores da decisão discente de não concluir um curso a distância. Esses dados avigoram algumas descobertas advindas de estudos da área, em especial daqueles que tratam da importância do planejamento instrucional. A constatação da influência do delineamento da ação educativa sobre a evasão foi ressaltada na investigação haja vista que, muitas das vezes a literatura trata esse aspecto como mais um elemento entre tantos outros na EAD; na verdade, esta variável destaca-se em relação aos demais fatores relativos aos cursos a distância (como tutores e ferramentas eletrônicas). Isto evidência que a grande preocupação mantida pelas instituições de ensino em oferecer recursos tecnológicos inovadores ou tutores que se assemelham a entertainers, embora positiva, não deve sobrepujar as preocupações para com os processos de organização e sequenciamento das ações educativas - medulares para ganhos educacionais efetivos.

Os modelos de predição aqui testados também forneceram indícios de que quanto mais forem aplicadas específicas estratégias de aprendizagem, maiores serão as chances do corpo discente perceber um conjunto específico de variáveis como muito influentes sobre a permanência ou saída dos mesmos de seus cursos. Logo, alunos que solicitam ajuda a outras pessoas e atentam-se para os processos de aquisição de conhecimento perceberão como altamente importantes as condições tecnológicas e de suporte a eles ofertadas. Já para indivíduos cujas estratégias de monitoramento da compreensão, busca de ajuda interpessoal e cognitivo-comportamentais são as mais empregadas, os eventos provenientes do entorno social (como compromissos sociais e doenças) prejudicarão em maior intensidade a estadia do discente no curso. Para a identificação do conjunto de participantes que definiram as características internas dos aprendizes como intimamente ligadas à evasão/permanência em 
contextos de $\mathrm{EAD}$, além de todas as estratégias de aprendizagem identificadas, a composição familiar e estado civil também figuraram como variáveis preditivas. Por fim, os respondentes que fizeram acentuado uso das estratégias monitoramento da compreensão, autorregulatórias e cognitivo-comportamentais foram os mesmos que apontaram o planejamento instrucional como fator de maior influência para sua continuidade no evento.

A presença constante da estratégia voltada ao autogerenciamento dos processos de aprendizagem em todos os modelos testados remete à importância da investigação dos aspectos que possibilitam ao estudante regular, de modo substantivo e não arbitrário, as experiências relativas ao aprender efetivo. Tal variável se mostra intimamente correlacionada a elevados patamares de sucesso acadêmico, além de ser apontada pela literatura como vital para a sobrevida do estudante em cenários virtuais de ensino.

Talvez seja interessante averiguar o grau em que todas essas variáveis relacionam-se com os elementos ligados à desistência acadêmica nas diferentes modalidades educacionais. A depender da natureza do evento instrucional considerado poder-se-ia reconhecer distintos padrões de uso de estratégias de aprendizagem e, consequentemente, diferentes fatores preditivos, para as clientelas contatadas.

De modo geral, as implicações práticas do trabalho estão relacionadas à importância que de as ações instrucionais a distância sejam desenvolvidas com base nas reais habilidades e perspectivas de seus participantes.

Pontua-se que ao longo do desenvolvimento do presente trabalho foram vivenciadas algumas dificuldades, que resultaram em consequências para a pesquisa. A resistência por parte das instituições de ensino em não colaborar como partícipes exigiu que a amostra considerada viesse a ser composta por três distintas instituições de ensino. A diversidade que caracterizou os cursos e discentes contatos pode ter influenciado os resultados obtidos: talvez seja necessária a administração das ferramentas de medida utilizadas em contextos que melhor se assemelhem. É possível que a falta de homogeneidade entre as ações educativas tenha interferido no modo como os participantes avaliaram os elementos ligados à permanência em EAD. Ou seja, tendo em vista que eventos instrucionais de feitio díspares em termos de objetivos educacionais, complexidade, meios de entrega, natureza do curso requerem medidas para seu desenvolvimento igualmente distintas, é cabível que os resultados obtidos tenham diminuídas suas chances de generalidade.

Além disso, o baixo índice de retorno obtido impossibilitou que averiguações estatísticas mais robustas fossem empreendidas. Refletindo acerca deste desinteresse 
demonstrado por parte da população investigada, pode-se hipotetizar que o mesmo decorra da tão comentada complexidade social que recai sobre o estudante a distância e o faz relegar a segundo plano todas as atividades que não lhe pareçam prementes. Todavia, ainda resta outra possível explicação - muito mais preocupante - para tal ocorrência: a de que a educação a distância não só vem sendo tratada como produto mercadológico pelas corporações de ensino, mas também por seus principais beneficiários - os discentes. Ao enxergarem o ensino não presencial apenas como um meio mais célere, barato e fácil de obter determinada certificação, os estudantes estarão desperdiçando preciosas oportunidades de estabelecerem definitivamente uma nova lógica de aprendizado - a qual seria regida pela qualidade e eficiência de suas medidas. Pesquisas no campo de avaliação de ações educacionais a distância poderão colaborar para a persuasão dos discentes quanto aos benefícios da avaliação de seus programas educacionais.

Sintetizando, as contribuições deste estudo referem-se: (1) Revisão de literatura da seara de avaliação de ações instrucionais a distância em diferentes áreas do conhecimento (Psicologia Instrucional e Organizacional, Educação, Administração, entre outras), a qual fundamentou o embasamento teórico do texto, além de gerar os resultados de pesquisa sobre as temáticas de interesse; (2) Adaptação e verificação de evidências de validade do instrumento de "Fatores Relacionados à Evasão e à Persistência em EAD"; (3) Verificação de evidências de validade da escalas "Estratégias de Aprendizagem"; (4) Aprimoramento da estratégia de coleta de dados realizada pela internet em comparação a estudos anteriores (Brauer, 2005; Carvalho e Zerbini, 2006; Martins, 2012; Sales, 2009; Zerbini e Abbad, 2005).

Quanto às limitações do trabalho, são mencionadas:

(1) Baixo índice de devolução dos questionários nos momentos de coleta de dados realizados através da internet;

(2) Não inclusão de variáveis individuais que poderiam elevar a explicação dos modelos de predição, como autoeficácia, hábitos de estudo, etc;

(3) Não inclusão de dados referentes à frequência de acesso aos recursos da web, que poderiam contribuir para a explicação dos modelos testados;

(4) Não realização de análises de regressão stepwise, devido número insuficiente de casos - é necessária uma amostra maior que satisfaça a razão de 40 casos para cada variável antecedente;

(5) Inexistência de pré e pós-testes de estratégias de aprendizagem;

(6) Não realização de análises comparativas dos perfis de participantes concluintes e evadidos 
dos cursos considerados, bem como das diferentes organizações parceiras;

(7) Impossibilidade de identificar as variáveis preditoras de evasão dos cursos investigados devido à dificuldade em acessar a população evadida;

Diante dos resultados e das discussões promovidas na presente pesquisa, a seguinte agenda de pesquisa é proposta:

1. Aprimorar procedimentos de coleta de dados pela internet, intentando elevar os índices de retorno;

2. Aplicar as ferramentas de medida empregadas neste estudo em outros contextos e amostras;

3. Empreender análises confirmatórias das estruturas empíricas utilizadas neste trabalho;

4. Testar através de modelagem por equação estrutural ou de outras análises consideradas mais robustas, distintos relacionamentos entre as variáveis, incluindo relações de mediação e moderação;

5. Aprofundar as reflexões acerca das estratégias de aprendizagem e perfil sociodemográfico para eventos educacionais em contextos de IES e EAD;

6. Dedicar mais esforços para a identificação de aspectos que expliquem a evasão em cursos a distância;

7. Analisar diferenças entre gêneros, idade e experiências prévias com as TICs quanto à utilização de estratégias de aprendizagem e fatores ligados à evasão/permanência estudantil em EAD;

8. Buscar outros conjuntos de variáveis oriundos de diferentes áreas do conhecimento (Educação, Inovação, Tecnologia da Informação, etc), a fim de robustecer o poder de predição dos modelos de avaliação testados;

Espera-se que o presente estudo tenha contribuído com área de avaliação de cursos a distância, em especial, para a análise de modelos de avaliação de fatores ligados à evasão e à persistência acadêmica em contextos de IES e EAD. 


\section{REFERÊNCIAS BIBLIOGRÁFICAS ${ }^{4}$}

Abbad, G. (1999). Um modelo integrado de avaliação de impacto de treinamento no trabalho. Tese Doutorado, Instituto de Psicologia, Universidade de Brasília.

Abbad, G.S. (2007). Educação a Distância: O Estado da Arte e o Futuro Necessário. In International Seminar on Distance Learning. Brasília.

Abbad, G. S. (2009). Avaliação de Necessidades e Avaliação de Impactos de programas de Treinamento presenciais e a distância em organizações e trabalho. Pedido de renovação de bolsa de produtividade. CNPQ.

Abbad, G., \& Borges-Andrade, J. E. (2004). Aprendizagem humana em organizações de trabalho. In J. C. Zanelli, J. E. Borges-Andrade \& A.V. B. Bastos (Orgs.). Psicologia, Organizações e Trabalho no Brasil (pp. 237-275). Porto Alegre: Artmed.

Abbad, G., Carvalho, R. S., \& Zerbini, T. (2006). Evasão em curso via Internet: explorando variáveis explicativas. RAE-eletrônica, 5(2).

Abbad, G., Gama, A. L. G., \& Borges-Andrade, J. E. (2000). Treinamento: Análise do relacionamento da avaliação nos níveis de reação, aprendizagem e impacto do treinamento no trabalho. Revista de Administração Contemporânea - RAC, 4(3), 25-45.

Abbad, G., \& Meneses, P. P. M. (2004). Locus de controle: validação de uma escala em situação de treinamento. Estudos de Psicologia, 9(3), 441-450.

Abbad, G., Pantoja, M. J., \& Pilati, R. (2001). Avaliação de treinamento: o estado da arte e o futuro necessário. In Encontro anual da ANPAD, 25. Campinas: ANPAD.

Abbad, G., Pilati, R.; \& Pantoja, M. J. (2003). Avaliação de Treinamento: análise da literatura e agenda de pesquisa. Revista da Administração, 38(3), 205-218.

Abbad, G., Zerbini, T., Carvalho, R. S. \& Meneses, P. P. M. (2006). Planejamento instrucional em TD\&E. In J. E. Borges-Andrade, G. Abbad, L. Mourão (Orgs.), Treinamento, desenvolvimento e educação em organizações e trabalho: fundamentos para a gestão de pessoas (pp. 289-321). Porto Alegre, RS: Artmed.

\footnotetext{
${ }^{4}$ De acordo com o estilo APA - American Psychological Association
} 
Abbad, G., Zerbini, T., \& Souza, D. B. L. (2010). Panorama das pesquisas em educação a distância no Brasil. Estudos de Psicologia, 15(3), 291-298.

Abreu-e-Lima, D. M., \& Alves, M. N. (2011). O feedback e sua importância no processo de tutoria a distância. Pro-Posições, 22(2), 189-205.

Alliger, G. M., \& Janak, E. A. (1989). Kirkpatrick's levels of training criteria: thirty years later. Personnel Psychology, 42(2), 331-342.

Alliprandini, P. M. Z.; Lima, C. F.; Oliveira, D. .E.B.; \& Schiavoni, A. (2012). Diferenças entre gênero no uso de estratégias de aprendizagem na educação a distância. In IX ANPED SUL 2012, Caxias do Sul. Anais do IX Anped Sul, 2012. (pp. 1-14).

Almeida, L. (2001). Acesso, integração e sucesso académico: Uma análise reportada aos estudantes do $1^{\circ}$ ano. In R. Sousa., E. Sousa., F. Lemos \& C. Januário (Orgs.), Pedagogia na Universidade: Simpósio da Universidade Técnica de Lisboa (pp. 223-240). Lisboa: Universidade Técnica de Lisboa.

Almeida, M. E. B. (2003). Educação a distância na internet: abordagens e contribuições dos ambientes digitais de aprendizagem. Educação e Pesquisa, 29(2), 327-340.

Almeida, O. C. S. (2007). Evasão em cursos a Distância: validação de instrumento, fatores influenciadores e cronologia da desistência. Dissertação de Mestrado, Instituto de Psicologia, Universidade de Brasília.

Altman, H., \& Arambasich, L. (1982). A Study of Locus of Control with Adult Students. Canadian Counsellor Conseiller Canadien, 16(2), 97-101.

Alves, L. (2011). Educação a distância: conceitos e história no Brasil e no mundo. Revista Brasileira de Aprendizagem Aberta e a Distância, 10, 83-92.

Amidani, C. (2004). Evasão no ensino superior a distância: o curso de licenciatura em matemática a distância da Universidade Federal Fluminense/CEDERJ - RJ. Dissertação de Mestrado. Faculdade de Educação, Universidade de Brasília, Brasília.

Amorim, L. (2009). Os alunos estão cada vez mais longe [Versão eletrônica]. Revista Exame, 938.

Anuário Brasileiro Estatístico de Educação Aberta e a Distância. Instituto Monitor. São Paulo: 
Autor, 2007.

Anuário Brasileiro Estatístico de Educação Aberta e a Distância. Instituto Monitor. São Paulo: Autor, 2008.

Appana, S. (2008). A Review of Benefits and Limitations of Online Learning in the Context of the Student, the Instructor and the Tenured Faculty. International Journal on E-Learning, $7(1), 5-22$.

Associação Brasileira de Educação a Distância (2012).

Badia, A., \& Monereo, C. (2010). Ensino e aprendizagem de estratégias de aprendizagem em ambientes virtuais. In C. Coll \& C. Monereo (Orgs.). Psicologia da Educação virtual Aprender e ensinar com as tecnologias da informação e da comunicação. (pp. 311-328). Porto Alegre: Artmed.

Bartalo, L. \& Guimarães, S. E. R. (2008). Estratégias de estudo e aprendizagem de alunos universitários: Um estudo exploratório. Informação \& Informação, 13(2), 1-14.

Bastos, A. V. B. (1991). O suporte oferecido pela pesquisa na área de treinamento. Revista de Administração, 26(4), 87-102.

Belloni, M. L. (1999). Educação a distância. Campinas: Autores Associados.

Beluce, A. C. \& Oliveira, K. L. (2012). Ambientes virtuais de aprendizagem: das estratégias de ensino às estratégias de aprendizagem. In IX ANPED SUL (pp. 1-14).

Benson, P. (2001). Teaching and Researching Autonomy in Language Learning. Harlow: Longman.

Bessa, J., \& Tavares, J. (2001). Níveis de ajustamento e auto-regulação académica em estudantes do $1^{\circ}$ ano (comum) de Ciências e Engenharias da Universidade de Aveiro. In J. Tavares \& R. Santiago (Orgs). Ensino superior. (In)sucesso académico (pp. 107-132). Porto: Porto Editora.

Bird, J., \& Morgan, C. (2003). Adults contemplating university study at a distance: Issues, themes and concerns. International Review of Research in Open and Distance Learning, 4(1), $1-17$. 
Bjork, R. A.; Dunlosky, J.; \& Kornell, N. (2013). Self-Regulated Learning: Beliefs, Techniques, and Illusions. Annu. Rev. Psychol., 64, 417-44.

Bohadana, E. \& Valle, L. (2009). O quem da educação a distância. Rev. Bras. Educ. 14(42), 551-564.

Borges-Andrade, J. E. (1982). Avaliação somativa de sistemas instrucionais: integração de três propostas. Tecnologia Educacional, 11(46), 29-39.

Borges-Andrade, J. E. (1986). Por uma competência técnica no treinamento. Psicologia, Ciência e Profissão, 2, 9-17.

Borges-Andrade, J. E. (2006). Avaliação integrada e somativa em TD\&E. In J. E. BorgesAndrade, G. Abbad, L. Mourão (Orgs.). Treinamento, desenvolvimento e educação em organizações e trabalho: fundamentos para a gestão de pessoas (pp. 343-358). Porto Alegre: Artmed.

Borges-Andrade, J. E., \& Abbad, G. (1996). Treinamento no Brasil: reflexões sobre suas pesquisas. Revista de Administração, 31(2), 112-125.

Borges-Ferreira, M. F. (2005). Avaliação de reações e aprendizagem em disciplinas de curso técnico profissionalizante oferecidas a distância. Dissertação de Mestrado, Instituto de Psicologia, Universidade de Brasília.

Boruchovitch, E. (1995). A identificação e o estudo das variáveis associadas ao fracasso escolar brasileiro. Projeto de pesquisa (CNPq- processo No 300162/95-2). Faculdade de Educação, Departamento de Psicologia Educacional, Universidade Estadual de Campinas, Campinas-SP.

Boruchovitch, E. (2006). Avaliação psicoeducacional: desenvolvimento de instrumentos à luz da Psicologia Cognitiva baseada na teoria do processamento da informação. Avaliação Psicológica, 5(2), 145-152.

Boruchovitch, E., \& Santos, A. A. A. (2004). Escala de avaliação de estratégias de aprendizagem para crianças do ensino fundamental. Manuscrito não publicado, Universidade São Francisco, Bragança Paulista.

Boruchovitch, E., \& Santos, A. A. A. (2006). Estratégias de aprendizagem: conceituação e avaliação. In A. P. P. Noronha \& F. F. Sisto (Orgs.), Facetas do fazer em avaliação 
psicológica (pp. 107-124). São Paulo: Vetor.

Boruchovitch, E., Santos, A. A. A., Costa, E. R., Neves, E. R. C., Cruvinel, M., Primi, R., \& Guimarães, S. E. R. (2006). A construção de uma escala de estratégias de aprendizagem para alunos do ensino fundamental. Psicologia: Teoria e Pesquisa, 22(3), 297-304.

Brandão, H. P.; \& Borges-Andrade, J. E. (2011). Desenvolvimento e Validação de uma Escala de Estratégias de Aprendizagem no Trabalho. Psicologia: Reflexão e Crítica, 24(3), 448-457.

Brandão, H. P.; \& Guimarães, T. A. (2001). Gestão de competências e Gestão de desempenho: tecnologias distintas ou instrumentos de um mesmo construto? Revista de Administração de Empresas, 41(1), 8-15.

Brauer, S. (2005). Avaliação de um Curso a Distância: Valor Instrumental do Treinamento, Barreiras Pessoais à Conclusão e Evasão. Instituto de Psicologia, Universidade de Brasília, Brasília.

Campbell, J. P. (1971). Personnel Training and Development. Annual review of Psychology, $22,565-602$.

Carr, R., \& Ledwith, F. (2000). Helping disadvantaged students. Teaching at a Distance, 18, 77-85.

Carswell, A. D., \& Venkatesh, V. (2002). Learner outcomes in an asynchronous distance education environment. International Journal of Human-Computer Studies, 56, 475-494.

Carvalho, R. S. (2003). Avaliação de treinamento a distância via internet: reação, suporte à transferência e impacto do treinamento no trabalho. Dissertação de Mestrado, Instituto de Psicologia, Universidade de Brasília.

Carvalho, R. S., \& Abbad, G. (2006). Avaliação de treinamento a distância: reação, suporte à transferência e impactos no trabalho. Revista de Administração Contemporânea, 10(1), 95116.

Castro, M. N. M., \& Ferreira, L. D. V. (2006). TD\&E a distância: múltiplas mídias e clientelas. In J. E. Borges-Andrade, G. Abbad, L. Mourão (Orgs.), Treinamento, desenvolvimento e educação em organizações e trabalho: fundamentos para a gestão de pessoas (pp. 322-339). Porto Alegre: Artmed. 
Chen, C. S. (2002). Self-regulated learning strategies and achievement in an introduction to information systems course. Information Technology, Learning and Performance Journal, 20(1), 11-25.

Chen, S. Y.; \& Paul, R. J. (2003). Editorial: Individual differences in web-based instruction an overview. British Journal Educational Technology, 34(4), p.385-392.

Chiecher, A., Donolo, D., \& Rinaudo, M. C. (2008). Aprendizaje virtual en asignaturas presenciales. Incidencia sobre la motivación y el uso de estrategias. Revista Virtual UDESC, $1(1), 1-24$.

Chyung, Y, Winiecki, D., \& Fenner, J. (1999). Evaluation of Effective Interventions to Solve the Drop out Problem in Adult Distance Education. In. Collis, B., \& Oliver, R. (Eds.), Proceedings of World Conference on Educational Multimedia, Hypermedia and Telecommunications. 51-55.

Cobb, R. J. (2003). The relationship between self-regulated learning behaviors and academic performance in web-based courses. Tese de Doutorado, Faculty of Virginia Polytechnic Institute and State University.

Coelho Jr., F. A. (2004). Avaliação de Treinamento a Distância: Suporte à Aprendizagem e Impacto do Treinamento no Trabalho. Dissertação de Mestrado, Instituto de Psicologia, Universidade de Brasília.

Coelho Jr., F. A. (2008). Análise da Relação entre Variáveis de Clientela, Suporte à Aprendizagem e Impacto de Treinamento a Distância. RAC-Eletrônica, 2(1), 88-104.

Coelho, M. L. A. (2003). Formação continuada do docente universitário em cursos a distância via Internet: um estudo de caso. Monografia de Conclusão de Curso. Belo Horizonte: ABED.

Coll, C., \& Monereo, C. (2010). Educação e aprendizagem no século XXI: novas ferramentas, novos cenários, novas finalidades. In C. Coll \& C. Monereo (Orgs.). Psicologia da Educação virtual - Aprender e ensinar com as tecnologias da informação e da comunicação (pp. 1546). Porto Alegre: Artmed.

Collins, H. (2008). Distance Learning, Autonomy Development and Language: Discussing Possible Connections. Revista de Documentação de Estudos em Lingüística Teórica e Aplicada, 24, 529-550. 
Costa, E. R., \& Boruchovitch, E. (2000). Fatores que influenciam o uso de estratégias de aprendizagem. Psico-USF, 5, 11-24.

Costa, E. R., \& Boruchovitch, E. (2004). Compreendendo as relações entre estratégias de aprendizagem e ansiedade de alunos do ensino fundamental de Campinas. Psicologia Reflexão e Crítica, 17(1), 15-24.

Costa, E. R., \& Boruchovitch, E. (2009). As estratégias de aprendizagem e a produção de textos narrativos. Psicologia: Reflexão e Crítica, 22(2), 173-180.

Cruvinel, M. (2002). Depressão infantil, rendimento escolar e estratégias de aprendizagem em alunos dos ensino fundamental. Dissertação de Mestrado. Faculdade de Educação, Universidade Estadual de Campinas, Campinas.

Curless, T. A. (2004). Motivating Students in Distance Education. Distance Learning, 1(5), 19-22.

Dean, A., \& Webster, L. (2000). Simulations in distance education-progress towards an evaluation instrument. Distance Education, 21(2), 344-360.

Decreto $\mathrm{n}^{\mathrm{o}}$ 5.622, de 19 de dezembro de 2005. (2005, 19 de dezembro). Regulamenta o artigo 80 da LDB. Diário Oficial da União. Brasília, DF.

Decreto $\mathrm{n}^{\circ}$ 5.800, de 08 de junho de 2006. (2006, 08 de junho). Dispõe sobre o Sistema Universidade Aberta do Brasil - UAB. Diário Oficial da União. Brasília, DF.

Decreto $\mathrm{n}^{\circ}$ 6.301, de 12 de dezembro de 2007. (2007, 12 de dezembro). Institui o Sistema Escola Técnica Aberta do Brasil - E-tec Brasil. Diário Oficial da União. Brasília, DF.

Deimann, M. \& Bastiaens, T. (2010). The Role of Volition in Distance Education: An Exploration of its Capacities. International Review of Research in Open and Distance Learning Volume 11, Number 1. 1-16.

Dembo, M. H. (1994). Applying educational psychology. New York: Longman Publishing Group.

De Paula e Silva, A. (2004). Avaliação de uma disciplina semipresencial de graduação ofertada por meio da internet pela Universidade de Brasília. Dissertação de Mestrado, 
Instituto de Psicologia, Universidade de Brasília.

Diaz, D. P. (2002). Online drop rates revisited. The Technology Source, 13, 93-106.

Donolo, D.; Chiecher, A.; \& Rinaudo, C. M. (2004). Estudiantes, Estrategias y Contextos de Aprendizaje Presenciales y Virtuales. Primer congreso virtual latinoamericano de educación a distancia. Ciudad de México. México.

Eboli, M. (2004). Educação Corporativa no Brasil: Mitos e Verdades. São Paulo: Editora Gente.

Favero, R. V. M., \& Franco, S. R. K. (2006). Um estudo sobre a permanência e a evasão na educação a distância. CINTED-UFRGS, 4(2).

Fahy, P. J. (2003). Indicators of Support in Online Interaction. International Review of Research in Open and Distance Learning, 4(1), 1-16.

Flavell, J. H. (1970). Developmental studies of mediated memory. In H.W. Reese y L.P. Lipsitt (Eds.), Advances in child development and behavior (Vol. 5). New York: Academic Press.

França, G. (2009). Os ambientes de aprendizagem na época de hipermídia e da Educação a distância. Perspectivas em Ciência da Informação, 14(1), 55-65.

Frankola, K. (2001). Why online learners dropout. Find Articles.

Galusha, J. M. (1997). Barriers to learning in distance education. Interpersonal Computing and Technology, 5(3-4), 6-14.

Garrison, D. R. (2003). Cognitive Presence for Effective Asynchronous Online Learning: The role of reflective inquiry, self-directed learning and metacognition. In J. Bourne \& J. C. Moore (Eds.), Elements of quality online education: Practice and direction (Sloan C Series,) Needham: The Sloan Consortium.

Goldstein, I. L. (1991). Training in work organizations. In Dunnette \& Hough (Orgs.). Handbook of Industrial and Organizational Psychology (pp. 507-619). Palo Alto, California: Consulting Psych. 
Gomes, M.A.M. (2002). Aprendizagem auto-regulada em leitura numa perspectiva de jogos de regras. Dissertação de Mestrado. Universidade Estadual de Campinas, Campinas.

Gomes, M. A M. \& Boruchovitch, E. (2005). Desempenho no jogo, estratégias de aprendizagem e compreensão na leitura. Psicologia Teoria e Pesquisa, 21(3), 319-326.

Gondim, S. M. G. \& Silva, N. (2004). Motivação no Trabalho. In J. C. Zanellie, J. E. BorgesAndrade \& A. V. B. Bastos (Orgs.), Psicologia, organizações e trabalho no Brasil (pp. 145176). Porto Alegre: Artmed.

Guimarães, S. E. R. \& Boruchovitch, E. (2004). O Estilo Motivacional do Professor e a Motivação Intrínseca dos Estudantes: Uma Perspectiva da Teoria da Autodeterminação. Psicologia: Reflexão e Crítica, 17(2), 143-150.

Hair, J. F., Anderson, R. L., Tatham, R. L. \& Black, W. C. (2005). Análise Multivariada de dados (5a ed.). Porto Alegre: Bookman.

Hamblin, A. C. (1978). Avaliação e controle do treinamento. São Paulo: McGraw-Hill do Brasil.

Hall, R. H.; Watkins, S. E.; \& Eller, V. E. (2003). A model of web based design for learning. In: Moore, M.; Anderson, B. The handbook of distance education (pp. 367-376). Mahwah, NJ: Erlbaum.

Henke, H. \& Russum, J. (2000). Factors Influencing Attrition Rates in a Corporate Distance Education Program. Education at a Distance Journal, 14(11).

Holder, B. (2007). An investigation of hope, academics, environment, and motivation as predictors of persistence in higher education online programs. Internet and Higher Education, $10,245-260$.

Holec, H. (1981). Autonomy in Foreign Language Learning. Oxford: Pergamon.

Iglesias, M; \& Salgado, J. F. (2012). Effectiveness of Occupational Training Through Videoconferencing: Comparison with Classroom Training and Individual Differences. Revista de Psicología del Trabajo y de las Organizaciones, 28(3), 183-188 
Ihamaki, H., \& Vilpola, I. Usability of a Virtual Learning Environment Concerning Safety at Work. Electronic Journal on e-Learning, 2(1), 103-112.

Instituto Nacional de Estudos e Pesquisas Educacionais Anísio Teixeira. Ministério da Educação. Censo da Educação Superior 2006: resumo técnico. Brasília, 2007.

Instituto Nacional de Estudos e Pesquisas Educacionais Anísio Teixeira. Ministério da Educação. Censo da Educação Superior 2007: resumo técnico. Brasília, 2009.

Jamison, T. M. (2003). Ebb from the Web: using motivational systems theory to predict student completion of asynchronous web-based distance education courses. George Mason University.

Joia, L. A., \& Costa, M. F. C. (2007). Fatores-chave de sucesso no treinamento corporativo a distância via web. Revista de Administração Pública, 41(4), 607-637.

Joly, M. C. R. A.; Cantalice, L.M. \& Vendramini, C. M. M. (2004). Evidências de validade de uma escala de estratégias de leitura para universitários. Interação em Psicologia, 8, 261-270.

Kearley, K.; Moore, M. G. (2005) Distance education a system view. 2. ed. Belmont, CA, USA: Thomson Wadsworth.

Kember, D. (2000). Misconceptions about the learning approaches, motivation and study practices of Asian students. Higher Education, 40, 99-121.

Kirkpatrick, D. L. (1976). Evaluation of training. In R. L. Craig (Org.), Training and Development Handbook (pp. 18.1-18.27). New York: McGraw-Hill.

Lacerda, E. R. M., \& Abbad, G. (2003). Impacto do Treinamento no Trabalho: Investigando Variáveis Motivacionais e Organizacionais como suas Preditoras. Revista de Administração Contemporânea, 7(4), 77-96.

Laros, J. A. (2004). O uso da análise fatorial: algumas diretrizes para pesquisadores. In: L. Pasquali (Org.). Análise fatorial para pesquisadores. Petrópolis: Vozes.

Leasure, A. R., Davis, L., \& Thievon, S. L. (2000). Comparison of student outcomes and preferences in a traditional vs. World Wide Web based baccalaureate nursing research course. Journal of Nursing Education, 39(4), 149-154. 
Leaver, B. L. (1997). Teaching the whole class. Thousand Oaks: Corwin Press Inc.

Lee, H. S. \& Anderson, J. R. (2013). Student Learning: What Has Instruction Got to Do With It?. Annu. Rev. Psychol.,64(3),1-25.

Leh, A. S. (2001). Computer-mediated communication and social presence in a distance learning environment. International Journal of Educational Telecommunications, 6(4), 317338.

Lei No. 9.394, de 20 de dezembro de 1996. (1996, 20 de dezembro). Estabelece as Diretrizes e Bases da Educação Nacional. Diário Oficial da União, seção 1. Brasília, DF.

Lei No. 10.172, de 9 de janeiro de 2001. (2001, 09 de janeiro). Aprova o Plano Nacional de Educação e dá outras providências. Diário Oficial da União. Brasília, DF.

Lei $n^{\circ}$ 11.494, de 20 de junho de 2007. (2007, 20 de junho). Institui o Fundo de Manutenção e Desenvolvimento da Educação Básica. Diário Oficial da União. Brasília, DF.

Lei $\mathrm{n}^{\mathrm{o}}$ 12.056, de 13 de outubro de 2009. (2009, 13 de outubro). Acrescenta parágrafos ao artigo 62 da LDB. Diário Oficial da União. Brasília, DF.

Lentell, H. (2003). The importance of the tutor in open and distance learning. In A. Tait, R. Millis (Orgs.). Rethinking learner support in distance education (pp. 64-76). London: Routledge Falmer.

Levin, J. R. (1986). Four cognitive principles of learning-strategy instruction. Educational Psychologist, 21, 3-17.

Little, D. (1991). Autonomy: Definitions, Issues and Problems. Dublin: Authentik.

Litwin, E. (2001). Educação a Distância: temas para o debate de uma nova agenda educativa. Porto Alegre: Artmed Editora.

Machado, O. A. (2005). Evasão de alunos de cursos superiores: fatores motivacionais e de contexto. Dissertação de Mestrado em Educação, Universidade Estadual de Londrina, Londrina.

Maia, C. (2002). Guia brasileiro de educação a distância 2002/2003. São Paulo: Esfera. 
Maia, M. C. (2003). O Uso da Tecnologia de Informação para a Educação a Distância no Ensino Superior. Tese de Doutorado, programa de Pós-Graduação em Administração de Empresas da FGV-EAESP.

Maggio, M. (2001). O Tutor na Educação a Distância. In E. Litwin (Org.). Educação a distância: temas para o debate de uma nova agenda educativa (pp. 93-110). Porto Alegre: Artmed.

Magno e Silva, W. (2008). Um modelo para o desenvolvimento da autonomia. DELTA, 24, 469-492.

Marinho, S. P. (2002). Tecnologia, educação contemporânea e desafios ao professor. In M. C. R. A. Joly (Org.). A tecnologia no ensino: implicações para a aprendizagem (pp. 41-62). São Paulo: Casa do Psicólogo.

Martins, L. B. (2012). Aprendizagem em ações educacionais a distância: fatores influentes no desempenho acadêmico de universitário. Dissertação de Mestrado, Faculdade de Filosofia, Ciências e Letras de Ribeirão Preto, Universidade de São Paulo, São Paulo.

McCormick, C. B. (2003). Metacognition and learning. In:W. M. Reynolds; G. E. Miller (Orgs.). Handbook of Psychology. Educational Psychology.

Mehlecke, T. C. \& Guedes, A. T. (2006). Estratégias do professor para promover a interação dos alunos nas aulas a distância on-line. Revista Liberato, 7(8).

Meneses, P. P. M. (2002). Auto-eficácia, locus de controle, suporte à transferência e impacto do treinamento no trabalho. Dissertação de Mestrado. Brasília: Instituto de Psicologia, Universidade de Brasília.

Meneses, P. P. M. \& Abbad, G. (2003). Preditores individuais e situacionais de auto e heteroavaliação de Impacto do Treinamento no Trabalho. Revista de Adminstração Contemporânea, 7, ed. especial.

Meneses, P. P. M., Abbad, G, Zerbini, T., \& Lacerda, E. (2006). Medidas de características da clientela em avaliação de TD\&E. In J. E. Borges-Andrade, G. Abbad, L. Mourão (Orgs.). Treinamento, desenvolvimento e educação em organizações e trabalho: fundamentos para a gestão de pessoas (pp. 422 - 442). Porto Alegre: Artmed.

Meneses, P. P. M., Zerbini, T. \& Abbad, G. (2010). Manual de Treinamento Organizacional. 
Porto Alegre: Artmed.

Miles, J. \& Shevlin, M. (2001). Applying regression \& correlation: a guide for students and researchers. London: SAGE Publications.

Ministério da Educação (2009). Avaliação do Plano Nacional de Educação 2001-2008, 1.

Ministério da Educação (2009). Avaliação do Plano Nacional de Educação 2001-2008, 2.

Ministério da Educação (2011). http://portal.mec.gov.br/index.php

Moore, M. G., \& Kearsley, G. (1996). Distance education. A systems view. Belmont: Wadsworth Publishing Company.

Moore, M., \& Kearsley, G. (2007). Educação a distância: uma visão integrada. São Paulo: Thomson.

Morin, E. (2001). Os sete saberes necessários à educação do futuro. São Paulo: Cortez.

Morgan, C. K, \& McKenzie, A. D. (2003). Is Enough Too Much? The dilemma for online distance learner supporters, International Review of Research in Open and Distance Learning,4(1), 1-13.

Morris, L. V., Finnegan, C., \& Wu, S. (2005). Tracking student behavior, persistence, and achievement in online courses. The Internet and Higher Education, 8(3), 221-231.

Mory, E. H. (2004). Feedback research review. In D. Jonassem (Org.). Handbook of research on educational communications and technology (pp. 745-783). Mahwah: Lawrence Erlbaum.

Nesler, M. S. (1999). Factors associated with retention in a distance-based liberal arts program. Paper presented at the north east association for Institutional Research Conference. 26th, Newport, RI, November.

Ngoma, P. S., Simwanza, A., \& Makukna, C. K. (2004). Investigating the Drop Out Problem Amongst University Extension Studies Learners in Zambia. Third Pan- Commonwealth Forum on Open Learning, Dunedin, New Zealand. Acessado em 12 de setembro de 2011 em: http://www.col.org/pcf3/Papers/PDFs/Ngoma_Simwanza_Makunka.pdf. 
Oliveira, G. P. (2010). Estratégias multidimensionais para a avaliação da aprendizagem em cursos on-line. Ensaio: Avaliação e Políticas Públicas em Educação, 18(66), 105-138.

Oliveira, K. L., Boruchovitch, E., \& Santos, A. A. A. (2006) Escala de Estratégias de Aprendizagem: estudo das propriedades psicométricas. In C. Machado; L. Almeida; M. A. Guisande; M. Gonçalves \& V. Ramalho (Orgs.), XI Conferência Internacional - Avaliação Psicológica: formas e contextos (pp. 509-516). Braga: Psiquilibrios Edições.

Oliveira, K. L., Boruchovitch, E., \& Santos, A. A. A. (2009). Estratégias de aprendizagem e desempenho acadêmico: evidências de validade. Psicologia: teoria e pesquisa, 25(4), 531536.

Oliveira, K. L.; Boruchovitch, E.; \& Santos, A. A. A. (2011). Estratégias de aprendizagem no ensino fundamental:análise por gênero, série escolar e idade. Psico, 42(1), 98-105.

Oliveira, E. A., \& Tedesco, P. (2010). I-collaboration: Um modelo de colaboração inteligente personalizada para ambientes de EAD. Revista Brasileira de Informática na Educação, 18(1), 17-31.

Paas, L. (2001). Design educacional. Florianópolis:UFSC/LIED.

Pacheco, A. S. V.; Rissi, M.; Nakayama, M. K.; Silveira, R. A.; \& Spanhol, F. J. (2010). A desistência de estudantes de um curso na modalidade a distância voltado para adolescentes. Revista Novas Tecnologias na Educação, 8(3).

Paiva, V. L. M. O. (2006). Autonomia e complexidade. Linguagem \& Ensino, 9(1), 77-127.

Pallof, R. M., \& Pratt, K. (2004). O aluno virtual: um guia para trabalhar com alunos online. Porto Alegre: Artmed.

Pantoja, M. J. \& Borges-Andrade, J. E. (2009). Estratégias de aprendizagem no trabalho em diferentes ocupações profissionais. RAC-Eletrônica, 3(1), 41-62.

Parker, A. (1995). Distance Education Attrition. International Journal of Educational Telecommunications, 1(4), 389-406.

Pasquali, L. (2004). Análise fatorial para pesquisadores. Petrópolis: Vozes. 
Pereira, E. W. (2003). Educação a Distância: Concepção e Desenvolvimento. Revista da Faculdade de Educação, 9(17), 197-212.

Perrenoud, P. (2000). Dez novas competências para ensinar. Porto Alegre: Artmed, 2000.

Peters, O. (2004). A educação a distância em transição: tendências e desafios. São Leopoldo: Editora UNISINOS.

Petty, L., Johnston, J., \& Shafer, D. (2004). Handbook of distance education for adult learners. $3^{\circ} \mathrm{ed}$. University of Michigan.

Pierrakeas, C., Xenos, M., Panagiotakopoulos, C., \& Vergidis, D. A. (2004). Comparative Study of Dropout Rates and Causes for Two Different Distance Education Courses. International Review of Research in Open and Distance Learning, 5(2).

Pilati, R. (2004). Modelo de efetividade do treinamento no trabalho: aspectos dos treinandos e moderação do tipo de treinamento. Tese de Doutorado, Instituto de Psicologia, Universidade de Brasília.

Pintrich, P. R., Smith, D. A., Garcia, T., \& Mckeachie, W. J. (1991). A manual for the use of the Motivated Strategies for Learning Questionnaire (M.S.L.Q.). National Center for Research to Improve Postsecondary Teaching and Learning. University of Michigan.

Plano de Desenvolvimento da Educação, de 24 de abril de 2007. (2007, 24 de abril). Ministério da Educação. Brasília, DF.

Poole, D. M. (2000). Student Participation in a Discussion-Oriented Online Course: A case study. Journal of Research on Computing in Education, 33(2), 162-177.

Portal INEPAD: $\underline{\text { www.inepad.org.br }}$

Portal Licenciatura em Ciências: licenciaturaciencias.usp.br

Portaria Ministerial $\mathrm{n}^{\circ}$ 301. (1998, 07 de abril). Normatiza os procedimentos de credenciamento de instituições para a oferta de cursos de graduação e educação profissional tecnológica a distância. Diário Oficial da União. Brasília, DF. 
Portaria Ministerial $\mathrm{n}^{\circ}$ 522. (1997, 09 de abril). Cria o Programa Nacional de Informática na Educação - ProInfo. Diário Oficial da União. Brasília, DF.

Portaria Ministerial $n^{\circ}$ 4.361. (2004, 29 de dezembro). Credenciamento de Instituições de Ensino Superior para oferta de cursos a distância. Diário Oficial da União. Brasília, DF.

Powarczuk, E. (2002). A interação entre professor/tutor e aluno nas modalidades presencial e a distância do curso IPGN-Sebrae. Dissertação de Mestrado. Escola de Administração. Progrma de Pós-Graduação em Administração. Universidade Federal do Rio Grande do Sul. Porto Alegre: RS.

Pretto, N. L. (2001). Desafios para a educação na era da informação: o presencial, a distância, as mesmas políticas e o de sempre. In R. G. Barreto (Org.). Tecnologias educacionais e educação a distância: avaliando políticas e práticas (pp. 29-53). Rio de Janeiro: Quartet.

Previdelli, A. (2012, agosto). Ensino à distância: isso ainda vai ser grande no Brasil [Versão eletrônica]. Revista Exame, 1021.

Ramal, A. C. (2002). Educação na cibercultura: hipertextualidade, leitura, escrita e aprendizagem. Porto Alegre: Artmed.

Reis, F. L. (2009). Do ensino presencial ao ensino a distância no contexto universitário na Península Ibérica. Revista Brasileira de Aprendizagem Aberta e a Distância, 8, 1-28.

Resolução CNE/CES n ${ }^{\circ}$ 1, de 3 de abril de 2001. (2001, 03 de abril). Explicita normas para o funcionamento da pós-graduação. Diário Oficial da União. Brasília, DF.

Resolução CoG n ${ }^{\circ}$ 5539, de 08 de maio de 2009. (2009, 08 de maio). Altera dispositivo da Resolução CoG $n^{\circ}$ 5520, de 12 de março de 2009, que estabeleceu diretrizes gerais para a elaboração de propostas de criação de Cursos de Graduação no âmbito do programa USP/UNIVESP. Diário Oficial do Estado. São Paulo, SP.

Ribeiro, C. (2003). Metacognição: um apoio ao processo de aprendizagem. Psicologia, Reflexão e Crítica, 16(1), 109-116.

Ribeiro, I. S., \& Silva, C. F. (2007). Auto-regulação: diferenças em função do ano e área em alunos universitários. Psicologia: Teoria e Pesquisa, 23(4), 443-448.

Ribeiro, R. M. C. \& Carvalho, C. M. C. N. (2012). O desenvolvimento da autonomia no 
processo de aprendizagem em Educação a Distância (EAD). Revista Aprendizagem em EAD, $1,1-10$.

Riveiro, J. M. S. \& Nieto, D. A. (2004). Educación a Distancia y Presencial: Diferencias em los Componentes Cognitivo y Motivacional de Estudiantes Universitarios. Revista Iberoamericana de Educación a Distancia, 7(1/2), 65-75.

Robertshaw, M. (2000). Support groups in distance education (Knowledge Series) Commonwealth of Learning.

Romero, M., \& Barberà, E. (2011). Quality of Learners' Time and Learning Performance Beyond Quantitative Time-on-Task. The International Review Of Research In Open And Distance Learning, 12(5), 125-137.

Rourke, L., Anderson, T., Garrison, D. R., \& Archer, W. (2001). Assessing social presence in asynchronous text-based computer conferencing. Journal of Distance Education 14(2), 50-71.

Rovai, A. (2002). Building sense of community at a distance. International Review of Research in Distance Learning, 3(1).

Salas, E., \& Cannon-Bowers, J. A. (2001). The science of training: a decade of progress. Annual Review of Psychology, 52, 471-499.

Sales, P. A. O. (2009). Evasão em Cursos a Distância: Motivos Relacionados às Características do Curso, do Aluno e do Contexto de Estudo. Dissertação de Mestrado, Instituto de Psicologia, Universidade de Brasília, Brasília.

Sallorenzo, L. H. (2000). Avaliação de impacto de treinamento no trabalho: analisando e comparando modelos de predição. Dissertação de Mestrado, Instituto de Psicologia, Universidade de Brasília.

Sallorenzo, L. H., Abbad, G., Botelho, F. V. U., \& Silva, M. L. B. (2004). Avaliação de Efetividade de Cursos a Distância: A Experiência da Universidade Católica de Brasília. In: $11^{o}$ Congresso Internacional de Educação a Distância - ABED. Salvador. Anais do $11^{\circ}$ Congresso Internacional de Educação a Distância - ABED, 2004.

Sant'anna, A. S. (2002). Competências Individuais Requeridas, Modernidade Organizacional e Satisfação no Trabalho: uma análise de organizações mineiras sob a ótica de profissionais da área de administração. Tese de Doutorado, Faculdade de Ciências Econômicas, Universidade Federal de Minas Gerais. 
Santos, A. A. A., \& Boruchovitch. E. (2001). Escala de avaliação de estratégias de aprendizagem em universitários. Manuscrito não publicado. Universidade São Francisco, Bragança Paulista-SP.

Santos, A. A. A., Boruchovitch, E., Primi, R., Zenorini, R. P. C., \& Bueno, J. M. H (2004). Escala de avaliação de estratégias de aprendizagem para universitários (EAP-U): aplicação do Modelo de Rasch de créditos parciais. Braga-PT: Psicologia: Teoria, Investigação e Prática, 9(2), 227-242.

Santos, J. F. S. (2006). Avaliação no ensino a distância. Revista Iberoamericana de Educación, 38(4), 1-9.

Sarmet, M. M., \& Abrahão, J. I. (2007). O tutor em Educação a Distância: análise ergonômica das interfaces mediadoras. Educação em Revista, 46, 109-141.

Scharle, Á. \& Szabó, A. (2000). Learner Autonomy: a guide to developing learner responsibility. Cambridge: Cambridge.

Shea, T.; Motiwalla, L.; Lewis, D. (2001). Internet-based distance education - the administrator's perspective. Journal of Education for Business, 77(6), 113-117.

Shin, N. \& Kim, J. (1999). An exploratory of learner progress and drop-out in Korea National Open University. Distance Education, 20(3), 81-95.

Schlieper, M.D.E.P. (2001). As estratégias de aprendizagem e as atribuições de causalidade de alunos do ensino fundamental. Dissertação de Mestrado. Universidade Estadual de Campinas, Campinas.

Schlieper, M.D.E.P. \& Boruchovitch, E. (2001). Mantendo a atenção em sala de aula: o que alunos do ensino fundamental fazem. XXXI Reunião Anual de Psicologia: Sociedade Brasileira de Psicologia - livros de resumos, 215.

Silva, M. (2003). Criar e professorar um curso online: relato de experiência. In M. Silva (Org.). Educação online: teorias, práticas, legislação, formação corporativa. São Paulo: Edições Loyola.

Silva, D. R., \& Tomaz, J. B. C. (2006). Porque a evasão? Escola de Saúde Pública do Ceará. Fevereiro. 
Simpson, O. (2004). Access, Retention and Course Choice in Online, Open and Distance Learning. European Journal of Open, Distance and E-Learning.

Siqueira, K. F. (2009). Alguns estudos sobre evasão e persistência de estudantes. Eccos Revista Científica, 11(1), 247-264.

Shute, V. J. (2008). Focus on formative feedback. Review of Educational Research, 1(78), 153-189.

Skaalvik, E.M. (1997). Self-enhancing and self-defeating ego orientation: Relations with task and avoidance orientation, achievement, self-perceptions, and anxiety. Journal of Educational Psychology, 89(1), 71-81.

Song, L., Singleton, E. S., Hill, J. R., \& Koh, M. H. (2004). Improving online learning: Student perceptions of useful and challenging characteristics. Internet and Higher Education, 7, 59-70.

Sonnentag, S.; Niesse, C.; \& Ohly, S. (2004). Learning at work: training and development. In C. L. Cooper, \& I. T. Robertson (Eds), International Review of industrial and organizational psychology, (pp. 249-289). London: John Wiley and Sons.

Souza, D. J. (2002). Educação a distância e cultura organizacional no Banco do Brasil: um estudo de caso. Dissertação de Mestrado, Programa de Pós-Graduação em Engenharia de Produção, Universidade Federal de Santa Catarina, Santa Catarina.

Souza, L. F. N. I. (2010). Estratégias de aprendizagem e fatores motivacionais relacionados. Educar, 36, 95-107.

Tabachnick, B.G., \& Fidell, L.S. (2001). Using multivariate statistics. New York: HarperCollins College Publishers.

Tait, A. (1996). Conversation and community in open and distance learning. In J. Frankl, B. O'Reilly (Orgs.). In EDEN Conference: Lifelong learning, open learning, distance learning. (pp. 12-16). Poitiers: France.

Tannenbaum, S. I., \& Yukl, G. (1992). Training and development in work organizations. Annual Review of Psychology, 43, 399-441. 
Tamayo, N. (2002). Autoconceito Profissional, Suporte à Transferência e Impacto de Treinamento no Trabalho. Dissertação de Mestrado, Instituto de Psicologia, Universidade de Brasília.

Testa, M. G. \& Luciano, E. M. (2010). A influência da autorregulação dos recursos de aprendizagem na efetividade dos cursos desenvolvidos em ambientes virtuais de aprendizagem na Internet. Revista Eletrônica de Administração, 16(2), 176-208.

Tinto, V. (1975). Dropout from higher education: A theoretical synthesis of recent research. Review of Educational Research, 45(1), 89-129.

Tobin, J. (1995). Evaluation and research frontiers: What do we need to know? In J. M. Roberts, E. M. Keough (Orgs.). Why the information highway? Lessons from open and distance learning (pp. 201-225). Toronto: Trifolium Books Inc.

Tresman, S. (2002). Towards a Strategy for Improved Student Retention in Progremmes of Open, Distance Education: A Case Study from the Open University UK. International Review of Research in Open and Distance Learning, 3(1).

Tsai, M. J. (2009). The Model of Strategic e-Learning: Understanding and Evaluating Student e-Learning from Metacognitive Perspectives. Educational Technology \& Society, 12(1), 3448.

Tucho, A. E. (2000). Factors Influencing the Successful Completion of the General Educational Development (GED) Program at the Community College of Philadelphia (CCP) as Perceived by the GED students. EdD, Temple University.

Tyler-Smith, K. (2006). Early Attrition among First Time eLearners: A Review of Factors that Contribute to Drop-out, Withdrawal and Non-completion Rates of Adult Learners undertaking eLearning Programmes. MERLOT Journal of Online Learning and Teaching, 2(2).

Valdés, M. T. M. (2003). Estrategias de aprendizaje: bases para la intervención psicopedagógica. Revista de Psicopedagogía, 20, 136-142.

Varanda, R. C., Zerbini, T., \& Abbad, A. (2010). Construção e Validação da Escala de Reações à Interface Gráfica para Cursos de Educação a Distância. Psicologia: Teoria e Pesquisa, 26(2), 371-380.

Vargas, M. R. M. (2000). Treinamento à distância por videoconferência: o caso da EMBRAPA. In Encontro Nacional da Associação Nacional dos Programas de Pós- 
graduação e Pesquisa em Administração, 24. Anais. Florianópolis: ANPAD.

Vargas, M. R. M. (2004). Barreiras à implantação de programas de educação e treinamento a distância. Tese de Doutorado. Universidade de Brasília. Brasília.

Vargas, M. R. M., \& Abbad, G. S. (2006). Bases conceituais em treinamento, desenvolvimento e educação - TD\&E. In J. E. Borges-Andrade, G. Abbad, L. Mourão (Orgs.). Treinamento, desenvolvimento e educação em organizações e trabalho: fundamentos para a gestão de pessoas (pp. 137-158). Porto Alegre: Artmed.

Veenman, M. V. J.; Wilhelm, P.; \& Beishuizen, J. J. (2004). The relation between intellectual and metacognitive skills from a developmental perspective. Learning and Instruction, 14, 89109.

Visser, L., Plomp, T., Amirault, R., \& Kuiper, W. (2002). Motivating students at a distance: The case of an international audience. Educational Technology Research and Development, 50(2), 94-110.

Vovides, Y., Sanchez-Alonso, S., Mitropoulou, V., \& Nickmans, G. (2007). The use of elearning course management system to support learning strategies and to improve selfregulated learning. Educational Research Review, 2(1), 64-74, 2007.

Xenos, M., Pierrakeas, C. \& Pintelas, P. (2002). A survey on student dropout rates and dropout causes concerning the students in the Course of Informatics of the Hellenic Open University. Computers \& Education, 39, 361-377.

Walter, A. M. (2006). Variáveis preditoras de evasão em cursos a distância. Dissertação de mestrado. Universidade de Brasília, Distrito Federal, Brasil.

Walter, A. M. (2008). Variáveis Preditoras de Evasão em Dois Cursos a Distância. In XXXII Encontro da ANPAD. Rio de Janeiro.

Wang, G., Foucar-Szocki, D., Griffin, O., O’Connor, C. \& Sceiford, E. (2003). Departure, Abandonment, and Dropout of E-learning: Dilemma and Solutions. James Madison University.

Warr, P., \& Allan, C. (1998). Learning strategies and occupational training. Internacional Review of Industrial and Organizational Psychology, 13, 83-121. 
Warr, P., \& Downing, J. (2000). Learning strategies, learning anxiety and knowledge acquisition. British Journal Psychology, 91, 311-333.

Weinstein, C. E., \& Palmer, D. R. (1987). Learning and Study Strategies Inventory (LASSI). Clearwater: H \& H Publishing Company.

Weinstein, C. E., \& Palmer, D. R. (1990). Learning and Study Strategies Inventory (LASSI). Clearwater: H \& H Publishing Company.

Wexley, K. N. (1984). Personnel Training. Annual review of Psychology, 35, 519-551.

Yukselturk, E. \& Inan, F. A. (2006). Examining the Factors Affecting Student Dropout in an Online Certificate Program. Turkish Online Journal of Distance Education-TOJDE, 7(3), 7688 .

Zabalza, M. (2005). O ensino universitário: seu cenário e seus protagonistas. Artmed.

Zerbini, T. (2003). Estratégias de aprendizagem, reações aos procedimentos de um curso via internet, reações ao tutor e impacto do treinamento no trabalho. Dissertação de Mestrado, Instituto de Psicologia, Universidade de Brasília, Brasília.

Zerbini, T. (2007). Avaliação da transferência de treinamento em curso a distância. Tese de Doutorado, Instituto de Psicologia, Universidade de Brasília.

Zerbini, T. \& Abbad, G. (2007). Variáveis Preditoras da Transferência de Treinamento em Curso a Distância. In 5th International Conference of the Iberoamerican Academy of Management IAM. Santo Domingo, República Dominicana.

Zerbini, T. \& Abbad, G. (2005). Impacto de treinamento no trabalho via internet. Revista de Administração de Empresas Eletrônica, 4 (2).

Zerbini, T., \& Abbad, G. (2008). Estratégias de aprendizagem em curso a distância: validação de uma escala. Psico-USF, 13, 177-187.

Zerbini, T. \& Abbad, G. (2010). Aprendizagem induzida pela instrução em contexto de organizações e trabalho: uma análise crítica da literatura. Cadernos de Psicologia Social do Trabalho, 13(2), 177-193. 
Zerbini, T.; Borges-Ferreira, M. F. \& Abbad, G. S. (2012). Medidas de reação a cursos a distância. In G. S. Abbad, L. Mourão, P. P .M. Meneses, T. Zerbini, J. E. Borges-Andrade, R. Vilas-Boas (Orgs). Medidas de Avaliação em Treinamento, Desenvlvimento e Educação (pp. 91 - 107). Porto Alegre: Artmed.

Zerbini, T., Carvalho, R. S., \& Abbad, G. (2005). Treinamento a distância via internet: construção e validação de escala de estratégias de aprendizagem [CD-Rom]. Em Associação Nacional dos Programas de Pós-Graduação em Administração (Org.). Anais do XXIX ENANPAD. Brasília: ANPAD.

Zimmerman, B. J., \& Bandura, A. (1994). Impact of self-regulatory influences on writing course attainment. American Educational Research Journal, 31, 845-862.

Zimmerman, B. J., \& Martinez-Pons, M. (1986). Development of a structured interview for assessing student use of self-regulated learning strategies. American Educational Research Journal, 23, 614-628. 


\section{ANEXO A - CARTA AOS TUTORES}

Prezados Tutores,

A Universidade de São Paulo (USP - Ribeirão Preto) em parceria com (nome comercial da instituição) está desenvolvendo uma pesquisa sobre cursos de graduação oferecidos a distância via internet.

A sua tarefa consiste em incentivar os seus alunos a responderem aos questionários no prazo estabelecido, para que possamos realizar a nossa avaliação e, assim, sugerir melhorias para as próximas turmas dos cursos de EAD. Você poderá fazer isso por meio de lembretes ou avisos hospedados no ambiente virtual de aprendizagem (AVA) ou enviados aos e-mails pessoais dos alunos durante todo o período da coleta de dados.

Os questionários abordam as estratégias de aprendizagem utilizadas pelos alunos ao longo do curso e os possíveis fatores que afetam a decisão discente de persistir ou evadir-se do evento instrucional, bem como solicita alguns dados pessoais do alunado. Além de seus lembretes, a pesquisadora da USP enviará cartas a todos os alunos explicando o procedimento correto para efetuar a avaliação. Os instrumentos de medida utilizados serão enviados por $e$ mail aos respondentes por intermédio de uma carta orientando quanto aos procedimentos e objetivos da pesquisa, bem como solicitando ao participante que preencha o questionário hospedado em endereço da internet, indicado em link específico.

Os questionários estarão disponíveis a partir do dia $\mathbf{x x} / \mathbf{x x} / \mathbf{x x x x}$. Os alunos terão o período que compreende as datas das provas $(\mathbf{x x} / \mathbf{x x} / \mathbf{x x x x}$ a $\mathbf{x x} / \mathbf{x x} / \mathbf{x x x x})$ para responder aos questionários. Após esse período, os alunos terão ainda um prazo de $\mathbf{1 5}$ dias para participar.

O seu incentivo para que os alunos respondam aos questionários irá contribuir para a melhoria dos cursos nas próximas turmas, sendo a sua colaboração essencial para o sucesso da avaliação.

Desde já, nossos sinceros agradecimentos pela contribuição para o desenvolvimento deste estudo que certamente irá beneficiar todos os envolvidos nos cursos de EAD do referido Polo.

Favor acusar o recebimento desta.

Atenciosamente,

Coordenadoria de EAD e Pesquisadoras da USP.

Em caso de dúvidas, entre em contato com:

Elienay Eiko Rodrigues Umekawa: elienay@usp.com.br 


\section{ANEXO B - E-MAIL AOS ALUNOS}

Prezado estudante

A Universidade de São Paulo (USP - Ribeirão Preto) em parceria com (nome comercial da instituição) está desenvolvendo uma pesquisa sobre cursos de graduação oferecidos a distância via internet.

Solicitamos sua colaboração para responder aos questionários que tratam das estratégias de aprendizagem usadas por você durante todo o curso e de alguns fatores que podem afetar sua decisão de persistir ou não no curso realizado. Você deverá também informar alguns dados pessoais. A duração prevista para o preenchimento dos dois questionários é de 30 (trinta) minutos.

Link

para

questionário: https://docs.google.com/spreadsheet/viewform?formkey=dE1QWjhWQ2J0b21r R3M1Vk0yVmt0a1E6MQ

Assumimos o compromisso de manter a confidencialidade sobre a sua participação e esclarecemos que as respostas fornecidas serão analisadas coletivamente, o que torna desnecessário a identificação pessoal ou nominal.

A sua opinião como aluno será de extrema importância para o aperfeiçoamento dos cursos a ser desenvolvidos pela sua instituição de ensino.

Os questionários estão disponíveis a partir de hoje $\mathbf{x x} / \mathbf{x x} / \mathbf{x x x x}$ e você terá até o dia $\mathbf{x x} / \mathbf{x x} / \mathbf{x x x x}$ para respondê-los e enviá-los.

Desde já nossos sinceros agradecimentos pela contribuição para o desenvolvimento desta pesquisa. Sua participação é muito importante para nós. Colabore!

Atenciosamente,

Coordenadoria de EAD e Pesquisadoras da USP.

Em caso de dúvidas, entre em contato com:

Elienay Eiko Rodrigues Umekawa: elienay@usp.br 


\section{ANEXO C- QUESTIONÁRIO SOCIODEMOGRÁFICO}

\section{TERMO DE CONSENTIMENTO LIVRE E ESCLARECIDO}

Prezado participante,

Convido-o a participar voluntariamente da pesquisa intitulada "Preditores de Evasão em Ações Educacionais a Distância", que faz parte do meu projeto de mestrado no curso de Psicologia (FFCLRP-USP). O objetivo deste estudo é propor e testar um modelo de avaliação de ações educacionais ofertadas a distância, visando identificar variáveis preditoras de evasão relacionadas às características da clientela, e a fatores relacionados à evasão e persistência em EAD. Para tal, preciso de sua colaboração para poder obter as informações necessárias. Sua forma de participação consiste em responder a um conjunto de questionários. Como forma de sigilo, seu nome não será utilizado em qualquer fase da pesquisa, garantindo seu anonimato.

Coloco-me à disposição para mais informações pelo e-mail elienay@usp.br. Outros esclarecimentos sobre a pesquisa, favor entrar em contato com a Prof. ${ }^{a}$ Dr. ${ }^{a}$ Thaís Zerbini, responsável pela orientação deste projeto: (16) 3602-4687/ thaiszerbini@ffclrp.usp.br.

Li e compreendi este Termo de Consentimento Livre e Esclarecido, portanto, concordo em dar meu consentimento para participar como voluntário desta pesquisa.

Por favor, informe alguns dados pessoais:

\begin{tabular}{|c|c|}
\hline \multicolumn{2}{|c|}{ QUESTIONÁRIO SOCIODEMOGRÁFICO } \\
\hline Sexo & Feminino \\
\hline & Masculino \\
\hline \multicolumn{2}{|l|}{ Idade } \\
\hline \multirow[t]{5}{*}{ Estado civil } & solteiro \\
\hline & casado \\
\hline & divorciado \\
\hline & separado \\
\hline & outro \\
\hline \multirow[t]{2}{*}{ Composição familiar } & filhos \\
\hline & não \\
\hline \multirow[t]{3}{*}{ Escolaridade } & Ensino Médio Completo \\
\hline & Superior Incompleto \\
\hline & Superior Completo \\
\hline \multicolumn{2}{|l|}{ Profissão/Ocupação atual } \\
\hline \multirow[t]{5}{*}{ Renda (salários mínimos) } & até 1 \\
\hline & $2-3$ \\
\hline & $4-5$ \\
\hline & $6-7$ \\
\hline & 7 ou mais \\
\hline \multirow[t]{5}{*}{ Região geográfica } & Norte \\
\hline & Nordeste \\
\hline & Centro-Oeste \\
\hline & Sudeste \\
\hline & Sul \\
\hline \multirow[t]{2}{*}{ Experiência anterior no uso da internet } & Sim \\
\hline & Não \\
\hline Código do aluno de acesso ao AVA & \\
\hline
\end{tabular}




\section{ANEXO D - QUESTIONÁRIO DE FATORES RELACIONADOS À EVASÃO E À PERSISTÊNCIA EM EAD}

Para responder às próximas questões, pense nos fatores que podem facilitar ou dificultar a sua permanência em um curso a distância. A escala abaixo varia de -5 (dificultou muito) a +5 (facilitou muito). Leia atentamente os itens listados e avalie cada um deles de acordo com a escala.

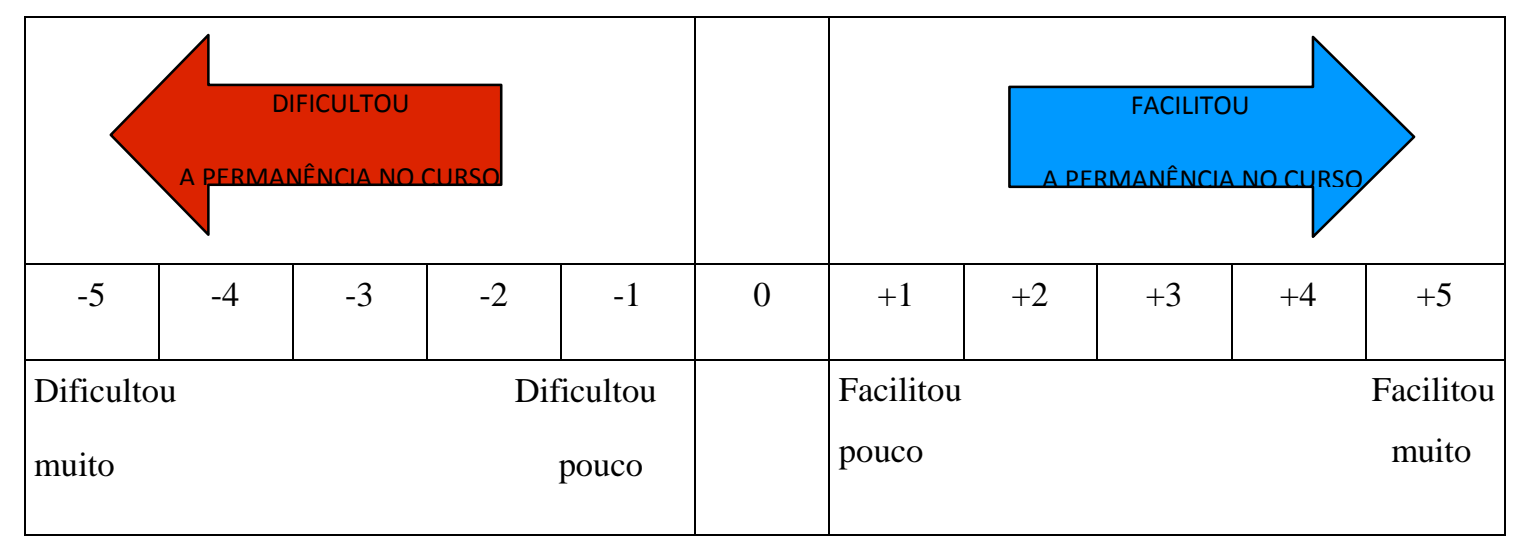

Analise primeiramente se os itens facilitam ou dificultam sua permanência em um curso a distância e depois marque o número da escala que corresponde à intensidade dessa influência, ou seja,

- Se o item facilita sua permanência no curso a distância avalie a intensidade dessa contribuição por meio da escala positiva (escala azul que varia de $+1 \mathrm{a}+5$ ).

- Se o item dificulta sua permanência no curso a distância avalie a intensidade dessa contribuição por meio da escala negativa (escala vermelha que varia de -1 a -5 ).

- Se o item não dificulta nem facilita sua permanência no curso a distância dê uma nota 0 .

Por favor, não deixe questões em branco.

\begin{tabular}{|l|l|l|l|l|l|l|l|l|l|l|}
\hline \multicolumn{1}{|c|}{ Itens } \\
\hline O apoio fornecido pelo tutor à interação entre os \\
participantes do curso.
\end{tabular}




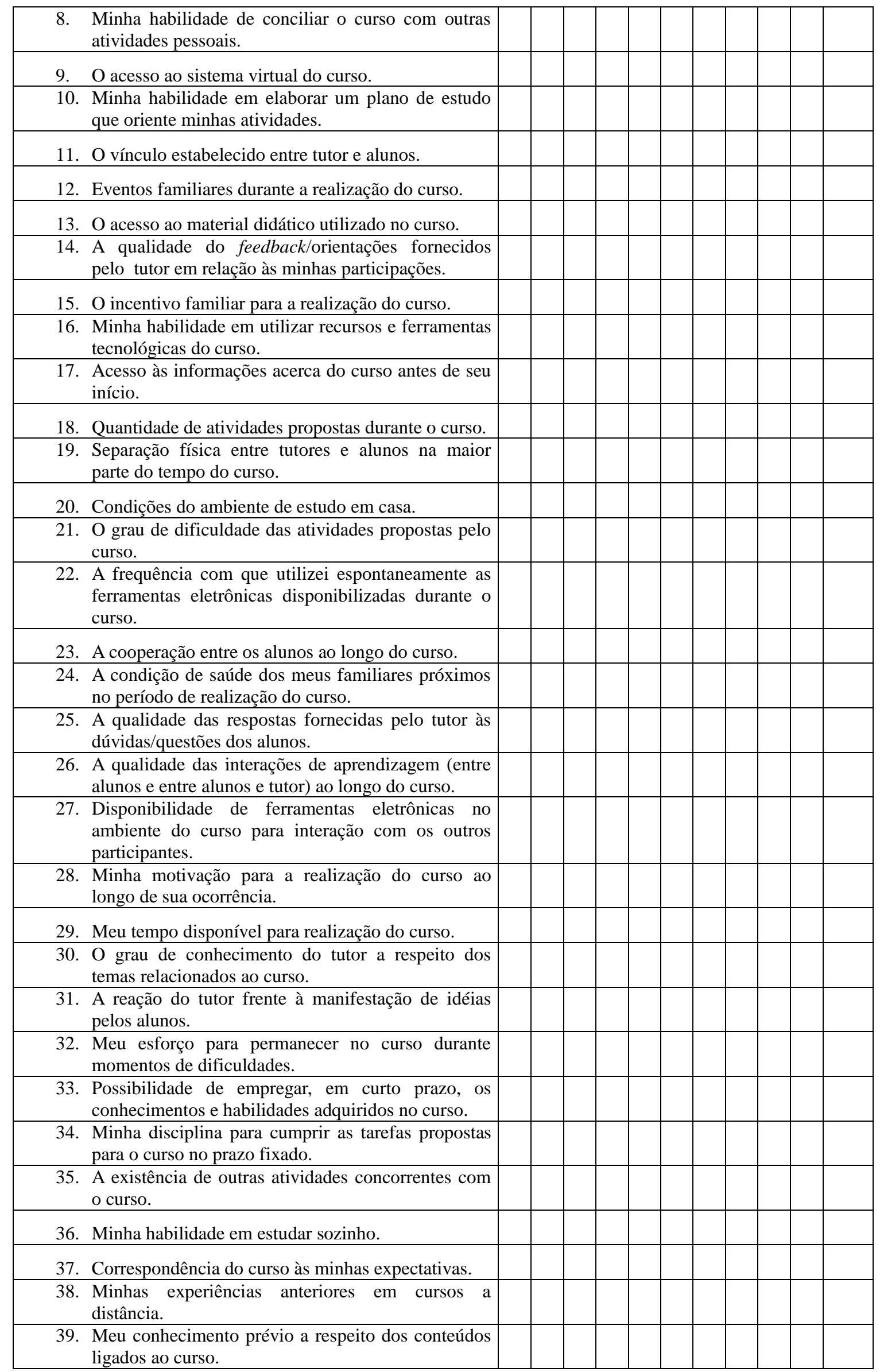




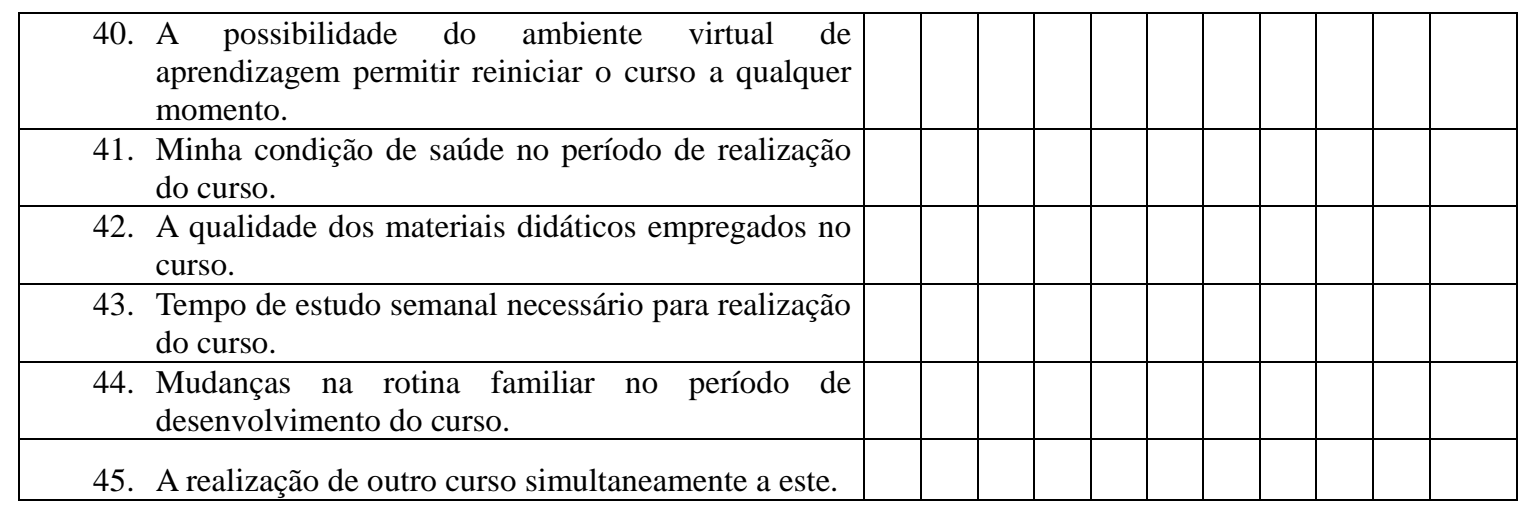




\section{ANEXO E - QUESTIONÁRIO DE ESTRATÉGIAS DE APRENDIZAGEM}

Para responder às próximas questões, pense nos comportamentos utilizados por você durante o curso. A escala abaixo varia de 0 (nunca) a 10 (sempre). Leia atentamente os itens listados e escolha o ponto da escala $(0,1,2,3,4,5,6,7,8,9$ ou 10) que melhor representa a frequência com que você se comportou da maneira descrita em cada item. Registre sua resposta à direita de cada item com o número escolhido. Por favor, não deixe questões em branco.

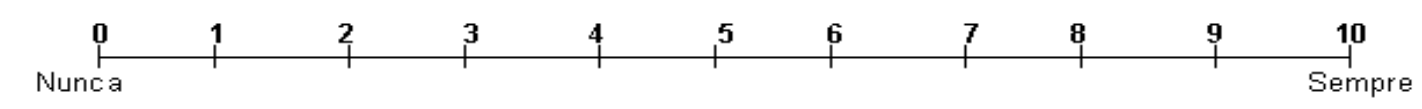

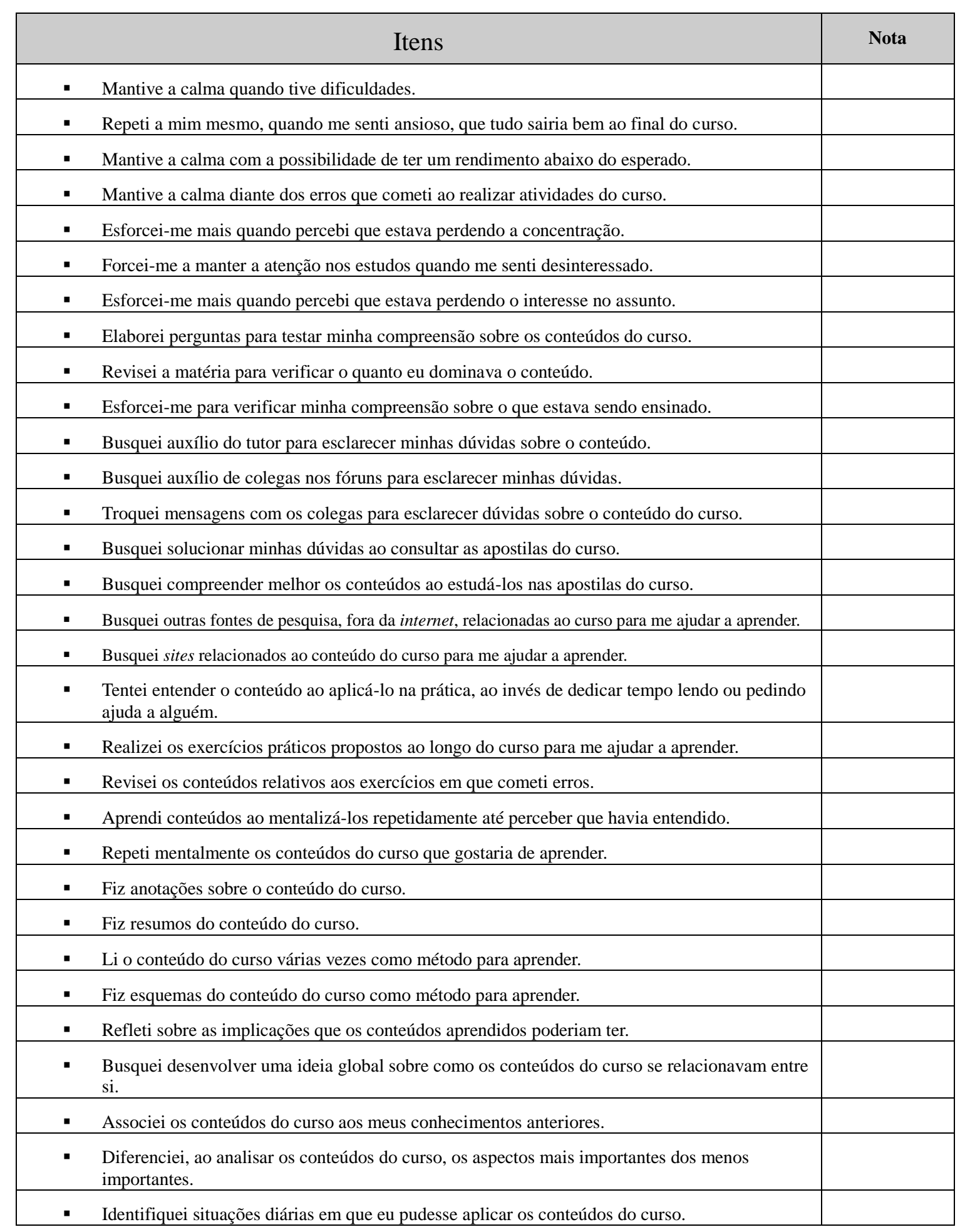


